\title{
Synthesis of Orotidine-5'-monophosphate modifications for the study of the catalytic activity of the enzyme Orotidine-5'-monophosphate decarboxylase
}

\author{
Dissertation \\ for the award of the degree \\ “Doctor rerum naturalium" (Dr. rer. nat.) \\ of the Georg-August-Universität Göttingen \\ within the doctoral program Chemistry of the \\ Georg-August University School of Science
}

(GAUSS)

submitted by

TOBIAS SCHMIDT

from Kassel

Göttingen, 2021 



\section{Thesis Committee}

Prof. Dr. Kai Tittmann

Department of Molecular Enzymology, University of Göttingen

Prof. Dr. Lutz Ackermann

Institute of Organic and Biomolecular Chemistry, University of Göttingen

Prof. Dr. Ricardo Mata

Institute of Physical Chemistry, University of Göttingen

\section{Members of the Examination Board}

Reviewer:

Prof. Dr. Kai Tittmann

Department of Molecular Enzymology, University of Göttingen

Second Reviewer:

Prof. Dr. Lutz Ackermann

Institute of Organic and Biomolecular Chemistry, University of Göttingen

Third Reviewer:

Prof. Dr. Ricardo Mata

Institute of Physical Chemistry, University of Göttingen

\section{Further members of the Examination Board}

Prof. Dr. Ulf Diederichsen

Institute of Organic and Biomolecular Chemistry, University of Göttingen

Dr. Holm Frauendorf

Institute of Organic and Biomolecular Chemistry, University of Göttingen

Dr. Michael John

Institute of Organic and Biomolecular Chemistry, University of Göttingen

Date of the oral examination: 09.12.2021 
The work described in this thesis was carried out under the supervision of Prof. Dr. Ulf DiEDERICHSEN at the Institute of Organic and Biomolecular Chemistry, Georg-August University of Göttingen between May 2018 and October 2021 in close cooperation with Prof. Dr. KAI TiTTMANn at the Department of Molecular Enzymology of the Georg-August University Göttingen.

Parts of this thesis are going to be published in: Nature Catalysis, in revision.

\section{Declaration of authorship}

I hereby declare that I prepared the doctoral thesis entitled "Synthesis of Orotidine-5'-monophosphate modifications for the study of the catalytic activity of the enzyme Orotidine-5'-monophosphate decarboxylase" on my own and with no other sources and aids than quoted.

Göttingen, 29.10.2021

(Tobias Schmidt) 
DEDICATED TO MY FAMILY 



\section{Table of Contents}

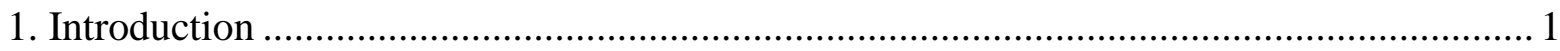

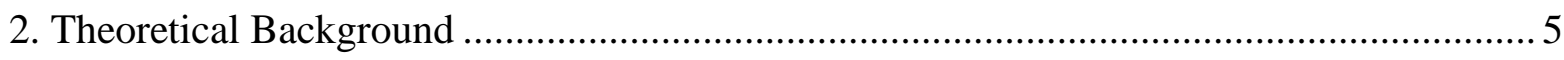

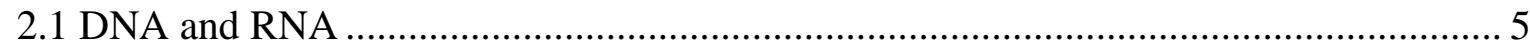

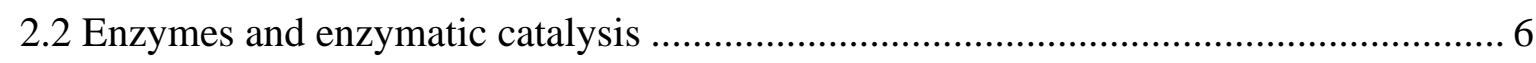

2.3 Orotidine-5'-monophosphate decarboxylase (OMPD) ............................................ 7

2.3.1 Pyrimidine de novo synthesis ........................................................................ 7

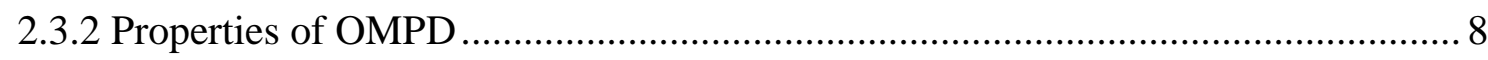

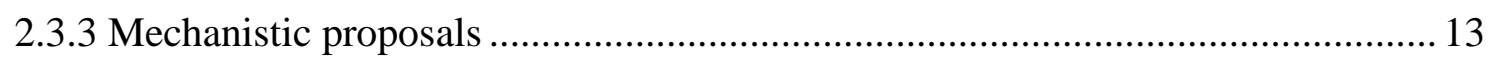

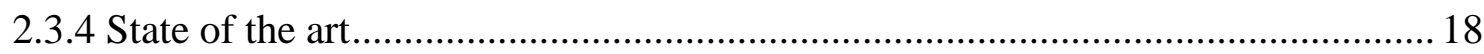

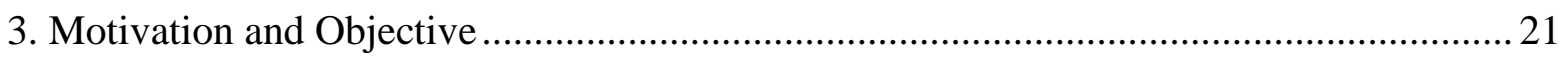

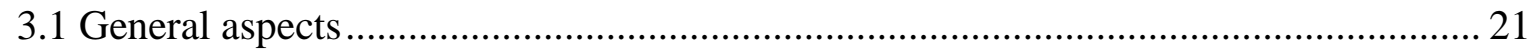

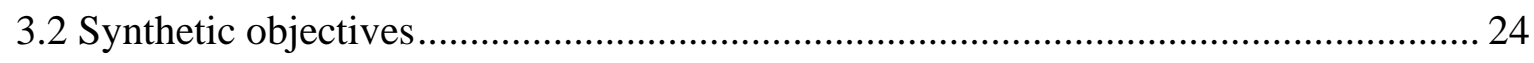

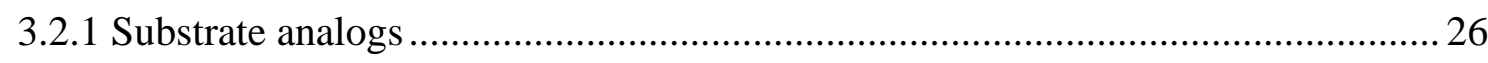

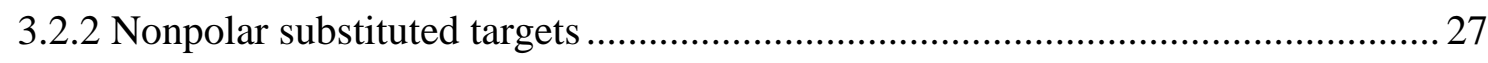

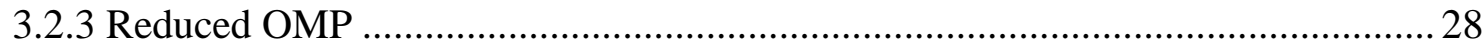

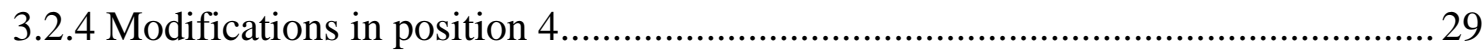

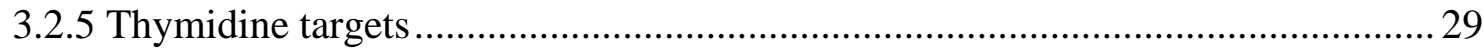

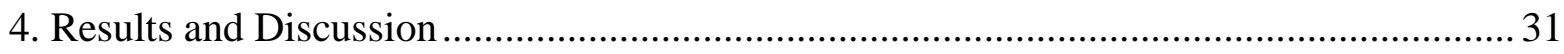

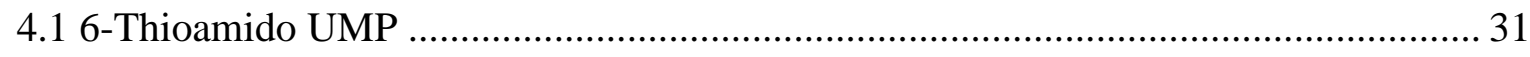

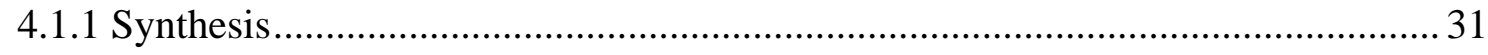

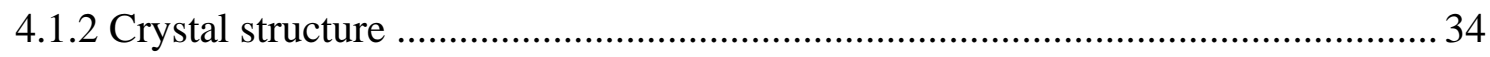

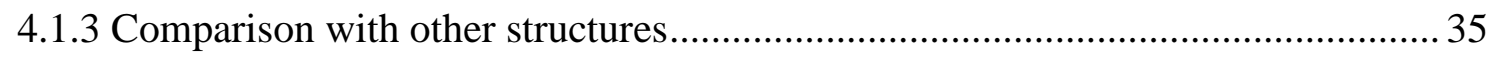

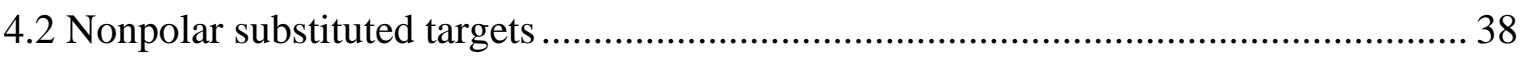

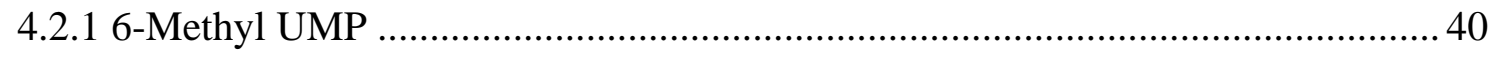

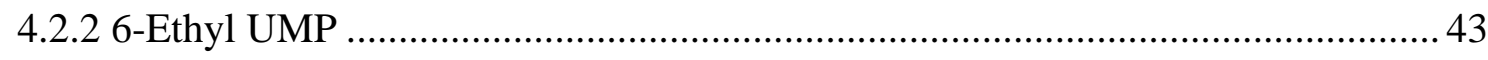

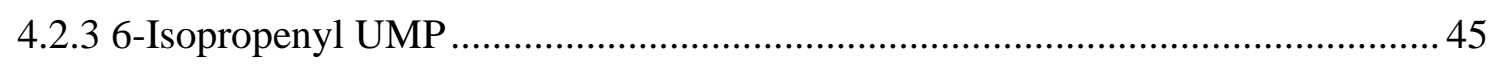

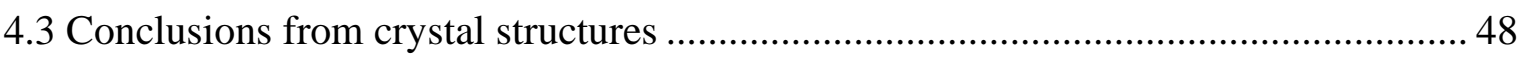

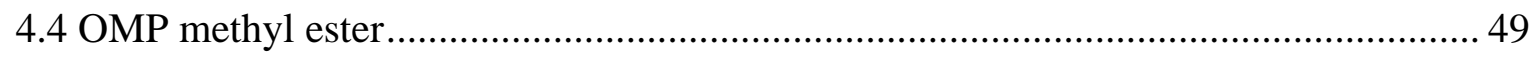




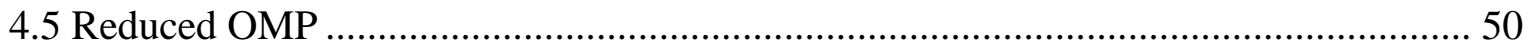

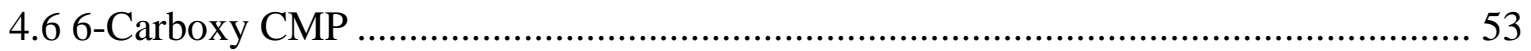

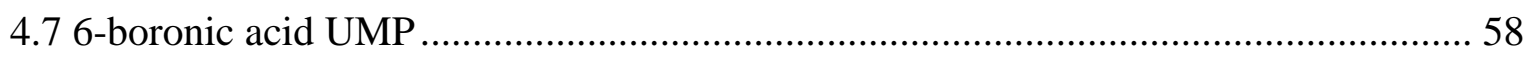

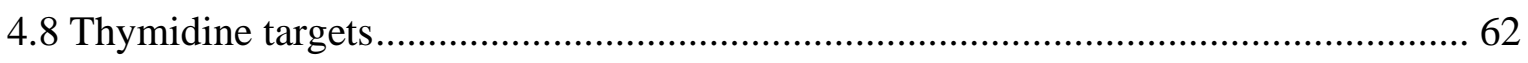

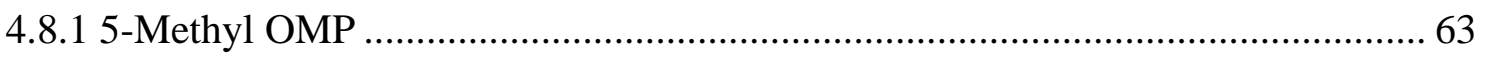

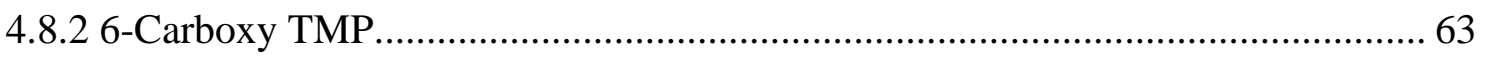

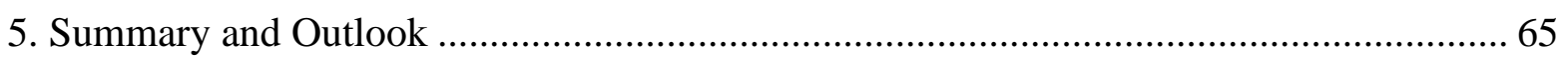

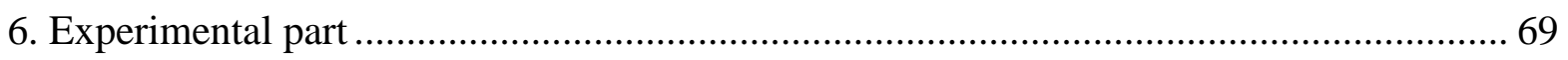

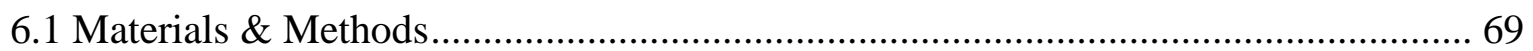

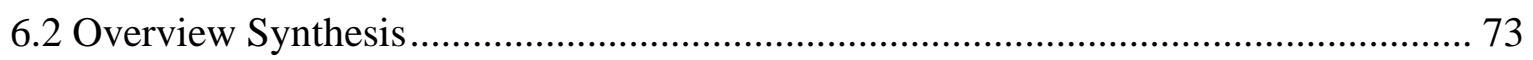

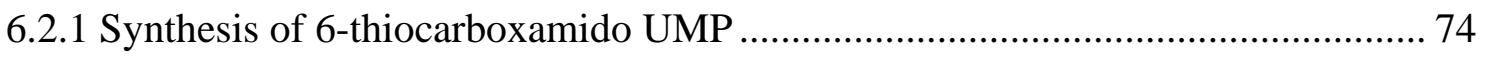

6.2.2 Synthesis of 6-carboxymethylester UMP (OMP methyl ester)........................... 84

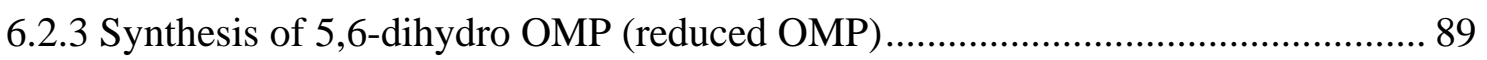

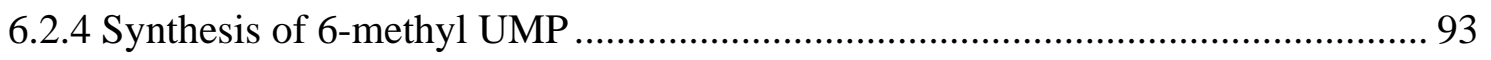

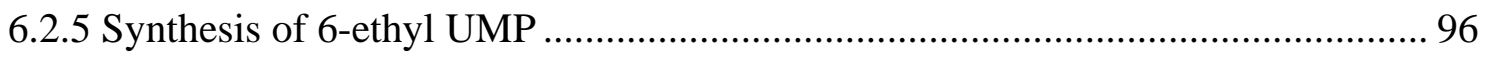

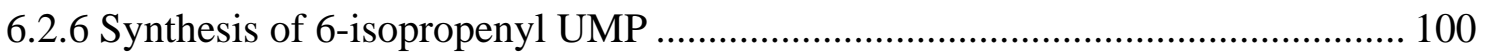

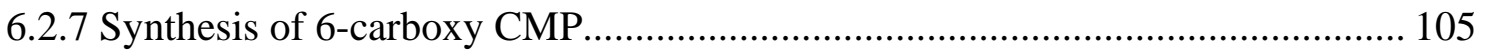

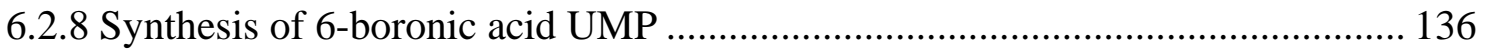

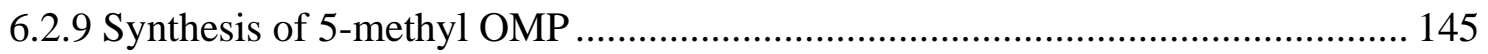

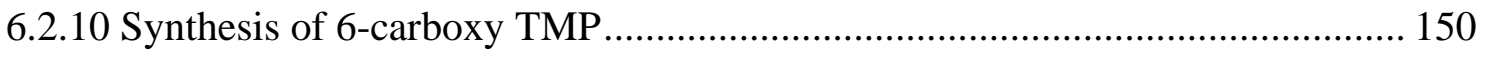

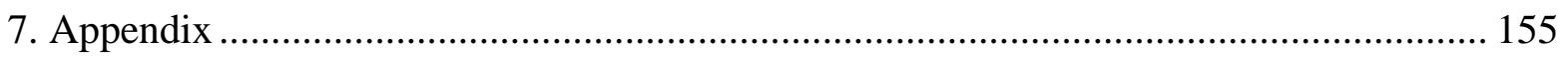

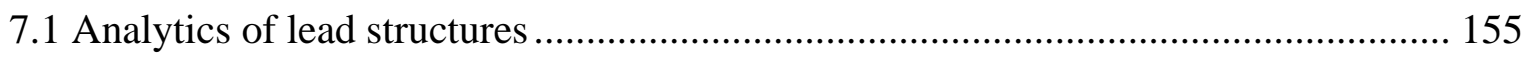

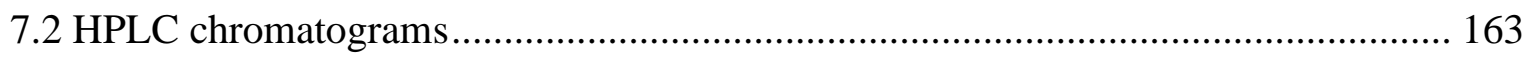

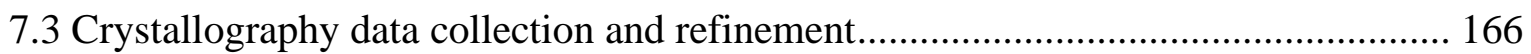

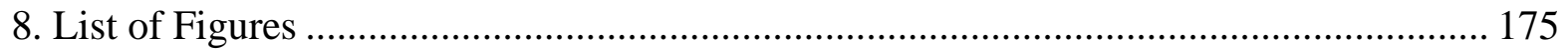

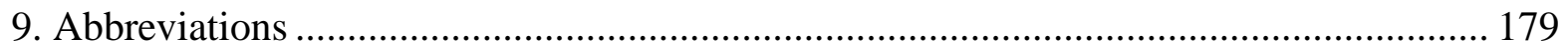

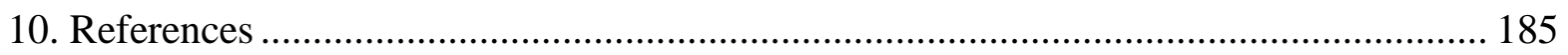

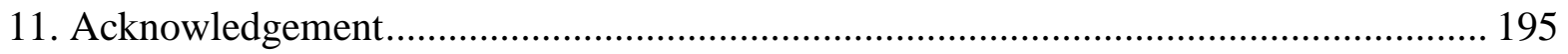

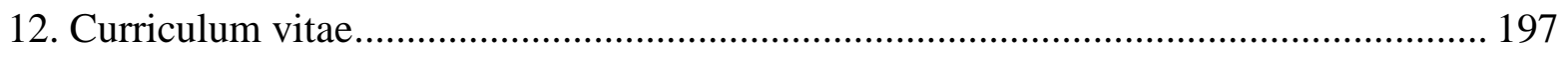






\section{Introduction}

All living organisms contain deoxyribonucleic acid (DNA), which is essential for life, as it is known today. The entirety of the genetic information is encoded in the DNA, making it one of life's most fundamental molecules. ${ }^{[1,2]}$ DNA, as well as ribonucleic acid (RNA) consists of pyrimidine and purine bases, essential for the formation, replication and repair of DNA and RNA sequences. ${ }^{[3,4]}$ Since these molecules are constantly being reproduced, the synthesis of the individual building blocks is indispensable to life. In higher organisms multiple pathways are accessible, such as the biosynthesis, degradation as well as recycling via the salvage pathway. ${ }^{[2,5]}$ In bacteria and archaea the pyrimidine de novo synthesis is to some extend the only possibility to form pyrimidine nucleotides. ${ }^{[5]}$ The last step of the pyrimidine de novo synthesis is the decarboxylation of orotidine-5'-monophosphate (OMP) yielding uridine-5'-monophosphate (UMP) shown in Figure $1 .{ }^{[5-7]}$ The resulting UMP is the starting material for many other pyrimidine nucleotides like the cytidine analogs, the di- and triphosphates and deoxynucleotides, demonstrating how essential this reaction is for all living organisms. ${ }^{[5,6,8]}$ The orotidine-5'-monophosphate decarboxylase (OMPD) catalyzes the reaction without the need of any cofactor and accelerates the decarboxylation by a factor of $10^{17}$ which makes the OMPD the fastest working enzyme of its kind. ${ }^{[7,9-12]}$ The exact mechanism of the enzymatic reaction has been extensively studied. However, despite several contributions and many different postulates up to this day, no complete explanation of the mechanism of OMPD has been given. ${ }^{[7,13-16]}$
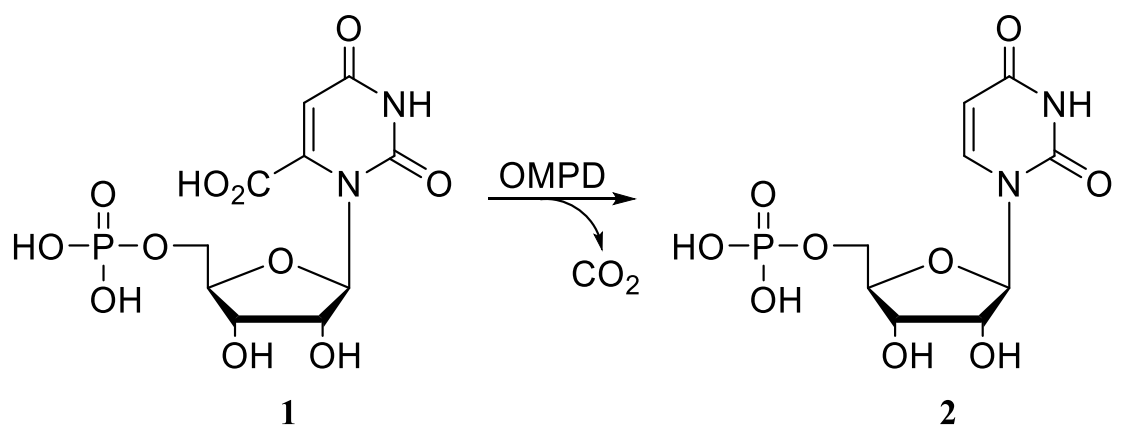

Figure 1: Decarboxylation of OMP (1) to UMP (2). 


\section{Introduction}

The overall goal is to fully understand the function and the exact mechanism of this outstanding enzyme. Different medical applications could be derived from the study of OMPD. The selective inhibition of the enzyme, for instance, could slow down cell growth ${ }^{[17,18]}$ thus be applied in the field of anti-cancer agents. ${ }^{[19,20]}$ In addition, the OMPD is associated with an anti-malarial potential ${ }^{[21,22]}$ since the malaria causing parasites are completely dependent on the pyrimidine de novo synthesis. ${ }^{[23,24]}$ The inhibition of OMPD would shut down the metabolism of these parasites thus targeting "the world's deadliest infectious disease", according to the World Health Organization (WHO). ${ }^{[24,25]}$

The decarboxylation reaction catalyzed by OMPD, and its mechanism have been studied for decades, it is remarkable that the tremendous catalytic efficiency, which is one major reason for the interest of the scientific community, is also the reason researchers could not clarify the mechanism. Until today there is no crystal structure of the original enzyme-substrate complex (MichAELIS complex) of OMPD. ${ }^{[26]}$ That is the reason why researchers are using enzyme mutational studies to substitute single amino acids or small fragments like loop regions of the enzyme to be able to observe crystal structures of the OMPD with the associated substrate or known inhibitors. ${ }^{[16,27,28]}$ Another starting-point is the synthesis of substrate analogs which have slight modifications in regard to OMP. The crystal structures of these enzyme-substrate analog complexes and the resulting observed interactions lead to investigation of mechanistic aspects. ${ }^{[13,16,29,30]}$ To further elucidate the mechanism, research in the DIEDERICHSEN group is focused on synthesizing substrate analogs which are either electronical or geometrical similar to OMP or analogs which represents postulated transition states. ${ }^{[13,16,29]}$

The intention of this work was to investigate and synthesize new substrate analogs of OMPD, which can be crystallized with human wildtype OMPD ( $h$ OMPD ${ }_{\text {WT }}$ ) by either co-crystallization or soaking techniques. The yielding crystals were examined by $\mathrm{x}$-ray crystallography measurements obtaining new crystal structures of enzyme-substrate complexes in high resolution, that were performed in close cooperation with the TiTTMANN group. ${ }^{[31,32]}$ These structures yield information about crucial interactions of the analogs with the enzymes active site. ${ }^{[16,33,34]}$

This thesis targets at the synthesis of the following lead structures (Figure 2), which are either isosteric analogs like methyl ester, amide and thioamide, or electronical analogs like the boronic acid towards the carboxyl group of OMP. In addition, a set of nonpolar substituted uridines (methyl, ethyl, isopropyl, isopropenyl) was synthesized to investigate sterical interaction inside the active site of the enzyme without the influence of polar interactions. Furthermore, the 
synthesis of 6-carboxycytidine and analogs was chosen to evaluate the impact of $C 4$ carbonyl in the enzymatic pocket by inverting the H-bonding character through the cytidine amino functionality.
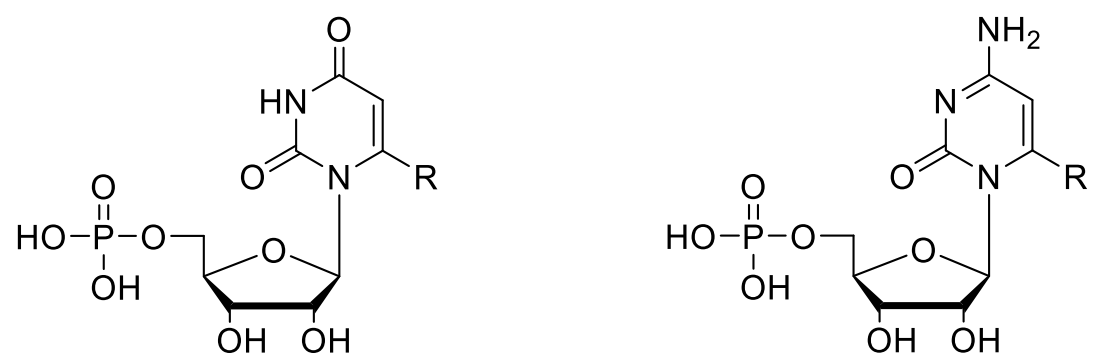

$\mathrm{R}=\mathrm{CSNH}_{2}(\mathbf{3}), \mathrm{CONH}_{2}(\mathbf{4}), \mathrm{CO}_{2} \mathrm{Me}(\mathbf{5})$,

$\mathrm{B}(\mathrm{OH})_{2}(\mathbf{6}), \mathrm{Me}(\mathbf{7}), \mathrm{Et}(\mathbf{8}), \mathrm{i}-\mathrm{Pr}(\mathbf{9}), \quad \mathrm{R}=\mathrm{COOH}(\mathbf{1 1}), \mathrm{CONH}_{2}(\mathbf{1 2}), \mathrm{CO}_{2} \mathrm{Me}(\mathbf{1 3})$ isopropenyl (10)

Figure 2: Targeted lead structures within the scope of this thesis. 



\section{Theoretical Background}

In this chapter the theoretical background of the enzyme OMPD is professed. The following subchapters are going to discuss the structure and properties of the enzyme (chapter 2.3.2) and the proposed mechanistic approaches during the last decades (chapter 2.3.3) leading to a closer look at the state-of-the-art opinion (chapter 2.3.4). But first, a very brief introduction into DNA and RNA basics (chapter 2.1) is given as well as some fundamentals about enzymes and enzyme catalysis (chapter 2.2).

\subsection{DNA and RNA}

DNA and RNA are the fundamental and vital molecules of life guaranteeing the storage and transfer of genetic information. ${ }^{[35]}$ DNA consists of two polynucleotide chains which are coiling to form a double helix structure as shown in Figure $3 .{ }^{[36]}$ The polynucleotide chains simplified contain four different nucleobases, without including noncanonical bases, adenine (A), thymine $(\mathrm{T})$, guanine $(\mathrm{G})$ and cytosine $(\mathrm{C})$, which are bound to deoxyribose and connected through phosphate groups. ${ }^{[35,37,38]}$ These canonical nucleotides build the helical structure induced by strong hydrogen bonds between one purine base and one pyrimidine base yielding the WATSON-CRICK base pairs, A-T and G-C, with two and three hydrogen bonds, respectively (Figure 3). ${ }^{[37,39,40]}$
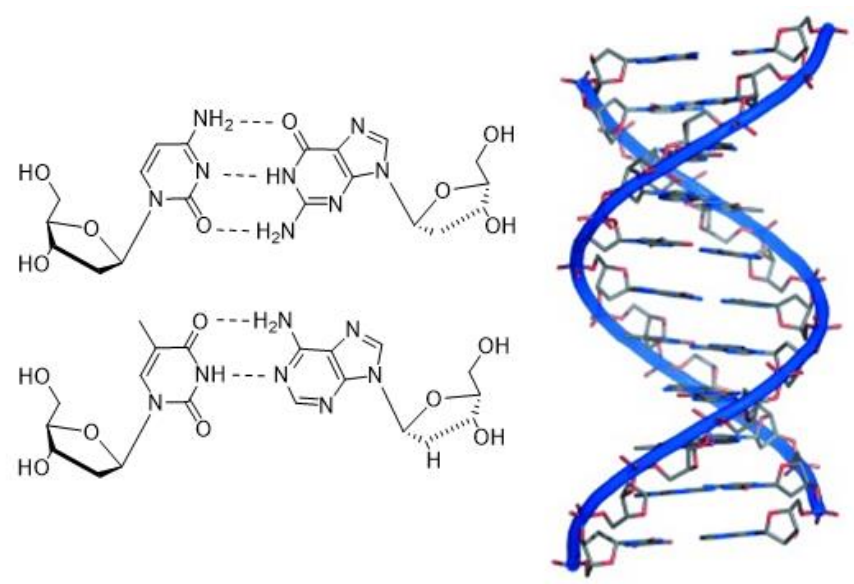

Figure 3: DNA base pairing, top row C-G and bottom row T-A with hydrogen bonds as dotted lines. ${ }^{[36]}$

In addition, RNA is essential in biological processes like gene expression and regulation, coding and decoding as well as protein biosynthesis. ${ }^{[41-43]}$ The structural difference between DNA and RNA is a hydroxy group in position 2' of the ribose moiety. Furthermore, RNA is just single 


\section{Theoretical Background}

stranded, the chains are comparable short, and the pyrimidine base thymine is exchanged by uracil (U). This lead to a decreased stability and higher chance of decomposition reactions in regard to DNA. ${ }^{[44]}$ The most important forms of RNA are the messenger RNA (mRNA), the transfer RNA (tRNA) and the ribosomal RNA (rRNA). ${ }^{[42]}$

\subsection{Enzymes and enzymatic catalysis}

Enzymes are biological macromolecules, which catalyze chemical reactions in a specific manner. ${ }^{[45,46]}$ They can be divided into different classes, either split depending on function, steric properties or the catalyzed reaction. ${ }^{[47]}$ Nearly every metabolic process is linked to an enzyme catalyzing the reaction and regulating the metabolism of living organism. ${ }^{[48-51]}$ The steric complexity of enzymes can vary as much as their functionality, given a wide range from a single polypeptide chain enzyme up to multienzyme complexes in which multiple enzymes interact in combination or subsequent reactions. ${ }^{[52-54]}$ In addition, the enzyme activity is often dependent on incorporated cofactors such as coenzymes, metal centers or prosthetic groups. ${ }^{[41]}$

The first description of the enzyme substrate binding process was postulated by EMIL FISCHER, that is known as the lock and key model, ${ }^{[55]}$ in which the enzyme and substrate are featured specific complementary geometric shapes that fit perfectly into one another. The enzymatic pocket is related to the lock and the substrate corresponds to the key, obtaining a high substrate specificity, even small structural changes like isomerism can be distinguished. ${ }^{[55,56]}$ D. E. Koshland published a more precise characterization of the enzyme substrate binding process, known as the induced fit model, ${ }^{[45]}$ accepting that neither enzyme nor substrate are that rigid and stiff like described in lock and key model, but having a certain flexibility, which enables an enzyme substrate interaction based on structural changes of the active site. ${ }^{[45]}$

To further discuss the activity of an enzyme and the rate enhancement of the enzymatic reaction a few basic principles of the kinetics and thermodynamics need to be recapped. In general, enzymatic reactions are dependent on the substrate concentration, the enzyme concentration and on the properties of the surrounding, like $\mathrm{pH}$ and temperature. ${ }^{[57]}$ Depending on the organism the $\mathrm{pH}$ and temperature optimum can differ, for many human enzymes this temperature optimum is at physiological temperature $\left(37^{\circ} \mathrm{C}\right) .{ }^{[56,57]}$ A first model of an enzymatic reaction was given by MICHAELIS and MENTEN, which describes the dependence of the reaction rate of the enzymatic reaction and the substrate concentration. This was further extended by BRIGGS resulting in a fundamental explanation of reaction kinetics. ${ }^{[58,59]}$ 
From an thermodynamic point of view, enzymes catalyze biochemical reactions by lowering the activation energy which is needed to form the transition state, thus accelerating the rate of the reaction. ${ }^{[56]}$ In theory, the catalyzed reaction is reversible, but in fact, the formation of an enzyme-substrate complex is just favored into one direction. ${ }^{[41,56]}$ The huge rate acceleration of enzymes comes from the high specificity in binding process of the reaction transition state, according to the PAULING Model. ${ }^{[60,61]}$ This was supported by the fact, that for many enzymes transition state analogs are potent inhibitors, due to the tight binding. ${ }^{[60]}$ In addition, besides making the transition state more favorable, another important point is the destabilization of the ground state, which occurs during the binding process of the substrate to the enzyme active site associated with changes in the protein structure (entropic changes). This means, that an energetically unfavored ground state would accelerate the formation of the transition state (lowering the energetic barrier). JENCKS was proposing that the intrinsic binding energies are much larger than believed and important parts of this energy may be provided as a potential driving force for catalysis, especially binding energies of components of the substrate which are not actively involved in the reaction. ${ }^{[62]}$ In both of these thermodynamic approaches, the enzymatic reaction is accelerated and in regard to the OMPD these concepts are frequently discussed.

\subsection{Orotidine-5'-monophosphate decarboxylase (OMPD)}

\subsubsection{Pyrimidine de novo synthesis}

In general, there are multiple pathways in nucleotide metabolism which can be divided into de novo synthesis, nucleotide degradation and recycling processes, such as the salvage pathway. The latter is utilized in higher organisms and can't be found in bacteria or microorganisms. Hence the remaining pyrimidine de novo synthesis is the major metabolic pathway in many species. ${ }^{[2,5,8]}$

In pyrimidine de novo synthesis (Figure 4), the start of pyrimidine formation is the synthesis of carbamoyl phosphate from hydrogen carbonate and ammonia. This reaction is catalyzed by carbamoyl phosphate synthetase II (CPS2). The next step is the reaction of carbamoyl phosphate with aspartate catalyzed by aspartate transcarbamoylase (ATC). The resulting carbamoyl aspartate is cyclizing with water as leaving group yielding dihydroorotate of eponymous enzyme dihydroorotase (DHO). The synthesis continues with a redox reaction catalyzed by dihydroorotate dehydrogenase (DHODH) with nicotinamide adenine dinucleotide 
(NAD) as oxidizing agent leading to orotate and NADH. A further step towards the pyrimidine nucleotide is, that the $N 1$ of orotate binds to phosphoribosyl pyrophosphate (PRPP) forming the glycosidic bond performed by orotate phosphoribosyl transferase (OPRT). In the last step OMP is decarboxylated to UMP by OMPD. This molecule is then the starting point for further pyrimidine nucleotides. ${ }^{[5,8]}$

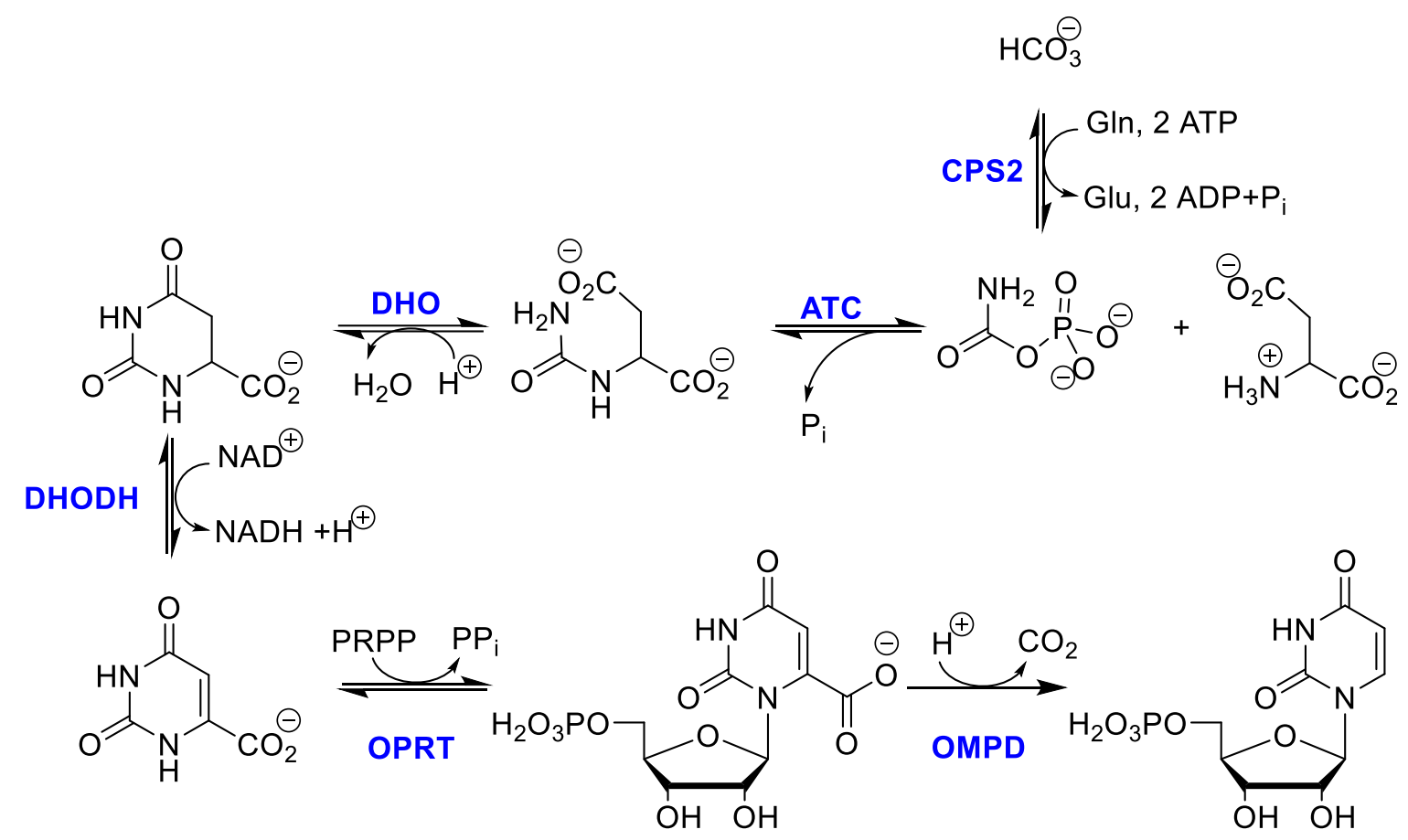

Figure 4: Pyrimidine de novo synthesis.

Interestingly, the pyrimidine de novo synthesis has slight differences regarding the enzymatic complexes depending on the organism. In bacteria it consists of six single steps catalyzed by different enzymes as shown in Figure 4. In mammals the first three steps are catalyzed by a multienzyme complex named carbamoylphosphate synthase-aspartate transcarbamoylasedihydroorotase (CAD). In addition, the last two steps - glycosidic bond formation and the decarboxylation - are catalyzed by the uridine- 5 ' -monophosphate synthetase (UMPS) ${ }^{\left[{ }^{[5]}\right.}{ }^{8]}$ With these variations in different species, also different binding affinities and reactions with ligands of OMPD can be observed, which will be explained in more detail in the next subchapter.

\subsubsection{Properties of OMPD}

Since all living organisms perform the biosynthesis of nucleotides, the OMPD is found in all domains of life. ${ }^{[14]}$ Despite being an ubiquitous enzyme, huge interest comes from the immense acceleration of the decarboxylation reaction by a factor $10^{17}$ which makes the OMPD the fastest enzyme without cofactors. ${ }^{[6]}$ That is the reason why WOLFENDEN and RADZICKA proclaimed it the most proficient enzyme. ${ }^{[6]}$ The enormous acceleration translates a change of timescale from 
millions of years without enzyme to milliseconds with enzymatic catalysis. ${ }^{[6,7]}$ In early studies this tremendous performance was explained by metals. ${ }^{[9,10,63]}$ This is done in fact without the need of any cofactor neither coenzyme, prosthetic groups nor metal center. ${ }^{[7,64]}$ The enzymatic pocket of OMPD solely consists of amino acid residues as major player for catalysis, which makes it even harder to understand the exact mechanism. ${ }^{[65]}$ A drawback of this acceleration rate is that the original reaction of OMP is too fast to be observed using x-ray crystallography. It seems to be nearly impossible to isolate or observe the enzyme-substrate complex (MichAELIS complex). In 2008, the first would-be crystal structure of OMP in OMPD of plasmodium falciparum was published at low resolution $\left(2.65 \AA\right.$ ). ${ }^{[66]}$ After ten years, this finding turned out to be incorrect, NOVAK et al. performed again a refinement of the original data with no evidence for OMP inside the enzymatic pocket. ${ }^{[26]}$

Having a closer look at the enzyme's architecture, the active form of OMPD is a homodimer, shown in Figure 5, which consists of two monomer units of triosephosphate isomerase (TIM barrel). BELL and JONES found that an aspartic acid residue extends from one monomer into the active site of the other monomer, respectively, which is very important for the enzymatic activity. The monomer activity was tested by inhibition of the dimerization with the result of drastic decrease in the catalytic activity. ${ }^{[67]}$

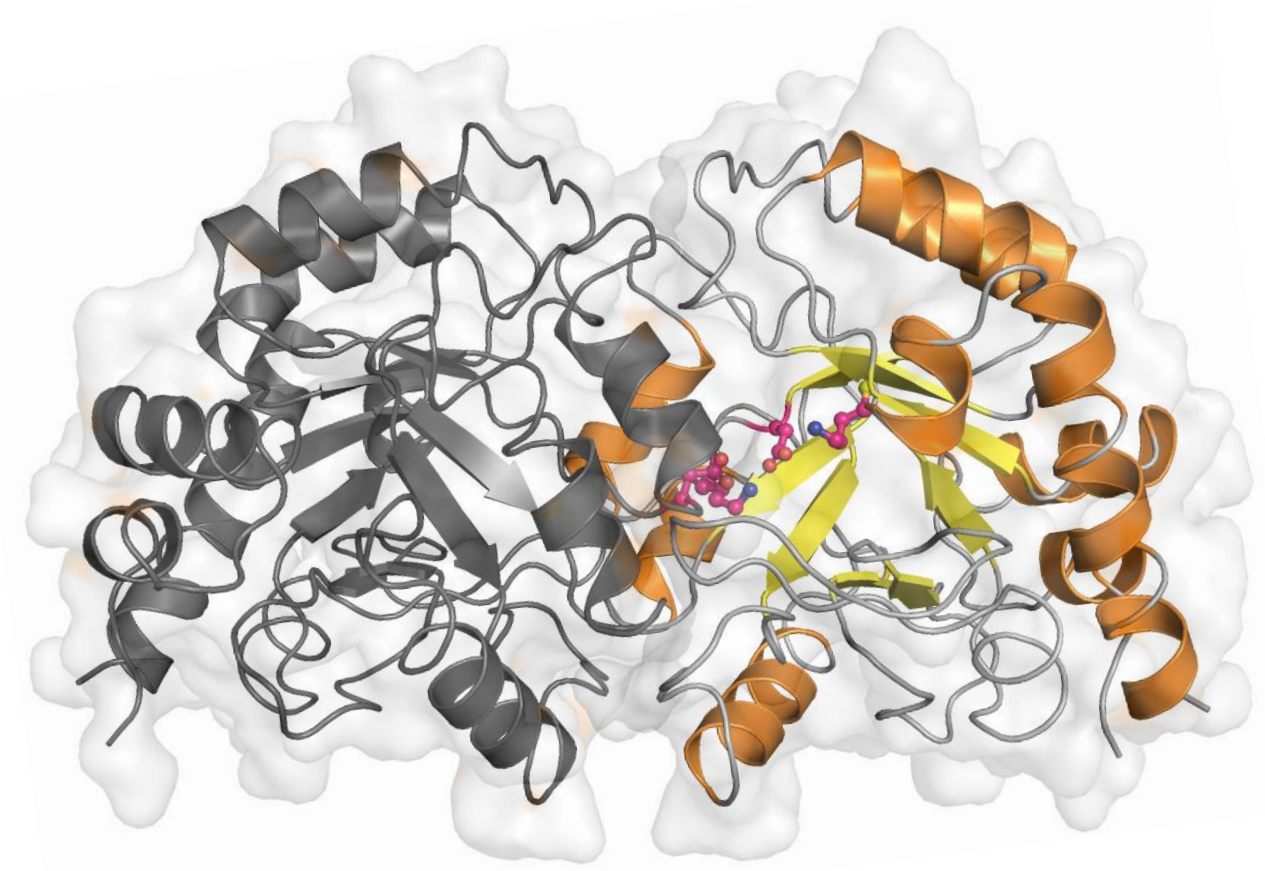

Figure 5: Structure of the resting state OMPD homodimer with one monomer colored in grey and the other one colored depended on secondary structure elements: $\alpha$-helices in orange, $\beta$-sheets in yellow and the rest of peptide chain in grey. The active site residues are shown in magenta with separate coloration of the heteroatoms. 
In some early mechanistic approaches without the access to OMPD crystal structures, several working groups postulated the influence of metal centers $e . g$. a potential zinc ion in the presence of the active site of OMPD monomer. ${ }^{[63,68]}$ In fact, for similar enzymes like iso-orotate decarboxylase a zinc ion plays a major role in the enzymatic mechanism. ${ }^{[69]}$ This was disproved in case of the OMPD by atomic and x-ray absorption spectroscopy. ${ }^{[64]}$

The more detailed investigation of the enzymatic pocket revealed the most important regions in terms of substrate interaction, the catalytic tetrad (Figure 7) and two loop regions as shown in Figure 6. The important loop regions, the phosphate gripper loop and the pyrimidine umbrella are highlighted in magenta, both have several polar contacts with the substrate which results in comparable high energies in terms of binding affinity. Especially the phosphate binding seems to be energetically important, so much that any modifications of phosphate or phosphate interacting amino acid residues are not tolerated without leading to a decrease in activity. ${ }^{[7,15,70,71]}$

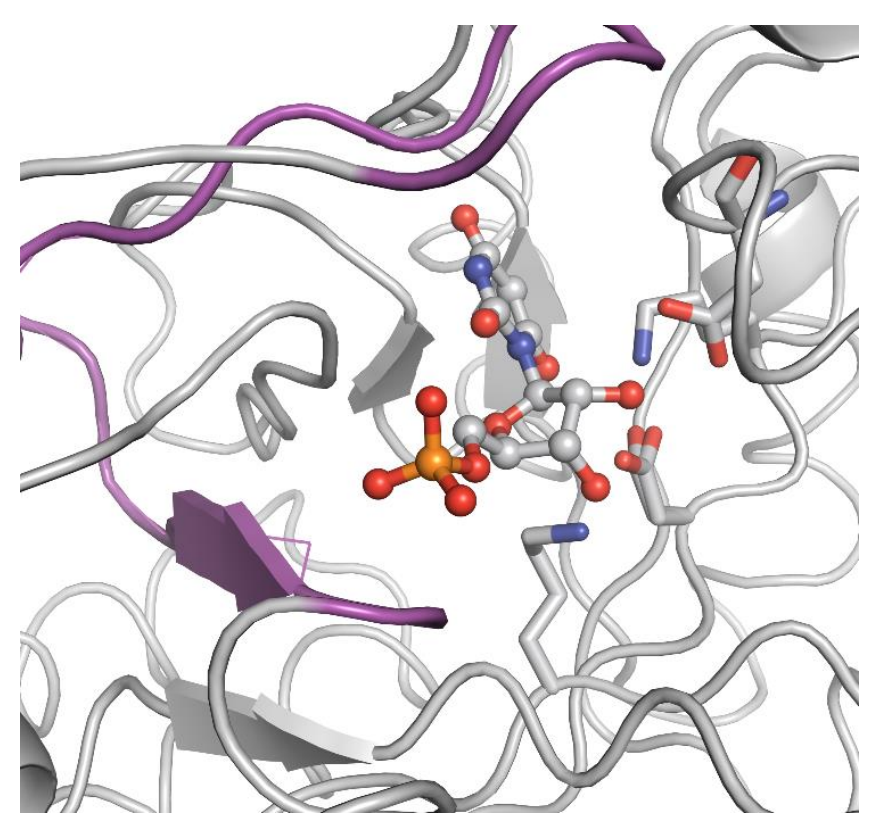

Figure 6: Loop regions, pyrimidine umbrella and phosphate gripper loop are colored magenta. Picture taken from crystal structure of BMP complex with $h O M P D_{W T}$.

The active site amino acid residues which are considered to interact the most with the OMP carboxyl group, the so-called catalytic tetrad, is pointed out in Figure 7. It consists of alternating two aspartic acid (D) residues and two lysines (K), being part of the DxKxxDx motif (the second lysine coming from the other monomer). ${ }^{[14]}$ All amino acid residues of the catalytic tetrad have proven to lower substrate binding and catalytic activity when exchanged by other residues in mutational studies. ${ }^{[27,28,72]}$ Most important is the influence of Lys314 of which a mutation is nearly shutting down the whole enzyme activity. ${ }^{[27,71]}$ 


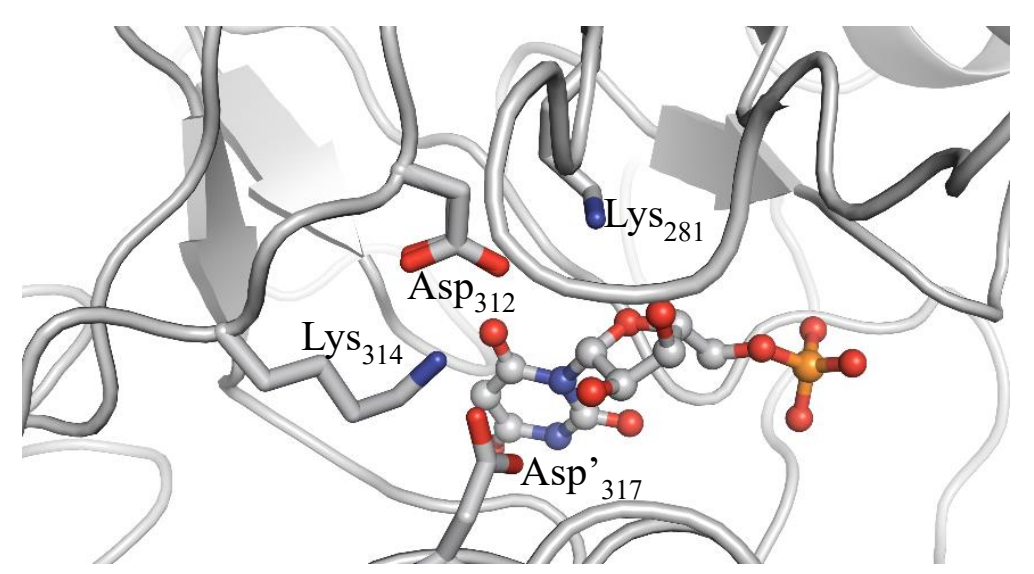

Figure 7: Catalytic tetrad consisting of Asp' ${ }_{317}$, Lys314, Asp312 and Lys281. Picture taken from crystal structure of BMP complex with $h O M P D_{W T}$.

Even though the catalytic tetrad and loop regions are known to be major players in substrate binding process and catalysis, more and more information concerning their importance was obtained from interactions observed in crystal structures of OMP-inhibitor complexes and of OMPD mutants. But even in the time before the first crystal structure of OMPD, a variety of different methods revealed insights. From a combinatorial approach one could ask how many different OMPD species exist and what they have in common, also, what kind of differences can be observed?

In 2000, TRAUT and TEMPLE used global sequence alignment to investigate the phylogeny of OMPD species and in addition they sought for signature pattern. When they sequenced more than 80 species with an average enzyme consisting of 270 amino acids, they found just eight invariant amino acids which all species had in common. Seven of these eight amino acids are incorporated in substrate binding. ${ }^{[73]}$ This sequence alignment was enlarged by FUJIHASHI et al. to give a bigger picture of the evolutionary tree of OMPD. Their effort resulted in 750 sequences of approx. 550 species. ${ }^{[14]}$ In contrast, at this time all the obtained crystal structures had their origin in 21 species. $^{[14]}$

OMPD, depending on the considered organism, has some differences in properties. In prokaryotic organisms OMPD is a single function enzyme, in contrast, in mammals it is part of a multi enzyme complex which is known as uridine-5' - monophosphat synthetase (UMPS). ${ }^{[74]}$ The covalent bond between two enzyme domains which catalyze two consecutive reactions occurs frequently in higher organisms. The constitution or number of $\alpha$-helices or $\beta$-sheets of a TIM barrel varies depending on the organism. ${ }^{[13]}$ However, the active site is always at the end of a TIM barrel which was proven by x-ray diffraction. ${ }^{[13]}$ Another interesting fact representing differences between the diverse OMPD species is the behavior of Methanothermobacter 
thermautotrophicus OMPD (MtOMPD) and human OMPD (hOMPD) towards 6-cyano UMP. In $h$ OMPD 6-cyano UMP is converted to UMP whereas in MtOMPD it is converted to 6-hydroxy UMP (BMP). ${ }^{[13,75]}$

A more detailed inspection of the consensus amino acids taking part in substrate binding is shown in Figure 8. The enzyme-substrate interaction in the active site relies on a complex hydrogen bond network, which is shown exemplary in the following by the $h$ OMPDwT complex with 6-hydroxy UMP (BMP). The crystal data is taken from HEINRICH and WITTMANN and the processed picture was provided by RINDFLEISCH. ${ }^{[13,29,33]}$ In addition, HEINRICH and WITTMANN described the closed enzymatic pocket having excrescences, probably derived from substrate binding, and associated with short time carbon dioxide storage. ${ }^{[19,58]}$ In addition, the loop regions can provide a relatively water free environment in closed conformation. ${ }^{[56,57]}$

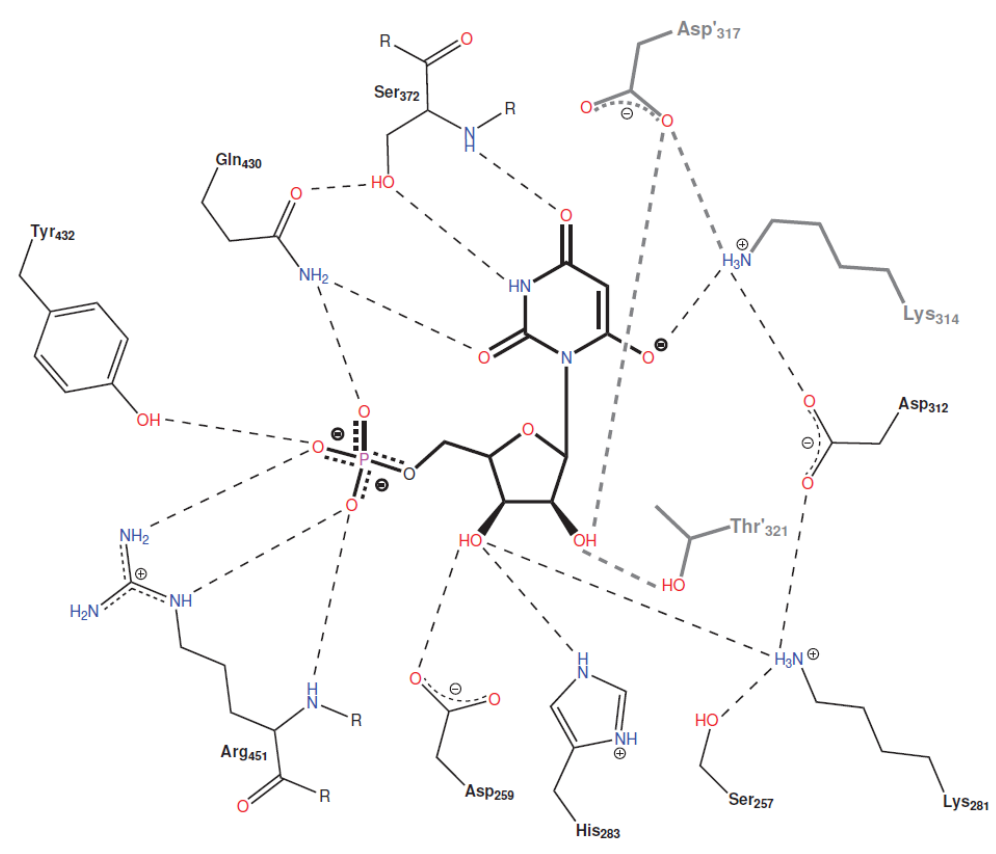

Figure 8: H-bond network of the substrate (e.g., BMP) in the enzymatic pocket. ${ }^{[33]}$

In 2018, RICHARD et al. emphasized the importance of these structural attributes and compared the phosphate loop of different OMPD species, trying to get more hints regarding the immense catalytic efficiency derived from a rather simple arrangement of amino acids. They summed up that the reaction and the mechanism itself are not "fundamentally different" from less efficient enzymes, but a few structural features were pointed out, showing that the substrate binding process induces significant changes of secondary structure of the enzymatic pocket. ${ }^{[15]}$ 


\subsubsection{Mechanistic proposals}

Since the 1970s, ${ }^{[78]}$ investigations of OMPD's mechanism have been made and different theories were proposed (Figure 9). The tremendous catalytic activity, while attracting the interest of many working groups at the same time complicates research of the mechanism. In Figure 9 an overview of several proposed mechanisms is shown. These proposals differ widely, suspecting nearly every position of OMPs pyrimidine moiety to undergo protonation or get attacked by a nucleophile in either a non-covalent mechanism, or ionic-like setup or acid base reactions up to a concerted reaction or a covalent mechanism. The following selection sums up the most important proposals concerning OMPD mechanisms which are subsequently introduced in a chronological order, starting with the publications of a pre crystal structure era. ${ }^{[79]}$

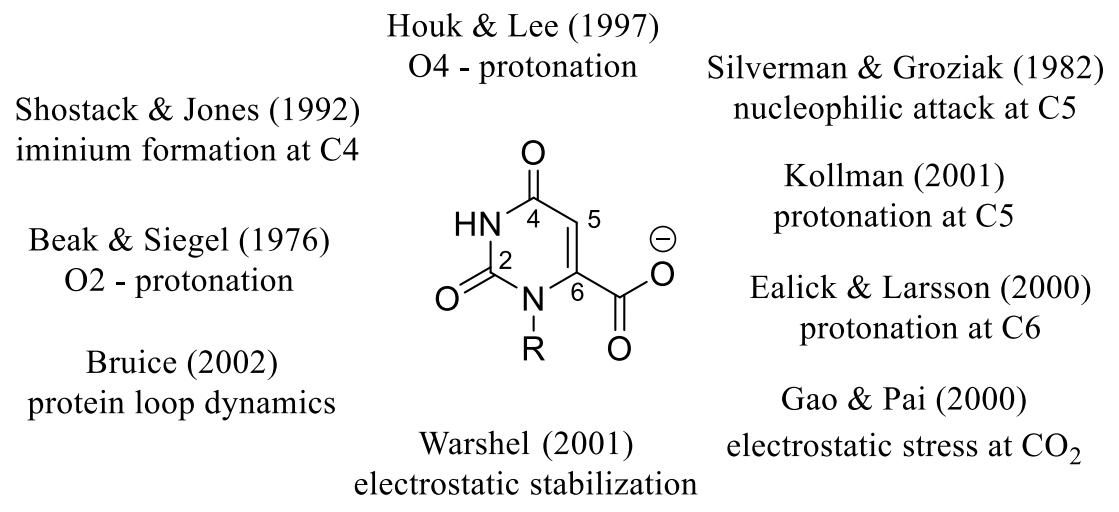

Figure 9: Overview of some predicted mechanisms. ${ }^{[79]}$

The first mechanistic proposal was published by BEAK and SIEGEL in 1976 shown in Figure 10. ${ }^{[78]}$ They proposed a non-covalent mechanism and suggested two possible pathways. one in which the carboxyl group gets deprotonated catalyzed by a base, followed by the cleavage of carbon dioxide leaving a negative charge in position 6 behind. The authors proposed stabilization by the formation of a double bond between $N 1$ and $C 2$. Then protonation in position 6 yields the product. The other path suggests a zwitterionic behavior, with deprotonated carboxyl group and protonated $C 2$ carbonyl. This leads to the loss of carbon dioxide and negatively charged position 6 . 
<smiles>Cn1c(C(=O)O)cc(=O)n(C)c1=O</smiles>

Figure 10: Proposed mechanism by BEAK and SIEGEL. ${ }^{[78]}$

A second mechanism was published in 1982 by SILVERMAN and GROZIAK. ${ }^{[80]}$ They suggested a covalent mechanism of MiCHAEL addition and subsequent elimination (Figure 11). The nucleophile attacks at position $C 5$ of the pyrimidine moiety, which leads to a change in double bond formation yielding an exocyclic double bond and protonation of the carboxyl group. Then, the protonated carboxyl group is deprotonated twice which leads to bond breaking between $C 6$ and carboxyl group, releasing carbon dioxide accompanied by the reformation of the endocyclic double bond.
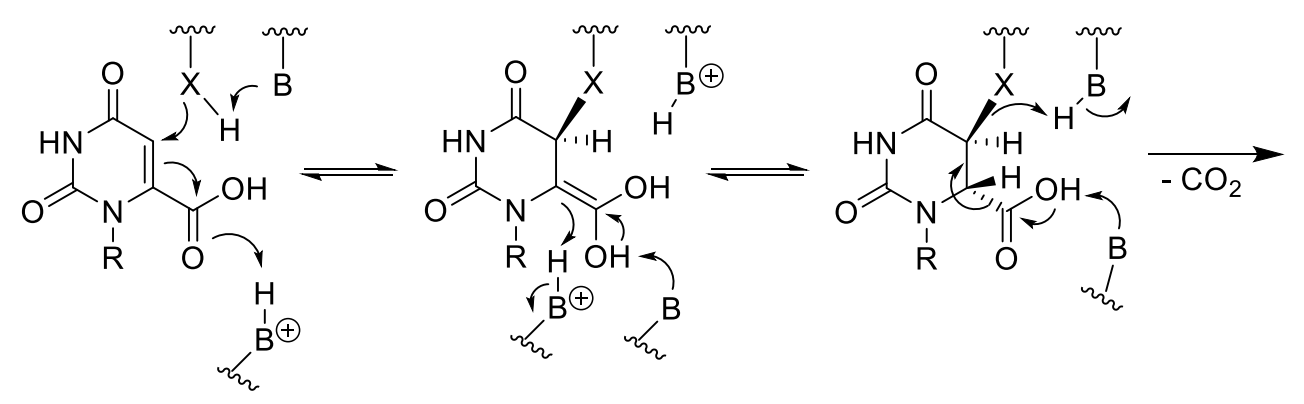<smiles>[R]n1ccc(=O)[nH]c1=O</smiles>

Figure 11: Mechanism of SILVERMAN and GroziaK. ${ }^{[80]}$

In the work of SILVERMAN and GROZIAK the origin of the nucleophile was not further explained. Ten years later the nucleophile was identified as a lysine by SMILEY und JONES who demonstrated the impact of this lysine residue in the active site. With the loss of lysine the enzymatic activity is decreased a 1000 fold. ${ }^{[81]}$ In addition, JONES and coworkers emphasized their findings point against the covalent mechanism and rather showed an $N$-ylide which supports the zwitterionic intermediate of BEAK and SIEGEL. This was provided by kinetic isotope effects experiments of ${ }^{13} \mathrm{C}$ enriched $\mathrm{BMP}$, indicating no changes in bond order between $C 5$ and $C 6 .{ }^{[76,82]}$ 
LEE und HouK proposed a mechanism based on quantum mechanical calculations in which the pyrimidine ring is protonated at the $C 4$ oxygen which should lower the activation free energy and leads to decarboxylation via neutral carbene species (Figure 12). ${ }^{[83]}$ However, the first bunch of x-ray crystallography studies revealed that no proton donor is in close proximity to C4 oxygen. ${ }^{[84]}$<smiles>O=C([O-])c1cc(=O)[nH]c(=O)[nH]1</smiles>

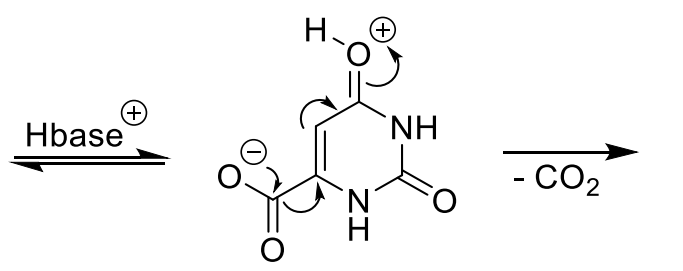<smiles></smiles><smiles>O=c1cc[nH]c(=O)[nH]1</smiles>

Figure 12: Proposed mechanism by LEE and Houk. ${ }^{[83]}$

In the end of 1999 till early 2000 the first crystal structures were obtained by different groups almost at the same time starting a period of new insights deduced from their structures. ${ }^{[77,85-87]}$ APPLEBY et al. published an electrophilic substitution mechanism in which protonation by Lys and decarboxylation occur in a concerted reaction. ${ }^{[77]}$ In addition, they described the destabilized ground state by electrostatic repulsion of the OMP carboxyl group and aspartic acid residue in the active site derived from UMP crystal structures (Figure 13). The $C 6$ of the substrate is in proximity to the positively charged lysine residue which was interpreted as a reason for destabilizing the ground state and stabilizing the transition state. These results were reinforced by secondary isotope effects. ${ }^{[77]}$<smiles>[R]n1c(C(=O)[O-])cc(=O)[nH]c1=O</smiles>

Figure 13: Mechanism proposed by APPLEBY.$^{[77]}$

GAO and PAI proposed their mechanism based on ground state destabilization due to "electrostatic stress" between the carboxyl group of OMP and the Asp of the catalytic tetrad as driving force for catalysis, derived from crystal structure of 6-aza UMP complexed in MtOMPD in combination with their results from quantum mechanics and molecular dynamics calculation in which they simulated OMP in the active site. ${ }^{[87]}$ The authors used to build their hypothesis on the fundament of combination of strong attractive and repulsive interactions in the active 


\section{Theoretical Background}

site which was first described by JENCKS as the circe effect. ${ }^{[62]}$ In OMPD active site the strong attraction comes from the intensive hydrogen network, especially around the phosphoribose moiety which can lead to changes in substrate geometry. ${ }^{[87]}$ The repulsive interaction described as "electrostatic stress" is embodied by carboxylic functions getting in close proximity pointing at each other. ${ }^{[87]}$

WARSHEL and coworkers were proposing the complete opposite. They mentioned that the driving force and the huge rate enhancement result rather from transition state stabilization than from ground state destabilization. ${ }^{[88-90]}$ The authors demonstrated by quantum mechanical/molecular mechanics (QM/MM) and empirical valence bond (EVB) calculations that a charged catalytic tetrad while having two carboxylic functions in proximity, also has a positively charged lysine which can stabilize a carboxylate. ${ }^{[88-90]}$

HARRIS et al. proposed another mechanistic idea based on the proximity of the OMPs carboxylate to the aspartate residue. Instead of stressing repulsive interactions they propose a short, strong hydrogen bond between carboxylate of the substrate and Asp residue which could then also lower the activation barrier of decarboxylation reaction. This assumption was made transferring their structural insight from BMP in complex with OMPD from Escherichia coli. ${ }^{[85]}$ In 2001, KOLLMAN and coworkers presented their research results in which they disproved the mechanistic approaches of BEAK and SIEGEL and the one of LEE and HOUK. They used the 2-thio and 4-thio analogs to be able to examine the role of position 2 and position 4 carbonyls. ${ }^{[84]}$ Both modifications led to a decrease of the enzyme activity. In case of the 4-thio analog the result was $50 \%$ reduction in $\mathrm{k}_{\mathrm{cat}}$. The position 2 exchange led to a drastic decrease, $\mathrm{k}_{\mathrm{cat}}$ was reduced by $10^{5}$, which was already discovered by SHOSTAK et al. and associated with more impact of $C 2$ in the substrate binding process than $C 4 .^{[11]}$ The before mentioned mechanism of BEAK and SIEGEL and of LEE and HOUK would not explain the difference in position 2 and position 4 substitution which also diminishes the ability of hydrogen bond formation respectively. ${ }^{[84]}$

KOLLMAN and coworkers performed gas phase ab initio QM calculations and molecular dynamic simulations. ${ }^{[91,92]}$ In addition, they predicted proton affinities and calculated logarithmic acid dissociation constants $\left(\mathrm{p} K_{\mathrm{a}}\right)$ of substrate functionalities and amino residues of the active site. ${ }^{[93]}$ The authors got to the conclusion that all before published mechanisms were incorrect to some extend and pointed out the results of other groups which were in conflict to each of the proposals respectively. ${ }^{[84]}$ Then, they mentioned five mechanistic ideas themselves: simple decarboxylation driven by ground state destabilization; protonation of $O 2, O 4, C 5$ or $C 6$ 
respectively, of which the $C 5$ position is energetically the most favorable. But the calculations of free energies and of the $\mathrm{p} K_{\mathrm{a}}$ values as well as the major origin of a ground state destabilization was in conflict to Wu et al. ${ }^{[87]}$

WOLFENDEN und MILLER published a mechanism in which the release of carbon dioxide was driven by electrostatic stress between OMP and Asp, by this agreeing with WU et al ${ }^{[7,86,87]}$ The resulting carbanion would be stabilized through the lysine in close proximity according to the authors. In addition, this transition state of 6-vinylic anion was supported by the high affinity of 6-hydroxy UMP (BMP) and calculations of $\mathrm{p} K_{\mathrm{a}}$ values of the $C 6$ carboxyl group. ${ }^{[27,70,71,86]}$ Furthermore they used mutational studies of the catalytic tetrad to evaluate the impact of the single residues, the exchange with Ala led to decreased activity by $10^{5}{ }^{[27]}$<smiles>O=C([O-])c1cc(=O)[nH]c(=O)[nH]1</smiles><smiles>CCOC(=O)O</smiles><smiles>O=c1cc[nH]c(=O)[nH]1</smiles><smiles>C[18CH]</smiles><smiles>O=c1cc[nH]c(=O)[nH]1</smiles>

Figure 14: Mechanism proposed by WOLFENDEN.

LEWIS et al. published new insights which dissent with their idea of electrostatic stress. ${ }^{[94]}$ They synthesized sulfite addition products of UMP and OMP and examined the influence of this electronegative substitution which should, in regard to the electrostatic stress theory, increase the repulsive interaction. Surprisingly, they found relatively good binding affinities of these substrates. ${ }^{[94]}$ They also discussed syn- and anti-conformation of these substrates in comparison to the data from 6-aza UMP, which is known to bind in anti-conformation. ${ }^{[94]}$

CHAN et al. published results of kinetic and structural studies using mutants of $M t O M P D$ and Saccharomyces cerevisiae OMPD (ScOMPD) and compared 5-fluoro OMP and OMP with the resulting products 5-fluoro UMP and UMP respectively. The fluorinated OMP is even a better substrate than OMP which is in agreement with SHOSTAK et al. ${ }^{[11]}$ The mutation of aspartic acid, D70N in MtOMPD and D91N in ScOMPD nomenclature led to decrease of activity. They also performed the reactions in semi deuterated water and found H/D in statistic amounts which excluded the selective and specific reaction in position $6 .{ }^{[95]}$ Furthermore they used the UMPH6 exchange rate in deuterium to calculate the $\mathrm{p} K_{\mathrm{a}}$ values in the active site. ${ }^{[96]}$

FUJIHASHI et al. published new crystal structures of 6-Me UMP and 6- $\mathrm{NH}_{2} \mathrm{UMP}$ bound to wild type and one mutant of MtOMPD and supported their findings with molecular dynamics and quantum mechanics. ${ }^{[30]}$ They found that the methyl substituent was distorted in regard to the 


\section{Theoretical Background}

pyrimidine plane and a sterically competition of $C 6$ substituent with Lys72 in 6-amino UMP. They suggested that this distortion leads to a lower activation barrier and supported this with calculations of $10-15 \%$. They concluded that destabilization of ground state as well as stabilization of transition state is part of the mechanism of OMPD. ${ }^{[30]}$

FUJIHASHI et al. proposed a mechanism, starting with OMP entering in syn-conformation the active site of OMPD. ${ }^{[97]}$ The binding process starts several changes in active site structure, especially closure of before flexible loop regions. ${ }^{[98,99]}$ The OMP carboxylate is close to the catalytic tetrad and in proximity to the hydrophobic pocket $\mathrm{Ile}_{96}, \mathrm{Leu}_{123}, \mathrm{Val}_{155}$ (nomenclature of $M t \mathrm{OMPD}$ ) which may be involved in hydrating the carboxylate. ${ }^{[100]}$ Steric repulsion and electrostatic interaction with $\mathrm{Asp}_{70}$ lead to substrate distortion, the needed energy is paid by the intensive hydrogen bond network. The most binding energy could be obtained from the phosphate group having five direct interactions and the authors mentioned the difference that the nucleoside was also converted but with a difference of 8 orders of magnitude. ${ }^{[101,102]}$ This is approximately the influence which was measured with OMPD mutants lacking the key interacting amino acids with the phosphate moiety. ${ }^{[102,103]}$ Then the carboxylate dissociates from the pyrimidine ring as $\mathrm{CO}_{2}$ leaving the negatively charged vinyl anion behind. ${ }^{[104]}$ The stabilization is pointed out as key interaction ${ }^{[95,96,105]}$, most probably with Lys72 and with additional interaction of Ser with the $C 4$ carbonyl oxygen. ${ }^{[106]}$ The final step is the neutralization of negative charge by proton transfer from the Lys72. ${ }^{[14]}$ Closing the mechanistic proposals subchapter by this presentation of FUJIHASHI and of all the information given above, the state of the art is concluded within the next subsection.

\subsubsection{State of the art}

The unique rate enhancement by OMPD, thus the difference in binding affinity of the ground state substrate and the transition state, raises the question how this can be attained by the given amino acid residues in the enzymatic pocket. It is a comparable simple arrangement of interactions with single residues, leading to a broad-spectrum of ideas and hypotheses. The majority of the scientific society supports the electrostatic repulsion mechanism based on ground state destabilization. Thereby, in the binding process the OMP's carboxyl group (assumed as carboxylate) is close to the negatively charged aspartic acid residue which would cause "electrostatic stress". ${ }^{[86,87]}$ This additional negative repulsive interaction was described to disfavor the position of the carboxyl group in the active site and by this promoting the decarboxylation reaction energetically. This proposed concept of binding interactions between 
enzyme and substrate while having a repulsive interaction was described by JENCKS as the circe effect. ${ }^{[62]}$ While there was immediate protest by WARSHEL and others, especially in pondering the impact of "electrostatic stress" and the resulting ground state destabilization with the transition state stabilization, the majority of publications are based on the stress mechanism. The state-of-the-art opinion emphasizes the formation of a localized vinyl anion at $C 6$ position after $\mathrm{CO}_{2}$ dissociation which interacts with the positively charged lysine residue. This local anion was supported by the fact that 6-hydroxy UMP (BMP) is the best-known inhibitor, assuming the 6-hydroxy group to be deprotonated. In structural studies many crystal structures were obtained, bearing a variety of inhibitors in divers OMPD species to deduce key interactions and mechanistic steps from these structures, but no direct finding against the stress mechanism was gained. ${ }^{[13,30,107]}$

The latest results were published by RICHARD and coworkers. They presented their results of mutational studies as well as calculation to evaluate the influence of the amino acid residues of the phosphate gripper loop and key residues of the pyrimidine umbrella. In addition, they divided the substrate into orotate, ribosyl and phosphate moiety to further investigate the needed stabilization energies of the transition state. The authors mentioned potential changes in enzyme's closed form geometry, which cannot be seen in crystal structure because every single modification or mutation will influence the observation. In addition, they performed measurements of isotope effects which also supported a stepwise decarboxylation and the presence of a local vinyl anion after $\mathrm{CO}_{2}$ cleave installing potential shielding interactions with the departing carbon dioxide. ${ }^{[15,108-111]}$ There is still need in getting better insight in the mechanism of OMPD and further investigations are need to clarify this controversy. 



\section{Motivation and Objective}

In this chapter, the interest in research in the field of OMPD is elucidated. The following subchapters are going to profess the general motivation and influence from medical investigation (chapter 3.1). The next subsections deal with the description of our research goals, project outline of this thesis and synthetic objectives regarding the later mentioned lead structures (chapter 3.2).

\subsection{General aspects}

The fascinating and challenging part in research about OMPD is that we are dealing with a textbook enzyme with high efficiency and activity. Despite all the effort and the abundance of mechanistic proposals which were mentioned before, the OMPD's mechanism remains not fully understood. ${ }^{[65]}$ In addition, the ongoing research is motivated by potential medical applications. ${ }^{[22]}$ The OMPD could be targeted in the field of drug design, more precisely in research of prodrugs, which are inactive substances with the aim to get metabolized to the active species. ${ }^{[12]}$ Approximately $10 \%$ of all medical drugs around the world are considered as prodrug. ${ }^{[112]}$ In addition, the field of prodrugs is expanding, there are already modified nucleosides approved by the Food and Drug Administration (FDA) divided into the prodrug type I subclass. ${ }^{[113]}$ Inspired by this gained interest a protide approach, origin of the name prodrug and nucleotide, is currently investigated aiming for modified nucleosides with medical potential. ${ }^{[114,115]}$ One medical application would be the specific inhibition of OMPD, which would slow down the biosynthesis and the cell growth. This also takes advantage of the fact that in rapidly dividing cells (cell proliferation) pyrimidine synthesis occurs mainly using the energy demanding pyrimidine de novo synthesis. ${ }^{[17,116]}$ That would also point to an inhibition of the de novo synthesis in case of cancer cells. ${ }^{[17,20]}$ Then, OMPD inhibitors would be possibly associated with anti-cancer nucleosides. ${ }^{[19,20,117]}$ Additionally, the therapeutic potential of OMPD inhibitors was already discussed in several publications with the following targets: malaria, leishmaniasis, bacterial infections and RNA viral infections. ${ }^{[118-124]}$ The anti-viral activity ${ }^{[125]}$ was attracting even more interest and public awareness since the global pandemic in $2020 .{ }^{[23]}$ Nevertheless, despite more than a hundred million infected people and many people 


\section{Motivation and Objective}

who died of the coronavirus disease 2019 (COVID-19), the most common infectious disease is malaria with about 200 million cases per year. ${ }^{[126]}$ One major difference between both is, COVD-19 is caused by the virus SARS-CoV-2 and malaria is caused by parasites of plasmodium group. ${ }^{[23,24]}$ Furthermore, SARS-CoV-2 is spread by droplet infection and malaria is spread by mosquitos as major disease carrier which are causing an estimated 1.2 million deaths per year in 2010. ${ }^{[25]}$ Infected mosquitos can be mainly found in tropic regions but also in the subtropic area, which is expanding due to the climate change. ${ }^{[127]}$ There are several antimalarial drugs available but the malaria causing parasite (plasmodium falciparum) has developed resistance towards most of them. ${ }^{[128]}$ However, plasmodia does not perform the salvage pathway, so it is completely dependent on the pyrimidine de novo synthesis. By inhibition of OMPD the metabolism of these parasites can be shut down, while the host organism can perform alternative pyrimidine synthesis; this makes the OMPD an important target. ${ }^{[21,120]} \mathrm{A}$ few inhibitors of OMPD have been tested regarding antimalarial activity with the most promising investigations regarding the covalent inhibitor 6-iodouridine by BELLO et al. ${ }^{[21,22,107]}$ In addition, a few studies were investigating OMPD inhibitors, not only inspired by the original substrate or known inhibitors, instead using computational studies and in silico screening. ${ }^{[24,129]}$ TAKASHIMA et al. presented 4-(2-hydroxy-4-methoxyphenyl)-4-oxobutanoic acid (HMOA) as their best inhibitor candidate, which is obviously not a nucleoside and interestingly it is not occupying the pyrimidine interactions with the active site, instead taking over the position of phosphate and additional interactions outside the enzymatic pocket. ${ }^{[129]}$

This represents the potential applications and impact of OMPD, but no matter if research focused on anti-viral, anti-cancer or anti-malaria drugs the enzyme inhibitor interactions need to be understood and therefore the OMPD mechanism further elucidated. As mentioned in chapter 2.3.3, most mechanistic proposals for OMPD were published around the turn of the millennium. ${ }^{[77,85,87,88]}$ At this time researchers were benefitting from the first crystal structures of OMPD of multiple organisms and ongoing improvements in x-ray crystallography and structure determination of macromolecules, especially of proteins. ${ }^{[77,84,85,87]}$ Nowadays an even better resolution is available and has the potential to shed light on previously inaccessible parts of crystal structures, obtaining the potential of massive improvements in revealing interactions at ultra-high resolution and giving hints towards enzyme mechanism. ${ }^{[31,32]}$

Since it was not possible to isolate the MiCHAELIS complex of OMP in OMPD, ${ }^{[26]}$ different strategies were used to get new insights regarding the mechanism. One approach is based on investigations regarding interactions of the original substrate and a modified enzymatic pocket 
by mutational studies, exchanging or removing single amino acid residues or small fragments to evaluate their contribution to enzyme-substrate interaction. ${ }^{[16,27,28,70]}$ Another possibility is to target these interactions or the specific active site residues by modifying the interacting positions of the substrate molecule to be able to rate their individual importance and eventually gain information about key mechanistic steps. ${ }^{[13,16,29,30]}$ Both approaches have been investigated for several years by different working groups. ${ }^{[7,13,15]}$ Various substrate analogs have been synthesized in recent years which help to complete the understanding of the mechanism. ${ }^{[13,21]}$ Furthermore, with newly synthesized substrate analogs in combination with modern x-ray crystallography techniques yielding ultra-high resolution crystal structures an excellent setup for research on OMPD mechanism is set. The enzymatic affinity as well as structural deductions can be investigated with a library of substrate analogs which can help to confirm or disprove proposed key interactions, postulated transition states or mechanistic steps.

Research in the DIEDERICHSEN group is focused on synthesizing lead structures with slight modifications in comparison to the original substrate, mostly at the position 6 and 5 of the pyrimidine ring, since these positions were found to interact with the catalytic tetrad. ${ }^{[13,16,29]}$ These target structures are designed to either mimic the OMP carboxy function electronically or sterically. Moreover, other lead structures are modified inspired by proposed transition states. In addition, substitution of position 5 was targeted to further investigate the influence of electron donating or electron withdrawing groups in comparison to the original substrate. ${ }^{[13,16,29]}$ In early studies of our working group, the substrate analogs shown in Figure 15 were synthesized by D. HEINRICH and investigation regarding the mechanism of OMPD was performed in cooperation with M. G. RUDOLPH. ${ }^{[13,29,130]}$

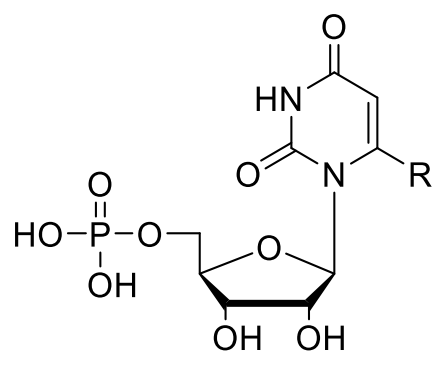

$\mathrm{R}=\mathrm{CN}(\mathbf{1 4}), \mathrm{I}(\mathbf{1 5}), \mathrm{N}_{3}(\mathbf{1 6}), \mathrm{OH}(\mathbf{1 7}), \mathrm{SH}(\mathbf{1 8}), \mathrm{PO}_{3} \mathrm{H}_{2}(\mathbf{1 9})$

Figure 15: Synthesized Inhibitors by D. HeINRICH. ${ }^{[13,29,130]}$

The best-known OMPD inhibitor, 6-hydroxy UMP (BMP, 17), and the corresponding thio analog, 6-mercapto UMP (18), were synthesized to analyze the ability of stabilizing a negative charge and evaluate the possibility of an anionic mechanism as proposed by MILLER and 


\section{Motivation and Objective}

Wolfenden. ${ }^{[71]}$ Further investigation about 6-iodo UMP and 6-azido UMP were made, identifying them as real covalent inhibitors. ${ }^{[21,107]}$ The interest in synthesizing 6-cyano UMP was pushed by the fact that FUJIHASHI et al. presented that MtOMPD and $h$ OMPD species show different behavior when 6-cyano UMP is complexed. In case of the human enzyme it is converted to UMP and for the OMPD from thermophilic bacteria 6-cyano UMP is converted to 6-hydroxy UMP. ${ }^{[75]}$ In addition first ideas of synthesizing electronically mimics of the carboxy function, like 6-phosphono UMP or 6-nitro UMP were considered. ${ }^{[130]}$ Based on the synthetic concepts and crystallization methods from these earlier studies the development of the current substrate analogs was initiated.

The aim of this thesis was the synthesis of new OMPD substrate analogs and investigations of the synthesized ligands using x-ray crystallography to be able to come up with new insights regarding the mechanism of the enzyme which may later be a helpful step for further applications. In the next subsection the synthetic procedures are described in detail.

\subsection{Synthetic objectives}

In general, there are few ways to synthesize or modify nucleosides and nucleotides. First, a divergent synthetic strategy of introducing the desired modification(s) directly into uridine moiety, in either the nucleoside or directly using nucleotide depending on the reaction, is shown in Figure 16. The major advantage of this divergent synthesis is that all stereo centers are set in the correct stereochemistry, especially the glycosidic bond. A disadvantage is the presence of the hydroxy groups which need a proper protecting group (PG) strategy to not interfere in the following reactions. On the stage of nucleotide, synthetic routes need to take into consideration tolerance for the phosphate group. Second, convergent synthetic pathways can be investigated, offering more synthetic opportunities and benefiting from numerous literatures. ${ }^{[20]}$ But the biggest drawback is the formation of the glycosidic bond which can lead to issues regarding stereochemistry. Nevertheless, this convergent pathway can be very helpful to make reactions work which need a more aromatic ring system as starting material (compare chapter 4.7). ${ }^{[131]}$ However, the divergent synthesis is favorable for synthesizing most of the OMP analogs and the convergent pathway will be only considered when needed, because of the low yields of nucleosidation reactions, independent of using silyl-HILBERT-JOHNSON reaction (VORBRÜGGEN) or other methods. ${ }^{[132-134]}$ 


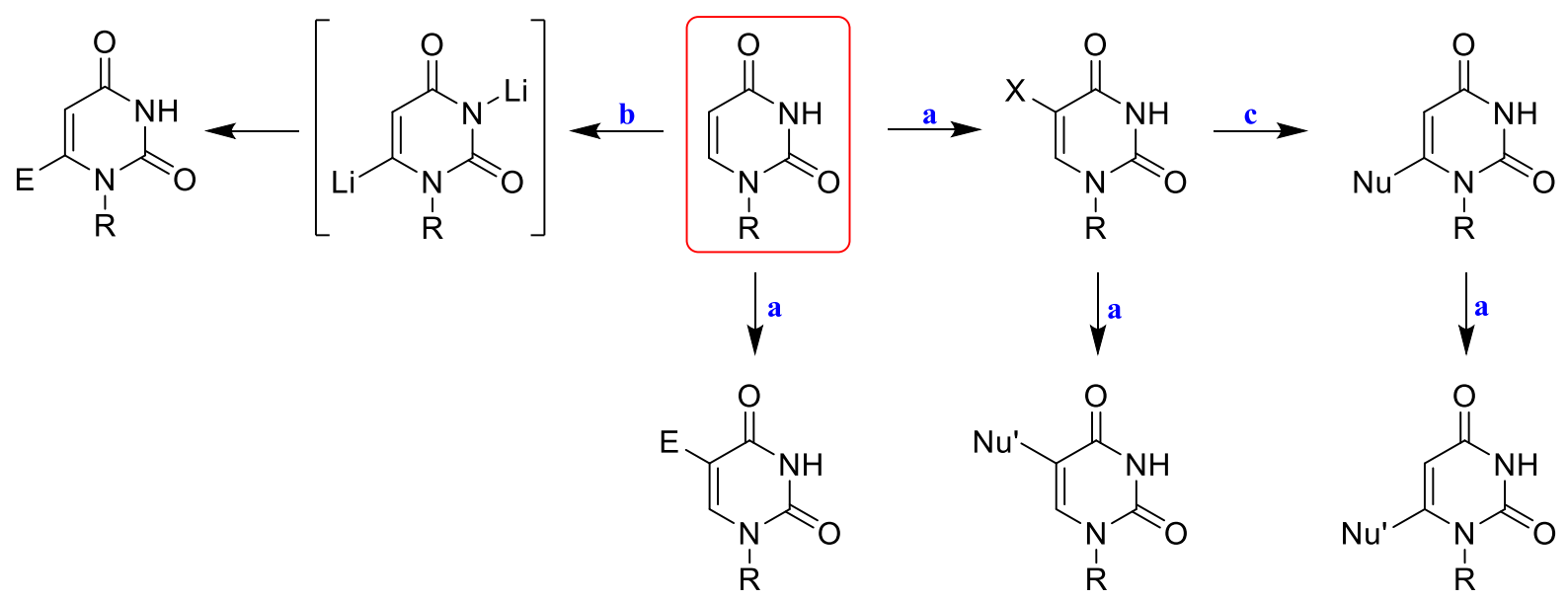

Figure 16: General synthetic strategy of modified uridines.

Depending on the desired modification of the lead structure, different reactions can be performed (Figure 16). Starting with the uridine scaffold substitution reactions, abbreviated as (a), can be conducted not differentiating in between nucleophilic substitution or electrophilic aromatic substitution. Comparable soft nucleophiles are abbreviated as (Nu) and rather hard nucleophiles as (Nu'). Electrophiles are represented as $(\mathbf{E})$ and Halogens as $(\mathbf{X})$. To be able to direct electrophiles in position 6 an umpolungs reaction, abbreviated as (b), needs to be performed ${ }^{[135]}$ Reaction step (c) embodies the introduction of softer nucleophiles by a MICHAEL like addition accompanied by elimination of the halogen in position 5 .

To be able to perform these pyrimidine modifications the ribose hydroxyl groups needed to be protected. There are many literature-known procedures of protecting the sugar hydroxy groups in nucleoside chemistry. Depending on the synthetic route different protecting groups (PGs) can be used in esterification or ether synthesis e.g., acetylation, trityls, silyls or cyclic groups are well known and established. ${ }^{[136,137]}$ Most of the reactions carried out in this thesis are using the combination of acid catalyzed acetal formation to protect the 2' and 3'-OH and silyl protection of 5'-OH sustaining orthogonality of PGs as shown in Figure 17. ${ }^{[138-140]}$

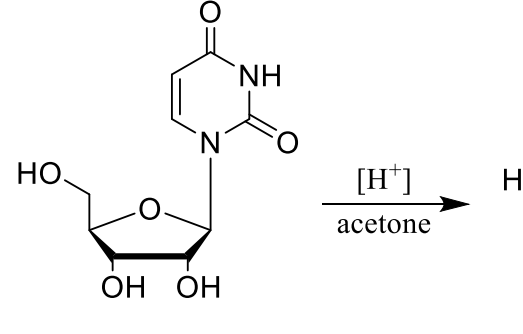

20<smiles>CC1(C)O[C@H]2O[C@@H](CO)[C@H](O1)[C@H](n1ccc(=O)[nH]c1=O)O2</smiles>

21

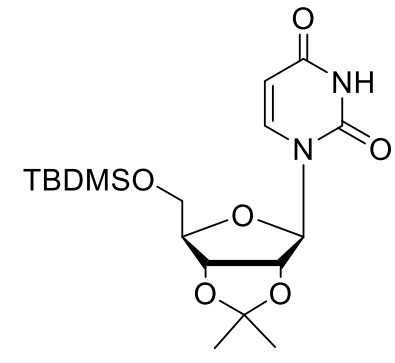

22

Figure 17: Standard procedure of hydroxy group protection in uridines. 
With the synthetic potential demonstrated above, the lead structures of this thesis are presented in Figure 18. Most of these structures were chosen to interact with the catalytic tetrad by mimicking the OMP carboxyl group. In contrast the cytidine derivatives were investigated to evaluate the interactions of position 4 carbonyls oxygen with active site $\operatorname{Ser}_{372}$. This is done by inverting the $\mathrm{H}$-bonding character from acceptor $(\mathrm{C}=\mathrm{O})$ interacting with Ser-backbone to donor $\left(\mathrm{NH}_{2}\right)$ potentially interacting with Ser-OH or weakening this hydrogen-bond. Furthermore, lead structures with missing 2'-OH, deoxynucleotides were considered which would elucidate the significance of 2'-OH interaction with $\mathrm{Thr}_{321}$. The individual motivation of each target molecule will be discussed in more detail in the following subsections.
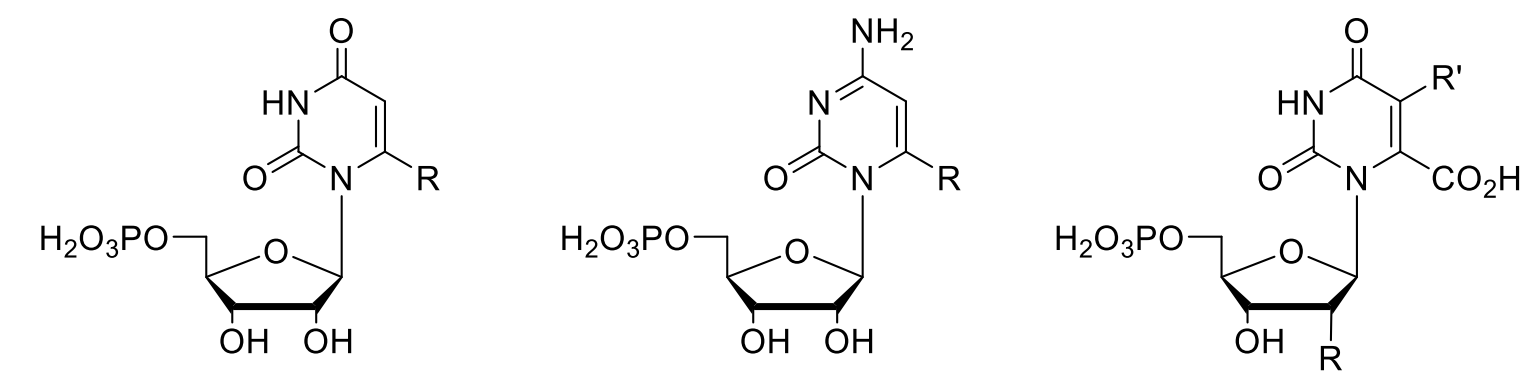

$$
\begin{aligned}
\mathrm{R}= & \mathrm{CSNH}_{2}(\mathbf{3}), \mathrm{CO}_{2} \mathrm{Me} \mathrm{(5),} \\
& \mathrm{B}(\mathrm{OH})_{2}(\mathbf{6}), \mathrm{Me}(\mathbf{7}), \mathrm{Et}(\mathbf{8}), \\
& \text { i-pr (9), propenyl (10) }
\end{aligned}
$$$$
\mathrm{R}=\mathrm{CO}_{2} \mathrm{H}(\mathbf{1 1}), \mathrm{CONH}_{2}(\mathbf{1 2})
$$$$
\mathrm{CO}_{2} \mathrm{Me}(\mathbf{1 3}), \mathrm{CN}(\mathbf{1 4})
$$$$
\mathrm{R}=\mathrm{OH} ; \mathrm{R}^{\prime}=\mathrm{H}(\mathbf{1}), \mathrm{Me}(\mathbf{2 3})
$$$$
\mathrm{R}=\mathrm{H} ; \mathrm{R}^{\prime}=\mathrm{H}(\mathbf{2 4}), \mathrm{Me}(\mathbf{2 5})
$$

Figure 18: Targeted lead structures of this thesis.

\subsubsection{Substrate analogs}

In the beginning of this project the lead structures were focusing on electronic similarities to the carboxylic function, investigating synthetic ideas of 6-boronic acid UMP and the isoelectronic 6-nitro UMP. The latter was attempted to be synthesized by M. KRULL, and the 6-boronic acid UMP was targeted within the scope of this thesis. In addition, isosteric lead structures were examined, inspired by derivatives like the carboxylic ester and carboxamide. The following target molecules were aimed to be synthesized and crystal structures tried to be obtained. Figure 19 shows a very important generation of target molecules representing a major part of this thesis. The 6-thioamido UMP is known as the second best inhibitor of OMPD. ${ }^{[7,141]}$ In addition, it is the substrate analog with the highest binding affinity, five orders of magnitude higher than 6-amido UMP. ${ }^{[7]}$ This was another motivation to further evaluate the influence of the sulfur in thioamide moiety in the active site of the enzyme in comparison to the 6-amido UMP which was aimed to be synthesized by M. KRULL. ${ }^{[16,34]}$ Another substrate analog we were seeking for is the 6-carboxy methyl ester UMP (OMP methyl ester) which bears a 
methyl unit instead of the proton, embodying minimal changes in H-bonding network as long as we precondition the carboxyl group in the active site as protonated. ${ }^{[30]}$<smiles>COC(=O)c1cc(=O)[nH]c(=O)n1C1O[C@H](CO[18OH])[C@@H](O)[C@@H](O)[C@@H]1O</smiles>

5<smiles>NC(=S)c1cc(=O)[nH]c(=O)n1C1O[C@H](COP(O)O)[C@@H](O)[C@H](O)[C@@H]1O</smiles>

3<smiles>O=c1cc(Br)n(C2OC(COP(O)O)[C@@H](O)[C@H](O)[C@H]2O)c(=O)[nH]1</smiles>

6

Figure 19: Left to right: OMP methyl ester, 6-thioamido UMP and 6-boronic acid UMP.

\subsubsection{Nonpolar substituted targets}

One goal of this project is the synthesis of position 6 nonpolar substituted UMPs to be able to examine steric demands in the enzymatic pocket without the influence of attractive or repulsive polar interactions. Within the scope of this thesis several nonpolar substituents were targeted, as shown in Figure 20.

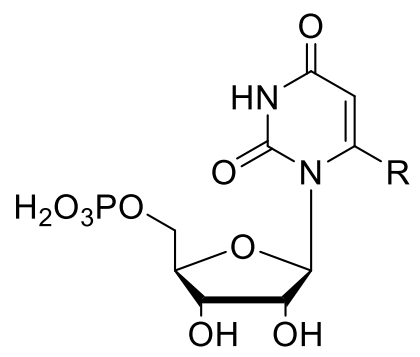

$\mathrm{R}=\operatorname{Me}(\mathbf{7}), \operatorname{Et}(\mathbf{8}), i-\operatorname{Pr}(\mathbf{9})$

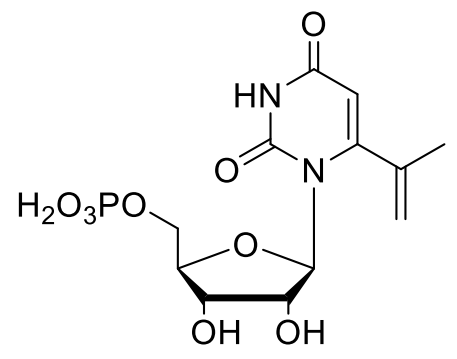

10

Figure 20: Non polar substituted lead structres.

The synthesis of 6-methyluridine was reported by BELLO et al. in the context of inhibitor screening of potential malaria agents. ${ }^{[142]}$ The nucleotide was synthesized by FUJIHASHI et al. observing a strong distortion of the 6-methyl substituent out of pyrimidine plane. They compared this deformed binding situation to their results of 6-cyano UMP and BMP. ${ }^{[30]}$ This should be further investigated within the scope of this thesis by synthesizing the 6-methyl UMP and obtaining the first crystal structure in $h \mathrm{OMPD}_{\mathrm{WT}}$, reevaluating the strain and distortion of the herein synthesized nonpolar substituted ligands of OMPD. Despite 6-methyl UMP we are interested in the trend of growing alkyl chain aiming to the synthesis of 6-ethyl and 6-isopropyl UMP. The latter will be synthesized by M. KRULL. In addition, 6-isopropenyl was investigated 


\section{Motivation and Objective}

as a lead structure, due to the double bond and the $\mathrm{sp}^{2}$ hybridized carbon center it would be an even better sterical mimic of the carboxyl group than 6-isopropyl UMP. Moreover, a crystal structure of 6-isopropenyl UMP could help further structure refinements as well as building potential constraints for modelling the OMP carboxyl group. This approach of optimizing models for x-ray crystallography by using data from similar crystal structures is used quite frequently, MiLlER et al. did this even for substrates with substantial differences, modeling OMP $(\mathrm{COOH})$ into a binding site observed from a BMP $(\mathrm{OH})$ complex even though sterical clashes resulted from this fitting. ${ }^{[86]}$

\subsubsection{Reduced OMP}

Besides the lead structures shown in the general overview, 5,6-dihydro OMP (reduced OMP) was chosen as a synthetic target to further investigate its crystal structure. The reduced pyrimidine moiety is similar to the transition state postulated by APPLEBY et al. and to SILVERMAN and GROZIAK. ${ }^{[77,80]}$ In addition, WOLFENDEN et al. published in 2007 that reduced OMP analogs can be substrates for OMPD, but they were not able to get a crystal structure which was another motivation to work on this target. ${ }^{[94]}$

The synthesis was attempted by D. HEINRICH in earlier studies, but it was not successful either because of side reactions or purification issues. ${ }^{[130]}$ The synthesis performed in this thesis is adapted from the literature known OMP synthesis with an reducing step in the very end yielding 5,6-dihydro OMP (Figure 21). Furthermore, CHAN et al. used the method from WOLFENDEN to synthesize this lead structure and in contrast to WOLFENDEN, Chan was able to get a crystal structure of the reduced OMP in $M t O M P D C$ at a resolution of $2.5 \AA$ which is rather low. ${ }^{[143]}$

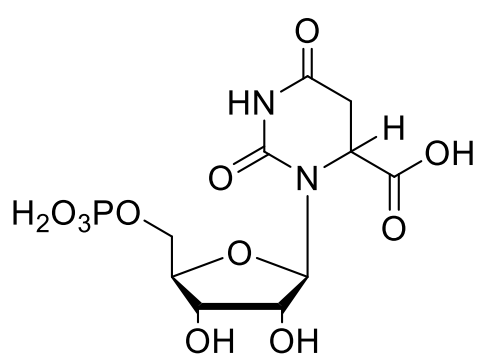

26

Figure 21: Reduced OMP. 


\subsubsection{Modifications in position 4}

Most of the desired target molecules are aiming to a modification in position 6 being similar to the carboxy function of OMP, since the major interactions of catalytic tetrad (Asp-Lys-AspLys) are in proximity with the C6-substituent. Both the carbonyls in position 2 and position 4, were also under investigation e.g., by substitution with the thio analogs and the resulting decrease in catalytic activity. ${ }^{[11,84]}$ In addition, the constitution of the carbonyls was discussed in the BMP complexes, investigating the double bond character of them, especially the potential C-6 hydroxyl group in BMP by M. KRULL. ${ }^{[16,34]}$

LEE et al. claimed $C 2$ and $C 4$ modifications were not tolerated by OMPD. ${ }^{[84]}$ In case of cytidine scaffold, a few complexes of CMP derivatives were investigated by WU and PAI. ${ }^{[144]}$ The authors showed that the cytidine was less efficient in binding to the active site $\left(10^{-3}\right.$ or undetectable inhibition). ${ }^{[145]}$ In contrast, they synthesized $N 4$ modified CMPs (N4-OH) which were bound in similar manner into the active site like BMP and UMP. ${ }^{[146]}$ Surprisingly, SMILEY and SALEH reported their finding that CMP carboxylate isn't tolerated by OMPD. ${ }^{[63]}$

In this thesis the OMP carbonyl in position 4 should be exchanged by an amino function which can be done replacing the synthetic scaffold of uridines by synthetic approaches of cytidine derivatives (Figure 22). This would invert the H-bonding character of our ligand, yielding a $\mathrm{H}$-bond donor instead of the carbonyl as H-bond acceptor interacting with Ser 372 of the active site. In addition, the thio analogs are also promising targets for further investigations of differences of carbonyls vs. thiocarbonyl, and their interactions in the active site.
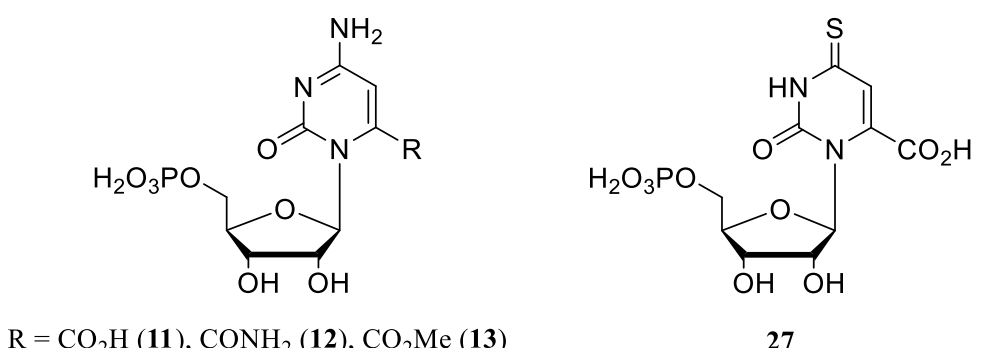

27

Figure 22: Position 4 modified targets.

\subsubsection{Thymidine targets}

The latest generation of lead structure is inspired by thymidine and deoxy uridine. In early studies, it was proposed that the enzyme is not tolerating changes in the phosphate or the ribose moiety, ${ }^{[7]}$ since these modifications would switch off high energetic interactions in the 
enzymatic pocket, especially the phosphate gripper loop. ${ }^{[15,70]}$ In recent studies, the exchange of single interactions was possible and their impact could be evaluated. Replacement of 2'-OH with fluorine by LEWIS et al. did not change the general interaction enzyme-substrate interaction, but weakened the binding affinity. ${ }^{[147]}$ RICHARD and coworkers were able to predict the different contributions of the loop amino acids to the hydrogen-bond network using mutational studies. ${ }^{[111]}$

In this thesis, the OMP analogs missing the 2'-OH were targeted as well as an additional 5-methyl group, moving from uridine to thymidine scaffold (Figure 23). To be able to discuss the differences between OMP and 6-carboxy TMP the other two lead structures 23, 24 were formulated. This will be helpful to divide the differences either in x-ray structures or in kinetics, binding affinity behavior to the 5-methyl group and the 2'-OH group. In case of the deoxy lead structures the used protecting agents needs to be adapted, but the general synthetic pathway should be taken from OMP synthesis.

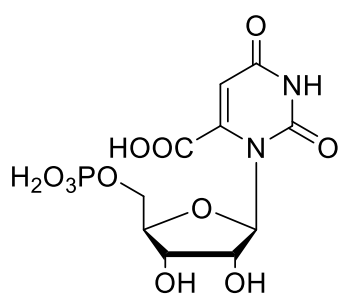

1

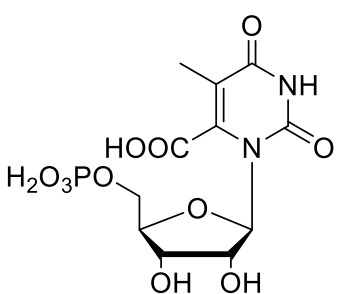

23

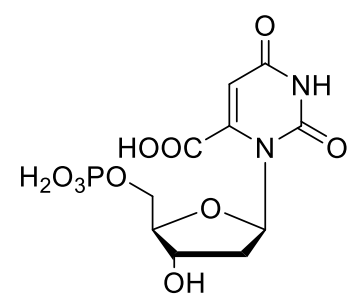

24

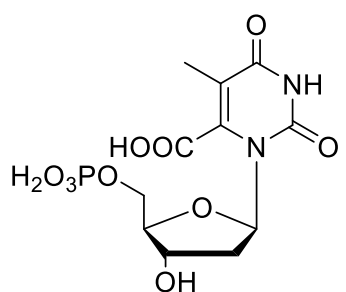

25

Figure 23: Targets bearing 5-Methyl and/or missing 2‘-OH group.

The synthetic results as well as the evaluation of obtained crystal structures of all the abovementioned lead structures will be further discussed within the next chapter. 


\section{Results and Discussion}

In this chapter, the results of the beforehand mentioned synthetic approaches and the crystallographic data of lead structures are evaluated. The following subchapters are dedicated to each of the lead structures, respectively. Starting with the lead structures of which crystal structures were obtained, the first subchapter deals with the isosteric substrate analog and the second-best inhibitor ${ }^{[7]}$ 6-thioamido UMP (chapter 4.1). In the next subchapter the nonpolar substituted targets namely 6-methyl, 6-ethyl, 6-isopropyl and 6-isopropenyl UMP are discussed (chapter 4.2), followed by a comparison and conclusion of all the obtained data (chapter 4.3). Then two lead structures with successful synthesis but without obtaining crystal structure are evaluated, OMP methyl ester (chapter 4.4) and reduced OMP (chapter 4.5). The results of synthetic approaches towards 6-carboxy CMP can be seen in chapter 4.6 and 6-boronic acid UMP in chapter 4.7. The last subchapter will present further attempts regarding 5-methyl OMP and 6-carboxy TMP (chapter 4.8).

\subsection{6-Thioamido UMP}

Herein, the synthesis of 6-thioamido UMP is described (chapter 4.1.1) and the resulting crystal structure is discussed (chapter 4.1.2), especially in comparison with the 6-amido UMP and OMP in complex with the mutant $h \mathrm{OMPD}_{\mathrm{Ac} 314 \mathrm{~K}}$ (chapter 4.1.3).

\subsubsection{Synthesis}

The general idea for the setup of the synthesis of 6-thioamido UMP was inspired by the procedure of synthesizing 6-cyanouridine published by INOUE and UEDA, followed by basic additions of $\mathrm{H}_{2} \mathrm{O}$ and $\mathrm{H}_{2} \mathrm{~S}$, respectively, to obtain amide or thioamide functionalities. ${ }^{[141,148]}$ The synthesis started with commercially available uridine (see Figure 24). In the first step, position 5 of the pyrimidine ring was brominated using NBS in DMF in good yield. Next the free hydroxy groups were protected by acid catalyzed acetal formation of 2' and 3'-OH with acetone and subsequently tert-butyldimethylsilyl chloride (TBDMSCl) as protecting agent of 5 '-OH to maintain orthogonality of protecting groups, both in very good yields. ${ }^{[136,139]}$ This step was followed by the introduction of the cyano functional group in position 6 of the pyrimidine ring 


\section{Results and Discussion}

by a MICHAEL addition. ${ }^{[148]}$ This introduction was optimized by adjusting equivalents and temperature, because both excess of cyanide and high temperature with longer reaction time lead to the side product 5-cyanouridine. ${ }^{[148]}$<smiles>O=c1ccn(C2OC(CO)C(O)C2O)c(=O)[nH]1</smiles>

$\mathbf{2 0}$

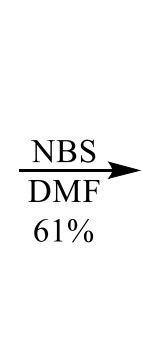<smiles>O=c1[nH]c(=O)n(C2OC(O)C(O)C(O)C2O)cc1Br</smiles>

28<smiles>CC1(C)OC2OC(CO)C1OC2n1cc(Br)c(=O)[nH]c1=O</smiles>

29<smiles>CC(C)COCC1OC2OC(C)(C)OC1OC2n1c(C#N)cc(=O)[nH]c1=O</smiles>

31

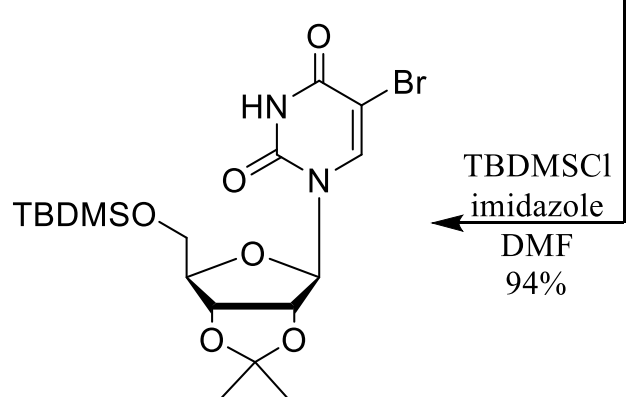

30

Figure 24: Synthesis of protected 6-cyanouridine.

In the next step, the cyano functionality was transformed into the thioamide by addition of hydrogen sulfide under mild basic conditions. This was followed by deprotection of the hydroxy groups yielding compound $\mathbf{3 3}$ shown in Figure 25.<smiles>CC(C)COCC1CC2OC(O1)OC2n1c(C#N)cc(=O)[nH]c1=O</smiles>

Figure 25: Synthesis of 6-thioamidouridine.

The attempted phosphorylation reaction as shown in Figure 26 was performed multiple times, following two major synthetic approaches. ${ }^{[149]}$ One using phosphoryl chloride in trimethyl phosphate and a comparable mild reaction condition using phosphoryl chloride in the presence of water and pyridine in acetonitrile. ${ }^{[150]}$ In some attempts the starting material was reisolated and to some extend the glycosidic bond was cleaved. However, the different conditions were 
tested modifying the reaction time, temperature and equivalents, unfortunately the formation of lead structure 3 was not successful.<smiles>NC(=S)c1cc(=O)[nH]c(=O)n1C1OC(O)C(O)C1O</smiles>

33

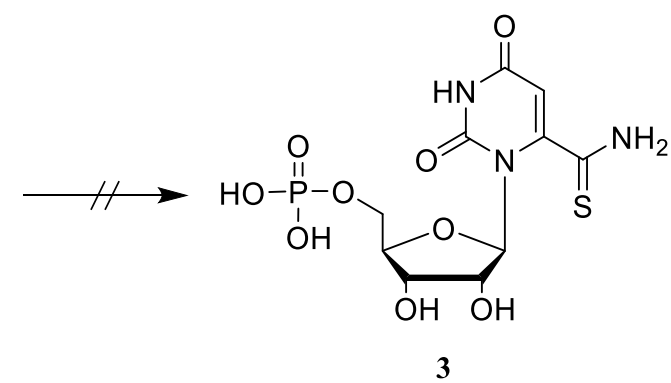

3

Figure 26: Attempted phosphorylation reaction.

That is the reason why the deprotection and phosphorylation of 6-cyanouridine was taken into account. The protected 6-cyanouridine (31) was deprotected with methanolic $\mathrm{HCl}$ yielding 6-cyanouridine (34), which was directly used in the subsequent phosphorylation reaction. 6-Cyano UMP (14), which was the product of the former described reaction, was purified by HPLC using ion-exchange chromatography and therefore was obtained in good yield and high purity. This compound (14) was then suspended in pyridine, $\mathrm{H}_{2} \mathrm{~S}$ solution was added and stirred overnight to yield the lead structure (3). More information regarding the reaction conditions, the analytics or the HPLC purification is to be found in the experimental part and the appendix.

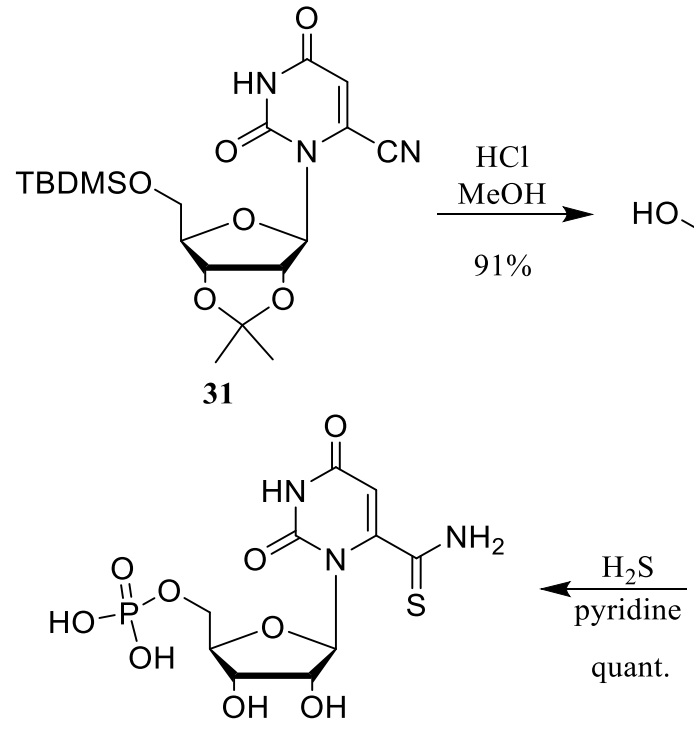

3<smiles>CCc1cc(=O)[nH]c(=O)n1C1O[C@H](CO)[C@@H](O)[C@H]1O</smiles>

34<smiles>N#Cc1cc(=O)[nH]c(=O)n1C1O[C@H](O)[C@@H](COP(=O)(O)O)[C@H](O)[C@@H]1O</smiles>

Figure 27: Synthesis of 6-thioamido UMP. 


\section{Results and Discussion}

\subsubsection{Crystal structure}

To gain more information about the enzyme-substrate complex, the human wildtype OMPD ( $h \mathrm{OMPD}_{\mathrm{WT}}$ ) was pre-crystallized and 6-thioamido UMP solution $(10 \mathrm{mM})$ was soaked into the resting state crystals. The crystals were measured at "Deutsches Elektronen-Synchrotron" (DESY) at beamlines 13 and 14 in Hamburg. The Data collection was obtained with a resolution of $1.20 \AA$ in the $\mathrm{C} 222_{1}$ space group, the asymmetric unit carrying one monomer.

Assuming the protonated form of the carboxyl group of OMP in the enzyme's active site, 6-amido UMP and 6-thioamido UMP can be seen as isosteric substrate analogs. In addition, the thioamide or amide functionalities are expected to be hydrogen bond acceptors interacting with Asp $_{312}$. Figure 28 shows that the ligand is bound to the active site in syn-conformation and that the loop region is in closed conformation. The thioamide group is tilted out of the pyrimidine plane by $12^{\circ}$ and a torsion angle of $82^{\circ}$ can be measured. The thioamide is in proximity to the catalytic tetrad with different interactions as expected for the transition state analogs. ${ }^{[16]}$ Lys 314 is shifted out of its original position due to the steric demand of the thioamide. The Lys 314 position in thioamide complex is also more far away from the $\mathrm{Asp}_{317}$ and closer to His 281 which is rotated by $180^{\circ}$ in comparison to the resting state crystal (for simplification reasons not shown in the picture). This may also give a hint, that His 281 is involved in the H-bond network and potential proton/electron transfer processes.

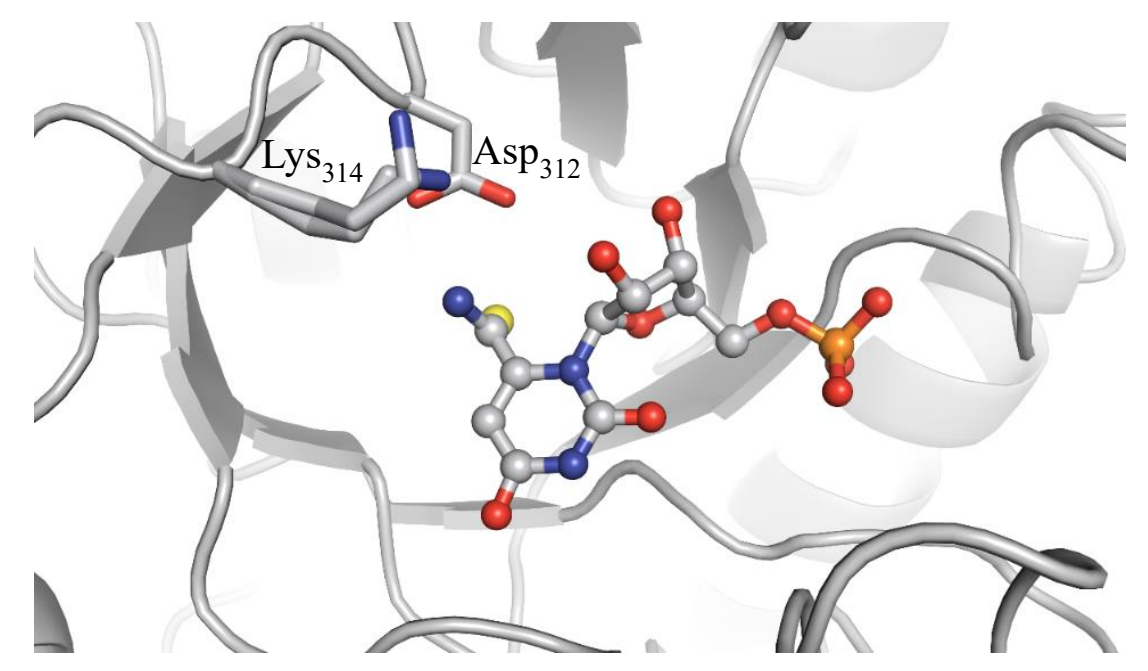

Figure 28: Structure of 6-thioamido UMP in complex with $h$ OMPDwT. 


\subsubsection{Comparison with other structures}

To be able to compare the structure of 6-thioamido UMP with 6-amido UMP the crystal structure of the $h \mathrm{OMPD}_{\mathrm{wT}}$ 6-amido UMP complex is shown in Figure 29. Both complexes result in a similar overall picture: the ligands are tightly bound, the pyrimidine moiety is in syn-conformation, the loops are in closed conformation and the $C 6$ functionality is pointing in the direction of the catalytic tetrad. Inside the tetrad the hydrogen bonds remain very similar between Lys314, Asp312, Lys281, Asp' 317 and His281. Having a closer look at the H-bond network, a few differences can be seen. First, the thioamide H-bond with $\mathrm{Asp}_{312}$ is formed to the other oxygen of the Asp-carboxylate by this yielding a slightly shorter bond ( $2.86 \AA$ ) compared to the amido H-bond with Asp-carboxylate (2.93 $\AA$ ). Second, the thioamide is closer to Asp' 317 which could indicate an additional H-bond formation. Third, as described above, some of the residues have a second conformation with just slightly different positions. In case of the 6-amido UMP the Lys 281 is having two conformers (70:30 occupancy), in the pocket with 6-thioamido UMP it is just one conformation.

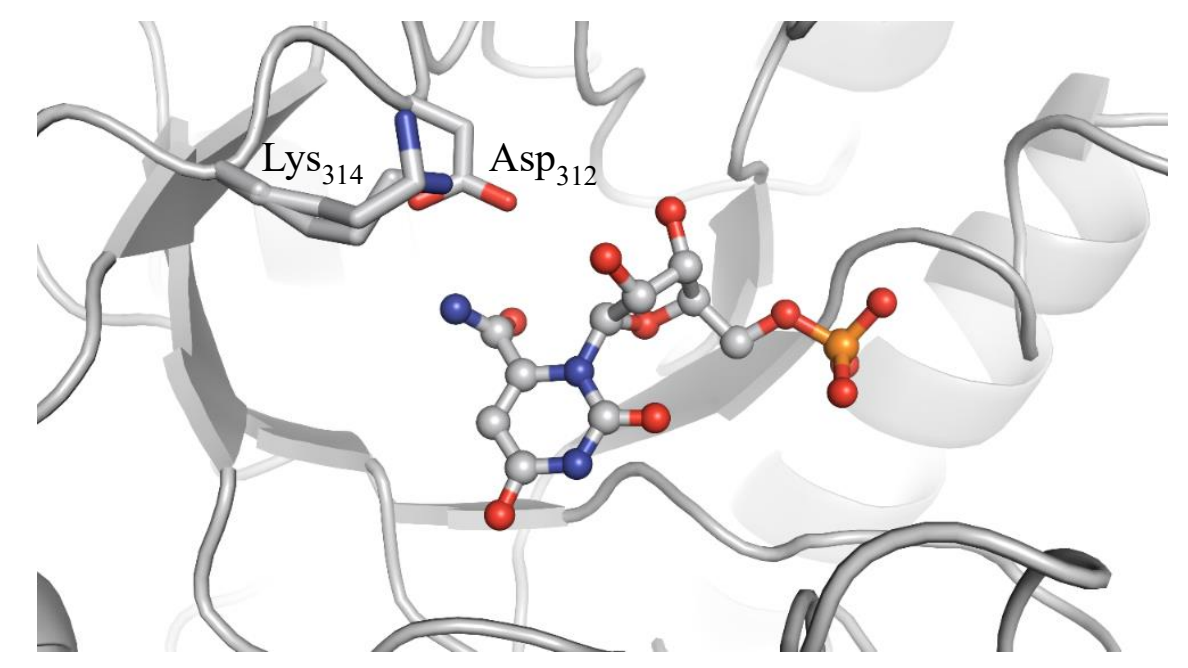

Figure 29: Structure of 6-amido UMP in complex with $h \mathrm{OMPD}_{\mathrm{wT}}$.

The above-mentioned observations should be compared to a OMP complex. Since the original enzyme-substrate complex cannot be observed in crystal structure due to the high reactivity, ${ }^{[26]}$ the mutant $\mathrm{OMPD}_{314 \mathrm{AcK}}$, bearing an acetylated Lys 314 , was investigated by S. RINDFLEISCH to be able to get structural information with OMP. The crystallized OMP in $h \mathrm{OMPD}_{314 \mathrm{AcK}}$ shows a similar ligand orientation and angles than in the 6-amido UMP and 6-thioamido UMP complexes in the $h \mathrm{OMPD} \mathrm{wT}_{\mathrm{W}}$ (Figure 30 ). The phosphate gripper loop is fully closed, which indicates a high occupancy of inhibitor as for the 6-amido UMP and 6-thioamido UMP. The OMP is bound in syn-conformation and the carboxyl group is close to Asp $\mathrm{p}_{312}$. The general arrangement of the catalytic tetrad is similar to the ones in the $h \mathrm{OMPD}_{\mathrm{WT}}$ complexes, except 


\section{Results and Discussion}

for the acetylated Lys314, of course, which adopts an alternative position. The distance between the Asp 312 and the OMP carboxyl group was measured $2.45 \AA$, indicating the formation of a hydrogen bond, ${ }^{[16,33]}$ rather than having "stressed" repulsive interactions.

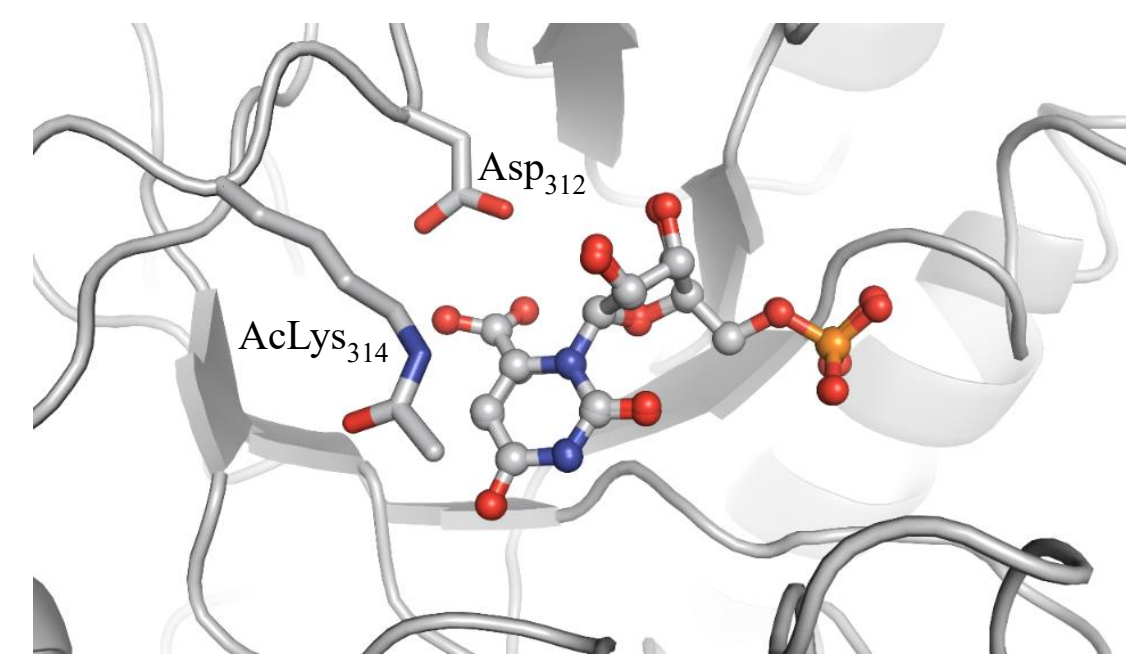

Figure 30: Structures of OMP in complex with $h \mathrm{OMPD}_{\mathrm{Ac} 314 \mathrm{~K}}$.

In Figure 31 the crystal structures of the ligands are shown to illustrate the torsion angle, out of plane distortion and the orientation of the $C 6$-substituent more clearly.

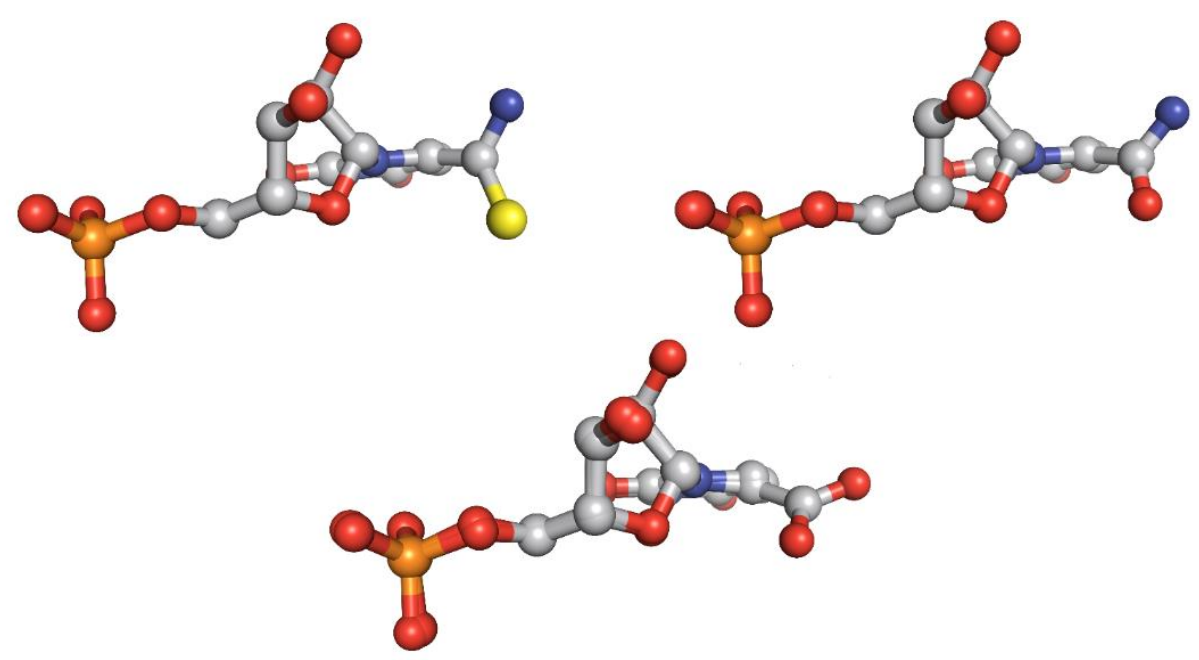

Figure 31: Crystal structures of 6-amido UMP, 6-thioamido UMP in the wild type enzyme and OMP in $\mathrm{OMPD}_{\mathrm{Ac314K}}$. The position of the phosphate and ribose is in all of the three nearly identical, just the C6 substituent has different position and angles, respectively.

Beside the substrate analog structures, we were interested in the crystal structures of the proposed transition state analogs. Therefore, BMP and 6-aza UMP were synthesized by M. KRULL and co-crystallized with $h$ OMPDwT performed by S. RINDFLEISCH. ${ }^{[16,33,34]}$ BMP is 
the best-known inhibitor ${ }^{[151]}$ of OMPD which was referred to the $C 6$ hydroxy group which should be deprotonated in regard to the state of the art opinion. ${ }^{[7]}$ The obtained crystal structure of BMP in $h \mathrm{OMPD}_{\mathrm{WT}}$ clearly indicates no difference in bond length between the $C 2(1.24 \AA)$ and $C 4(1.26 \AA)$ carbonyls and the $C 6(1.25 \AA)$ hydroxy/carbonyl function. In addition, none of the oxygen was protonated which can be easily seen at atomic resolution below $1.0 \AA$.

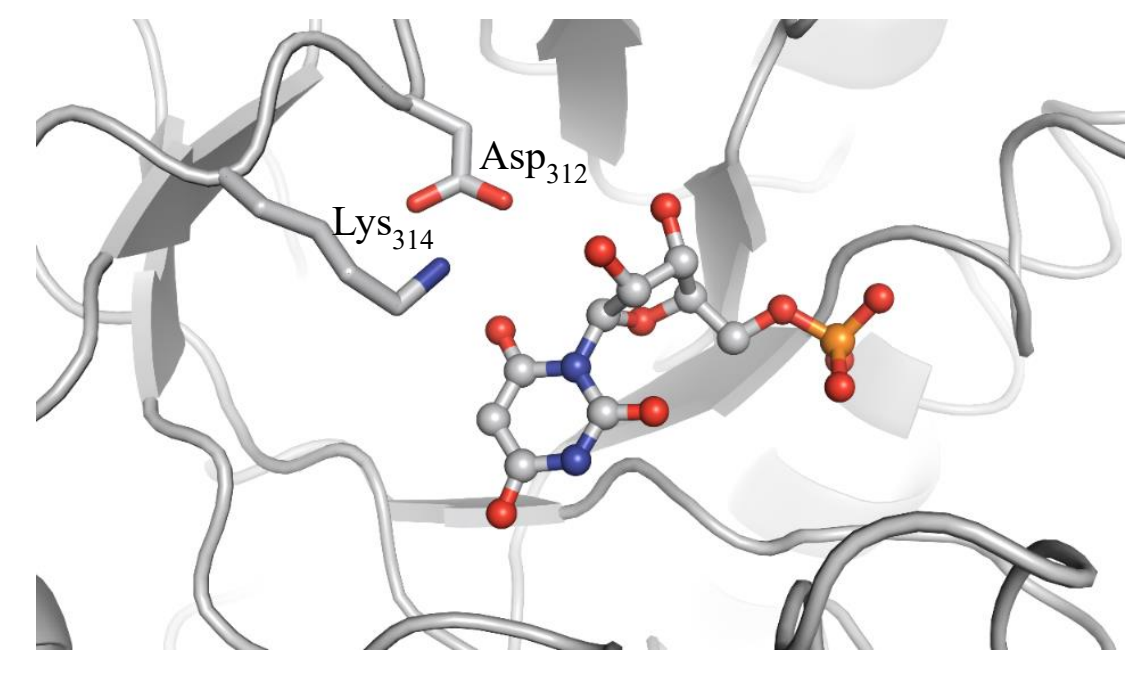

Figure 32: Crytal structure of BMP complexed in $h$ OMPDWT.

6-Aza UMP, the inhibitor with the second highest affinity, ${ }^{[151]}$ should support the state of the art opinion with the N6 lone pair as the localized negative charge. But the structure shows clearly the pyrimidine is in anti-conformation, which leads to $C 2$ carbonyl points towards the catalytic tetrad and N6 into direction of Gln 430 (Figure 33). This is additionally important, because lots of the early pro "electrostatic stress" publications were based on 6-aza UMP structures and calculations, assuming the $N 6$ being close to the tetrad, but this is not the case.

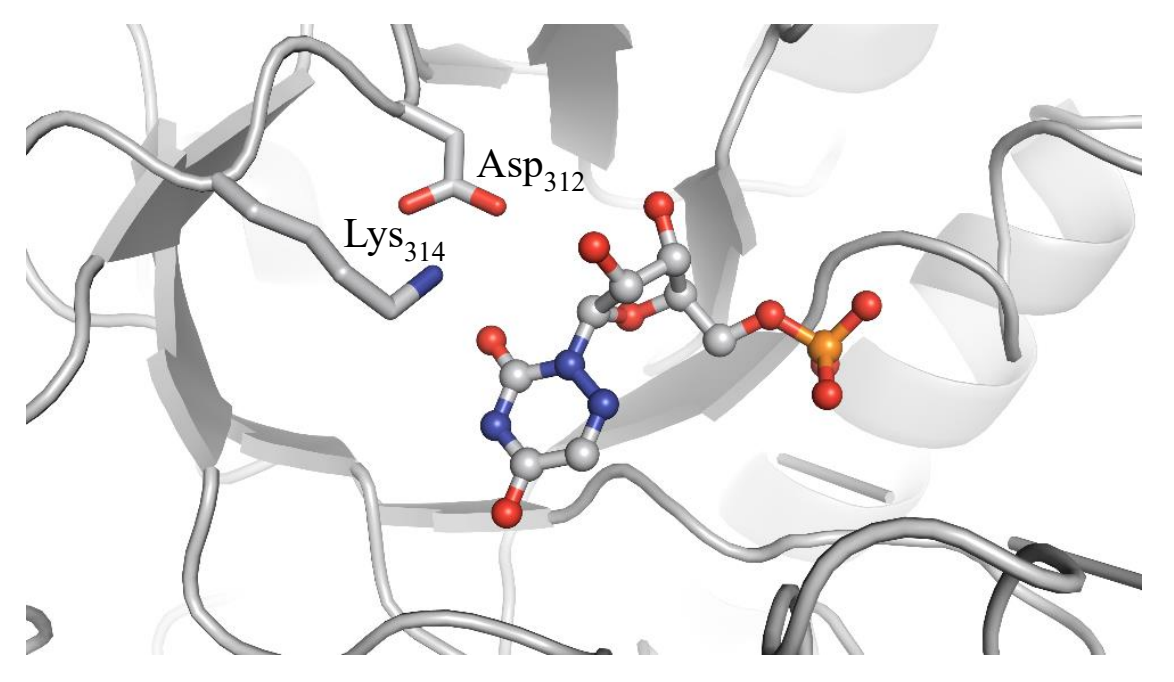

Figure 33: Crytal structure of 6-aza UMP complexed in $h O M P D_{W T}$. 


\subsection{Nonpolar substituted targets}

In this subchapter, the idea of synthesizing nonpolar substituted UMPs is described more in detail. The main reason for seeking after this target molecules is to be able to judge steric demands of substituents in the enzymatic pocket without having the influences of polar interactions. We are aiming at the synthesis and structural investigation of 6-methyl UMP, 6-ethyl UMP, 6-isopropyl UMP and 6-isopropenyl UMP. There are in general many synthetic possibilities divided into three major ideas for achieving this $\mathrm{C}-\mathrm{C}$ bond formation. First, as introduced in the general synthetic chapter, using electrophilicity and direct these electrophiles in either position 5 or 6 , the latter can be achieved after inverting polarity by an umpolung reaction. ${ }^{[135]}$ In this case, the alkyl reagents will react as alkyl halides as shown in Figure 34.

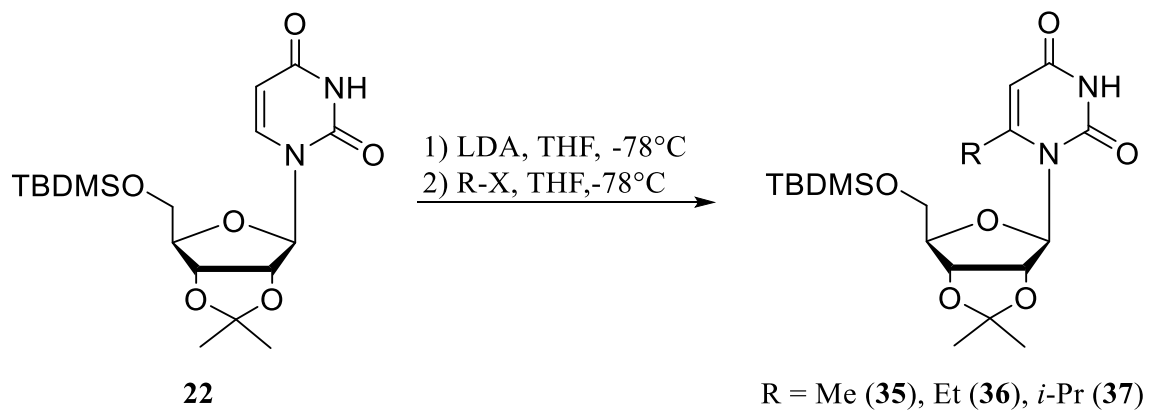

Figure 34: Reaction pathway of introducing alkyl substituents.

As a second synthetic idea, one could perform an alternative approach published by SHIH et al. using GRIGNARD reagents of the desired alkyls to react with 6-cyanouridines (Figure 35). ${ }^{[152]}$ This seemed to be a very promising pathway since the synthesis of 6-cyanouridine is well established in our working group through earlier studies and needs to be performed within the scope of this thesis regarding the synthesis of amide and thioamide substituted derivatives. $^{[130,148]}$

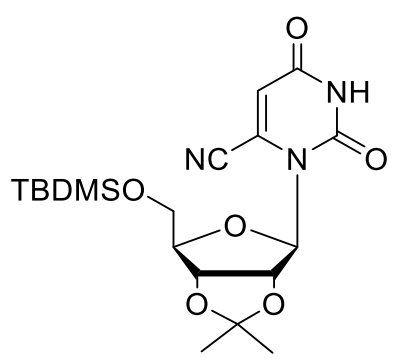

31
$\mathrm{R}-\mathrm{MgX}$
$\underset{\mathrm{ZnCl}}{2}$,

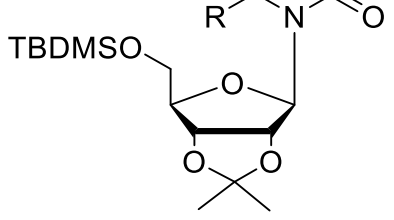

$\mathrm{R}=\operatorname{Me}(\mathbf{3 5}), \operatorname{Et}(\mathbf{3 6}), i-\operatorname{Pr}(\mathbf{3 7})$

Figure 35: Synthetic pathway of alkyl uridines using Grignard reagents. ${ }^{[152]}$ 
The third synthetic approach is probably the most famous and nowadays most common in use, the cross-coupling reaction. The utilization of cross-coupling reactions in organic synthesis and pharmaceutical chemistry is outstanding, with an estimated $25 \%$ of all reactions in pharmaceutical industry consisting of cross-coupling reaction. ${ }^{[153]}$ Furthermore, they are also found in the field of nucleoside modifications. ${ }^{[154]}$ However, one limitation is the introduction of alkyl substituents in sufficient manner due to carbon $\mathrm{sp}^{3}$ hybridization. ${ }^{[155]}$ In comparison, approaches for the use of cross-coupling reaction with aromatic, vinylic or allylic reagents are known for nucleosides. ${ }^{[155-157]}$ For these targets with either $\mathrm{sp}$ or $\mathrm{sp}^{2}$ hybridized carbon the cross-coupling is the reaction of choice. From all the different cross-coupling reactions, the first attempts will be SUZUKI-MIYAURA couplings shown in Figure 36. In addition, SHIH and CHIEN reported the synthesis of 6-aryluridines using cross-coupling reaction. ${ }^{[157]}$

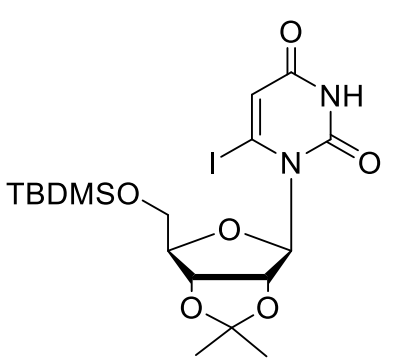

38

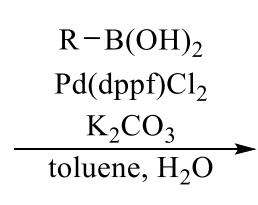

$\underset{\text { toluene, } \mathrm{H}_{2} \mathrm{O}}{\stackrel{\mathrm{K}_{2}}{\longrightarrow}}$

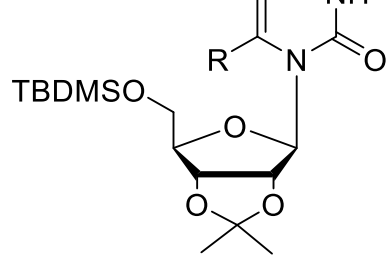

$R=\prod^{29}$

Figure 36: Synthesis of 6-aryl- or 6-vinyl uridines using Suzuki Miyaura coupling.

With these three possible pathways in mind, all targeted nonpolar lead structures were successfully synthesized and crystallized in human wild type OMPD ( $h$ OMPDwT). First, the synthetic procedure of the introduction of nonpolar substituents was performed using an umpolung reaction and alkyl halides, but the decreasing reactivity with longer alkyl chain $(\mathrm{MeX}>\mathrm{EtX}>i$-PrX) drastically lower the yield of this reaction. Therefore, these target molecules were additionally tested in the approach of SHIH et al. based on alkyl GRIGNARD compounds to react with 6-cyanouridines. ${ }^{[152]}$ The following subchapters deal with the evaluation of synthesis and crystal structures of 6-methyl UMP (chapter 4.2.1), 6-ethyl UMP (chapter 4.2.2) and 6-isopropenyl UMP (chapter 4.2.3), respectively. The last subsection compares the observations from crystal structures with each other and in addition with the structure of 6-isopropyl UMP from KRULL. ${ }^{[34]}$ 


\section{Results and Discussion}

\subsubsection{6-Methyl UMP}

The synthesis of 6-methyl UMP was adapted from BELLO et al. with slight modifications as shown in Figure 37. ${ }^{[142]}$ The first steps of the synthesis were the protection of the hydroxyl groups using an acid catalyzed acetal formation as protection of 2'-OH and 3'-OH and a silyl protection with TBDMSCl of 5'- $\mathrm{OH}$. Followed by an inversion of the reactivity by lithiation which was used to enable electrophiles to attack at position 6 of the pyrimidine ring. ${ }^{[135]}$ The methylation was performed using methyl iodide at low temperatures obtaining the protected 6-methyluridine (35). The deprotection was done in methanolic $\mathrm{HCl}$ resulting compound (40) in quantitative yields. The phosphorylation following protocols of SOWA and OUCHI led to lead structure (7). which was obtained as bis(triethyl) ammonium salt, purified twice using ion-exchange chromatography followed by reversed-phase chromatography, both in preparative HPLC scale. ${ }^{[150]}$

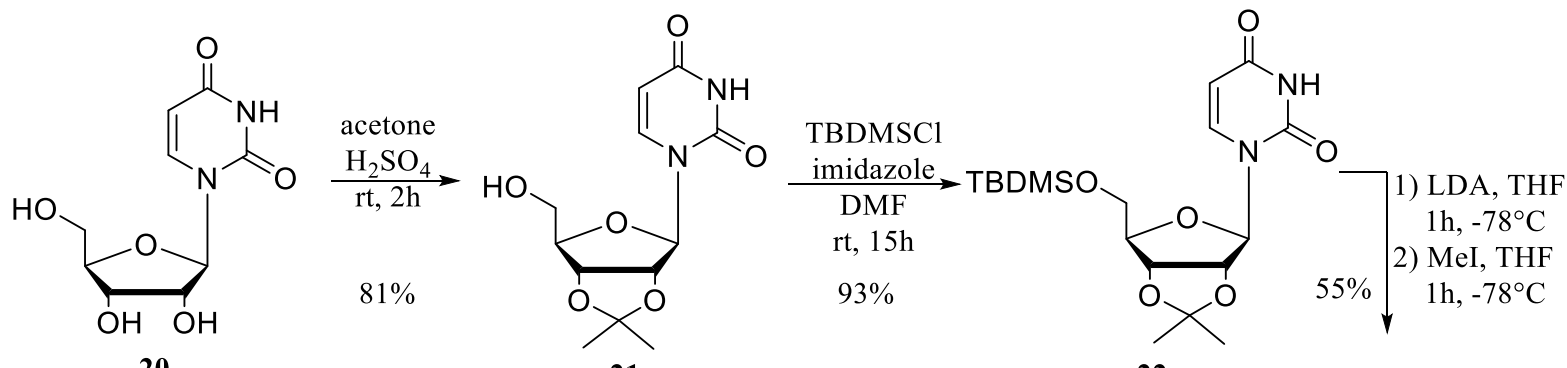

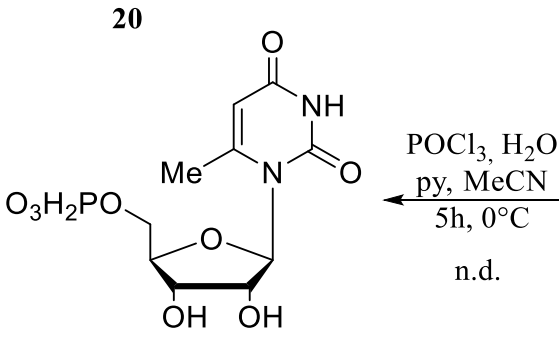

7
21<smiles>Cc1cc(=O)[nH]c(=O)n1C1OC(O)C(O)C1O</smiles>

40

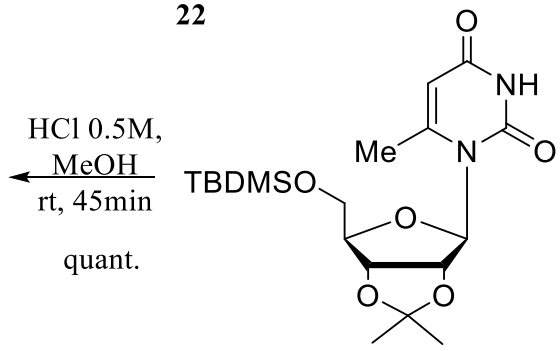

35

Figure 37: Synthesis of 6-methyl UMP.

In addition to the analysis of the crystal structures, the kinetic parameters of the nonpolar substituted targets should be determined using isothermal titration calorimetry (ITC) performed together with LAURA KIRCK. Before the measurement could be started, OMPD $(20 \mu \mathrm{M})$ and OMP (10 mM, $40 \mu \mathrm{L})$ were dissolved in 4-(2-hydroxyethyl)-1-piperazine-ethanesulfonic acid (HEPES) buffer (20 mM, pH = 7.4) and the inhibitors were dissolved in HEPES buffer (20 mM, $\mathrm{pH}=7.4)$ and injected to the measuring chamber. The aimed concentration $(10 \mathrm{mM})$ of inhibitor injection volume was not reached due to solubility issues and the experiment was performed with 6-methyl UMP solution $(390 \mu \mathrm{M})$. Surprisingly, just a baseline measurement was obtained, leading to the conclusion that 6-methyl UMP is not competitive inhibiting the 
OMPD in the presence of OMP. To exclude that the lower concentration of 6-methyl UMP is causing the observations, the same experimental setup was tested with 6-aza UMP leading to complete inhibition. The experimental data (thermogram in the experimental part) of 6-methyl UMP is shown in Figure 38, evaluated in a MiCHAELIS-MENTEN plot.

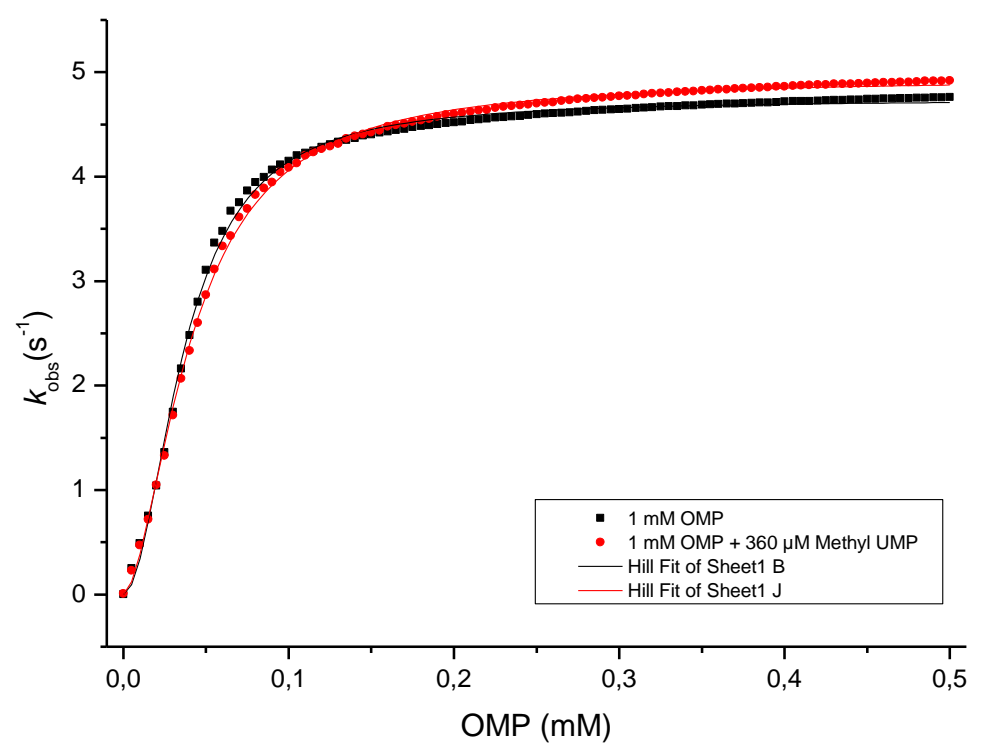

Figure 38: MICHAELIS MENTEN plot of $h$ OMPDwt and with 6-methyl UMP (black).

The measured parameters are $k_{c a t}=4.74(4.94), K_{m}=0.037(0.042)$ and $n=1.96(1.74)$.

The crystal data were collected at a resolution of $1.35 \AA$ in the $\mathrm{C} 222_{1}$ space group with one monomer in the asymmetric unit. The crystal structure of 6-methyl UMP in $h \mathrm{OMPD}_{\mathrm{wT}}$ is shown in Figure 39. The ligand is bound to the active site in syn-conformation, the loop region is in closed conformation and the methyl substituent geometry is described subsequently. The methyl substituent is widely tilted out of the pyrimidine plane by $39^{\circ} \pm 4^{\circ}$. Even though, the nonpolar group is not expected to be part in the hydrogen bond network, in addition, the methyl group is not close enough to the catalytic tetrad to be possibly involved in such interactions. The arrangement of $\mathrm{Lys}_{314}, \mathrm{Asp}_{312}, \mathrm{Lys}_{281}, \mathrm{Asp}_{317}$ and His 281 is similar to their positions in complexes with transition state analogs. ${ }^{[16]}$ 


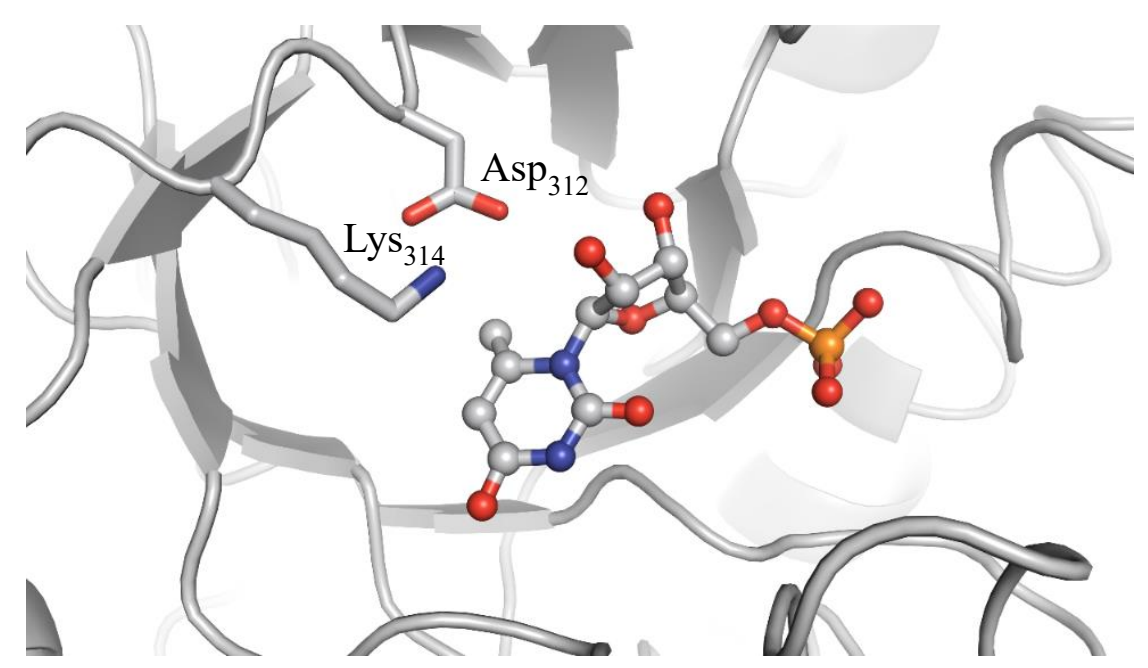

Figure 39: Crystal structure 6-methyl UMP.

FUJIHASHI et al. reported that the methyl substituent was bent $16^{\circ}$ out of plane, derived from a structure of 6-methyl UMP MtOMPD ${ }_{\text {wT }}$ complex at $1.6 \AA$ resolution. ${ }^{[30]}$ They compared the 6-methyl UMP with 6-cyano UMP and BMP with the given distortion. In our obtained structures the methyl group is drastically distorted and in contrast the BMP C6 carbonyl is rather in plane. The direct comparison is shown in Figure 40. The rather big difference between the findings of FUJIHASHI and the herein obtained structures can be dependent on the different OMPD species, in which the different pocket constitutions e.g. length of the gripper loop. In addition, the higher resolution in the obtained crystal structures lead to a more precise description of the localization of atoms. This led to a rather planar pyrimidine plane of which the substituent distortion can be distinguished.
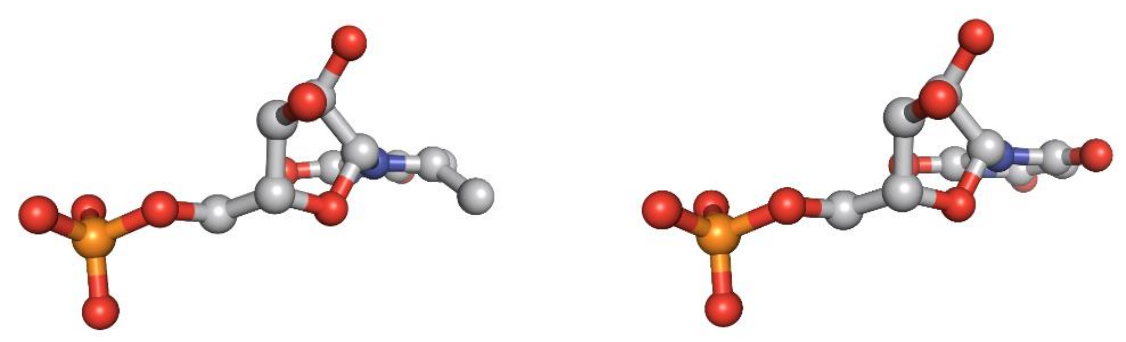

Figure 40: 6-Methyl UMP (left) and BMP (right). The out of plane distortion differs clearly, 6-methyl UMP $\left(39^{\circ} \pm 4^{\circ}\right)$ with $\operatorname{BMP}\left(8.0^{\circ} \pm 0.6^{\circ}\right)$ 


\subsubsection{6-Ethyl UMP}

The synthesis of 6-ethyl UMP was adapted from 6-methyl UMP, the ethylation was performed in a similar manner as the methylation reaction shown in Figure 41. The protected uridine was dissolved in THF and lithiated at low temperature $\left(-78^{\circ} \mathrm{C}\right)$, the addition of ethyl iodide led to the formation of the protected 6-ethyl uridine in comparable low yields (22\%) and purification by column chromatography revealed aside from product and reisolated starting material a double ethylated species. In test reaction scale the alternative synthetic pathway using the 6-cyanouridine and GRIGNARD compounds led to higher yields. Since no further synthetics steps needed to be performed despite deprotection and phosphorylation this low yield was acceptable even though it leaves lots of space for improvements. The deprotection and phosphorylation reaction were working quite good leading to the desired 6-ethyl UMP which was then further investigated in X-ray crystallography studies.

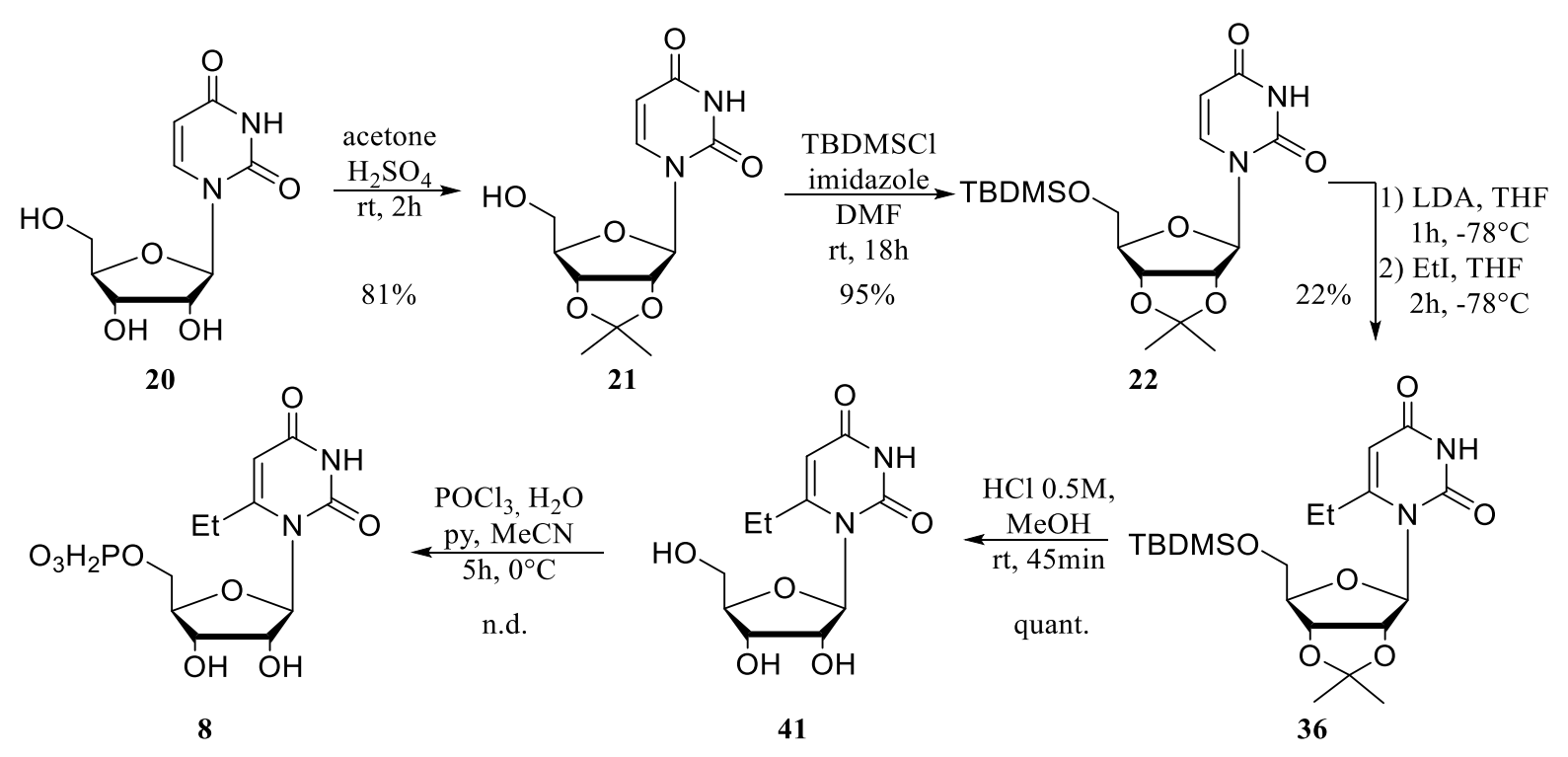

Figure 41: Synthesis of 6-ethyl UMP.

6-Ethyl UMP solution $(10 \mathrm{mM})$ was soaked into resting state crystals of $h \mathrm{OMPD} \mathrm{WT}_{\mathrm{W}}$ The data collection was obtained with a resolution of $1.30 \AA$ in the $\mathrm{C} 222_{1}$ space group, the asymmetric unit carrying one monomer. The crystal structure of 6-ethyl UMP should serve as an important comparison to 6-methyl UMP because of the finding that the methyl group was drastically distorted out of the pyrimidine plane. ${ }^{[30]}$ In contrast the crystal structures of 6-isoproyl UMP and 6-isopropenyl UMP did not show such severe distortion (structures below). The expectation for the ethyl chain was assumed to be in between the observations from methyl and isopropyl, but as it can be seen in Figure 42, the ethyl chain is behaving completely different. The ligand is bound to the active site in syn-conformation and the loop region is in closed conformation. 


\section{Results and Discussion}

The ethyl substituent, also described as $C 7$ and $C 8$, is demonstrating its flexibility: the $C 7$ is nearly in plane with the pyrimidine ring $4.5^{\circ} \pm 0.3^{\circ}$, while the $C 8$ is completely pushed away from the catalytic tetrad $\left(77.4^{\circ} \pm 1.3^{\circ}\right.$, see Figure 44$)$, it has no participation in the H-bond network, as expected.

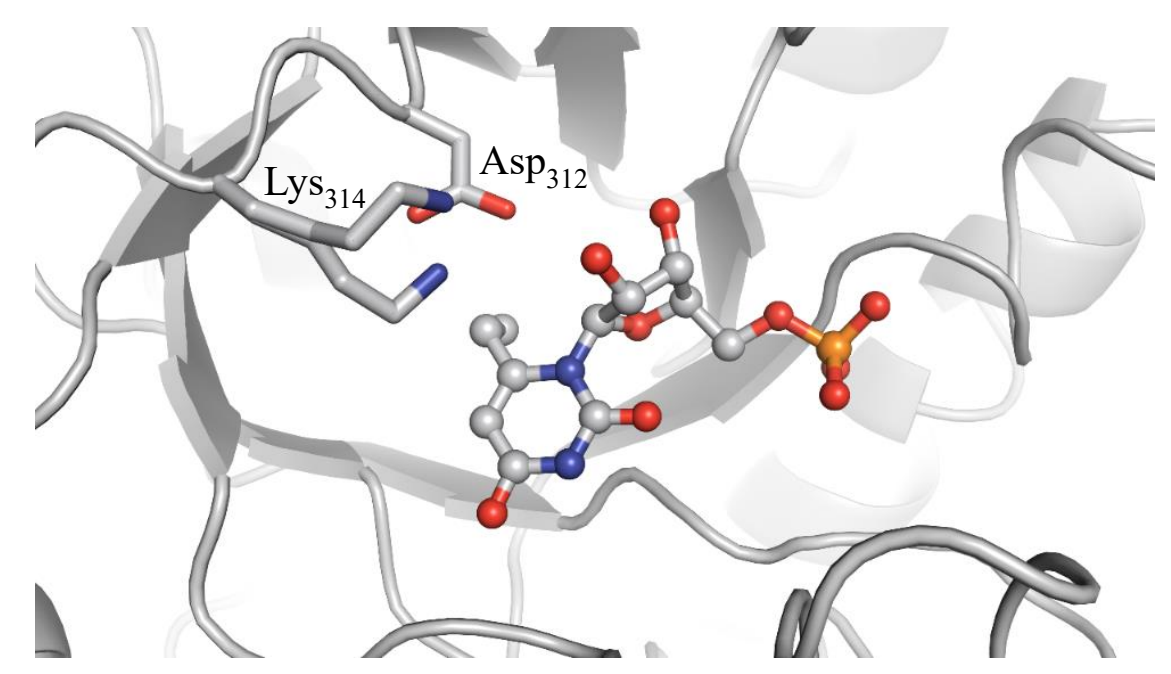

Figure 42: Crystal structure of 6-ethyl UMP in $h O M P D w T$.

The measured distances of the $C 7$ to Asp-COOH are $3.1 \AA$ and $3.4 \AA$, respectively. The $C 8$ is even further away with measured distances of $3.4 \AA$ and $3.9 \AA$. Lys 314 and Asp' ${ }_{317}$ have two conformations of which the distances from the ethyl substituent to the closer conformer measured as well, distance $C 7$ to $\operatorname{Lys}_{314} 2.8 \AA$ and $C 8$ to Lys314 $4.1 \AA$, demonstrating the strongly kinked structure.

To further compare the steric demands of these nonpolar substituted targets, 6-isopropyl UMP was synthesized by KRULL which can be additionally seen as a sterical mimic of OMP with the isopropyl group resembling the carboxyl group, while being completely hydrophobic. The 6-isopropyl UMP solution was soaked into resting state $h$ OMPDwT crystals and diffraction data was obtained at a resolution of $1.30 \AA$ in space group $\mathrm{C} 222{ }_{1}$ with one monomer in the asymmetric unit. The crystal structure of 6-isopropyl UMP is shown in Figure 43. It is bound in syn-conformation, the isopropyl group is pointing towards the catalytic tetrad and the phosphate gripper loop is fully closed. The catalytic tetrad residues are in similar position as in 6-thioamido UMP or 6-amido UMP complexes. The Lys 314 occupies the position between Asp' $_{317}$, Asp $_{312}$ and His 281 conformation is flipped forming hydrogen bonds to each residue. Asp' $_{317}$ is dragged towards the pyrimidine ring. 


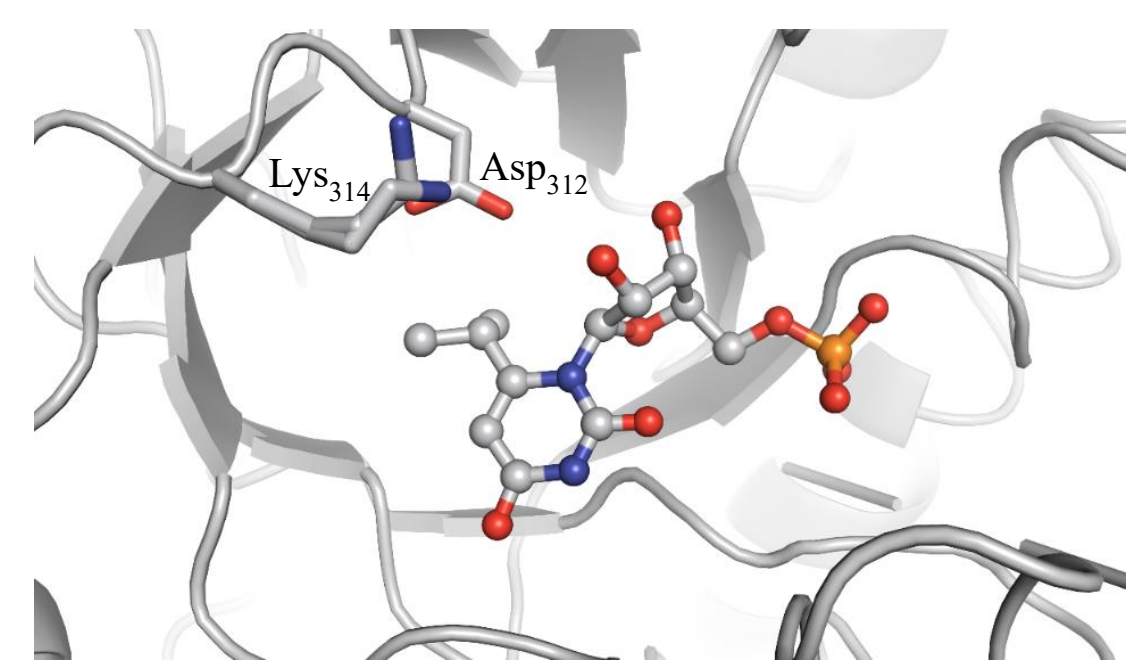

Figure 43: Crystal structure of 6-isopropyl UMP in $h O M P D_{W T}$.

In Figure 44 the crystal structures of the nonpolar substituted ligands are shown to illustrate the torsion angle, out of plane distortion and the orientation of the C6-substituent more clearly.

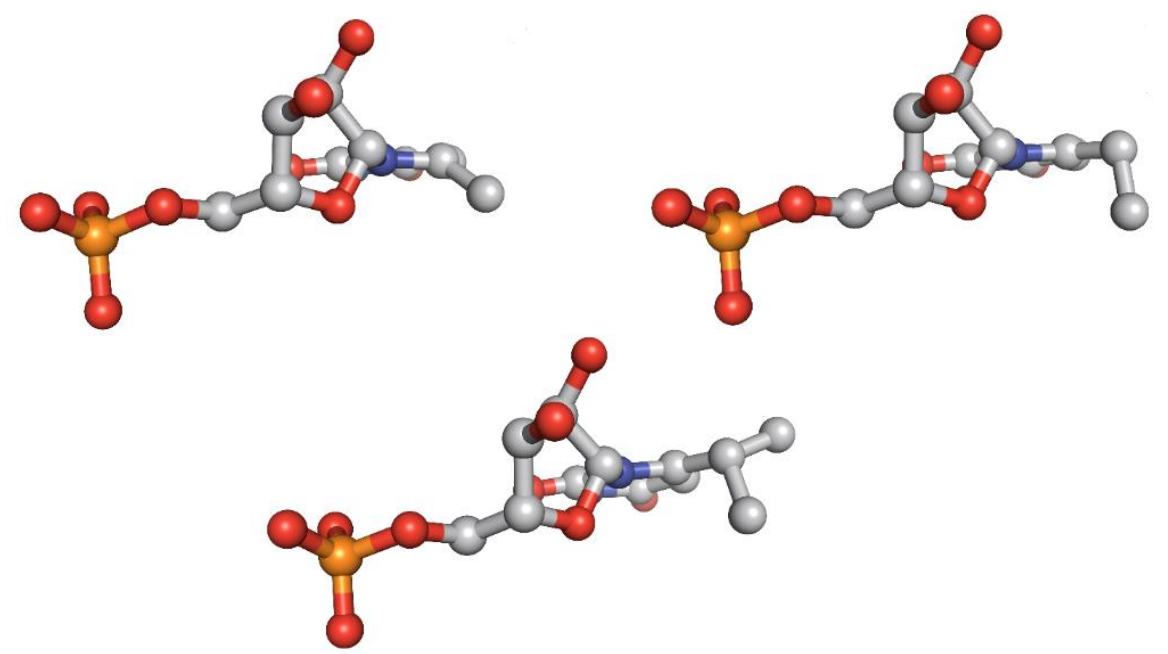

Figure 44: Comparison of crystal structures of 6-methyl UMP (top left), 6-ethyl UMP (top right) and 6-isopropyl UMP (bottom) complexed in hOMPDwt. The out of plane distortion was measured of 6-methyl UMP $\left(39^{\circ} \pm 4^{\circ}\right)$ with 6-ethyl UMP $\left(C 7: 4.5^{\circ} \pm 0.3^{\circ}, C 8: 77.4^{\circ} \pm 1.3^{\circ}\right)$ and 6-isopropyl UMP $\left(2.5^{\circ} \pm 1.2^{\circ}\right)$

\subsubsection{6-Isopropenyl UMP}

The last lead structure of the nonpolar quartet is the 6-isopropenyl UMP which fits sterically the most with the original substrate, it is mimicking the carbonyl by its double bond and the $\mathrm{sp}^{2}$ hybridized carbon atom. The synthesis of 6-isopropenyl UMP was performed with MORITZ VON GEYSO within the scope of his bachelor's thesis (Figure 45). The protecting group strategy was adapted from the other nonpolar target molecules, and they were introduced in very good yields. In the following reaction a good leaving group was introduced in $C 6$ position. 


\section{Results and Discussion}

In this case, iodine was chosen as an electrophile after umpolung reaction to yield protected 6-iodouridine and to be able to perform SUZUKI-MIYAURA coupling afterwards. ${ }^{[154,156]}$

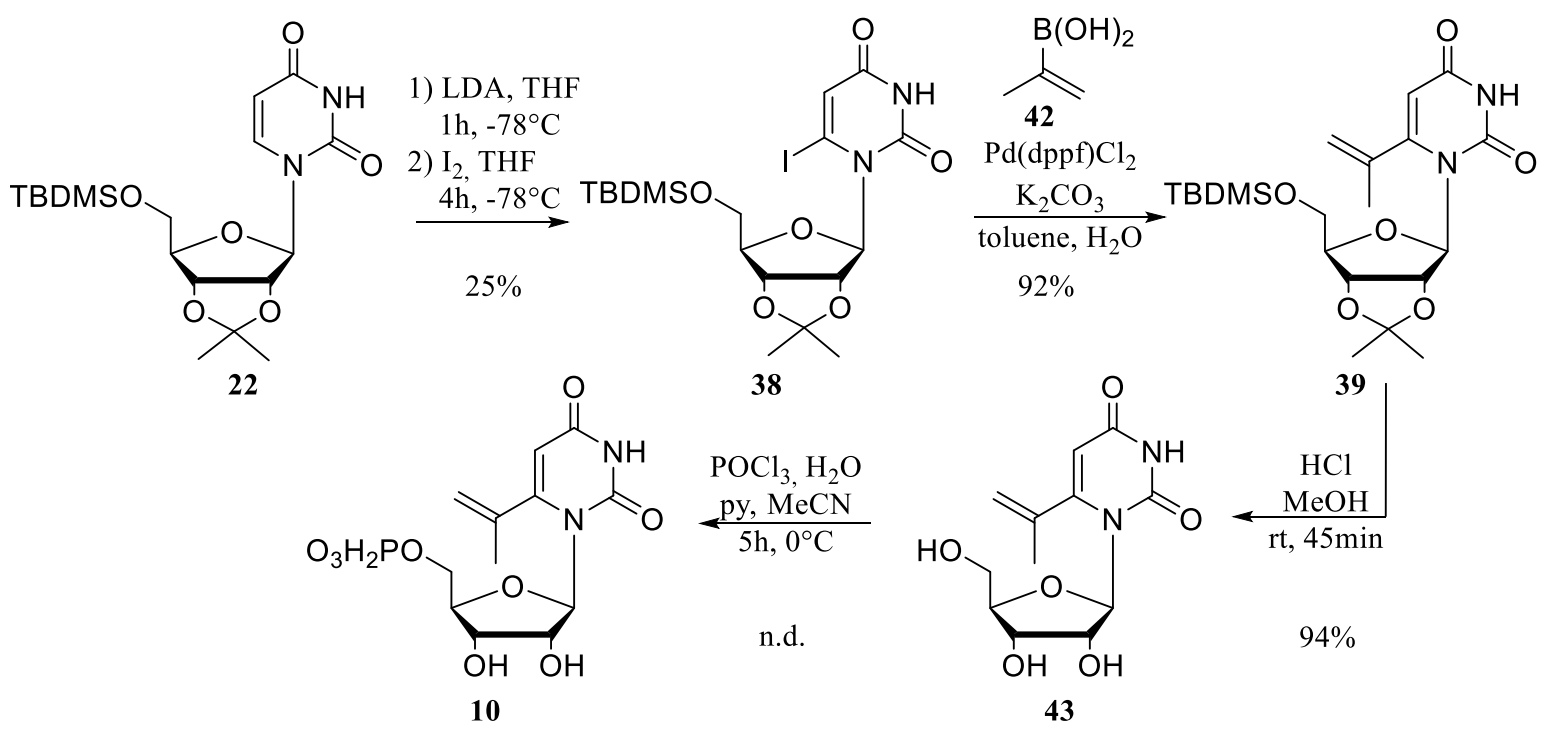

Figure 45: Synthesis of 6-isopropenyl UMP.

The isopropenyl boronic acid was synthesized from triethyl borate and propenyl magnesium bromide at low temperature $\left(-78^{\circ} \mathrm{C}\right)$ adapted from procedures of related compounds (Figure 46). ${ }^{[158,159]}$ The freshly synthesized boronic acid was directly used in the following SUZUKI MIYAURA coupling, using potassium carbonate and [1,1'-Bis(diphenylphosphino)ferrocene] dichloropalladium(II)-complex with DCM, obtaining 6-isopropenyluridine in very good yields. Followed by deprotection reaction and phosphorylation obtaining 6-isopropenyl UMP.

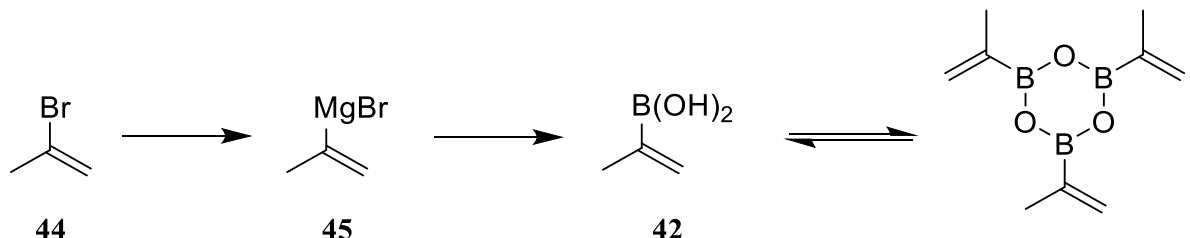

Figure 46: Synthesis of boronic acid precursor.

6-Isopropenyl UMP solution (10mM) was soaked into resting state crystals of $h$ OMPDWT and data collection was obtained with a resolution of $1.15 \AA$ in the $\mathrm{P} 2{ }_{1}$ space group, the asymmetric unit consists of the homodimer. In Figure 47 the crystal structure is shown with the ligand bound to the active site in syn-conformation and that the loop region is in closed conformation. The electron density map revealed two conformations of the substrate. Most probably induced by sterical interaction of the 6-isopropenyl with the catalytic tetrad leading to a minimal rotation obtaining a second conformation of the ribose moiety as well, both presented in Figure 47. The 
arrangement of Lys314, Asp312, Lys281, Asp' 317 and His281 is similar to their positions in complexes with 6-amido UMP and 6-thioamido UMP. ${ }^{[16]}$

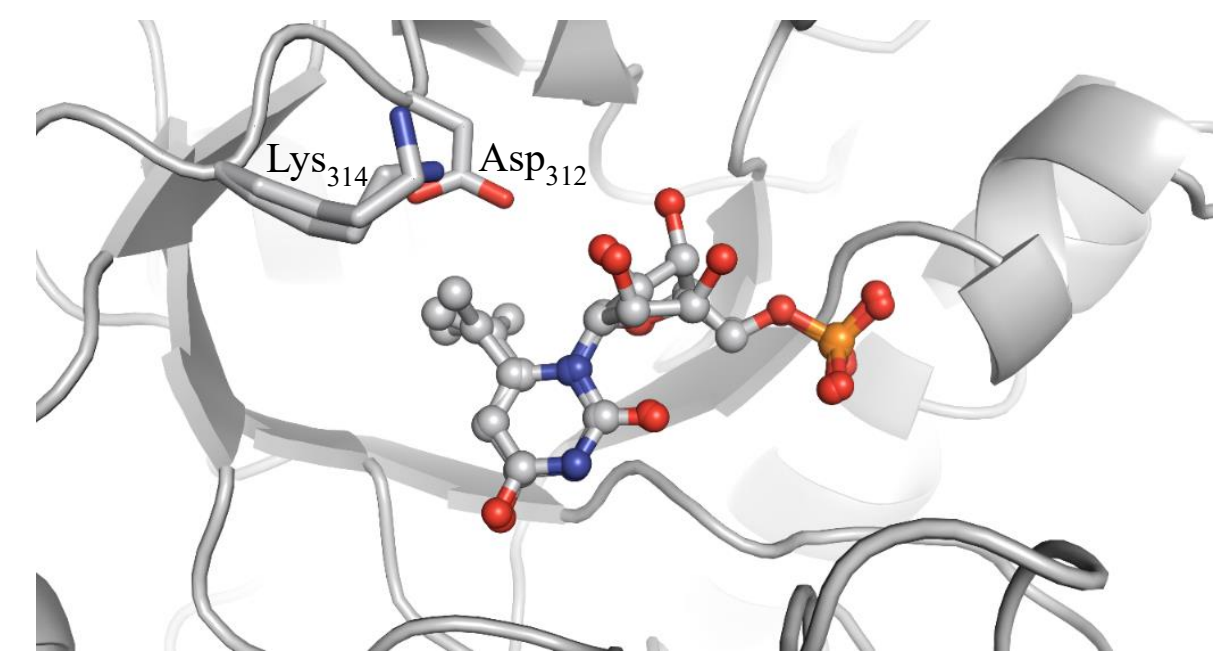

Figure 47: Structures of 6-isopropenyl UMP in $h O M P D_{w T}$.

In Figure 48 the crystal structures of the 6-isopropyl UMP, 6-isopropenyl UMP and 6-thioamido UMP wild type complexes as well as the OMP of the mutant complex are shown to illustrate the torsion angle, out of plane distortion and the orientation of the C6-substituent more clearly. The 6-isopropenyl structure, one of the two conformers shows very similar angles and distortions like OMP from the $h \mathrm{OMPD}_{\mathrm{Ac} 314 \mathrm{~K}}$ complex.
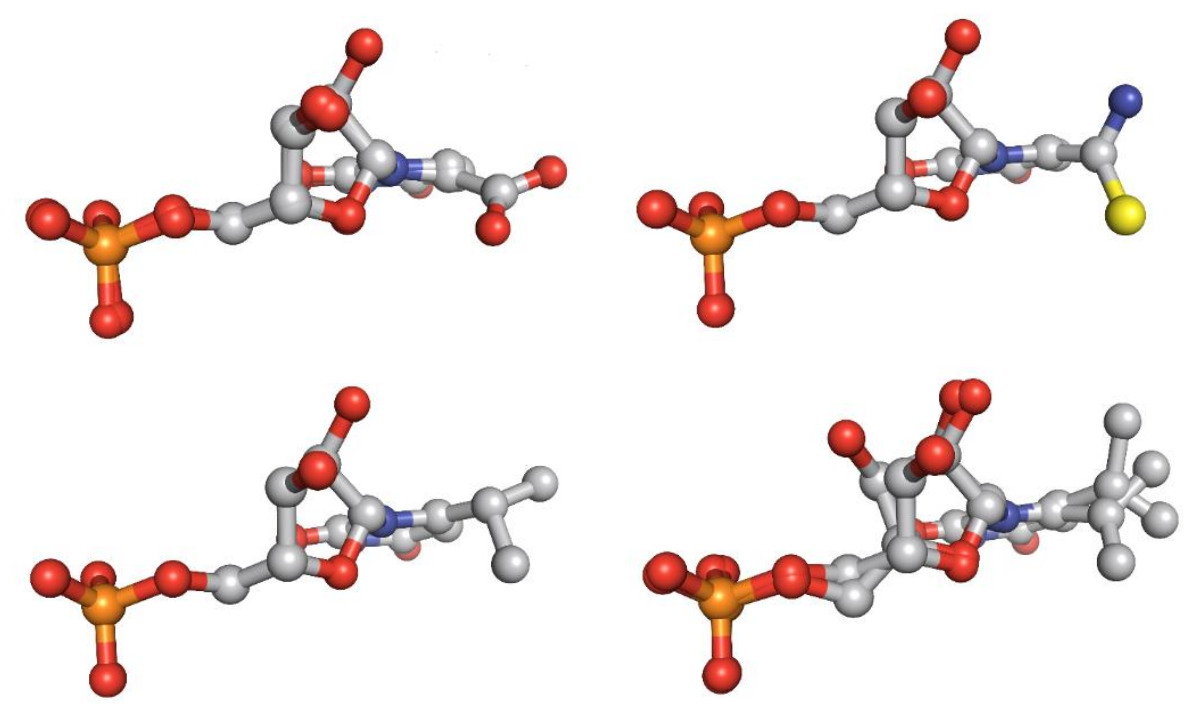

Figure 48 Comparison of structures of 6-isopropyl (left) and 6-isopropenyl UMP (right, bottom row) and OMP and 6-thioamido UMP (top row). 


\subsection{Conclusions from crystal structures}

The studies of the obtained $h \mathrm{OMPD}_{\mathrm{wT}}$ structures with the different inhibitors indicate interactions against the hypothesis of electrostatic stress as driving force of the decarboxylation. In addition, it seems unlikely that a located negative charge as a vinyl anion is the key intermediate. If it would be the vinyl anion, the question is why is it not directly reacting with a proton from solvent or even with carbon dioxide as an electrophile in the potential backreaction the re-association of $\mathrm{CO}_{2} \cdot{ }^{[88,160]}$ The observations from crystal structures directly imply the negative charge left behind after $\mathrm{CO}_{2}$ dissociation is rather delocalized over the pyrimidine moiety and the steric repulsive interactions with the catalytic tetrad, especially Lys 314 , might be stronger than expected. ${ }^{[16]}$

The most important observations are the crystal structures of the substrate analogs 6-thioamido UMP and 6-amido UMP in $h \mathrm{OMPD}_{\mathrm{WT}}$ in direct comparison with OMP in complex with $h \mathrm{OMPD}_{314 \mathrm{Ack}}$. All of them show a very similar conformation of the $C 6$ substituent in regard of out of plane distortion and distances to catalytic tetrad residues, deducing the OMP carboxyl group in protonated form with no hint for electrostatic stress. Instead, the formation of a short hydrogen bond with Asp 321 was observed. ${ }^{[16]}$

In addition, the crystal structures of BMP and 6-aza UMP in $h \mathrm{OMPD}_{\mathrm{wT}}$ obtained by M. KRULL and S. RINDFLEISCH in earlier studies, reinforced the refusal of the theory of electrostatic stress. Neither BMP nor 6-aza UMP were observably charged in proximity of catalytic tetrad. KRULL described the binding situation in the BMP as three equivalent carbonyl groups whereas the 6aza UMP was bound in anti-conformation, means the $N 6$ is interacting with Gln 430 instead that with the tetrad. ${ }^{[16,33,34]}$

Another important assumption can be made from the obtained crystal structures which is "size matters". In early studies from D. HEINRICH the influence of the size of the $C 6$ substituents and the resulting interactions were already discussed. ${ }^{[13]}$ In addition, FUJIHASHI et al. evaluated the steric impact of substituents by substrate distortion as energetical contribution to catalysis. ${ }^{[30]}$ The results deduced from our structures, as mentioned before, are showing the sterical influence of the substituents is clearly interacting with the positions of the catalytic tetrad residues and by this affecting their role in catalysis. This was assumed by comparing enzyme-substrate structures of substrate analogs with transition state analogs and further investigated by the structures of the nonpolar inhibitors. One would expect that a rather big substituent in 
position 6, like in 6-isopropyl or 6-isopropenyl UMP, would have more sterical clashes with active site than a comparable smaller substituent like in 6-mehtyl or 6-ethyl UMP due to the more required space. These steric interactions were observable in ligand structure in either slight rotations, bond distortion or strain observed by measuring bond length and angles. The most obvious distortion is the C6-C7 bond in regard to the pyrimidine plane. The expectation on this distortion was that it would increase with the growing alkyl chain (nonpolar targets) but instead the bigger substituents push the residues Lys314 and Asp'317 in alternative conformations. In case of 6-methyl UMP and 6-ethyl UMP, the catalytic tetrad is in its original conformation, but the methyl or ethyl substituent respectively are kinked drastically. Concluding these observations, the catalytic tetrad amino acids have a certain flexibility as well as rigidity to some extent $e . g$., Lys 314 in 6-methyl UMP-hOMPD $\mathrm{WT}_{\mathrm{W}}$ complex is stiff enough to strongly push the methyl substituent out of plane and Lys 314 in 6-isopropenyl UMP-hOMPDwT complex is flexible enough to be reversibly displaced while itself is orientated in an alternative conformation with alternative hydrogen bond network.

\subsection{OMP methyl ester}

The general synthetic procedure was adapted from FUJIHASHI et al. with slight modifications shown in Figure 49. ${ }^{[30]}$ The protection of the hydroxyl groups was performed in the before described manner, followed by an inversion of the reactivity by umpolung reaction. ${ }^{[135]}$ This is also the original synthetic pathway of the OMP synthesis exchanging the electrophile. ${ }^{[13]}$ In case of the methyl ester this reaction was even more successful, benefiting from the better electrophilic character of methyl chloroformate in comparison to carbon dioxide. While reaction times between $30 \mathrm{~min}$ to $6 \mathrm{~h}$ were screened, sufficient product formation was observed even 30 min after addition of methyl chloroformate. Longer reaction time or the use of more equivalents did not afford more yield, instead pushing towards the side reaction of carbamate formation at $N 3$.

The deprotection using methanolic $\mathrm{HCl}$ was yielding the orotidine methyl ester quantitatively. Subsequently performing the phosphorylation reaction, one problem did arise. In the first attempt OMP was obtained after purification instead of the OMP methyl ester. The phosphorylation method was identified as the would-be weak spot and milder conditions were employed. ${ }^{[150]}$ But this was not the case for several attempts, the OMP methyl ester was confirmed by High-resolution mass spectrometry (HRMS) and ${ }^{1} \mathrm{H}-\mathrm{NMR}$ of crude reaction and even after neutralizing no methyl ester cleavage was observed. 


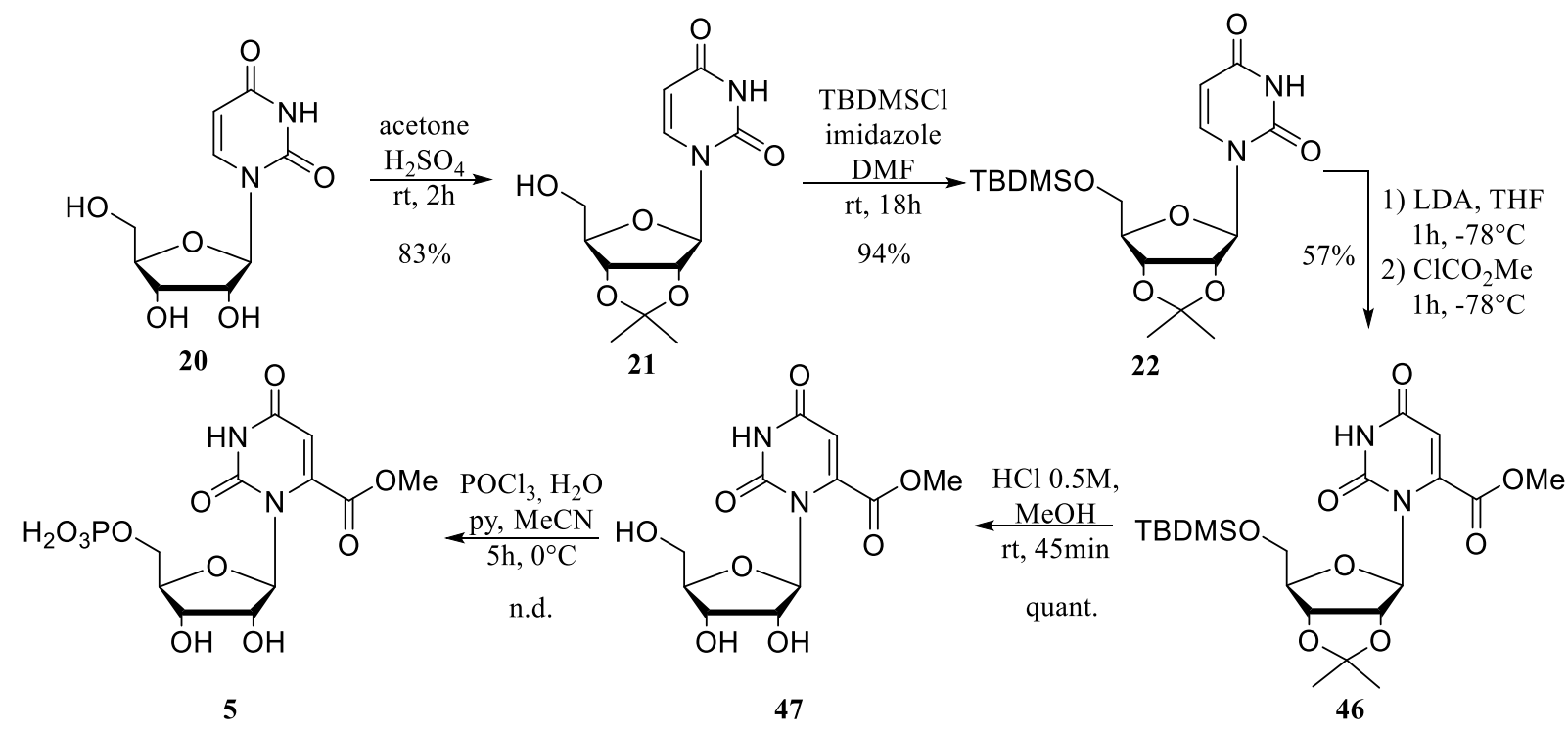

Figure 49: Synthesis of OMP methyl ester

Further investigation identified the purification method of HPLC, ion-exchange chromatography using triethylammonium acetate buffer at $\mathrm{pH}=7.0$ as the potential cause. However, it's quite astonishing to perform an ester cleavage at neutral $\mathrm{pH}$, it remains under discussion how exactly the methyl ester bond is broken, if the column material of ion-exchange column (details see experimental part) can do it or not. In contrast, protocols of methyl ester cleavage in nucleotide system suggest $1.0 \mathrm{M}$ hydroxide solution and higher temperature $\left(100^{\circ} \mathrm{C}\right) .{ }^{[161]}$ Nevertheless, once the purification was identified as potentially ester cleaving, the solvent system was changed from 0.5 M TEAA buffer $\mathrm{pH}=7.0$ to $0.1 \mathrm{M}$ formic acid countering the slightly basic column material. The use of this rather acidic ammonium formate buffer $\mathrm{pH}=5.0$ maintained the ester bond while performing HPLC purification. Unfortunately, this small excess of rather acidic buffer may be the reason no crystal structure could be observed. The ligand soaking into resting state crystal was performed for all the lead structures in the same manner, just differing in soaking time if needed. But the OMP methyl ester crystals were the only ones damaged when trying to get diffraction data, maybe due to residual amounts of formic acid.

\subsection{Reduced OMP}

The synthetic route of 5,6-dihydro OMP was adapted from the literature known OMP synthesis shown in Figure 50. ${ }^{[13]}$ Performing the reduction reaction directly after introduction of carboxyl group led to difficulties in the following deprotection and phosphorylation reactions as 
described by HEINRICH ${ }^{[130]}$ who observed a rearrangement reaction while attempting to synthesize 5,6-dihydro OMP. Therefore, the reduction step was inserted last in the synthetic route using hydrogen atmosphere on $\mathrm{Pd} / \mathrm{C}$ in ethanol/water mixture in quantitative yields.

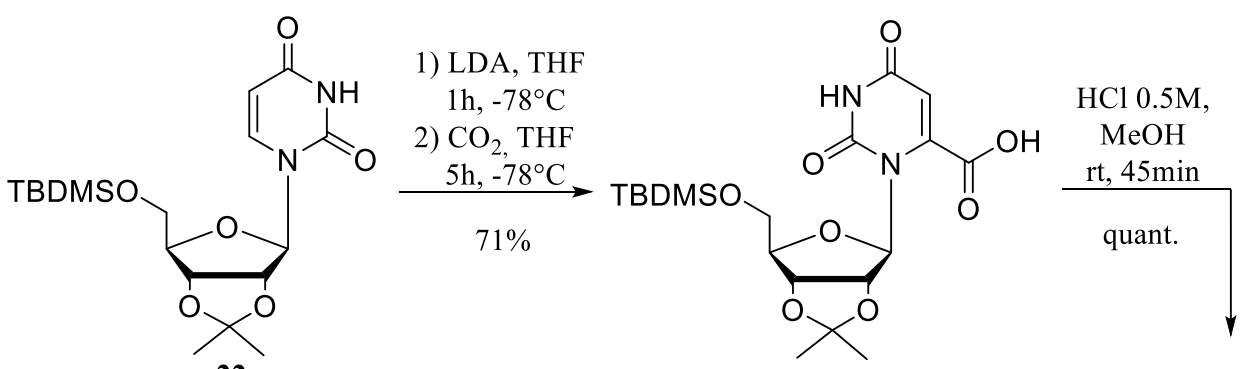

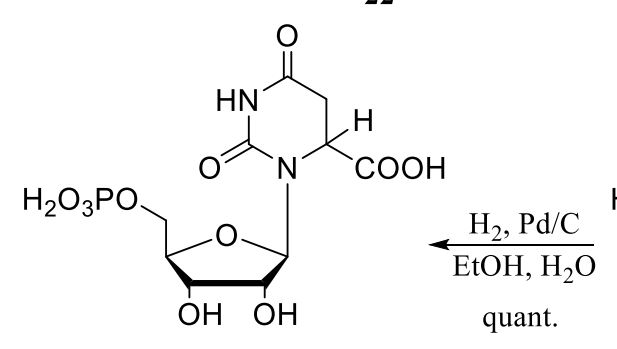

26

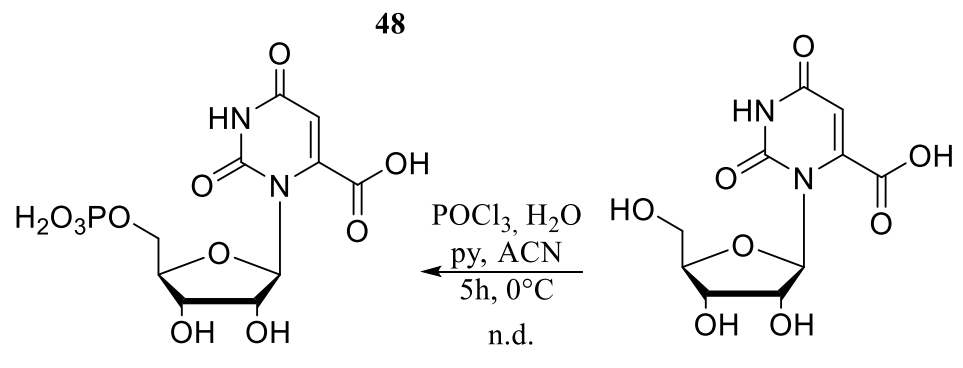

1

49

Figure 50: Synthetic pathway of reduced OMP.

In this thesis, OMP was synthesized and purified using ion-exchange chromatography to be able to exclude starting material of reduction reaction of any impurities as a potential reason for reaction failure. Then, reduction reaction was successfully performed even without the use of $\mathrm{H}_{2}$ overpressure, resulting in quantitative conversion.

The reduced OMP was soaked into resting state $h \mathrm{OMPD}_{\mathrm{WT}}$ crystals but surprisingly no clear crystal structure was obtained. Potential errors could be either rearrangements as described by HEINRICH directly after reduction reaction or in the dissolving process before soaking. ${ }^{[130]}$ Furthermore, whatever can be observed in Figure 51 is eventually happening inside the enzymatic pocket. After decarboxylation catalyzed by OMPD, a ring opening induced through angle compressions could occur, which would also explain these observations. 

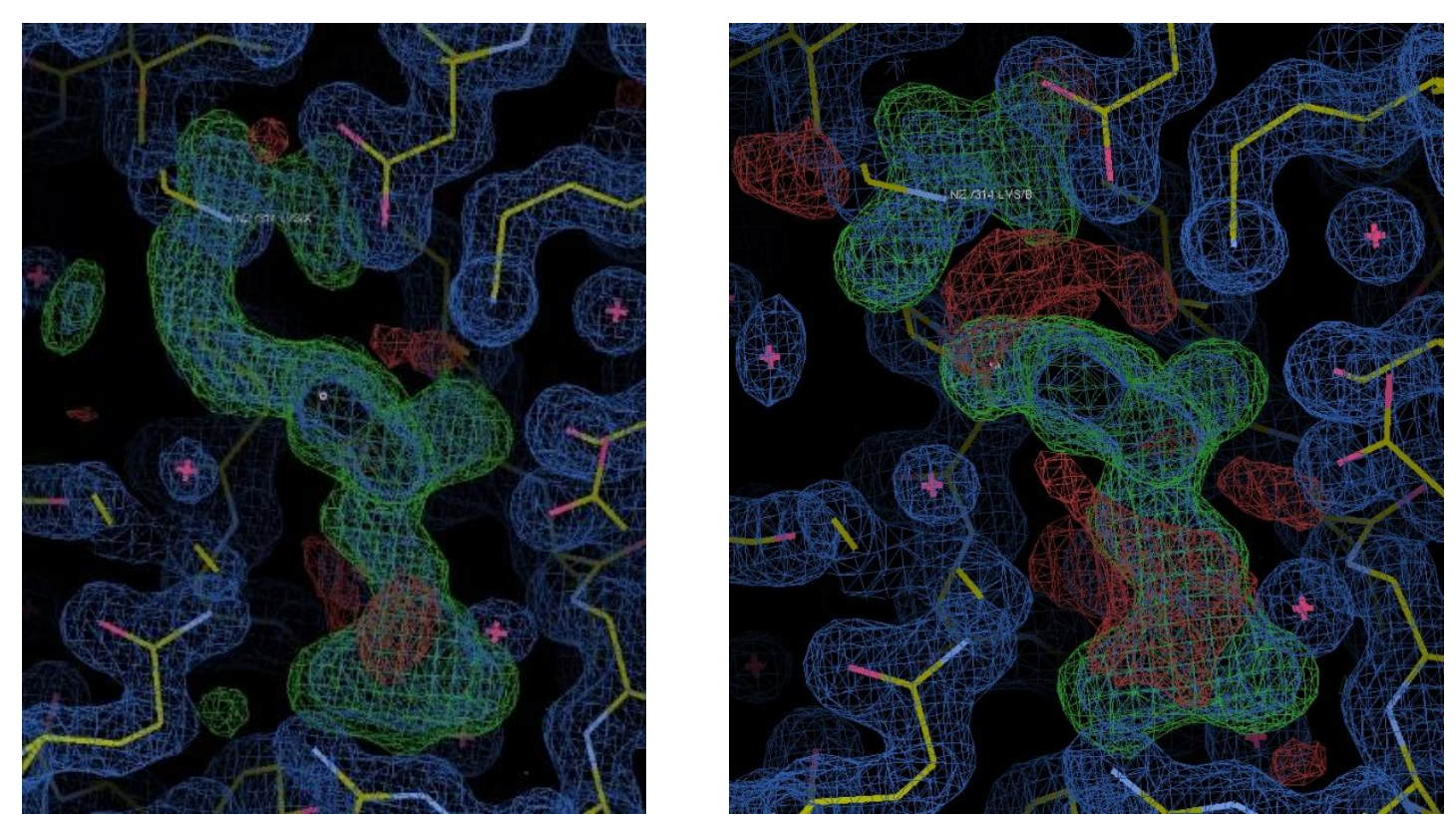

Figure 51: Electron density map of attempted crystal structure of reduced OMP. Enzymatic pocket A (left) and enzymatic pocket $B$ (right).

Another very interesting finding is the different electron density map observed in the enzymatic pocket $\mathrm{A}$ of the homodimer and the one in enzymatic pocket B. This would, even though the substrate is not intact, recommend a cooperative alternating activity of both active sites. Whereas in pocket $\mathrm{B}$ the potential processes after decarboxylation reaction are a little bit forge ahead than pocket A. In Figure 52 a trial of structure refinement is shown, which was performed by SÖREN RINDFLEISCH modeling the decarboxylated, ring opened species into the electron density map.

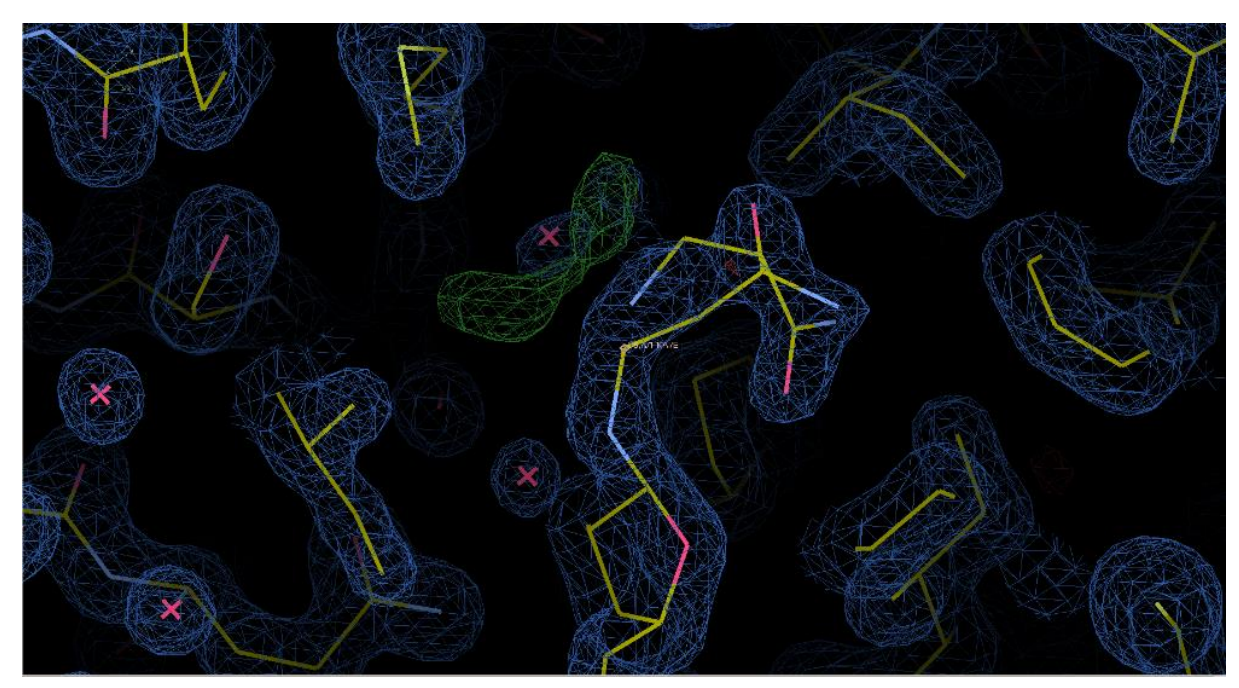

Figure 52: Modeling attempt of a potential ring opening. 


\subsection{6-Carboxy CMP}

Another important goal of this thesis was the synthesis and structural investigation of 6-carboxy CMP, another potential inhibitor of OMPD due to the modification of position 4, exchanging the carbonyl with an amino function. Different synthetic approaches were considered, and the results of each approach will be discussed in this subsection.

The first synthetic approach was directly taken from the corresponding uridine analog, starting with commercially available cytidine bearing the wanted amino moiety in the pyrimidine ring (Figure 53). After a well-considered protection strategy, the carboxy function can be introduced in position 6 followed by deprotection reactions and phosphorylation. The first difficulty was already the acid catalyzed acetal formation because the yields were low in comparison to the uridine derivatives. The hydrolysis of the cytidine amino function was monitored as a side reaction and depending on the acid used the rate of hydrolyzed product was increased or decreased. Using the strongest possible acid and extra water free conditions a yield of $85 \%$ was achieved, in comparison reaction conditions of weaker acids and acetone of HPLC grade yielded $21 \% .{ }^{[162]}$ The silyl protection was achieved using imidazole for activation of the 5'-OH group and TBDMSCl as silylating agent in comparable low yields of $82 \%$ (uridines 88-96\%). ${ }^{[140]}$ As amino protection, tert-butyloxycarbonyl (Boc), benzyloxycarbonyl (Cbz) and benzyl (Bn) were tested and additionally the unprotected amino functionality was used as the proof of concept reaction.

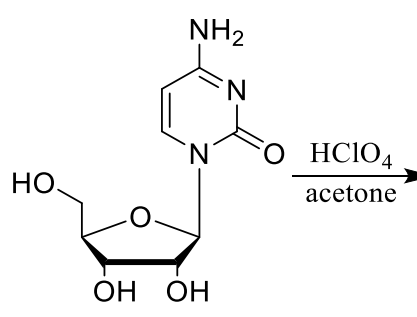

50

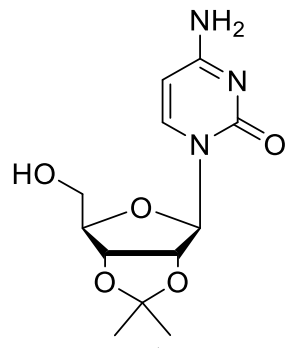

51

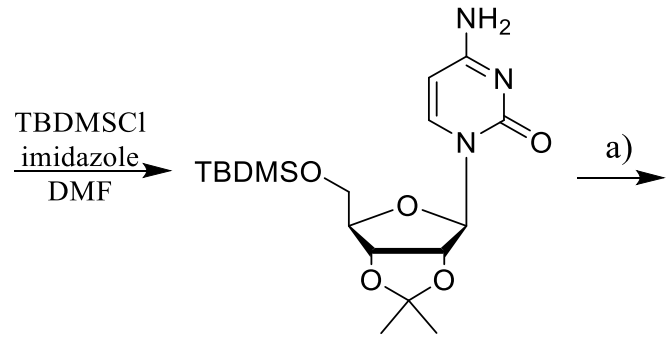

52

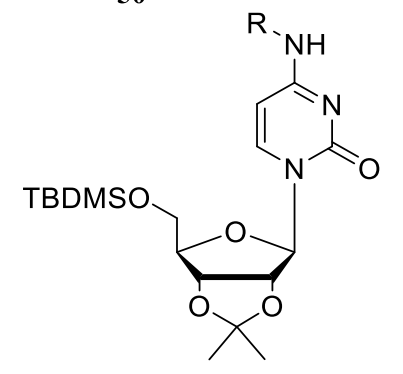

$\mathrm{R}=\mathrm{Boc}(\mathbf{5 3}), \mathrm{Cbz}(\mathbf{5 4}), \mathrm{Bn}(\mathbf{5 5})$

1) $\mathrm{LDA}, \mathrm{THF}$ $-78^{\circ} \mathrm{C}$ 2) $\mathrm{CO}_{2}, \mathrm{THF}$

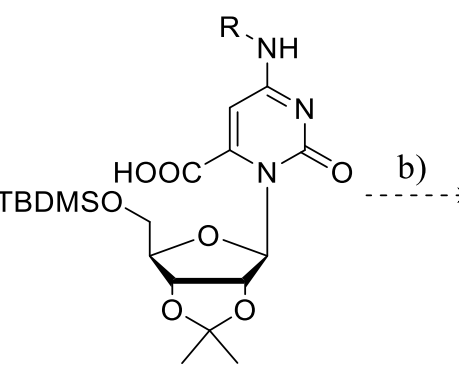

$\mathrm{R}=\mathrm{Boc}(\mathbf{5 6}), \mathrm{Cbz}(\mathbf{5 7}), \mathrm{Bn}(\mathbf{5 8})$

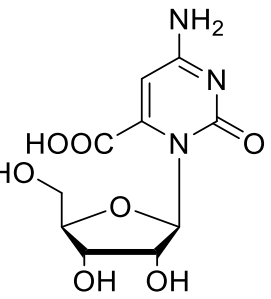

59

Figure 53: Synthetic pathway of 6-carboxycytidine, using differnt amino protecting groups in a) and the belonging deprotection conditions in $\mathbf{b})$. 


\section{Results and Discussion}

The boc and cbz protections were tested according to general procedures well established in the DIEDERICHSEN group. ${ }^{[136]}$ Surprisingly, leading to low yields $(27-32 \%)$ of fully protected cytidine. Increasing the equivalents of the protecting agents Boc anhydride and benzyl chloroformate respectively led to good yields (78-85\%). In contrast, benzyl protection using benzyl chloride was in comparison straight forward leading to excellent yields (94\%).

All the three protected cytidines could be used in umpolung reaction with either carbon dioxide or methyl chloroformate as electrophiles obtaining the desired 6-carboxy cytidines in a wide range of yield (42-81\%) which than needed to be deprotected, but at this point the protections turned out to be an issue. No matter which reaction conditions were tested only partly deprotected product was obtained, together with remaining protected starting material and using rather harsh conditions led to cleavage of the glycosidic bond. The deprotection conditions were tested using $\mathrm{HCl}$ in $\mathrm{MeOH}$, dioxane, and water with different ranges of equivalents, temperature and time. In addition, deprotections based on trifluoroacetic acid (TFA) were tested, either pure or in aq. solutions as well as dissolved in dichloromethane (DCM), also differing in equivalents, temperature, and time. $\mathrm{Cbz}$ and $\mathrm{Bn}$ can be cleaved by hydrogenolysis ${ }^{[163]}$ and this was attempted, unfortunately leading to the reduction of $\mathrm{C} 5=\mathrm{C} 6$ double bond as a side reaction. Furthermore, a benzyl deprotection was attempted which can be used in the presence of double bonds, but the required use of boron trichloride $\left(\mathrm{BCl}_{3}\right)$ also led to the cleavage of the glycosidic bond. ${ }^{[164]}$

At this point, a second synthetic approach of 6-carboxy CMP was considered based on the synthesis of 6-cyanocytidine ${ }^{[165]}$ and a third pathway based on the direct uridine to cytidine base modification. Both synthetic strategies were performed together with MARIUS REINHOLD within the scope of his bachelor's thesis. The planned synthesis of 6-cyanocytidine was benefiting from the experience along the synthesis with cyanouridines which was gained performing the synthesis of 6-thioamido UMP, starting with same synthetic route shown in Figure 54.

The first step is the bromination which was performed using sodium monobromoisocyanurate (SMBI) as brominating agent according to the procedure of MAITY et al. in comparable good yields $(65 \%)$ and high selectivity (Figure 54). ${ }^{[166]}$ In contrast to the established methods using either $\mathrm{Br}_{2}$ in mixture of acetic acid and pyridine or NBS in DMF, the use of SMBI improved the reaction outcome. ${ }^{[167,168]}$ Then the hydroxy groups were protected as mentioned before, using acid catalyzed acetal formation with perchloric acid and 5' $-\mathrm{OH}$ silyl ether formation with TBDMSCl, yielding compound 62. ${ }^{[138]}$ 

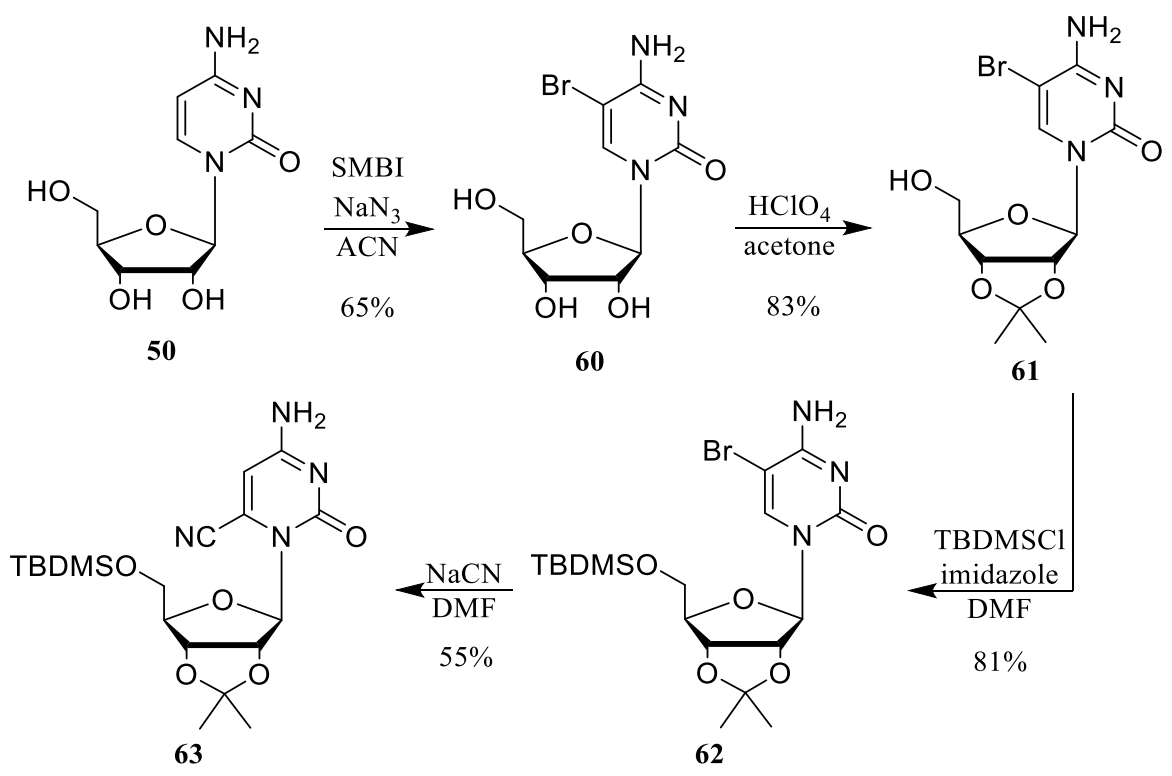

Figure 54: Synthesis of 6-cyanocytidine.

In the next step the protected 5-bromocytidinereacted with either $\mathrm{NaCN}$ or $\mathrm{KCN}$ in $\mathrm{DMF}$ or $\mathrm{MeCN}$ at different temperatures using complexing crone ethers as additives for $\mathrm{Na}$ and $\mathrm{K}$ respectively. ${ }^{[165]}$ The best reaction conditions yielded $55 \%$ of the protected 6-cyanocytidine, again less conversion in regard to the uridine analog. In addition, longer reaction time, higher temperature and additional cyanide led to the concurrence reaction of a nucleophilic attack at position 5 and eliminated the position 6 cyano group. ${ }^{[165]}$

The protected 6-cyanocytidine (63), should give the opportunity to transform the cyano functionality into different carboxy derivatives as shown in Figure 55. The carboxy function could be introduced either through basic or acidic conditions. The acidic hydrolysis was rejected due to potential side reaction with the $N 4$ amino group. Furthermore, a third possibility of using a methanolysis yielding a methyl carboximidate, which could be then hydrolyzed in an acidic work up to yield the carboxy methyl ester, compound 64.

Starting with the basic conditions, different organic bases were tested as well as mild aqueous and methanolic mixtures of lithium hydroxide $(\mathrm{LiOH})$ and other hydroxides. The tested organic bases did not yield a conversion into amide or carboxy function. The use of 1.5 equivalents of $\mathrm{LiOH}$ yielded 6-amidocytidine which was then further reacted using 5.0 equivalents of $\mathrm{LiOH}$ and slightly increased reaction temperatures $\left(50-60^{\circ} \mathrm{C}\right)$ to obtain 6 -carboxycytidine which was partly isolated as lithium salt. 


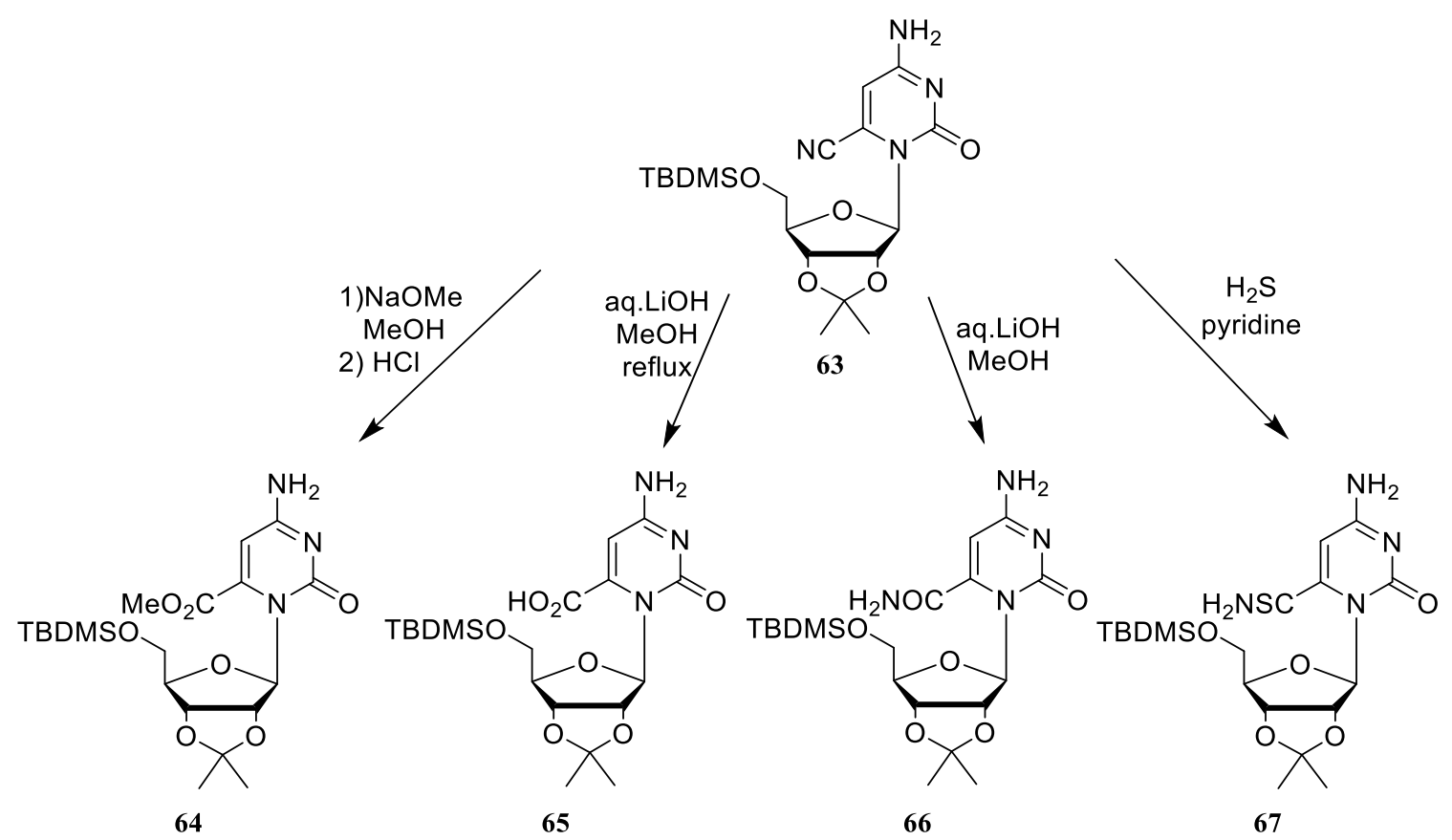

Figure 55: 6-Cyanocytidine as precursor of carboxy derivatives.

The path using a methanolysis was performed in parallel, yielding the methyl carboximidate, which was then further treated as planned, to yield the carboxy methyl ester, compound $\mathbf{6 4}$. Interestingly, in one of the methanolysis attempts, while screening the reaction conditions regarding alkoxide equivalents, time and temperature, a side reaction was observed where 6-amidocytidine was formed, probably through a nucleophilic attack of hydroxide due to basicity of the methanolate at the cyano group. Another surprising observation was made by longer neutralization reaction time with the use of ammonium chloride, which led to partly TBDMS deprotection most probably triggered through the chloride anion. ${ }^{[169]}$

However, 6-carboxycytidine and derivatives were deprotected using methanolic $\mathrm{HCl}$ or TFA and followed by an attempted phosphorylation reaction which was repeated several times with all possible changes in reaction conditions as well as screening the carboxy derivatives as starting material (also different batches) see Figure 56. At this point, we were doubting the feasibility of this reaction in general and we tried to phosphorylate different intermediate compounds as well as the proof-of-concept reaction by setting up the phosphorylation of cytidine and uridine, both were successful and surprisingly cytidine-5'-monophosphate was formed even in higher yields than uridine-5'-monophosphate. ${ }^{[150]}$ This led to the conclusion that either the nucleophilic attack of the $\mathrm{POCl}_{3}$ at the $5^{\prime}-\mathrm{OH}$ was hindered in a way or another nucleophilic group/moiety attacked the phosphate which is then later on hydrolyzed. In general, sterical or electronical properties of the substituents could be excluded since the uridine derivatives were phosphorylated in well-known procedures. Given the fact that the 
unsubstituted cytidine was easily phosphorylated in very good yields, the substitution itself seems to activate the $N 4$ amino functionality. Another idea was tested, if the effect of lacking phosphorylation is dependent on the MICHAEL system or the aromaticity of the pyrimidine moiety. The side product of introducing the cyano group, 5-cyanocytidine was set up to be phosphorylated but unfortunately this was not successful at all, pointing in the direction of the aromaticity of the pyrimidine ring.

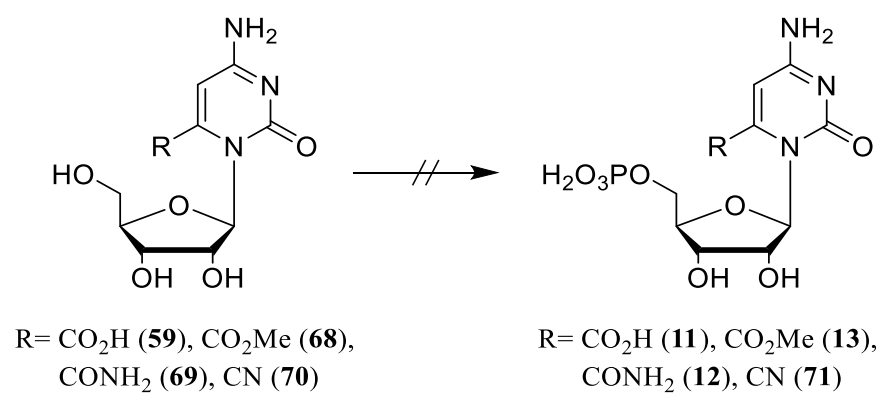

Figure 56: Attempted phosphorylation reactions.

The third synthetic approach towards 6-carboxy CMP was started since all the substituted cytidines were not feasible to be phosphorylated. The principle idea was exchanging the position 4 carbonyl with an amino function by using the already approved reaction in the uridine system according to the procedure of BECKER et al. ${ }^{[170]}$ This method is literature known for protected, unsubstituted uridines and was tested in this thesis with different substituted, unprotected or to some extend phosphorylated uridines as shown in Figure 57.

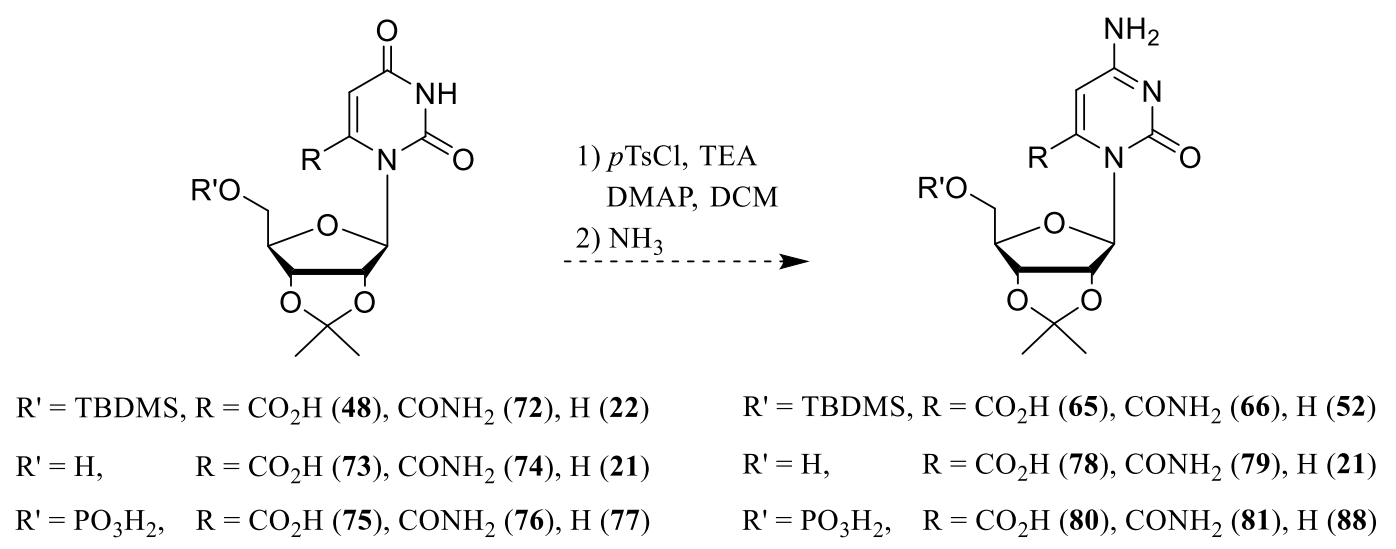

Figure 57: Synthesis of cytidines from uridines.

As a proof-of-concept reaction the non-substituted, fully protected uridine compound 22 was activated with $p$-TsCl and transferred into a good leaving group, catalyzed by DMAP, followed by the nucleophilic attack of ammonia yielding the desired amino function in position 4 . This reaction was tested with different substituted and protected uridine derivatives. In addition, the 


\section{Results and Discussion}

silyl ether deprotection using TBAF solution was performed using the protocol of COREY et al. ${ }^{[139]}$ Followed by the phosphorylation of these derivatives yielding a set of nucleosides and nucleotides which were tested in this substitutional approach. Unfortunately, just in case of the non-substituted uridines the substitution was obtained in good yields. The presence of functionalities in position 6 as well as unprotected hydroxyl groups or the phosphate, primarily lead to other reaction products, most probably through mistaken activation and subsequently substitution reaction.

One last attempt regarding the phosphorylation of substituted cytidines was considered using an enzymatic reaction. It is known that uridine-cytidine kinase 2 (UCK2) is phosphorylating different uridine and cytidine derivatives. ${ }^{[171]}$ The gene expression and enzyme purification was performed by Dr. FABIAN RABE VON PAPPENHEIM. The UCK2 was tested with the before not successful phosphorylation candidates leading to product formation in very low yields.

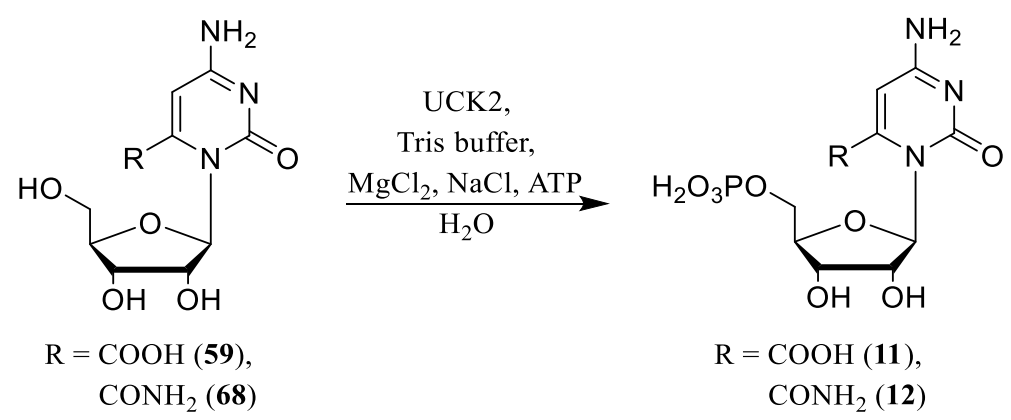

Figure 58: Enzymatic phosphorylation by UCK2.

\subsection{6-boronic acid UMP}

In the beginning of the work of this thesis the target molecules in our working group were focusing on electronical mimics of the carboxyl function. The first lead structure within the scope of this thesis was 6-boronic acid UMP. It can be seen in Figure 59, there are many ways to introduce boronic acids. One possibility is transmetalation using borates and $\mathrm{Mg}$ or $\mathrm{Li}$. ${ }^{[172,173]}$ Another method is C-H activation to form C-B bonds. ${ }^{[174]}$ Third, a Pd catalyzed MiYAURA borylation. ${ }^{[175]}$ However, despite all these possibilities we assumed the latter as the most suitable for the nucleoside system. 


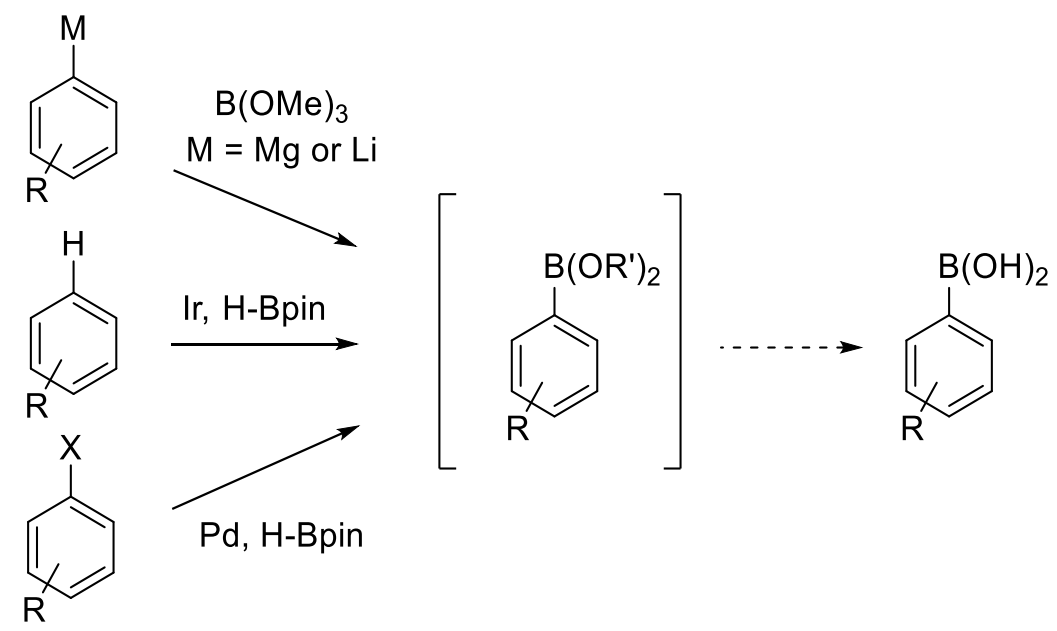

Figure 59: Methods of introducing boronic acids. ${ }^{[153]}$

Starting with the protected uridine a good leaving group e.g., iodine or bromine needs to be introduced in position 6 of the pyrimidine ring. It may be necessary to protect the $N 3$ by using benzyl protection as discussed by SHIH. ${ }^{[157]}$ Then, the boronic acid can be introduced as a boronic ester by one of the above mentioned approaches. This is followed by different deprotection reactions and in the final step 5'-OH will be phosphorylated.

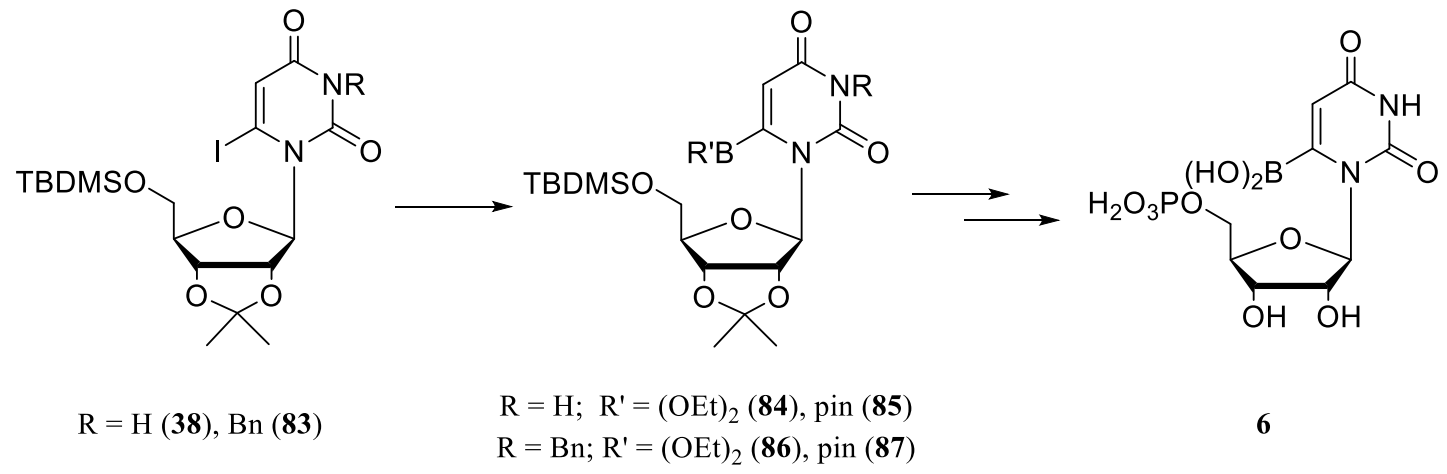

Figure 60: Planned synthesis of 6-boronic acid UMP.

The first attempt of borylation was a classical MIYAURA borylation using bis(pinacolato)diboron as borate of choice due to comparable high stability offering eased handling, catalyzed by (1,1'-bis(diphenylphosphino)ferrocene)palladium(II) dichloride ( $\left.\mathrm{PdCl}_{2}(\mathrm{dppf})\right)$ and potassium acetate (Figure 61). ${ }^{[175]}$ 
4. Results and Discussion

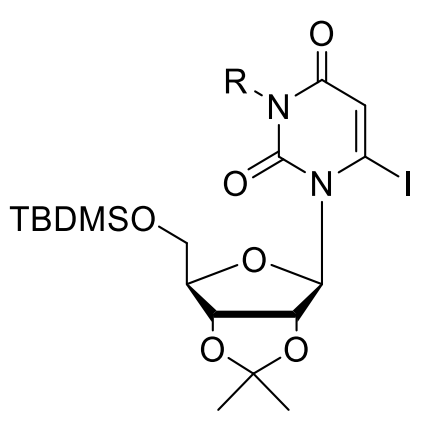

$\mathrm{R}=\mathrm{H}(\mathbf{3 8}), \mathrm{Bn}(\mathbf{8 3})$

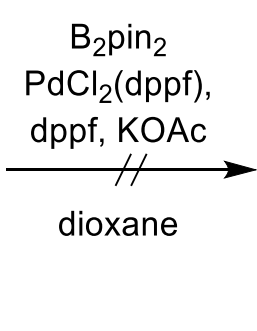

$\mathrm{R}=\mathrm{H}(\mathbf{8 5}), \mathrm{Bn}(\mathbf{8 7})$

Figure 61: Attempted MiYAuRA Borylation.

No matter if $N 3$ was benzyl protected or not, the C-B bond could not be formed using this reaction conditions. Therefore, attempts using activated boron species were considered. One of this activations was performed using organozinc species yielding in situ generated borylzincate which should be highly reactive as reported by NAGASHIMA et al. (Figure 62). ${ }^{[176]}$

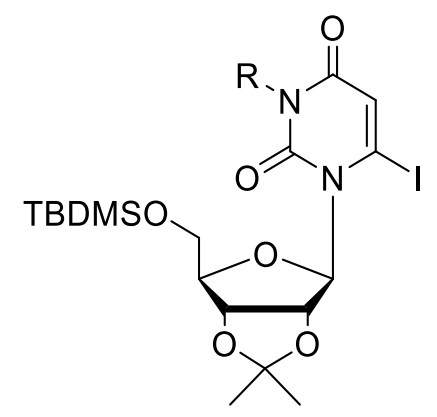

$\mathrm{R}=\mathrm{H}(\mathbf{3 8}), \mathrm{Bn}(\mathbf{8 3})$

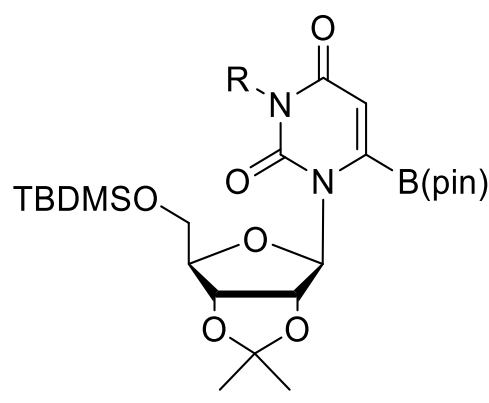

$\mathrm{R}=\mathrm{H}(\mathbf{8 5}), \mathrm{Bn}(\mathbf{8 7})$

Figure 62: Attempted Borylation using activated boron species.

Another activated boron species was used as reported by BETTINGER et al. ${ }^{[177]}$ In this approach was chloro b(pin) generated from pinacol and boron trichloride $\left(\mathrm{BCl}_{3}\right)$ which then should react with protected iodouridine as shown in Figure 63.

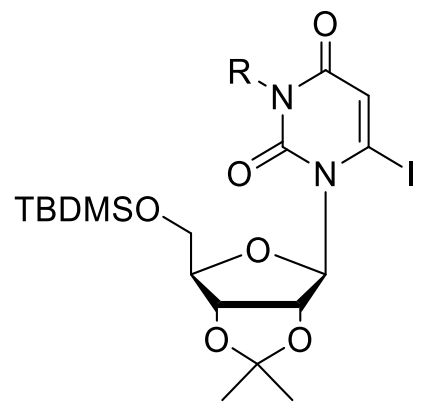

$\mathrm{R}=\mathrm{H}(\mathbf{3 8}), \mathrm{Bn}(\mathbf{8 3})$
1) $n \mathrm{BuLi}, \mathrm{THF}$

2) $\mathrm{ClB}($ pin), THF

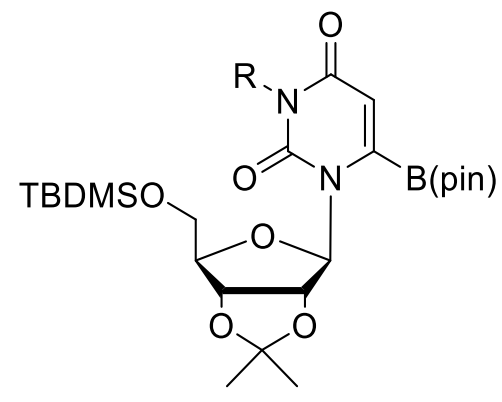

$\mathrm{R}=\mathrm{H}(\mathbf{8 5}), \mathrm{Bn}(\mathbf{8 7})$

Figure 63: Attempted Borylation using activated boron species. 
An alternative borylation was tested based on a radical borylation mechanism. This reaction was inspired by the mechanism of radical borylation published by ZHANG and JIAO. ${ }^{[178]}$ They showed that aryl halides can be transformed into aryl radicals via single electron transfer in presence of organic additives and the homolytic diboron bond can be cleaved by a Lewis base. $^{[178]}$

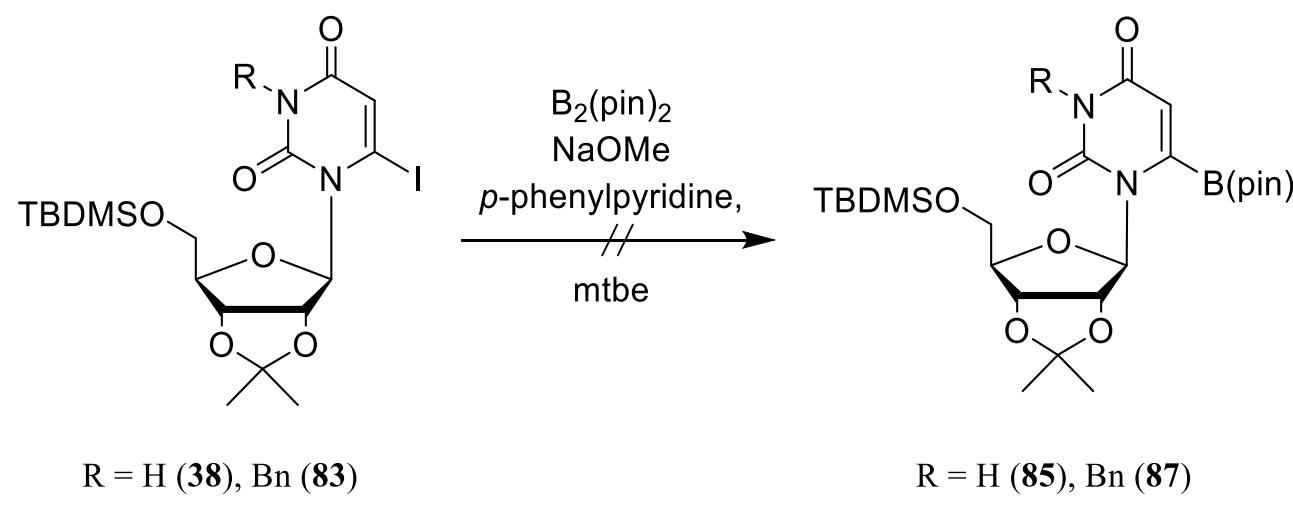

Figure 64: Attempted Borylation using activated boron species.

Since these attempts of boryl activation as well as the tests of radical reactions did not yield the desired product a very different approach was considered. A potential source of failure for the borylation reaction may be that the reaction conditions were adapted from arene scaffold while one could discuss how "aromatic" the uridine system is. To be able to perform these reactions adapted from aryl systems, the electron density was concentrated on the pyrimidine ring. This could be achieved following a convergent synthetic pathway, performing reactions on the nucleobase followed by a nucleosidation reaction in the end.<smiles>[R]Oc1cc([R10]([H])([H])O[M])nc([R])n1</smiles>

Figure 65: Convergent synthetic approach to synthesize 6-boronic acid UMP.

This synthetic approach was adapted from SCHINAZI and PRUSOFF with slight modifications. ${ }^{[131]}$ It started with commercially available barbituric acid which reacts with phosphoryl bromide $\left(\mathrm{POBr}_{3}\right)$ to yield 2,4,6-tribromopyrimidine. ${ }^{[179]}$ Then alkyloxy groups were introduced using sodium and benzylic alcohol. ${ }^{[180]}$ In the following step 2,4-bis(benzyloxy)-6-bromopyrimidine 


\section{Results and Discussion}

can react with butyllithium and subsequently different borates were tested to yield a 6-boron pyrimidine species.<smiles>O=C1CC(=O)NC(=O)N1</smiles>

92

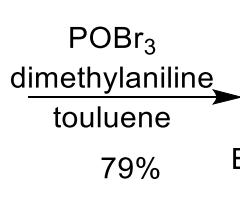

93

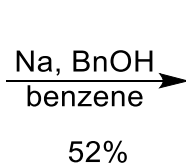

$52 \%$<smiles>Brc1cc(OCc2ccccc2)nc(OCc2ccccc2)n1</smiles>

94<smiles>BrOc1cc(OCc2ccccc2)nc(Br)n1</smiles>

95

Figure 66: Synthesis of 2,4-bis(benzyloxy)-6-bromopyrimidine. ${ }^{[131]}$

2,4-bis(benzyloxy)-6-bromopyrimidine (94) was obtained in moderate yield (52\%) with 4,6-bis(benzyloxy)-2-bromopyrimidine (95) as a side product (Figure 66).

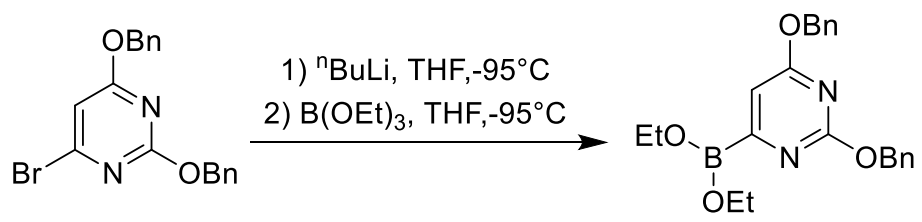

94

96

Figure 67: Attempted synthesis of introducing borates into position 6.

The reaction was performed several times with the addition of various boron species and screening of conditions without successful formation of C-B bond. In addition, a method was used combining the borate addition with boron trichloride aliquots which should improve the yield of the reaction but did not change the outcome.

\subsection{Thymidine targets}

In a chronological last approach in this thesis the synthesis of 5-methyl OMP 23 and 6-carboxy TMP 25 was attempted, shown in Figure 68. The scope of this approach is to evaluate the influence of the 2'-OH group as well as a 5-methyl substitution. The fourth lead structure in this scheme, 2'-deoxy OMP 24 is synthesized by Elisa SANTAGOSTINO. The general synthetic pathway was adapted from OMP synthesis changing the hydroxyl group protection from acetal to solely silyl protection in case of the deoxy lead structures. 


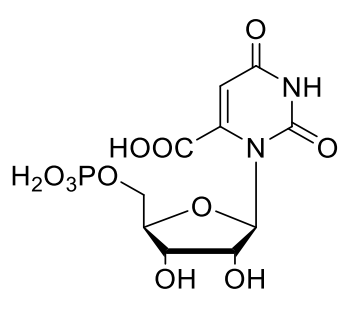

1

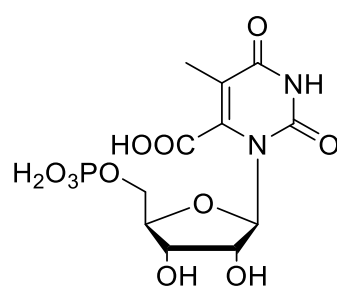

23

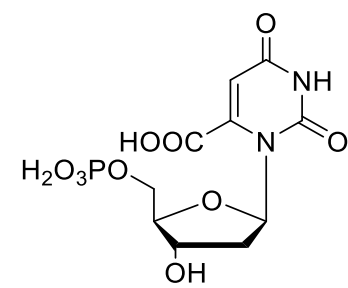

24

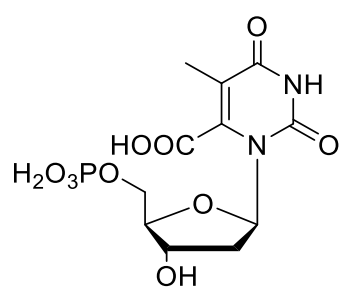

25

Figure 68: Targets bearing 5-Methyl and/or missing 2' OH group.

\subsubsection{5-Methyl OMP}

The synthesis started with 5-methyluridine performing the hydroxyl protection in the before described manner, as shown in Figure 69 The introduction of the carboxyl group was adapted from the OMP synthesis yielding the protected 5-methylorotidine in rather low yields, followed by deprotection reaction using methanolic $\mathrm{HCl}$ obtaining 5-methylorotidine. The phosphorylation was not successful.<smiles>Cc1cn(C2OC(CO)C(O)C2O)c(=O)[nH]c1=O</smiles>

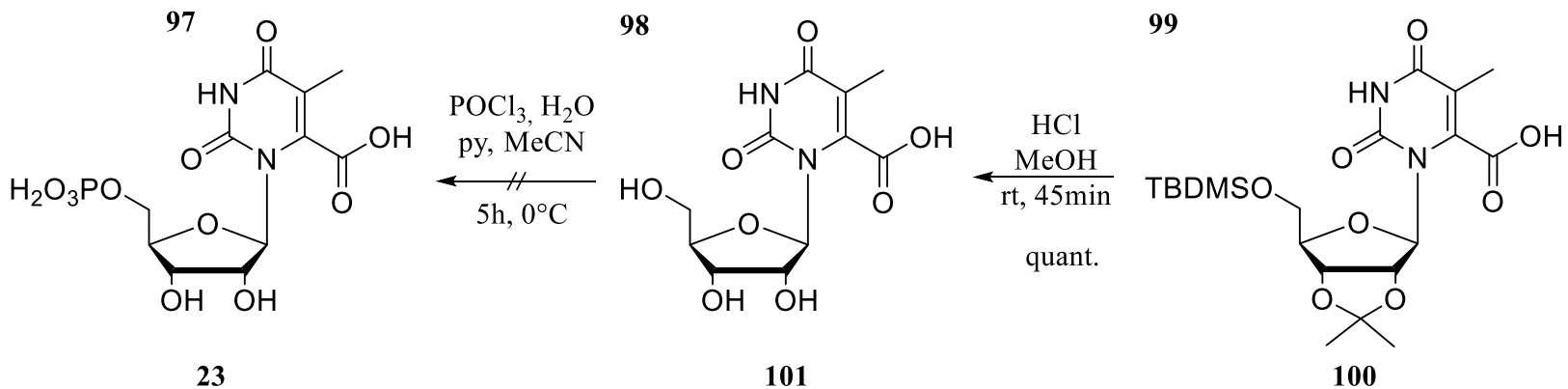

Figure 69: Synthesis of 5-methyl OMP.

\subsubsection{6-Carboxy TMP}

The synthetic procedure is shown in Figure 70, starting with thymidine both hydroxyl groups were protected using TBDMSCl. The attempts of introducing the carboxyl group were not successful changing the electrophile to methyl chloroformate yielding compound $\mathbf{1 0 4}$ in low yields, followed by deprotection reaction using methanolic $\mathrm{HCl}$ obtaining compound $\mathbf{1 0 5}$. 
4. Results and Discussion

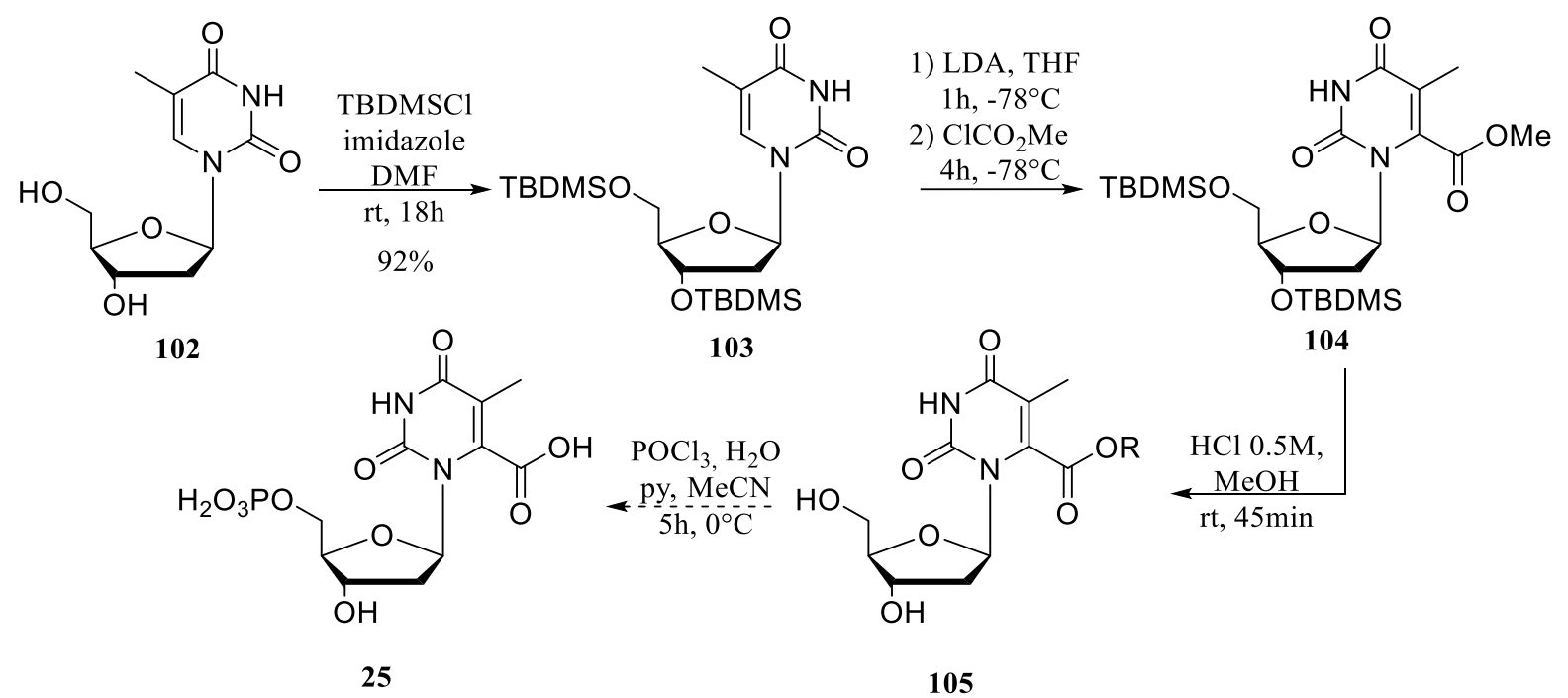

Figure 70: Synthesis of 6-carboxy TMP. 


\section{Summary and Outlook}

In this thesis, the synthesis of OMPD substrate analogs was investigated to further elucidate the mechanism of the OMPD. As inhibiting molecules, 6-thioamido UMP, OMP methyl ester, reduced OMP, and nonpolar substituted UMPs (6-methyl, 6-ethyl, 6-isopropenyl) were synthesized. In addition, several synthetic approaches to yield further target molecules were attempted. As described in chapter 4.6, synthetic approaches in the field of cytidine chemistry were examined trying to afford 6-carboxy CMP and derivatives. Furthermore, the synthesis of 6-boronic acid UMP as well as a few deoxy targets were attempted as explained in chapter 4.7 and 4.8.

The synthesized substrate analogs were obtained in high purity after HPLC purification as bis(triethylammonium) salts which were soaked into pre-crystallized resting state crystals of the $h \mathrm{OMPD}_{\mathrm{WT}}$, analyzed via $\mathrm{x}$-ray crystallography performed by the TITTMANN group. The obtained crystal structures of the synthesized ligands of OMPD were obtained in ultra-high resolution. ${ }^{[16]}$ The structure of 6-thioamido UMP showed a ligand position like in 6-amido UMP and OMP in $h \mathrm{OMPD}_{314 \mathrm{AcK}}$. The thioamide group is pointing towards the catalytic tetrad, the orientation and measured angles are almost identical to 6-amido UMP. Both structures were obtained with a resolution of $1.20 \AA$, but even the smallest differences in 6-amido UMP and 6-thioamido UMP structures may answer the questioned discrepancy in enzyme affinity. The thioamide $\mathrm{C}=\mathrm{S}$ bond is longer (measured 1.6 $\AA$, lit. 1.55-1.68 $\AA$ ) than the amide $\mathrm{C}=\mathrm{O}$ bond (measured $1.2 \AA$, lit. $1.21 \AA$ ) and sulfur is obviously bigger than oxygen. ${ }^{[181-184]}$ This leads to a difference in the torsion angle of the thioamide substituent of $82^{\circ}$ (amido $67^{\circ}$ ) and the formed $\mathrm{H}$-bond with the other oxygen of $\mathrm{Asp}_{312}$ and in addition the potential extra H-bond between thioamide $\mathrm{NH}_{2}$ and Asp' 317 with a measured distance of $2.8 \AA$. In the case of the 6-amido UMP this distance is $3.1 \AA$, giving a lower chance of the existence of this hydrogen bond.

The nonpolar substituted lead structures, 6-methyl-, 6-ethyl-, 6-isopropenyl UMP were examined in x-ray crystallography obtaining structures at atomic resolution, demonstrating the steric demand of the substituent in conflict with those of the amino acid residues of the catalytic tetrad in the enzymatic pocket without having any kind of polar interactions (chapter 4.2). The 
observed out of plane distortion in 6-methyl UMP $\left(39^{\circ} \pm 4^{\circ}\right)$ and 6-ethyl UMP $\left(C 7: 4.5^{\circ} \pm 0.3^{\circ}\right.$, C8: $77.4^{\circ} \pm 1.3^{\circ}$ ) represents the rigidity of the Lys 314 within the charged catalytic tetrad. In contrast the more sterically demanding substituents like 6-isopropyl and 6-isopropenyl UMP pushing the Lys $_{314}$ in an alternative conformation with changed interactions within the tetrad. The measurements of kinetic parameters for these ligands were attempted, but unfortunately, they weren't competitive regarding OMP which was present in the experimental setup using isothermal titration calorimetry (ITC).

The original enzyme-substrate complex cannot be observed in crystal structure due to the high reactivity. ${ }^{[26]}$ That is why the mutant $h \mathrm{OMPD}_{314 \mathrm{AcK}}$ was investigated by S. RINDFLEISCH, to find out more about the structure of the enzyme-substrate complex applying the original substrate. The mutant's Lys 314 is acetylated, because it is known that exchange of Lys 314 is nearly shutting down completely the enzyme activity. ${ }^{[27,71]}$ The obtained crystal structure of OMP-hOMPD 314 AcK complex indicates a similar ligand orientation and angles than in the wild type complexes of 6-amido UMP and 6-thioamido UMP, emphasizing the formation of the hydrogen bond between substrate $\mathrm{COOH}$ and tetrad Asp $312 .{ }^{[16,33]}$ In addition, to the described mutant-OMP structure the crystal structures of the transition state analogs BMP and 6-aza UMP showed no indication for a localized negative charged reaction intermediate. ${ }^{[16,33,34]}$ In contrast, instead of stressed repulsive interactions we were able to identify a productive hydrogen bond between carboxylate and Asp 312 .

The syntheses of OMP methyl ester and reduced OMP were both successful, but surprisingly no crystal structures were obtained. In case of the methyl ester the purification needs to be performed again followed by a neutralization step to tackle residual amounts of formic acid. The reduced OMP also needs to be analyzed again to further evaluate if the ring opening of the molecule took place before the x-ray crystallography or if the observations were induced by the enzyme or the measurement itself. The synthesis of 6-boronic acid was also not successful, the formation of the C-B seemed to be not feasible at least under the specified conditions. A changed protection strategy with less sterical groups and improved MIYAURA borylation conditions might help regarding the synthesis of the lead structures

A lot of synthetic effort was put into the synthesis of 6-carboxy CMP, unfortunately not yielding the desired lead structure. No matter which of the before described reaction pathways was used, one last step was missing or simply not successful, e.g., the phosphorylation of 6-substitued cytidines or the deprotection issue of a fully (boc/cbz/Bz, silyl and acetal) protected carboxycytidine. The recently attempted enzymatic approach using UCK2 still can be 
optimized and repeated soon. However, during the work of this thesis, especially while attempting to make an effort of the not successful synthesized lead structures, the introductions of some modifications in the nucleoside systems seemed much more complex and demanding than expected. Remembering a quote of Herbert C. Brown, Nobel Prize laureate of 1979: "[...] said that there are four types of chemistry, organic, inorganic, physical and pyrimidine [...]." ${ }^{[185,186]}$ Even though BROWN supposedly said this as a joke, for several reactions this fitted quite well.

To sum up, within the scope of this thesis new OMP analogs were designed and synthesized, and new crystal structures were obtained which gave further information of the complex network of enzyme-substrate interactions. New synthetic approaches of the syntheses of several other inhibitors were attempted. High resolution crystal structures were obtained of thioamido-, methyl-, ethyl-, isopropenyl UMP which provided new insights. Together with the analogs synthesized by KRULL, amido-, isopropyl, aza UMP and BMP, valid conclusions could be drawn. All the final crystal structures indicate interactions against the electrostatic stress hypothesis in the enzymatic pocket as a driving force of decarboxylation. In addition, it seems unlikely that a localized vinyl anion is the key intermediate. The negative charge is rather delocalized in the pyrimidine moiety and the steric repulsive interactions with the catalytic tetrad, especially Lys 314 , might be stronger than expected before. This was even seen for the nonpolar substituted lead structures, reinforcing that the ligand distortion contributes to catalysis, but to which extend is still under discussion. 



\section{Experimental part}

\subsection{Materials \& Methods}

\section{General Information about Reagents and Solvents}

All reagents, including anhydrous solvents, were acquired from commercial sources $(A B C R$, Acros-Organics, Alfa Aesar, Fisher Scientific, Fluorochem, Merck, Carl Roth GMBH, SigmaAldrich, TCI and $V W R$ ) and used without further purification. Technical solvents were distilled prior to use. Ultrapure water was obtained via purification of demineralized water by an arium mini water purification system by Sartorius.

\section{Moisture sensitive reactions}

All reactions were performed using standard reaction flasks, reflux condenser and heating or cooling baths. The reactions of water and air sensitive reagents were carried out under inert gas atmosphere, which was guaranteed using argon (> 99.996\%) and standard working techniques recording to SCHLENK. ${ }^{[187,188]}$ This means, the dry glass apparatus was heated with hot air and then cooled under reduced pressure. After that, it was filled with inert gas. This process was repeated three times. Every variation or other working technique is explicitly mentioned in the experimental part.

\section{Thin-layer chromatography (TLC) and column chromatography}

Analytical thin-layer chromatography (TLC) was performed on commercially available silica gel 60 F254 plates (MERCK) pre-coated with fluorescent indicator. The spots were visualized by UV light $(254 \mathrm{~nm})$ or using one of the stain solutions listed below. Column chromatography for the purification of crude products was carried out with Geduran silica gel 60, $0.040-$ $0.063 \mathrm{~mm}(230-450 \mathrm{mesh})$ from MERCK with solvents of technical quality.

\section{High Performance Liquid Chromatography (HPLC)}

HPLC purification was mainly carried out on devices from JASCO Deutschland GmbH (Pfungstadt, Germany). For sample purification on a preparative scale, a device equipped with PU-4086 pumps, a UV-4075 detector and a CO-4060 column oven was used at flow rates of 
$10 \mathrm{~mL} / \mathrm{min}$. Semi-preparative purification was performed on a system with PU-2080plus pumps and a MD-2010 detector at flow rates of $3 \mathrm{~mL} / \mathrm{min}$. A system with identical pumps and a MD-4015 detector was used for purification on an analytical scale at flow rates of $1 \mathrm{~mL} / \mathrm{min}$.

In addition, preparative HPLC purification was performed on the HPLC-system $\ddot{A} K T A$ basic by Amersham Pharmacia Biotech equipped with a P-900 pump system and a UV-900 UV detector. It was used an anion exchange column type Spherisorb SAX OBD 80A 5 $250 \mathrm{~mm} \times 19 \mathrm{~mm}$ from waters with a particle size of $5 \mu \mathrm{m}$. Purification was done at a flow of $10 \mathrm{~mL} / \mathrm{min}$ with a linear gradient of eluent A (ultrapure water) and eluent B (0.5 M TEAA-buffer at $\mathrm{pH}=7.0$ ). Nucleotides were detected at $254 \mathrm{~nm}, 260 \mathrm{~nm}$ and $270 \mathrm{~nm}$ if not noted otherwise.

\section{Freeze-Drying}

Nucleotide solutions in aqueous TEAA buffer were frozen in liquid nitrogen and the buffer was sublimated under reduced pressure ( $<1$ mbar) using an Alpha-2-4-LD plus freeze-dryer from Martin Christ Gefriertrocknungsanlagen GmbH (Osterode am Harz, Germany).

\section{Nuclear Magnetic Resonance (NMR)}

${ }^{1} \mathrm{H}-\mathrm{NMR}$ spectra were recorded on Avance III HD (300, 400 or $500 \mathrm{MHz}$ ) and Avance Neo (600 MHz) devices from Bruker BioSpin GmbH (Rheinstetten, Germany) at $25^{\circ} \mathrm{C} .{ }^{13} \mathrm{C}-\mathrm{NMR}$ spectra were recorded on the same devices at the corresponding frequencies of 75, 100, 125 and $150 \mathrm{MHz}$ at $25^{\circ} \mathrm{C}$. The utilized deuterated solvents are indicated for each compound individually. Chemical shifts are quoted in ppm and coupling constants in Hz. Multiplicities are abbreviated as follows: $\mathrm{s}=$ singlet, $\mathrm{sbr}=$ broad singlet, $\mathrm{d}=$ doublet, $\mathrm{dd}=$ doublet of doublets, $\mathrm{t}=$ triplet, $\mathrm{dt}=$ doublet of triplets, $\mathrm{m}=$ multiplet. ${ }^{13} \mathrm{C}$-NMR experiments were recorded with proton decoupling. The chemical shifts are reported relative to the residual proton signal of deuterated solvents in ppm: $\mathrm{CDCl}_{3}$ (7.26), DMSO- $d_{6}$ (2.50), $\mathrm{CD}_{3} \mathrm{OD}$ (3.31) for ${ }^{1} \mathrm{H}-\mathrm{NMR}$ spectra. The chemical shifts are in reference to the deuterated solvents: $\mathrm{CDCl}_{3}$ (77.16), DMSO-d $d_{6}$ (39.52), $\mathrm{CD}_{3} \mathrm{OD}$ (49.00) for ${ }^{13} \mathrm{C}-\mathrm{NMR}$ spectra.

\section{Mass Spectrometry}

Mass spectrometry was performed using electrospray ionization (ESI). High resolution ESI spectra were obtained using microTOF-Q II or maXis ESI-QTOF-MS instrument from Bruker. The values are given as $\mathrm{m} / \mathrm{z}$ relation. 


\section{Software}

ChemDraw Professional 16.0 (PerkinElmer Informatics, Waltham, MA, United States) was used for the drawing of chemical structures and calculation of molecular masses and data files from the RCSB protein data bank (pdb) were interpreted and modified using PyMol (Version 2.3.2). The codes to the corresponding pdb entry are indicated in the respective figures. NMR spectra were analyzed with MestReNova 10.0 (Mestrelab Research, S.L., Santiago de Compostella, Spain) and graphs were compiled using OriginPro 8.5G (OriginLab Corporation, Northampton, MA, United States).

\section{X-ray crystallography}

Crystallization of protein crystals was performed by SÖREN RINDFLEISCH using a protocol of WITTMANN et al. with slight modifications. ${ }^{[189]}$ Into the obtained resting state crystals the different synthesized ligands were soaked obtaining enzyme-ligand complexes. Alternatively, the nucleotides were co-crystallized with $h$ OMPDwT. Most of the inhibitors were crystallized according to a soaking procedure using nucleotides stock solutions of $10-15 \mathrm{mM} .^{[190,191]}$

X-ray measurement (data collection) was performed at "Deutsches Elektronen-Synchrotron" (DESY) at beamlines P13 and P14 at PETRA III storage ring in Hamburg. ${ }^{[192]}$ All datasets were gained under cryogenic conditions and to exclude protein damage due to radiation, the radiation dose was determined with each measurement. The analysis of obtained diffraction data, integration, correction, scaling and refinement was performed by SÖREN RINDFLEISCH using the program XDS. ${ }^{[193]}$ Further data procession, model building as well as refinements were done using COOT, refmac5 and SHELXL. ${ }^{[194,195]}$ The final presented pictures were processed with the help of FABIAN RABE VON PAPPENHEIM using PyMol.

The determined angles for out of pyrimidine plane distortion were measured using the dihedral measuring function in PyMol, calculating the dihedrals of C4-C5-C6-C7 and C2-N1-C6-C7 and averaging both values to target an eventually distortion of the pyrimidine plane.

\section{Kinetics measuring ITC}

The kinetic parameters of the substrate analogs inhibiting the OMPD were determined using isothermal titration calorimetry (ITC) performed together with LAURA KIRCK. The experimental setup consists of the enzyme (OMPD $(20 \mu \mathrm{M})$ ), the original substrate (OMP $(10 \mathrm{mM}, 40 \mu \mathrm{L}))$ and one of the potential inhibitors. Everything dissolved in HEPES buffer ( $20 \mathrm{mM}, \mathrm{pH}=7.4$ ) and injected to the ITC measuring chamber. The direct measured dimension is shown in the thermogram in Figure 71. The integral of the graph in the thermogram is the 
6. Experimental part

enthalpy, from which the kinetic parameters can be determined, demonstrated in a Michaelis-Menten plot, as shown in Figure 72.

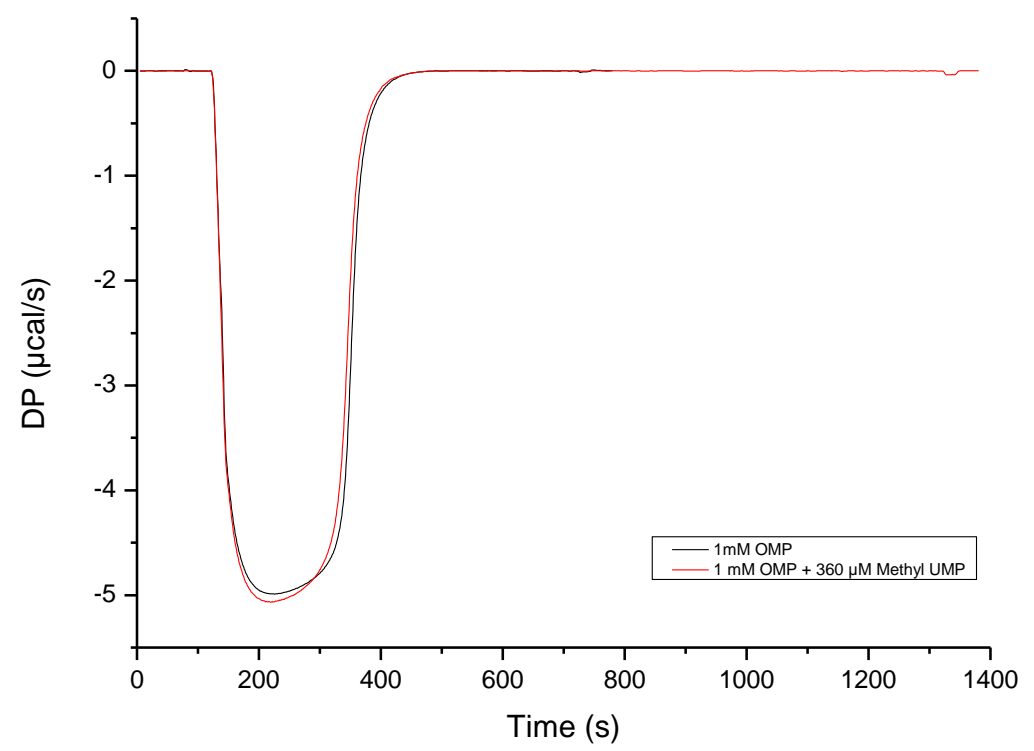

Figure 71: Thermogram of ITC measurement.

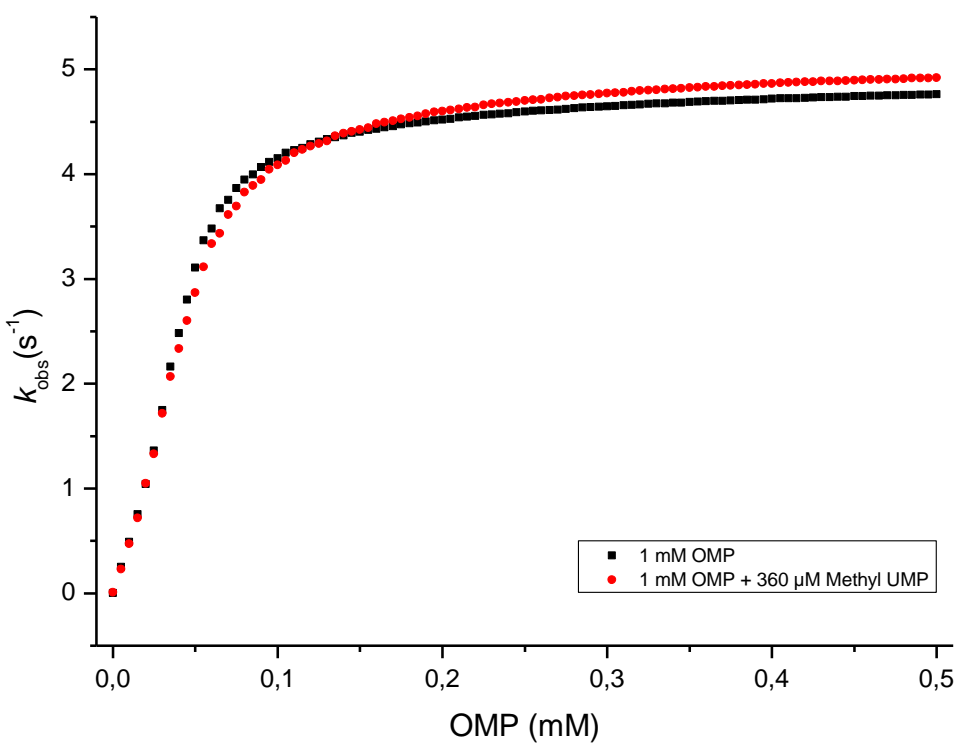

Figure 72: Michaelis-Menten Plot. 


\subsection{Overview Synthesis}

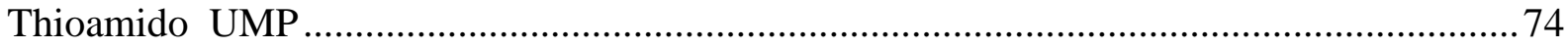

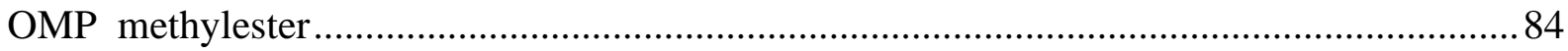

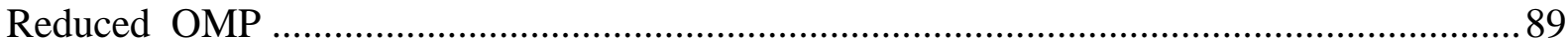

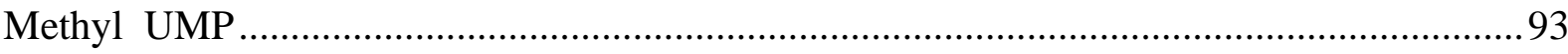

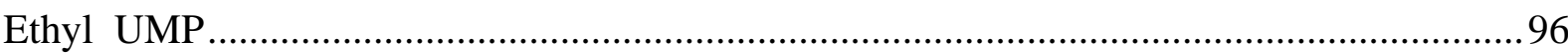

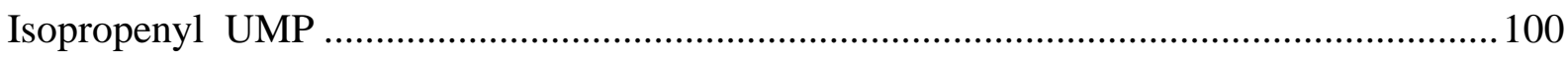

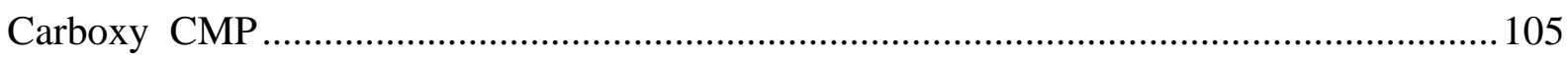

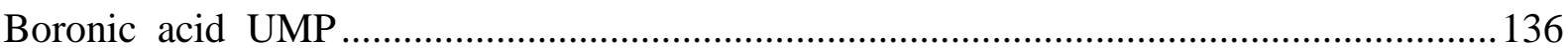

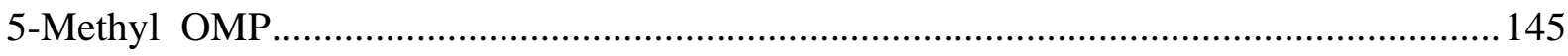

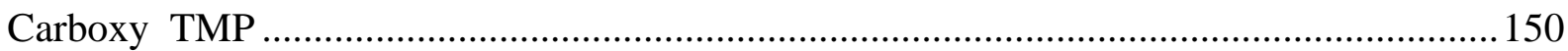


6. Experimental part

\subsubsection{Synthesis of 6-thiocarboxamido UMP}

\section{Synthesis of 5-bromouridine (28)}

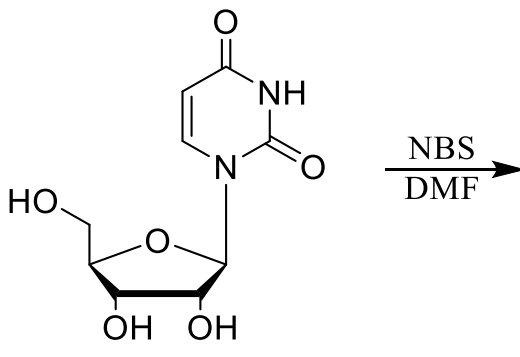

$M=244,20$

20<smiles>O=c1[nH]c(=O)n(C2OC(CO)[C@@H](O)[C@H](O)[C@H]2O)cc1Br</smiles>

$M=323,10$

28

Uridine (10.0 g, $40.9 \mathrm{mmol}, 1.0$ eq.) was dissolved in DMF (75 mL). Then, NBS (10.8 g, $60.6 \mathrm{mmol}$, 1.5 eq.) was added and the reaction mixture was stirred overnight at room temperature. The solvent was removed in vacuo and the crude product was purified by column chromatography $\left(\mathrm{SiO}_{2} ; \mathrm{DCM} / \mathrm{MeOH}\right.$, gradient 20:1 to 10:1) to afford 5-bromouridine (7.80 g, $24.2 \mathrm{mmol}, 59 \%$ ) as a white solid.

TLC, $R_{\mathrm{f}}=0.20 \mathrm{DCM} / \mathrm{MeOH}(20: 1)$.

${ }^{1} \mathbf{H}-\mathbf{N M R}\left(300 \mathrm{MHz}, \mathrm{DMSO}-d_{6}\right): \delta(\mathrm{ppm})=11.81(\mathrm{~s}, 1 \mathrm{H}, \mathrm{NH}), 8.48(\mathrm{~s}, 1 \mathrm{H}, \mathrm{C} 6 \mathrm{H}), 5.73(\mathrm{~d}$, $\left.J=4.4 \mathrm{~Hz}, 1 \mathrm{H}, \mathrm{C} 1{ }^{\prime} \mathrm{H}\right), 5.42(\mathrm{~d}, J=5.2 \mathrm{~Hz}, 1 \mathrm{H}, \mathrm{OH}), 5.27(\mathrm{t}, J=4.6 \mathrm{~Hz}, 1 \mathrm{H}, \mathrm{OH}), 5.06(\mathrm{~d}$, $J=5.3 \mathrm{~Hz}, 1 \mathrm{H}, \mathrm{OH}), 4.01\left(\mathrm{dq}, J=17.2,4.9 \mathrm{~Hz}, 2 \mathrm{H}, \mathrm{C} 2{ }^{\prime} \mathrm{H}, \mathrm{C} 3{ }^{\prime} \mathrm{H}\right), 3.86$ (m, 1H, C4'H), 3.64 (m, 2H, C5' $\mathrm{H}_{2}$ ).

${ }^{13}$ C-NMR (75 MHz, DMSO-d6): $\delta(\mathrm{ppm})=159.6$ (C4), 150.4 (C2), 140.8 (C6), 96.2 (C5), $89.0\left(\mathrm{C}^{\circ}\right), 85.1\left(\mathrm{C}^{\circ}\right), 74.4\left(\mathrm{C}^{\circ}\right), 69.7\left(\mathrm{C}^{\circ}\right), 60.6\left(\mathrm{C}^{\circ}\right)$.

MS (ESI+, $\mathrm{MeOH}): \mathrm{m} / \mathrm{z}=344.9[\mathrm{M}+\mathrm{Na}]^{+}$.

HRMS (ESI+): m/z calc. for $\mathrm{C}_{9} \mathrm{H}_{11} \mathrm{~N}_{2} \mathrm{O}_{6}{ }^{79} \mathrm{Br}[\mathrm{M}+\mathrm{H}]^{+}:$: 322.9873, found: 322.9874 .

(ESI+): $\mathrm{m} / \mathrm{z}$ calc. for $\mathrm{C}_{9} \mathrm{H}_{11} \mathrm{~N}_{2} \mathrm{O}_{6}{ }^{81} \mathrm{Br}[\mathrm{M}+\mathrm{H}]^{+}: 324.9853$, found: 324.9855 .

(ESI+): m/z calc. for $\mathrm{C}_{9} \mathrm{H}_{11} \mathrm{~N}_{2} \mathrm{O}_{6}{ }^{79} \mathrm{Br}[\mathrm{M}+\mathrm{Na}]^{+}: 344.9693$, found: 344.9701 .

(ESI+): $\mathrm{m} / \mathrm{z}$ calc. for $\mathrm{C}_{9} \mathrm{H}_{11} \mathrm{~N}_{2} \mathrm{O}_{6}{ }^{81} \mathrm{Br}[\mathrm{M}+\mathrm{Na}]^{+}: 346.9673$, found: 346.9677 . 


\section{Synthesis of 2',3'-O-isopropylidene-5-bromouridine (29)}<smiles>O=c1[nH]c(=O)n(C2OC(CO)C(O)C2O)cc1Br</smiles>

$M=323,10$

28

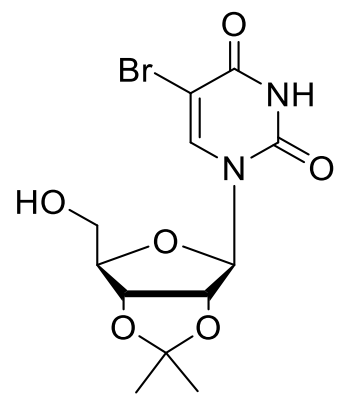

$M=363,16$

29

5-Bromouridine (4.20 g, $13.0 \mathrm{mmol}, 1.0$ eq.) was suspended in acetone (120 mL) and $\mathrm{H}_{2} \mathrm{SO}_{4}$ $(1.2 \mathrm{~mL})$ was added dropwise. The reaction mixture was stirred for $2 \mathrm{~h}$ at room temperature. The reaction was quenched adding triethylamine $(3.0 \mathrm{~mL})$ and the solvent was removed in vacuo. The crude product was purified by column chromatography $\left(\mathrm{SiO}_{2}\right.$; hexane/ EtOAc, 1:1) to afford the title compound (3.50 g, $9.60 \mathrm{mmol}, 74 \%)$ as a white solid.

TLC, $R_{\mathrm{f}}=0.25$ hexane/ EtOAc, $(1: 1)$.

${ }^{1}$ H-NMR (300 MHz, DMSO- $\left.d_{6}\right): \delta(\mathrm{ppm})=11.82(\mathrm{~s}, 1 \mathrm{H}, \mathrm{NH}), 8.32(\mathrm{~s}, 1 \mathrm{H}, \mathrm{C} 6 \mathrm{H}), 5.84 \mathrm{~d}$, $\left.J=2.5 \mathrm{~Hz}, 1 \mathrm{H}, \mathrm{C} 1{ }^{\prime} \mathrm{H}\right), 5.16(\mathrm{~s}, 1 \mathrm{H}, \mathrm{OH}), 4.92\left(\mathrm{dd}, J=6.3,2.5 \mathrm{~Hz}, 1 \mathrm{H}, \mathrm{C} 2{ }^{\prime} \mathrm{H}\right), 4.75(\mathrm{dd}, J=6.3$, $\left.3.5 \mathrm{~Hz}, 1 \mathrm{H}, \mathrm{C} 3{ }^{\prime} \mathrm{H}\right), 4.11$ (q, $\left.J=4.0 \mathrm{~Hz}, 1 \mathrm{H}, \mathrm{C} 4{ }^{\prime} \mathrm{H}\right), 3.61$ (m, 2H, C5' $\left.\mathrm{H}_{2}\right), 1.48\left(\mathrm{~s}, 3 \mathrm{H}, \mathrm{CH}_{3}\right)$, $1.29\left(\mathrm{~s}, 3 \mathrm{H}, \mathrm{CH}_{3}\right)$.

${ }^{13}$ C-NMR (126 MHz, DMSO- $\left.d_{6}\right): \delta(\mathrm{ppm})=159.0$ (C4), 149.5 (C2), 141.1 (C6), 112.7 ( $\left.\underline{\mathrm{C}}\left(\mathrm{CH}_{3}\right)_{2}\right), 95.7$ (C5), 91.3 (C1'), 86.8 (C4'), 83.8 (C2'), 80.1 (C3'), 61.0 (C5'), $27.0\left(\mathrm{CH}_{3}\right)$, $25.2\left(\mathrm{CH}_{3}\right)$.

MS (ESI+, MeOH): m/z = 385.0 [M+Na $]^{+}$.

HRMS (ESI+): $\mathrm{m} / \mathrm{z}$ calc. for $\mathrm{C}_{12} \mathrm{H}_{15} \mathrm{~N}_{2} \mathrm{O}_{6}{ }^{79} \mathrm{Br}[\mathrm{M}+\mathrm{H}]^{+}:$: 363.0186, found: 363.0181 .

(ESI+): $\mathrm{m} / \mathrm{z}$ calc. for $\mathrm{C}_{12} \mathrm{H}_{15} \mathrm{~N}_{2} \mathrm{O}_{6}{ }^{81} \mathrm{Br}[\mathrm{M}+\mathrm{H}]^{+}:$365.0166, found: 365.0159 .

(ESI+): $\mathrm{m} / \mathrm{z}$ calc. for $\mathrm{C}_{12} \mathrm{H}_{15} \mathrm{~N}_{2} \mathrm{O}_{6}{ }^{79} \mathrm{Br}[\mathrm{M}+\mathrm{Na}]^{+}:$385.0006, found: 385.0000 .

(ESI+): $\mathrm{m} / \mathrm{z}$ calc. for $\mathrm{C}_{12} \mathrm{H}_{15} \mathrm{~N}_{2} \mathrm{O}_{6}{ }^{81} \mathrm{Br}[\mathrm{M}+\mathrm{Na}]^{+}:$386.9986, found: 386.9979 . 
6. Experimental part

Synthesis of 5'-O-tert-butyldimethylsilyl-2',3'-O-isopropylidene-5-bromouridine (30)

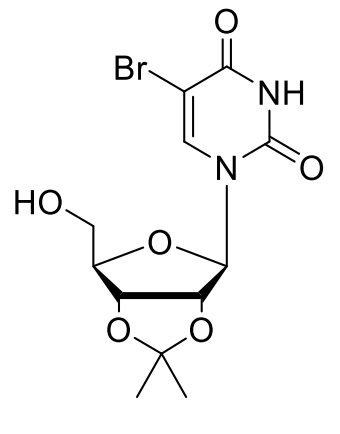

$M=363,16$

29

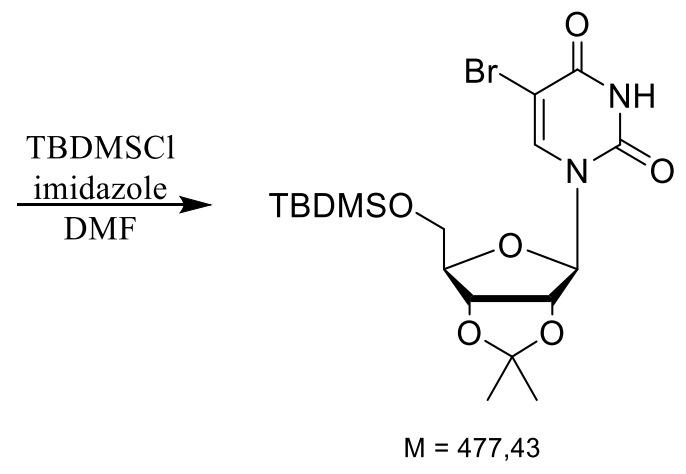

30

2',3'-O-isopropylidene-5-bromouridine (3.00 g, $8.26 \mathrm{mmol}, 1.0$ eq.) and imidazole (1.45 g, 20.7 mmol, 2.5 eq.) were dissolved in DMF (25 mL). TBDMSCl (1.86 g, 12.4 mmol, 1.5 eq.) was added and the reaction mixture was stirred overnight at room temperature. The solvent was removed in vacuo. The crude product was purified by column chromatography $\left(\mathrm{SiO}_{2}\right.$; hexane/ EtOAc, gradient 5:1 to 1:1) to obtain the product $(3.70 \mathrm{~g}, 7.76 \mathrm{mmol}, 94 \%)$ as a white solid.

TLC, $R_{\mathrm{f}}=0.20$ hexane / EtOAc, (5:1).

${ }^{1}$ H-NMR (300 MHz, DMSO-d6): $\delta(\mathrm{ppm})=11.89(\mathrm{~s}, 1 \mathrm{H}, \mathrm{NH}), 8.07(\mathrm{~s}, 1 \mathrm{H}, \mathrm{C} 6 \mathrm{H}), 5.75(\mathrm{~d}$, $\left.J=2.3 \mathrm{~Hz}, 1 \mathrm{H}, \mathrm{C} 1^{\prime} \mathrm{H}\right), 4.92\left(\mathrm{dd}, J=6.3,2.3 \mathrm{~Hz}, 1 \mathrm{H}, \mathrm{C} 2^{\prime} \mathrm{H}\right), 4.68(\mathrm{dd}, J=6.3,3.3 \mathrm{~Hz}, 1 \mathrm{H}$, C3'H), $4.18-4.14\left(\mathrm{~m}, 1 \mathrm{H}, \mathrm{C} 4{ }^{\prime} \mathrm{H}\right), 3.82$ (dd, $\left.J=11.4,3.8 \mathrm{~Hz}, 1 \mathrm{H}, \mathrm{C} 5^{\prime} \mathrm{H}\right), 3.74$ (dd, $J=11.4$, $\left.5.1 \mathrm{~Hz}, 1 \mathrm{H} \mathrm{C}{ }^{\prime} \mathrm{H}\right), 1.47$ (s, 3H, $\left.\mathrm{CH}_{3}\right), 1.28\left(\mathrm{~s}, 3 \mathrm{H}, \mathrm{CH}_{3}\right), 0.86\left(\mathrm{~s}, 9 \mathrm{H}, \mathrm{SiC}\left(\mathrm{CH}_{3}\right)_{3}\right), 0.06(\mathrm{~s}, 6 \mathrm{H}$, $\left.\mathrm{Si}\left(\mathrm{CH}_{3}\right)_{2}\right)$.

${ }^{13}$ C-NMR (126 MHz, DMSO- $\left.d_{6}\right): \delta(\mathrm{ppm})=159.0$ (C4), 149.4 (C2), 140.8 (C6), 112.7 $\left(\underline{\mathrm{C}}\left(\mathrm{CH}_{3}\right)_{2}\right), 95.7$ (C5), 92.3 (C1'), 86.8 (C4'), 83.9 (C2'), 80.2 (C3'), 62.9 (C5'), $26.9\left(\mathrm{CH}_{3}\right)$, $25.8\left(\mathrm{C}\left(\underline{\mathrm{CH}}_{3}\right)_{3}\right), 25.1\left(\mathrm{CH}_{3}\right), 18.0\left(\underline{\mathrm{C}}\left(\mathrm{CH}_{3}\right)_{3}\right),-5.4\left(\mathrm{Si}\left(\mathrm{CH}_{3}\right)_{2}\right)$.

MS (ESI+, MeOH): m/z = 477.1[M+H] $]^{+}, 479.1[\mathrm{M}+\mathrm{H}]^{+}$.

HRMS (ESI+): m/z calc. for $\mathrm{C}_{18} \mathrm{H}_{29} \mathrm{~N}_{2} \mathrm{O}_{6}{ }^{79} \mathrm{Br}[\mathrm{M}+\mathrm{H}]^{+}:$: 47.1051, found: 477.1051.

(ESI+): $\mathrm{m} / \mathrm{z}$ calc. for $\mathrm{C}_{18} \mathrm{H}_{29} \mathrm{~N}_{2} \mathrm{O}_{6}{ }^{81} \mathrm{Br}[\mathrm{M}+\mathrm{H}]^{+}:$479.1031, found: 479.1034.

(ESI+): $\mathrm{m} / \mathrm{z}$ calc. for $\mathrm{C}_{18} \mathrm{H}_{29} \mathrm{~N}_{2} \mathrm{O}_{6}{ }^{79} \mathrm{Br}[\mathrm{M}+\mathrm{Na}]^{+}: 499.0870$, found: 499.0872 .

(ESI+): $\mathrm{m} / \mathrm{z}$ calc. for $\mathrm{C}_{18} \mathrm{H}_{29} \mathrm{~N}_{2} \mathrm{O}_{6}{ }^{81} \mathrm{Br}[\mathrm{M}+\mathrm{Na}]^{+}:$501.0851, found: 501.0853 . 


\section{Synthesis of 5'-O-tert-butyldimethylsilyl-2',3'-O-isopropylidene-6-cyanouridine (31)}

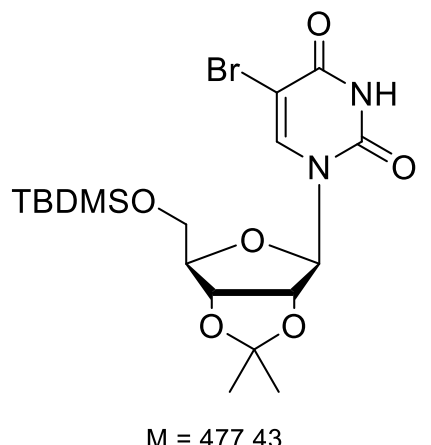

30

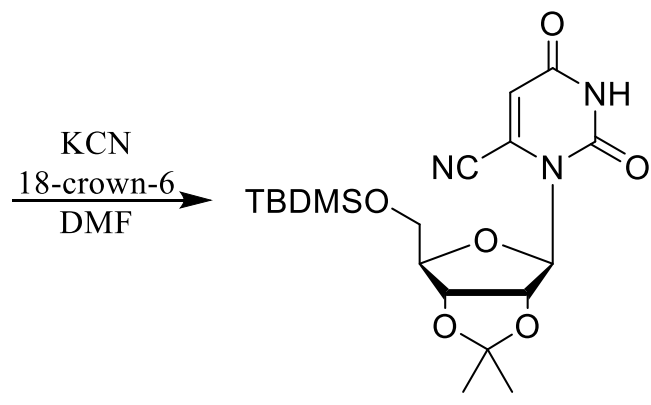

$M=423,54$

31

5'-O-tert-Butyldimethylsilyl-2',3'-O-isopropylidene-5-bromouridine $\quad(3.70 \mathrm{~g}, \quad 7.76 \mathrm{mmol}$, 1.0 eq.), potassium cyanide ( $0.55 \mathrm{~g}, 8.50 \mathrm{mmol}, 1.1$ eq.) and 18-crown-6 (0.20 g, $0.77 \mathrm{mmol}$, 0.1 eq.) were dissolved in DMF $(50 \mathrm{~mL})$. The reaction mixture was stirred overnight at room temperature. The solvent was removed in vacuo. The crude product was purified by column chromatography $\left(\mathrm{SiO}_{2}\right.$; hexane/ EtOAc, gradient 5:1 to $\left.1: 1\right)$ to obtain the product $(2.52 \mathrm{~g}$, $5.97 \mathrm{mmol}, 77 \%$ ) as a light-yellow solid.

TLC, $R_{\mathrm{f}}=0.25$ hexane / EtOAc, (5:1).

${ }^{1}$ H-NMR $\left(300 \mathrm{MHz}, \mathrm{DMSO}-d_{6}\right): \delta(\mathrm{ppm})=12.05(\mathrm{~s}, 1 \mathrm{H}, \mathrm{NH}), 6.74(\mathrm{~s}, 1 \mathrm{H}, \mathrm{C} 5 \mathrm{H}), 5.85(\mathrm{~d}$, $\left.J=1.9 \mathrm{~Hz}, 1 \mathrm{H}, \mathrm{C} 1^{\prime} \mathrm{H}\right), 5.22\left(\mathrm{dd}, J=6.6,1.9 \mathrm{~Hz}, 1 \mathrm{H}, \mathrm{C} 2^{\prime} \mathrm{H}\right), 4.71$ (m, 1H, C3'H), $4.07-4.01$ (m, 1H, C4'H), 3.79 - 3.72 (m, 2H, C5' $\left.\mathrm{H}_{2}\right), 1.49$ (s, 3H, $\left.\mathrm{CH}_{3}\right), 1.30$ (s, 3H, $\left.\mathrm{CH}_{3}\right), 0.85$ (s, 9H, $\left.\mathrm{SiC}\left(\mathrm{CH}_{3}\right)_{3}\right), 0.02\left(\mathrm{~s}, 6 \mathrm{H}, \mathrm{Si}\left(\mathrm{CH}_{3}\right)_{2}\right)$.

${ }^{13}$ C-NMR (126 MHz, DMSO- $\left.d_{6}\right): \delta(\mathrm{ppm})=160.8(\mathrm{C} 4), 149.0(\mathrm{C} 2), 126.2$ (C6), 113.6 (C5), $113.3\left(\underline{\mathrm{C}}\left(\mathrm{CH}_{3}\right)_{2}\right), 111.6(\mathrm{CN}), 92.8\left(\mathrm{C}^{\prime}\right.$ '), 88.2 (C4'), 83.1 (C2'), 81.1 (C3'), 63.1 (C5'), 27.0 $\left(\mathrm{CH}_{3}\right), 25.8\left(\mathrm{SiC}\left(\underline{\mathrm{CH}}_{3}\right)_{3}\right), 25.2\left(\mathrm{CH}_{3}\right), 18.0\left(\underline{\mathrm{C}}\left(\mathrm{CH}_{3}\right)_{3}\right),-5.4\left(\mathrm{Si}\left(\mathrm{CH}_{3}\right)_{2}\right)$.

MS (ESI+, MeOH): m/z = 424.2[M+H $]^{+}, 446.2[\mathrm{M}+\mathrm{Na}]^{+}, 462.2[\mathrm{M}+\mathrm{K}]^{+}$.

HRMS (ESI+): m/z calc. for $\mathrm{C}_{19} \mathrm{H}_{29} \mathrm{~N}_{3} \mathrm{O}_{6} \mathrm{Si}[\mathrm{M}+\mathrm{H}]^{+}:$424.1898, found: 424.1888 .

(ESI+): m/z calc. for $\mathrm{C}_{19} \mathrm{H}_{29} \mathrm{~N}_{3} \mathrm{O}_{6} \mathrm{Si}[\mathrm{M}+\mathrm{Na}]^{+}$: 446.1718, found: 446.1716 .

(ESI+): m/z calc. for $\mathrm{C}_{19} \mathrm{H}_{29} \mathrm{~N}_{3} \mathrm{O}_{6} \mathrm{Si}[\mathrm{M}+\mathrm{K}]^{+}:$462.1457, found: 462.1459 . 
6. Experimental part

\section{Synthesis of}

5'-O-tert-butyldimethylsilyl-2',3'-O-isopropylidene-6-thiocarboxamidouridine (32)

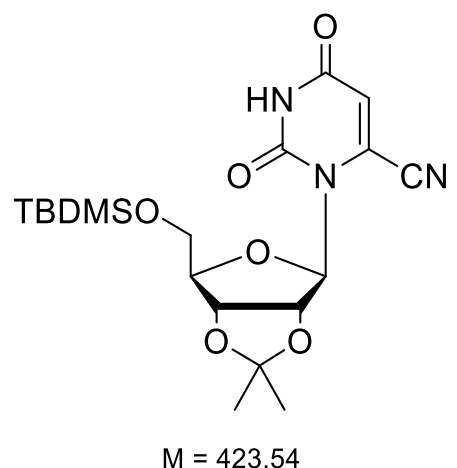

31

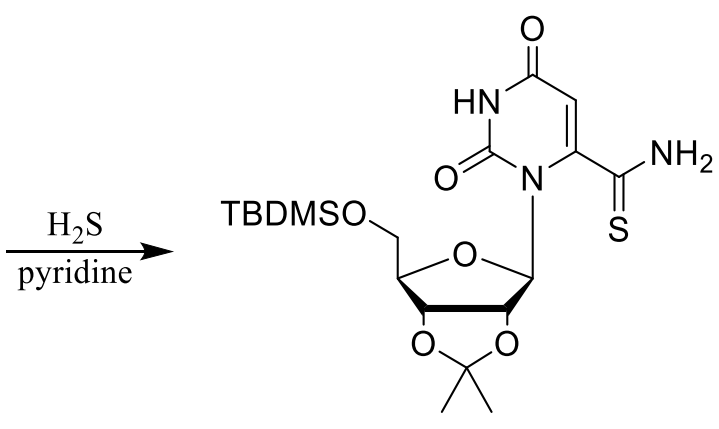

$M=457,62$

32

5'-O-tert-Butyldimethylsilyl-2',3'-O-isopropylidene-6-cyanouridine $\quad(0.50 \mathrm{~g}, \quad 1.18 \mathrm{mmol}$, 1.0 eq.) was dissolved in pyridine $(20 \mathrm{~mL})$. Then, $\mathrm{H}_{2} \mathrm{~S}$ dissolved in $\mathrm{THF}(0.8 \mathrm{M}, 1.50 \mathrm{~mL}$, $1.20 \mathrm{mmol}, 1.0 \mathrm{eq}$.) was added dropwise and the reaction mixture was stirred for $11 \mathrm{~h}$ at room temperature. The solvent was removed in vacuo. The crude product $(0.48 \mathrm{~g}, 1.05 \mathrm{mmol}, 89 \%)$ was used without further purification.

${ }^{1} \mathbf{H}-\mathrm{NMR}\left(300 \mathrm{MHz}, \mathrm{DMSO}-d_{6}\right): \delta(\mathrm{ppm})=11.59(\mathrm{~s}, 1 \mathrm{H}, \mathrm{NH}), 10.60\left(\mathrm{~s}, 1 \mathrm{H}, \mathrm{NH}_{2}\right), 10.25(\mathrm{~s}$, $\left.1 \mathrm{H}, \mathrm{NH}_{2}\right), 5.70\left(\mathrm{~s}_{\mathrm{br}}, 1 \mathrm{H}, \mathrm{C} 1{ }^{\prime} \mathrm{H}\right), 5.51(\mathrm{~m}, 1 \mathrm{H}, \mathrm{C} 5 \mathrm{H}), 5.15$ (d, J=6.3 Hz, 1H, C2'H), 4.74 (m, 1H, C3'H), 3.96 (m, 1H, C4'H), $3.74\left(\mathrm{~m}, 2 \mathrm{H}, \mathrm{C} 5^{\prime} \mathrm{H}\right), 1.44\left(\mathrm{~s}, 3 \mathrm{H}, \mathrm{CH}_{3}\right), 1.28\left(\mathrm{~s}, 3 \mathrm{H}, \mathrm{CH}_{3}\right), 0.86$ (s, $\left.9 \mathrm{H}, \mathrm{CH}_{3}\right), 0.02\left(\mathrm{~s}, 6 \mathrm{H}, \mathrm{CH}_{3}\right)$.

${ }^{13}$ C-NMR (75 MHz, DMSO- $\left.d_{6}\right): \delta(\mathrm{ppm})=191.4\left(\mathrm{CSNH}_{2}\right), 162.4(\mathrm{C} 4), 154.2(\mathrm{C} 2), 149.9(\mathrm{C} 6)$, $112.7\left(\underline{\mathrm{C}}\left(\mathrm{CH}_{3}\right)_{2}\right), 98.3\left(\mathrm{C}^{\circ}\right), 92.4(\mathrm{C} 5), 88.9\left(\mathrm{C}^{\circ}\right), 84.2\left(\mathrm{C} 2^{\circ}\right), 81.9\left(\mathrm{C} 3^{\circ}\right), 63.6\left(\mathrm{C}^{\circ}\right), 27.1$ $\left(\mathrm{CH}_{3}\right), 25.8\left(\mathrm{SiC}\left(\underline{\mathrm{CH}_{3}}\right)_{3}\right), 25.2\left(\mathrm{CH}_{3}\right), 18.0\left(\underline{\mathrm{C}}\left(\mathrm{CH}_{3}\right)_{3}\right),-5.2\left(\mathrm{Si}\left(\mathrm{CH}_{3}\right)_{2}\right),-5.3\left(\mathrm{Si}\left(\mathrm{CH}_{3}\right)_{2}\right)$.

MS (ESI+, MeOH): m/z = 458.2[M+H] $, 475.2\left[\mathrm{M}+\mathrm{NH}_{4}\right]^{+}, 480.2[\mathrm{M}+\mathrm{Na}]^{+}$.

HRMS (ESI+): m/z calc. for $\mathrm{C}_{19} \mathrm{H}_{31} \mathrm{~N}_{3} \mathrm{O}_{6} \mathrm{~S}_{1} \mathrm{Si}_{1}[\mathrm{M}+\mathrm{H}]^{+}:$458.1776, found: 458.1773 .

(ESI+): $\mathrm{m} / \mathrm{z}$ calc. for $\mathrm{C}_{19} \mathrm{H}_{31} \mathrm{~N}_{3} \mathrm{O}_{6} \mathrm{~S}_{1} \mathrm{Si}_{1}\left[\mathrm{M}+\mathrm{NH}_{4}\right]^{+}:$475.2041, found: 475.2038 .

(ESI+): $\mathrm{m} / \mathrm{z}$ calc. for $\mathrm{C}_{19} \mathrm{H}_{31} \mathrm{~N}_{3} \mathrm{O}_{6} \mathrm{~S}_{1} \mathrm{Si}_{1}[\mathrm{M}+\mathrm{Na}]^{+}:$480.1595, found: 480.1592 . 


\section{Synthesis of 6-thiocarboxamidouridine (33)}

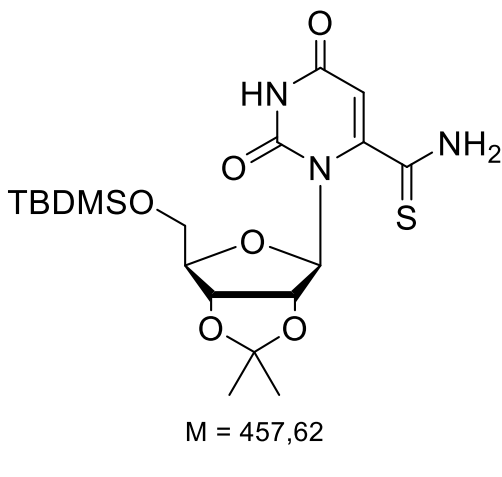

32

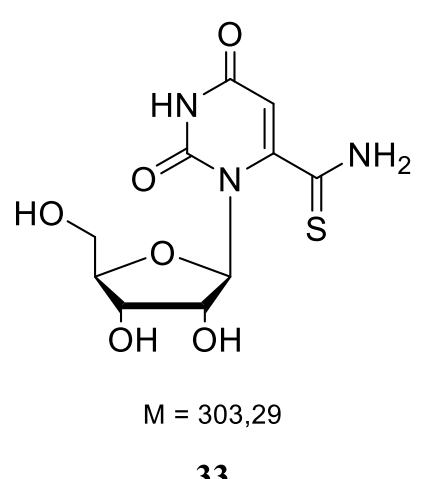

33

5'-O-tert-Butyldimethylsilyl-2',3'-O-isopropylidene-6-thiocarboxamidouridine

$(0.48 \mathrm{~g}$, $1.05 \mathrm{mmol}, 1.0$ eq. $)$ was dissolved in methanolic $\mathrm{HCl}(0.5 \mathrm{M}, 15 \mathrm{~mL})$. The reaction mixture was stirred for $45 \mathrm{~min}$ at room temperature. The solvent was removed in vacuo. The crude product was purified by column chromatography $\left(\mathrm{SiO}_{2} ; \mathrm{DCM} / \mathrm{MeOH}\right.$, gradient 98:2 to 90:10) to obtain the title product $(0.30 \mathrm{~g}, 0.99 \mathrm{mmol}, 94 \%)$ as a light-yellow solid.

${ }^{1}$ H-NMR $\left(300 \mathrm{MHz}, \mathrm{DMSO}-d_{6}\right): \delta(\mathrm{ppm})=11.44(\mathrm{~s}, 1 \mathrm{H}, \mathrm{NH}), 10.53\left(\mathrm{~s}, 1 \mathrm{H}, \mathrm{NH}_{2}\right), 10.24(\mathrm{~s}$, $\left.1 \mathrm{H}, \mathrm{NH}_{2}\right), 5.45\left(\mathrm{sbr}, 1 \mathrm{H}, \mathrm{C} 1{ }^{\prime} \mathrm{H}\right), 5.35(\mathrm{sbr}, 1 \mathrm{H}, \mathrm{C} 5 \mathrm{H}), 4.50\left(\mathrm{~m}, 1 \mathrm{H}, \mathrm{C} 2{ }^{\prime} \mathrm{H}\right), 4.11(\mathrm{t}, J=6.1 \mathrm{~Hz}$ 1H, C3'H), 3.68-3.58 (m, 2H, C4'H, C5'H), 3.46 (m, 1H, C5'H).

MS $(\mathrm{ESI}+\mathrm{MeOH}): \mathrm{m} / \mathrm{z}=326.0[\mathrm{M}+\mathrm{Na}]^{+}$.

HRMS (ESI+): m/z calc. for $\mathrm{C}_{10} \mathrm{H}_{13} \mathrm{~N}_{3} \mathrm{O}_{6} \mathrm{~S}[\mathrm{M}+\mathrm{H}]^{+}:$304.0598, found: 304.0595 .

(ESI+): $\mathrm{m} / \mathrm{z}$ calc. for $\mathrm{C}_{10} \mathrm{H}_{13} \mathrm{~N}_{3} \mathrm{O}_{6} \mathrm{~S}[\mathrm{M}+\mathrm{Na}]^{+}:$326.0417, found: 326.0427 . 
6. Experimental part

\section{Synthesis of 6-thiocarboxamido UMP (3)}<smiles>NC(=S)c1cc(=O)[nH]c(=O)n1C1OC(O)C(O)C1O</smiles>

$M=303,29$

33

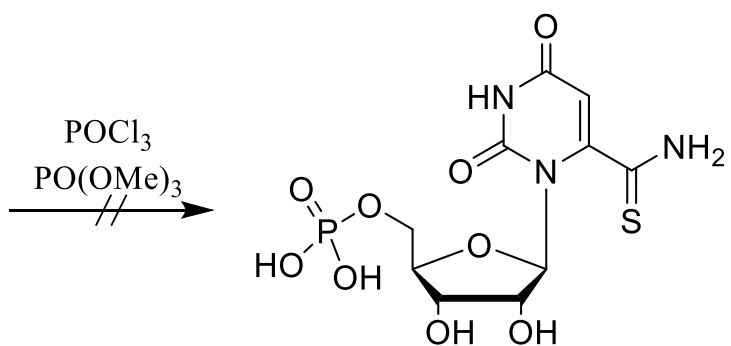

$M=383,27$

3

6-Thiocarboxamidouridine $(0.30 \mathrm{~g}, 0.99 \mathrm{mmol}, 1.0 \mathrm{eq}$. $)$ was dissolved in trimethyl phosphate $(2.0 \mathrm{~mL})$ and the mixture was cooled to $0^{\circ} \mathrm{C}$. Then, phosphoryl chloride $(180 \mu \mathrm{L}, 2.0 \mathrm{mmol}$, 2.0 eq.) was added slowly and the reaction mixture was stirred for $5 \mathrm{~h}$ at $0^{\circ} \mathrm{C}$. The reaction was quenched adding water $(20 \mathrm{~mL})$ and aqueous ammonium bicarbonate solution was added till neutral $\mathrm{pH}$. The solvent was removed in vacuo. ESI MS and HPLC confirmed that the title compound was not formed.

The reaction was repeated using fresh $\mathrm{POCl}_{3}$ and $\mathrm{PO}(\mathrm{OMe})_{3}$, as well as modified reaction conditions concerning time and temperature. Unfortunately, none lead to the desired product.

\section{Synthesis of 6-thiocarboxamido UMP (3)}<smiles>NC(=S)c1cc(=O)[nH]c(=O)n1C1O[C@H](CO)[C@@H](O)[C@H]1O</smiles>

$M=303,29$

33<smiles>NC(=S)c1cc(=O)[nH]c(=O)n1C1OC(COP(=O)(O)O)[C@@H](O)[C@H]1O</smiles>

$M=383,27$

3

Phosphoryl chloride (135 $\mu \mathrm{L}, 1.45 \mathrm{mmol}, 4.4$ eq.) was dissolved in acetonitrile $(0.50 \mathrm{~mL})$ at $0^{\circ} \mathrm{C}$. Then, water $(13.0 \mathrm{~mL})$ and pyridine $(115 \mu \mathrm{L}, 1.45 \mathrm{mmol}, 4.4$ eq. $)$ were added and the mixture was stirred for $10 \mathrm{~min}$. 6-Thiocarboxamidouridine (100 mg, $330 \mu \mathrm{mol}, 1.0$ eq.) was added, and the reaction mixture was stirred for $20 \mathrm{~min}$ at $0^{\circ} \mathrm{C}$. The mixture was poured into ice water $(90 \mathrm{~mL})$ and stirred for $30 \mathrm{~min}$. The solution was neutralized with $\mathrm{NaHCO}_{3}$ and the solvent was removed in vacuo. ESI MS and HPLC confirmed that the product was not formed. 


\section{Synthesis of 6-cyanouridine (34)}

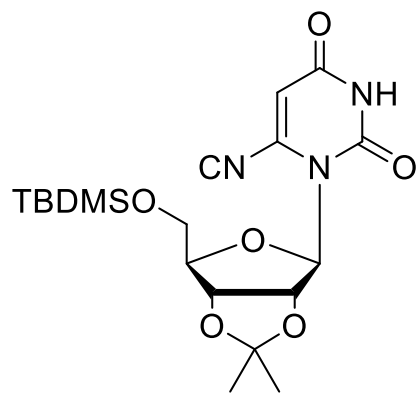

$M=423,54$

31

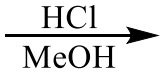

$\mathrm{HO}$<smiles>CCC1O[C@@H](O)[C@H](O)[C@H]1n1c(N)cc(=O)[nH]c1=O</smiles>

$M=269,21$

34

5'-O-tert-Butyldimethylsilyl-2',3'-O-isopropylidene-6-cyanouridine $\quad(1.86 \mathrm{~g}, \quad 4.40 \mathrm{mmol}$, 1.0 eq.) was dissolved in methanolic $\mathrm{HCl}(0.5 \mathrm{M}, 20 \mathrm{~mL})$. The reaction mixture was stirred for $45 \mathrm{~min}$ at room temperature. The solvent was removed in vacuo to yield 6-cyanouridine (1.16 g, $4.31 \mathrm{mmol}, 98 \%$.) which was used without further purification.

${ }^{1}$ H-NMR (300 MHz, DMSO- $\left.d_{6}\right): \delta(\mathrm{ppm})=11.98(\mathrm{~s}, 1 \mathrm{H}, \mathrm{NH}), 6.73(\mathrm{~d}, J=2.0 \mathrm{~Hz}, 1 \mathrm{H}, \mathrm{C} 5 \mathrm{H})$, $5.74\left(\mathrm{~d}, J=5.1 \mathrm{~Hz}, 1 \mathrm{H}, \mathrm{C} 1{ }^{\prime} \mathrm{H}\right), 4.43\left(\mathrm{t}, J=5.1 \mathrm{~Hz}, 1 \mathrm{H}, \mathrm{C} 2{ }^{\prime} \mathrm{H}\right), 4.00$ (t, $\left.J=6.0 \mathrm{~Hz}, 1 \mathrm{H}, \mathrm{C} 3{ }^{\prime} \mathrm{H}\right)$, $3.76\left(\mathrm{q}, J=6.1 \mathrm{~Hz}, 1 \mathrm{H}, \mathrm{C} 4{ }^{\prime} \mathrm{H}\right), 3.62\left(\mathrm{dd}, J=11.7,4.6 \mathrm{~Hz}, 1 \mathrm{H}, \mathrm{C} 5^{\prime} \mathrm{H}\right), 3.51(\mathrm{dd}, J=11.7$, $\left.6.6 \mathrm{~Hz}, 1 \mathrm{H}, \mathrm{C} 5^{\prime} \mathrm{H}\right)$.

${ }^{13}$ C-NMR $\left(126 \mathrm{MHz}, \mathrm{DMSO}-d_{6}\right): \delta(\mathrm{ppm})=160.9(\mathrm{C}=\mathrm{O}), 149.2(\mathrm{C}=\mathrm{O}), 125.9$ (C6), 114.5 (C5), 111.9 (CN), 91.8 (C1'), 85.4 (C4'), 71.2 (C2'), 69.5 (C3'), 61.6 (C5').

MS $(\mathrm{ESI}+\mathrm{MeOH}): \mathrm{m} / \mathrm{z}=270.1[\mathrm{M}+\mathrm{H}]^{+}, 292.0[\mathrm{M}+\mathrm{H}]^{+}$.

HRMS (ESI+): m/z calc. for $\mathrm{C}_{10} \mathrm{H}_{11} \mathrm{~N}_{3} \mathrm{O}_{6}[\mathrm{M}+\mathrm{H}]^{+}:$: 270.0721, found: 270.0714 .

(ESI+): $\mathrm{m} / \mathrm{z}$ calc. for $\mathrm{C}_{10} \mathrm{H}_{11} \mathrm{~N}_{3} \mathrm{O}_{6}[\mathrm{M}+\mathrm{Na}]^{+}:$292.0540, found: 292.0530 . 
6. Experimental part

\section{Synthesis of 6-cyano UMP (14)}<smiles>Cc1cc(=O)[nH]c(=O)n1C1OC(O)C(O)C1O</smiles>

$M=269,21$

34<smiles>Cc1cc(=O)[nH]c(=O)n1C1O[C@H](COP(=O)(O)O)[C@@H](O)[C@H]1O</smiles>

$M=349,19$

14

6-Cyanouridine (128 mg, $475 \mu \mathrm{mol}, 1.0$ eq.) was dissolved in trimethyl phosphate $(3.0 \mathrm{~mL})$. The mixture was cooled to $0^{\circ} \mathrm{C}$ and phosphoryl chloride $(90.0 \mu \mathrm{L}, 950 \mu \mathrm{mol}, 2.0$ eq.) was added. The reaction mixture was stirred for $6 \mathrm{~h}$ at $0^{\circ} \mathrm{C}$ and was quenched by addition of aqueous triethylammonium acetate buffer $(1.0 \mathrm{M}, \mathrm{pH}=7.0)$. The solvent was removed in vacuo. The crude product was purified by HPLC (ion-exchange column) to obtain 6-cyano UMP as bis(triethylammonium) salt.

${ }^{1}$ H-NMR (300 MHz, DMSO- $\left.d_{6}\right): \delta(\mathrm{ppm})=11.99(\mathrm{~s}, 1 \mathrm{H}, \mathrm{NH}), 6.73(\mathrm{~d}, J=2.0 \mathrm{~Hz}, 1 \mathrm{H}, \mathrm{C} 5 \mathrm{H})$, $5.74\left(\mathrm{~d}, J=5.1 \mathrm{~Hz}, 1 \mathrm{H}, \mathrm{C} 1{ }^{\prime} \mathrm{H}\right), 4.43\left(\mathrm{t}, J=5.1 \mathrm{~Hz}, 1 \mathrm{H}, \mathrm{C} 2^{\prime} \mathrm{H}\right), 3.99$ (t, $\left.J=6.0 \mathrm{~Hz}, 1 \mathrm{H}, \mathrm{C} 3{ }^{\prime} \mathrm{H}\right)$, $3.76\left(\mathrm{q}, J=6.1 \mathrm{~Hz}, 1 \mathrm{H}, \mathrm{C} 4^{\prime} \mathrm{H}\right), 3.62\left(\mathrm{dd}, J=11.7,4.6 \mathrm{~Hz}, 1 \mathrm{H}, \mathrm{C} 5^{\prime} \mathrm{H}\right), 3.51$ (dd, $J=11.7$, $\left.6.6 \mathrm{~Hz}, 1 \mathrm{H}, \mathrm{C} 5^{\prime} \mathrm{H}\right)$.

${ }^{13}$ C-NMR (126 MHz, DMSO- $\left.d_{6}\right): \delta(\mathrm{ppm})=160.8$ (C4), 149.2 (C2), 125.8 (C6), 114.4 (C5), $111.8(\mathrm{CN}), 91.8$ (C1'), 85.3 (C4'), 71.1 (C2’), 69.4 (C3'), 61.5 (C5').

MS (ESI-, MeOH): m/z = $348.0[\mathrm{M}-\mathrm{H}]^{-}$.

HRMS (ESI-): m/z calc. for $\mathrm{C}_{10} \mathrm{H}_{12} \mathrm{~N}_{3} \mathrm{O}_{9} \mathrm{P}[\mathrm{M}-\mathrm{H}]^{-}:$: 348.0238, found: 348.0246. 


\section{Synthesis of 6-thiocarboxamido UMP (3)}<smiles>N#Cc1cc(=O)[nH]c(=O)n1C1OC(O)C(COP(=O)(O)O)O1</smiles>

$M=349,19$

14<smiles>NC(=S)c1cc(=O)[nH]c(=O)n1C1O[C@H](COP(=O)(O)O)[C@@H](O)[C@H]1O</smiles>

$M=383,27$

3

6-Cyano UMP (120 mg, $344 \mu \mathrm{mol}, 1.0$ eq.) was dissolved in pyridine (5.0 mL). $\mathrm{H}_{2} \mathrm{~S}$ dissolved in THF (0.8 M, $1.00 \mathrm{~mL}, 800 \mu \mathrm{mol}, 2.3$ eq.) was added and the reaction mixture was stirred overnight at room temperature. The solvent was removed in vacuo. The crude product was purified by HPLC (reversed- phase column).

${ }^{1}$ H-NMR $\left(300 \mathrm{MHz}, \mathrm{D}_{2} \mathrm{O}\right): \delta(\mathrm{ppm})=5.86(\mathrm{~s}, 1 \mathrm{H}, \mathrm{CH}), 5.64(\mathrm{~s}, 1 \mathrm{H}, \mathrm{CH}), 4.46(\mathrm{~m}, 1 \mathrm{H}, \mathrm{CH})$, 4.15-3.95 (m, 4H, CH, $\left.\mathrm{CH}_{2}\right)$.

${ }^{13}$ C-NMR (126 MHz, $\left.\mathrm{D}_{2} \mathrm{O}\right): \delta(\mathrm{ppm})=191.9(\mathrm{C}=\mathrm{S}), 165.1$ (C4), 155.0 (C2), 150.6 (C6), 99.4 (C5), 94.1 (C1'), 93.1 (C4'), 82.8 (C2'), 69.4 (C3'), 64.4 (C5').

MS (ESI+, MeOH): m/z = $406.0[\mathrm{M}+\mathrm{Na}]^{+}$. $(\mathrm{ESI}-, \mathrm{MeOH}): \mathrm{m} / \mathrm{z}=382.0[\mathrm{M}-\mathrm{H}]^{-}$.

HRMS (ESI+): m/z calc. for $\mathrm{C}_{10} \mathrm{H}_{14} \mathrm{~N}_{3} \mathrm{O}_{9} \mathrm{P}_{1} \mathrm{~S}_{1}[\mathrm{M}+\mathrm{H}]^{+}$: 406.0081 , found: 406.0078 .

(ESI-): m/z calc. for $\mathrm{C}_{10} \mathrm{H}_{14} \mathrm{~N}_{3} \mathrm{O}_{9} \mathrm{P}_{1} \mathrm{~S}_{1}[\mathrm{M}-\mathrm{H}]^{-}: 382.0116$, found: 382.0120 . 
6. Experimental part

\subsubsection{Synthesis of 6-carboxymethylester UMP (OMP methyl ester)}

\section{Synthesis of 2',3'-O-isopropylideneuridine (21)}<smiles></smiles>

$M=244,20$

20

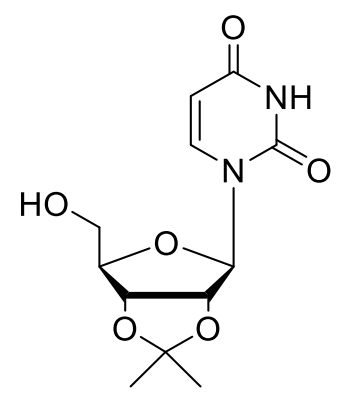

$M=284,27$

21

Uridine (7.0 g, $28.7 \mathrm{mmol}, 1.0$ eq.) was suspended in acetone (300 mL), $\mathrm{H}_{2} \mathrm{SO}_{4}(1.5 \mathrm{~mL})$ was added, and the reaction mixture was stirred at room temperature for $3 \mathrm{~h}$. The reaction was quenched by adding $\mathrm{NEt}_{3}(4.0 \mathrm{~mL})$ and the solvent was evaporated in vacuo. The crude product was purified by column chromatography $\left(\mathrm{SiO}_{2} ; \mathrm{DCM} / \mathrm{MeOH} 9: 1\right)$. The title product $(6.67 \mathrm{~g}$, $23.5 \mathrm{mmol}, 82 \%$ ) was obtained as a white solid.

TLC, $R_{\mathrm{f}}=0.45$ ethyl acetate $(100 \%)$.

${ }^{1}$ H-NMR (300 MHz, DMSO- $\left.d_{6}\right): \delta(\mathrm{ppm})=11.38(\mathrm{sbr}, 1 \mathrm{H}, \mathrm{NH}), 7.78(\mathrm{~d}, J=8.1 \mathrm{~Hz}, 1 \mathrm{H}, \mathrm{C} 6 \mathrm{H})$, $5.82(\mathrm{~d}, J=2.7 \mathrm{~Hz}, 1 \mathrm{H}, \mathrm{C} 1$ 'H), 5.56 (d, $J=8.1 \mathrm{~Hz}, 1 \mathrm{H}, \mathrm{C} 5 \mathrm{H}), 4.89$ (dd, $J=6.3,2.7 \mathrm{~Hz}, 1 \mathrm{H}$, C2'H), 4.74 (dd, $\left.J=6.3,3.6 \mathrm{~Hz}, 1 \mathrm{H}, \mathrm{C} 3{ }^{\prime} \mathrm{H}\right), 4.08-4.04\left(\mathrm{~m}, 1 \mathrm{H}, \mathrm{C} 4{ }^{\prime} \mathrm{H}\right), 3.63-3.50$ (m, 2H, $\left.\mathrm{C}^{\prime} \mathrm{H}_{2}\right), 1.48\left(\mathrm{~s}, 3 \mathrm{H}, \mathrm{CH}_{3}\right), 1.28\left(\mathrm{~s}, 3 \mathrm{H}, \mathrm{CH}_{3}\right)$.

${ }^{13}$ C-NMR (125 MHz, DMSO- $\left.d_{6}\right): \delta(\mathrm{ppm})=163.2$ (C4), 150.4 (C2), 141.7 (C6), $113.0\left(\underline{\mathrm{C}}\left(\mathrm{CH}_{3}\right)_{2}\right), 101.8$ (C5), 91.2 (C1'), 86.5 (C4'), 83.7 (C2’), 80.5 (C3'), 61.3 (C5'), $27.1\left(\mathrm{CH}_{3}\right), 25.2\left(\mathrm{CH}_{3}\right)$.

MS (ESI+, MeOH): m/z = 285.1 [M+H $]^{+}, 307.1[\mathrm{M}+\mathrm{Na}]^{+}, 591.2[2 \mathrm{M}+\mathrm{Na}]^{+}$.

HRMS (ESI+): m/z calc. for $\mathrm{C}_{12} \mathrm{H}_{16} \mathrm{~N}_{2} \mathrm{O}_{6}[\mathrm{M}+\mathrm{H}]^{+}:$: 285.1081, found: 285.1079.

(ESI+): m/z calc. for $\mathrm{C}_{12} \mathrm{H}_{16} \mathrm{~N}_{2} \mathrm{O}_{6}[\mathrm{M}+\mathrm{Na}]^{+}:$307.0901, found: 307.0900 . 
Synthesis of 5'-O-tert-butyldimethylsilyl-2',3'-O-isopropylideneuridine (22)

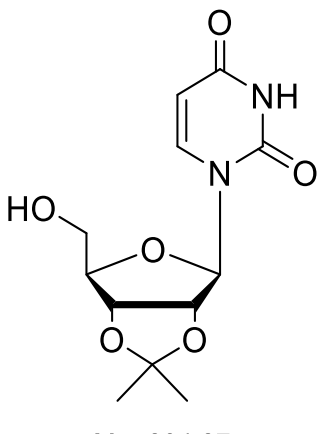

$M=284,27$

21

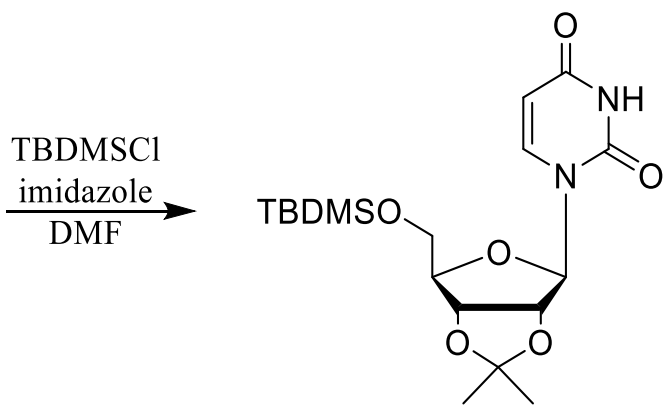

$M=398,53$

22

2',3'-O-Isopropylideneuridine ( $6.19 \mathrm{~g}, 21.8 \mathrm{mmol}, 1.0$ eq.), imidazole (3.70 g, $54.4 \mathrm{mmol}$, 2.5 eq.) and TBDMSCl (4.92 g, $32.7 \mathrm{mmol}, 1.5$ eq.) were dissolved in DMF (50 mL) and the solution was stirred for $22 \mathrm{~h}$ at room temperature. The solvent was evaporated in vacuo and the crude product was purified by column chromatography $\left(\mathrm{SiO}_{2}\right.$; hexane/ ethyl acetate 1:1). The product (8.30 g, $20.8 \mathrm{mmol}, 95 \%)$ was obtained as a white solid.

TLC, $R_{\mathrm{f}}=0.50$ hexane/ ethyl acetate $(1: 1)$.

${ }^{1}$ H-NMR (300 MHz, DMSO- $\left.d_{6}\right): \delta(\mathrm{ppm})=11.33\left(\mathrm{~s}_{\mathrm{br}}, 1 \mathrm{H}, \mathrm{NH}\right), 7.68(\mathrm{~d}, J=8.1 \mathrm{~Hz}, 1 \mathrm{H}, \mathrm{C} 6 \mathrm{H})$, $5.80\left(\mathrm{~d}, J=2.3 \mathrm{~Hz}, 1 \mathrm{H}, \mathrm{C} 1^{\prime} \mathrm{H}\right), 5.57$ (d, $\left.J=8.1 \mathrm{~Hz}, 1 \mathrm{H}, \mathrm{C} 5 \mathrm{H}\right), 4.90(\mathrm{dd}, J=6.3,2.3 \mathrm{~Hz}, 1 \mathrm{H}$, C2'H), 4.71 (dd, $\left.J=6.3,3.6 \mathrm{~Hz}, 1 \mathrm{H}, \mathrm{C} 3{ }^{\prime} \mathrm{H}\right), 4.13-4.09$ (m, 1H, C4'H), 3.83-3.71 (m, 2H, $\left.\mathrm{C}^{\prime} \mathrm{H}_{2}\right), 1.48$ (s, 3H, CH 3$), 1.29$ (s, 3H, CH 3$), 0.86$ (s, 9H, $\left.\mathrm{SiC}\left(\mathrm{CH}_{3}\right)_{3}\right), 0.04$ (s, 6H, Si( $\left.\left.\mathrm{CH}_{3}\right)_{2}\right)$.

${ }^{13}$ C-NMR (125 MHz, DMSO- $\left.d_{6}\right): \delta(\mathrm{ppm})=163.9$ (C4), 150.0 (C2), 141.6 (C6), $112.8\left(\underline{\mathrm{C}}\left(\mathrm{CH}_{3}\right)_{2}\right), 101.4$ (C5), 91.6 (C1'), 86.5 (C4'), 83.9 (C2’), 80.3 (C3'), 63.1 (C5'), $27.0\left(\mathrm{CH}_{3}\right), 25.7\left(\mathrm{SiC}\left(\underline{\mathrm{CH}}_{3}\right)_{3}\right), 25.2\left(\mathrm{CH}_{3}\right), 17.9\left(\mathrm{SiC}\left(\mathrm{CH}_{3}\right)_{3}\right),-5.5 \mathrm{Si}\left(\mathrm{CH}_{3}\right)_{2}$.

MS (ESI+, MeOH): m/z = $399.2[\mathrm{M}+\mathrm{H}]^{+}, 421.2[\mathrm{M}+\mathrm{Na}]^{+}$,

$$
819.4[2 \mathrm{M}+\mathrm{Na}]^{+}, 1217.6[3 \mathrm{M}+\mathrm{Na}]^{+} .
$$

HRMS (ESI+): m/z calc. for $\mathrm{C}_{18} \mathrm{H}_{30} \mathrm{~N}_{2} \mathrm{O}_{6} \mathrm{Si}[\mathrm{M}+\mathrm{H}]^{+}:$399.1946, found: 399.1941 .

(ESI+): $\mathrm{m} / \mathrm{z}$ calc. for $\mathrm{C}_{18} \mathrm{H}_{30} \mathrm{~N}_{2} \mathrm{O}_{6} \mathrm{Si}[\mathrm{M}+\mathrm{Na}]^{+}:$: 21.1765 , found: 421.1763 . 


\section{Synthesis of}

\section{5'-O-tert-butyldimethylsilyl-2',3'-O-isopropylideneorotidine methyl ester (46)}

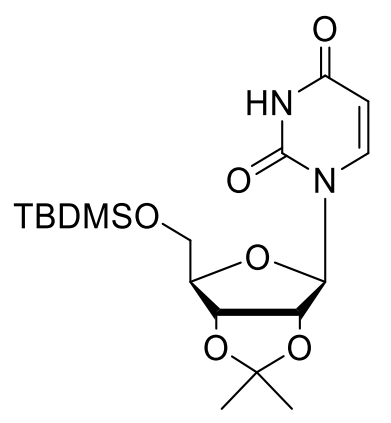

$M=398,53$

22

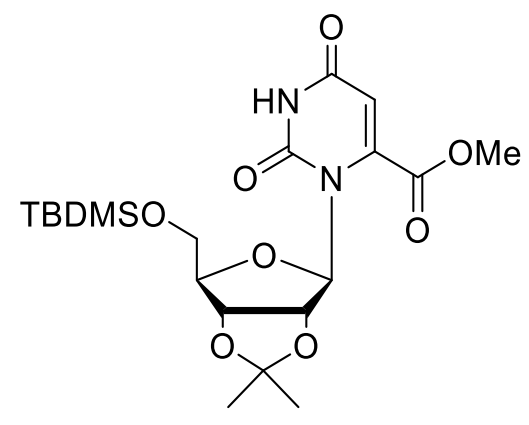

$M=456,57$

46

5'-O-tert-Butyldimethylsilyl-2',3'- $O$-isopropylideneuridine (2.15 g, $5.40 \mathrm{mmol}, 1.0$ eq.) was dissolved in THF $(30 \mathrm{~mL})$ and the solution was cooled to $-78^{\circ} \mathrm{C}$. LDA $(1.5 \mathrm{M}, 8.1 \mathrm{~mL}$, $12.1 \mathrm{mmol}, 2.25$ eq.) was added dropwise. The resulting brownish solution was stirred at $-78^{\circ} \mathrm{C}$ for $30 \mathrm{~min}$. Methyl chloroformate $(418 \mu \mathrm{L}, 510 \mathrm{mg}, 5.40 \mathrm{mmol}, 1.0$ eq.) was added dropwise at $-78^{\circ} \mathrm{C}$ and the solution was stirred for $4 \mathrm{~h}$ at the same temperature. The mixture was warmed to room temperature and quenched by the addition of acetic acid $(1.0 \mathrm{~mL})$ and the solvent was evaporated in vacuo. The crude product was purified by column chromatography $\left(\mathrm{SiO}_{2}\right.$; hexane/EtOAc 2:1). The product (1.41 g, $3.09 \mathrm{mmol}, 57 \%)$ was obtained as a greenish solid.

TLC, $R_{\mathrm{f}}=0.25$ hexane/EtOAc $(2: 1)$.

${ }^{1}$ H-NMR (300 MHz, DMSO-d6): $\delta(\mathrm{ppm})=11.78(\mathrm{~s}, 1 \mathrm{H}, \mathrm{NH}), 6.04(\mathrm{~s}, 1 \mathrm{H}, \mathrm{C} 5 \mathrm{H}), 5.70(\mathrm{~d}$, $\left.J=1.5 \mathrm{~Hz}, 1 \mathrm{H}, \mathrm{C} 1^{\prime} \mathrm{H}\right), 5.17\left(\mathrm{dd}, J=6.5,1.5 \mathrm{~Hz}, 1 \mathrm{H}, \mathrm{C} 2{ }^{\prime} \mathrm{H}\right), 4.64(\mathrm{dd}, J=6.5,4.6 \mathrm{~Hz}, 1 \mathrm{H}$, C3'H), 3.98- 3.92 (m, 1H, C4'H), 3.87 (s, 3H, $\mathrm{CO}_{2} \mathrm{CH}_{3}$ ), 3.75- 3.68 (m, 2H, C5' $\mathrm{H}_{2}$ ), 1.45 (s, $\left.3 \mathrm{H}, \mathrm{CH}_{3}\right), 1.28\left(\mathrm{~s}, 3 \mathrm{H}, \mathrm{CH}_{3}\right), 0.85$ (s, 9H, $\left.\mathrm{SiC}\left(\mathrm{CH}_{3}\right)_{3}\right), 0.01$ (s, 6H, $\left.\mathrm{Si}\left(\mathrm{CH}_{3}\right)\right)$.

${ }^{13}$ C-NMR $\left(75 \mathrm{MHz}, \mathrm{DMSO}-d_{6}\right): \delta(\mathrm{ppm})=162.1(\mathrm{C} 4), 161.9\left(\mathrm{CO}_{2} \mathrm{CH}_{3}\right), 150.1(\mathrm{C} 2)$, 144.5 (C6), 113.0 ( $\left.\underline{\mathrm{C}}\left(\mathrm{CH}_{3}\right)_{2}\right), 105.1$ (C5), 92.6 (C1'), 88.3 (C4'), 84.1 (C2'), 81.3 (C3'), $63.5\left(\mathrm{C} 5^{\prime}\right), 53.8\left(\mathrm{CO}_{2} \underline{\mathrm{CH}}_{3}\right), 27.0\left(\mathrm{CH}_{3}\right), 25.8\left(\mathrm{SiC}\left(\underline{\mathrm{CH}}_{3}\right)_{3}\right), 25.1\left(\mathrm{CH}_{3}\right), 18.0\left(\mathrm{SiC}\left(\mathrm{CH}_{3}\right)_{3}\right)$, $-5.3 \mathrm{Si}\left(\mathrm{CH}_{3}\right),-5.4 \mathrm{Si}\left(\mathrm{CH}_{3}\right)$.

MS (ESI+, MeOH): m/z = 457.2[M+H] $]^{+}, 479.2[\mathrm{M}+\mathrm{Na}]^{+}$.

HRMS (ESI+): $\mathrm{m} / \mathrm{z}$ calc. for $\mathrm{C}_{20} \mathrm{H}_{32} \mathrm{~N}_{2} \mathrm{O}_{8} \mathrm{Si}[\mathrm{M}+\mathrm{H}]^{+}:$457.2001, found: 457.2005. 


\section{Synthesis of orotidine methyl ester (47)}

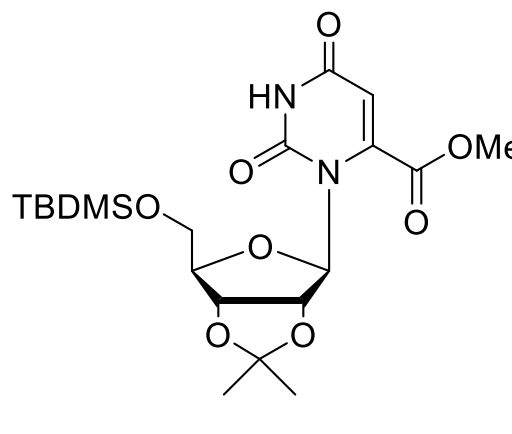

$M=456,57$

46

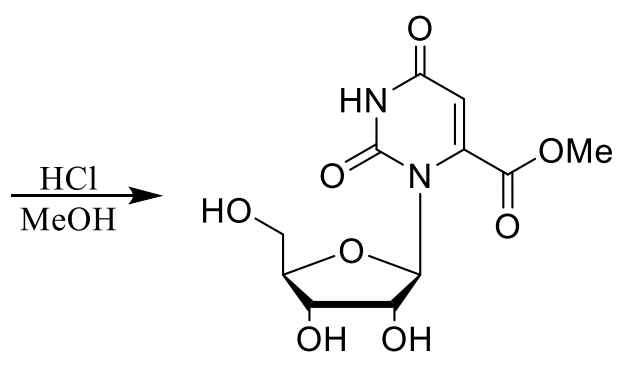

$M=302,24$

47

5'-O-tert-Butyldimethylsilyl-2',3'-O-isopropylideneorotidine methylester (290 mg, $636 \mu \mathrm{mol}$, 1.0 eq.) was dissolved in methanolic $\mathrm{HCl}(0.5 \mathrm{M}, 8.0 \mathrm{~mL})$. The reaction mixture was stirred for $45 \mathrm{~min}$ at room temperature. The solvent was removed in vacuo obtaining the deprotected orotidine methyl ester ( $0.19 \mathrm{~g}$, quant.) which was used without further purification.

${ }^{1}$ H-NMR (300 MHz, DMSO-d6): $\delta(\mathrm{ppm})=11.30(\mathrm{sbr}, 1 \mathrm{H}, \mathrm{NH}), 6.06(\mathrm{~s}, 1 \mathrm{H}, \mathrm{C} 5 \mathrm{H}), 5.93(\mathrm{~s}$, 1H, C1’H), 5.39 (m, 1H, C2’'H), 4.46 (m, 1H, C3’H), 3.95 (m, 1H, C4’H), 3.85 (s, 3H, $\left.\mathrm{CO}_{2} \mathrm{CH}_{3}\right), 3.68-3.62\left(\mathrm{~m}, 2 \mathrm{H}, \mathrm{C}^{\prime} \mathrm{H}_{2}\right)$.

MS (ESI+, MeOH): m/z = $303.0[\mathrm{M}+\mathrm{H}]^{+}, 325.0[\mathrm{M}+\mathrm{Na}]^{+}$.

HRMS (ESI+): $\mathrm{m} / \mathrm{z}$ calc. for $\mathrm{C}_{11} \mathrm{H}_{14} \mathrm{~N}_{2} \mathrm{O}_{8}[\mathrm{M}+\mathrm{Na}]^{+}: 325.0642$, found: 325.0641 . 
6. Experimental part

Synthesis of orotidine-5'-monophosphate methyl ester (5)<smiles>COC(=O)c1cc(=O)[nH]c(=O)n1C1OC(O)C(O)C1O</smiles>

47

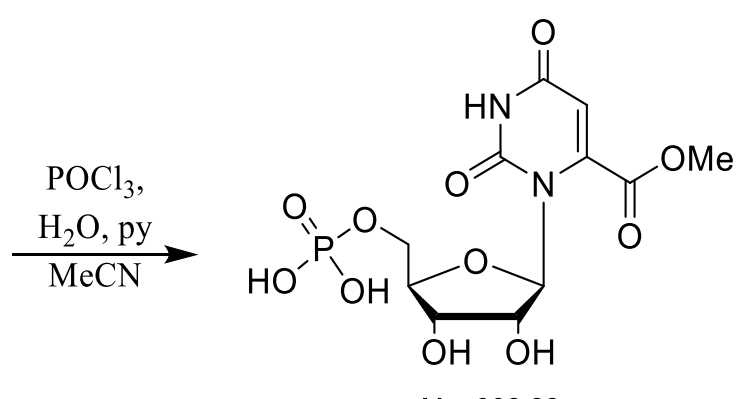

$M=382,22$

Phosphoryl chloride ( $160 \mu \mathrm{L}, 1.71 \mathrm{mmol}, 4.3$ eq. $)$ was dissolved in acetonitrile $(4.0 \mathrm{~mL})$ at $0^{\circ} \mathrm{C}$. Then, water ( $25 \mu \mathrm{L}, 1.23 \mathrm{mmol}, 3.1$ eq.) and pyridine (150 $\mu \mathrm{L}, 1.90 \mathrm{mmol}, 4.8$ eq.) were added and the reaction mixture was stirred for $30 \mathrm{~min}$. Orotidine methyl ester $(120 \mathrm{mg}, 397 \mu \mathrm{mol}$, 1.0 eq.) was added and the reaction mixture was stirred for $5 \mathrm{~h}$ at $0^{\circ} \mathrm{C}$. The reaction was quenched by adding aqueous triethylammonium acetate buffer $(1.0 \mathrm{M})$ until neutral $\mathrm{pH}$. The solvent was removed in vacuo. The crude product was purified by HPLC (ion-exchange column) to obtain the title compound.

${ }^{1}$ H-NMR (300 MHz, D2O): $\delta(\mathrm{ppm})=7.79(\mathrm{~s}, 1 \mathrm{H}, \mathrm{NH}), 6.11(\mathrm{~s}, 1 \mathrm{H}, \mathrm{C} 5 \mathrm{H}), 5.54(\mathrm{~d}, J=3.3 \mathrm{~Hz}$, 1H, C1'H), $4.60(\mathrm{~m}, 1 \mathrm{H}, \mathrm{CH}), 4.22(\mathrm{~m}, 1 \mathrm{H}, \mathrm{CH}), 4.03(\mathrm{~m}, 1 \mathrm{H}, \mathrm{CH}), 3.83\left(\mathrm{~s}, 3 \mathrm{H}, \mathrm{CH}_{3}\right), 3.62(\mathrm{~m}$, $\left.2 \mathrm{H}, \mathrm{CH}_{2}\right)$.

MS (ESI-, MeOH): m/z = $381.0[\mathrm{M}-\mathrm{H}]^{-}$.

HRMS (ESI-): $\mathrm{m} / \mathrm{z}$ calc. for $\mathrm{C}_{11} \mathrm{H}_{15} \mathrm{~N}_{2} \mathrm{O}_{11} \mathrm{P}[\mathrm{M}-\mathrm{H}]^{-}: 381.0341$, found: 381.0332 . 


\subsubsection{Synthesis of 5,6-dihydro OMP (reduced OMP)}

\section{Synthesis of 5'-O-tert-butyldimethylsilyl-2',3'-O-isopropylideneorotidine (48)}

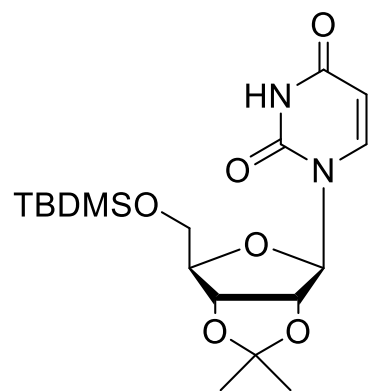

$M=398,53$

22

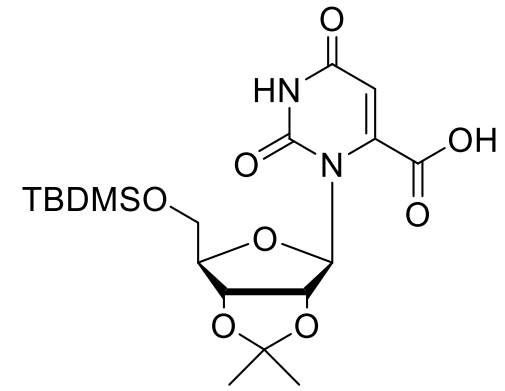

$M=442,54$

48

5'-O-tert-Butyldimethylsilyl-2',3'-O-isopropylideneuridine ( $1.25 \mathrm{~g}, 3.14 \mathrm{mmol}, 1.0 \mathrm{eq}$.) was dissolved in THF $(15 \mathrm{~mL})$ and the solution was cooled to $-78^{\circ} \mathrm{C}$. LDA $(2.0 \mathrm{M}, 3.14 \mathrm{~mL}$, $6.28 \mathrm{mmol}, 2.0$ eq.) was added dropwise. The resulting brownish solution was stirred at $-78^{\circ} \mathrm{C}$ for $30 \mathrm{~min}$ and subsequently $\mathrm{CO}_{2}$ was bubbled through the solution for $4 \mathrm{~h}$. The mixture was quenched by the addition of acetic acid $(1.0 \mathrm{~mL})$ and the solvent was removed under reduced pressure. The crude product was purified by column chromatography $\left(\mathrm{SiO}_{2} ; \mathrm{EtOAc} / \mathrm{MeOH}\right.$ $85: 15)$. The title compound (990 mg, $2.24 \mathrm{mmol}, 71 \%$ ) was obtained as a white solid.

TLC, $R_{\mathrm{f}}=0.27 \mathrm{EtOAc} / \mathrm{MeOH}(85: 15)$.

${ }^{1}$ H-NMR $\left(300 \mathrm{MHz}, \mathrm{DMSO}-d_{6}\right): \delta(\mathrm{ppm})=6.05\left(\mathrm{~s}, 1 \mathrm{H}, \mathrm{C} 1{ }^{\prime} \mathrm{H}\right), 5.35(\mathrm{~s}, 1 \mathrm{H}, \mathrm{C} 5 \mathrm{H}), 5.11(\mathrm{~d}$, $\left.J=6.4 \mathrm{~Hz}, 1 \mathrm{H}, \mathrm{C} 2{ }^{\prime} \mathrm{H}\right), 4.72\left(\mathrm{dd}, J=6.4,4.3 \mathrm{~Hz}, 1 \mathrm{H}, \mathrm{C} 3^{\prime} \mathrm{H}\right), 3.93-3.86$ (m, 1H, C4'H), 3.78-3.68 (m, 2H, C5'H2), 1.42 (s, 3H, CH 3$), 1.26$ (s, 3H, $\left.\mathrm{CH}_{3}\right), 0.85$ (s, 9H, $\left.\mathrm{SiC}\left(\mathrm{CH}_{3}\right)_{3}\right), 0.02$ (s, 3H, $\left.\mathrm{Si}\left(\mathrm{CH}_{3}\right)\right), 0.01\left(\mathrm{~s}, 3 \mathrm{H}, \mathrm{Si}\left(\mathrm{CH}_{3}\right)\right)$.

${ }^{13}$ C-NMR (125 MHz, DMSO-d $\left.d_{6}\right): \delta(\mathrm{ppm})=163.4(\mathrm{COOH}), 163.1$ (C4), 156.3 (C2), 150.5 (C6), 112.1 ( $\left(\mathrm{C}^{\left.\left(\mathrm{CH}_{3}\right)_{2}\right),} 97.0\right.$ (C5), 92.3 (C1'), 88.7 (C4'), 84.3 (C2'), 82.0 (C3'), 63.9 (C5'), $27.1\left(\mathrm{CH}_{3}\right), 25.8\left(\mathrm{SiC}\left(\mathrm{CH}_{3}\right)_{3}\right), 25.2\left(\mathrm{CH}_{3}\right), 18.0\left(\mathrm{Si} \underline{\mathrm{C}}\left(\mathrm{CH}_{3}\right)_{3}\right),-5.2 \mathrm{Si}\left(\mathrm{CH}_{3}\right)$, $-5.3 \mathrm{Si}\left(\mathrm{CH}_{3}\right)$.

MS (ESI+, MeOH): m/z = 465.2 [M+Na $]^{+}$.

HRMS (ESI+): m/z calc. for $\mathrm{C}_{19} \mathrm{H}_{30} \mathrm{~N}_{2} \mathrm{O}_{8} \mathrm{Si}[\mathrm{M}+\mathrm{Na}]^{+}: 465.1664$, found: 465.1663 . 
6. Experimental part

\section{Synthesis of orotidine (49)}

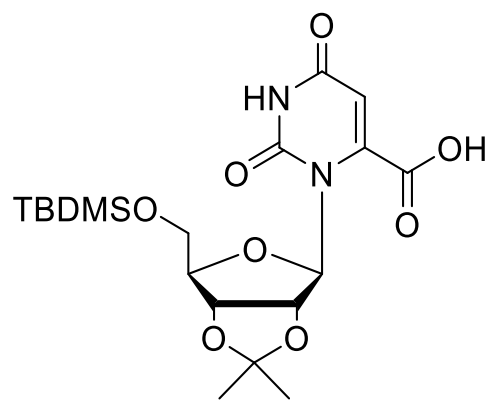

$M=442,54$

48<smiles>[R16][R16]#N</smiles>

49

5'-O-tert-Butyldimethylsilyl-2',3'-O-isopropylideneorotidine (450 mg, $1.02 \mathrm{mmol}, 1.0$ eq.) was dissolved in methanolic $\mathrm{HCl}(0.5 \mathrm{M}, 15 \mathrm{~mL})$ and the solution was stirred for $45 \mathrm{~min}$ at room temperature. The solvent was removed under reduced pressure and the crude product (293 mg, quant.) was obtained as a white solid and used without further purification.

${ }^{1} \mathrm{H}-\mathrm{NMR}\left(300 \mathrm{MHz}, \mathrm{DMSO}-d_{6}\right): \delta(\mathrm{ppm})=11.60(\mathrm{sbr}, 1 \mathrm{H}, \mathrm{NH}), 5.83(\mathrm{~d}, J=2.0 \mathrm{~Hz}, 1 \mathrm{H}, \mathrm{C} 5 \mathrm{H})$, $5.40\left(\mathrm{~d}, J=3.9 \mathrm{~Hz}, 1 \mathrm{H}, \mathrm{C} 1^{\prime} \mathrm{H}\right), 4.48$ (dd, $\left.J=6.2,4.0 \mathrm{~Hz}, 1 \mathrm{H}, \mathrm{C} 2^{\prime} \mathrm{H}\right), 3.98$ (t, $J=6.1 \mathrm{~Hz}, 1 \mathrm{H}$, C3'H), 3.71-3.65 (m, 1H, C4'H), 3.60-3.55 (m, 1H, C5' $\left.\mathrm{H}_{2}\right), 3.47-3.41$ (m, 1H, C5' $\left.{ }_{2}\right)$.

${ }^{13}$ C-NMR (75 MHz, DMSO-d6): $\delta(\mathrm{ppm})=163.2(\mathrm{C} 4), 162.3(\mathrm{COOH}), 150.0(\mathrm{C} 2), 147.9(\mathrm{C} 6)$, $102.3(\mathrm{C} 5), 94.0\left(\mathrm{C}^{\circ}\right), 85.2\left(\mathrm{C}^{\circ}\right), 71.5\left(\mathrm{C} 2^{\circ}\right), 69.7\left(\mathrm{C} 3^{\circ}\right), 61.9\left(\mathrm{C}^{\circ}\right)$.

MS (ESI-, MeOH): m/z $=287.0[\mathrm{M}-\mathrm{H}]^{-}$.

$(\mathrm{ESI}+\mathrm{MeOH}): \mathrm{m} / \mathrm{z}=311.0[\mathrm{M}+\mathrm{Na}]^{+}$.

HRMS (ESI+): m/z calc. for $\mathrm{C}_{10} \mathrm{H}_{12} \mathrm{~N}_{2} \mathrm{O}_{8}[\mathrm{M}+\mathrm{Na}]^{+}:$311.0486, found: 311.0480 .

(ESI-): m/z calc. for $\mathrm{C}_{10} \mathrm{H}_{12} \mathrm{~N}_{2} \mathrm{O}_{8}[\mathrm{M}-\mathrm{H}]^{-}:$287.0521, found: 287.0518 . 


\section{Synthesis of orotidine-5'-monophosphate (1)}<smiles>O=C(O)c1cc(=O)[nH]c(=O)n1C1OC(O)C(O)C1O</smiles>

$M=288,21$

49

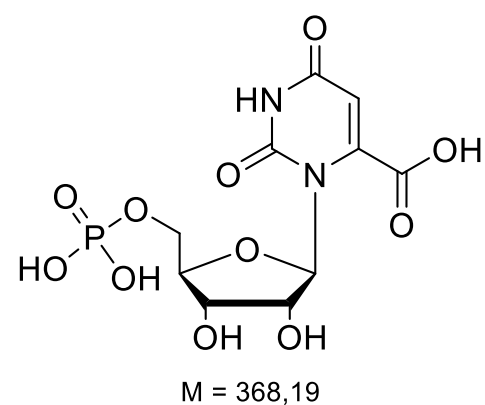

1

Orotidine (293 mg, $1.01 \mathrm{mmol}, 1.0$ eq.) was dissolved in trimethyl phosphate (3.0 mL) and was cooled to $0^{\circ} \mathrm{C}$. Phosphoryl chloride ( $236 \mu \mathrm{L}, 387 \mathrm{mg} 2.53 \mathrm{mmol}, 2.5$ eq.) was added and the solution was stirred for $6 \mathrm{~h}$ at $0^{\circ} \mathrm{C}$. The reaction mixture was quenched by pouring into water $(10 \mathrm{~mL})$ and adding triethylammonium acetate buffer till neutral $\mathrm{pH}$. The crude product was purified by HPLC (ion-exchange column) using a linear gradient of TEAA in water at $\mathrm{pH}=7$. The title compound was obtained as triethylammonium salt.

${ }^{1}$ H-NMR $\left(300 \mathrm{MHz}, \mathrm{D}_{2} \mathrm{O}\right): \delta(\mathrm{ppm})=5.88(\mathrm{~s}, 1 \mathrm{H}, \mathrm{C} 5 \mathrm{H}), 5.65\left(\mathrm{~d}, J=3.2 \mathrm{~Hz}, 1 \mathrm{H}, \mathrm{C} 1{ }^{\prime} \mathrm{H}\right)$, 4.86 (dd, $\left.J=6.5,3.2 \mathrm{~Hz}, 1 \mathrm{H}, \mathrm{C} 2^{\prime} \mathrm{H}\right), 4.54$ (t, $\left.J=6.5 \mathrm{~Hz}, 1 \mathrm{H}, \mathrm{C} 3{ }^{\prime} \mathrm{H}\right), 4.30-4.08$ (m, 3H, C4'H, $\left.\mathrm{C}^{\prime} \mathrm{H}_{2}\right)$.

${ }^{13}$ C-NMR (125 MHz, $\left.\mathrm{D}_{2} \mathrm{O}\right): \delta(\mathrm{ppm})=167.1(\mathrm{COOH}), 166.2(\mathrm{C} 4), 155.3$ (C2), 151.1 (C6), 98.5 (C5), 95.0 (C1'), 82.3 (C4’), 71.9 (C2'), 69.6 (C3'), 64.7 (C5').

MS (ESI-, MeOH): m/z = $367.0[\mathrm{M}-\mathrm{H}]^{-}$.

HRMS (ESI-): m/z calc. for $\mathrm{C}_{10} \mathrm{H}_{13} \mathrm{~N}_{2} \mathrm{O}_{11} \mathrm{P}$ [M-H] $]^{-}: 367.0184$, found: 367.0174 . 
6. Experimental part

Synthesis of 5,6-dihydro OMP (26)<smiles>O=C(O)c1cc(=O)[nH]c(=O)n1C1OC(O)C(COP(=O)(O)O)C1O</smiles>

$M=368,19$

1

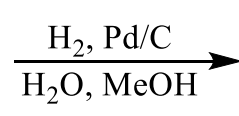<smiles>CC(C)(C)N(C=O)C1OC(COP(=O)(O)O)C(O)C1O</smiles>

$M=370,21$

26

Bis(triethylammonium) orotidine-5'-monophosphate (50 mg, $87 \mu \mathrm{mol}, 1,0$ eq.) was dissolved in $\mathrm{H}_{2} \mathrm{O}(7.0 \mathrm{~mL})$ and $\mathrm{MeOH}(6.0 \mathrm{~mL})$. Then $\mathrm{Pd} / \mathrm{C}(10 \%, 50 \mathrm{mg})$ was added, and the suspension was stirred for $12 \mathrm{~h}$ at room temperature under hydrogen atmosphere. The reaction mixture was filtered, and the solvents were removed in vacuo.

${ }^{1} \mathbf{H}-\mathbf{N M R}\left(300 \mathrm{MHz}, \mathrm{D}_{2} \mathrm{O}\right): \delta(\mathrm{ppm})=5.90\left(\mathrm{~d}, J=6.4 \mathrm{~Hz}, 1 \mathrm{H}, \mathrm{C} 1^{\prime} \mathrm{H}\right), 4.25(\mathrm{~m}, 2 \mathrm{H}, \mathrm{CH})$, 4.14 (m, 2H, CH), 4.04 (m, 2H, CH), 3.02-2.97 (m, 2H; C5H).

MS (ESI-, MeOH): m/z = $369.0[\mathrm{M}-\mathrm{H}]^{-}$.

HRMS (ESI-): m/z calc. for $\mathrm{C}_{10} \mathrm{H}_{15} \mathrm{~N}_{2} \mathrm{O}_{11} \mathrm{P}[\mathrm{M}-\mathrm{H}]^{-}: 369.0341$, found: 369.0341 . 


\subsubsection{Synthesis of 6-methyl UMP}

\section{Synthesis of 5'-O-tert-butyldimethylsilyl-2',3'-O-isopropylidene-6-methyluridine (35)}

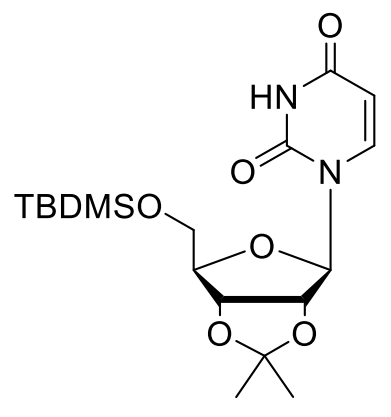

$M=398,53$

22

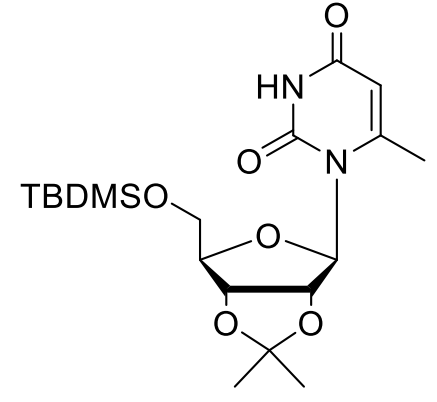

$M=412,56$

35

5'-O-tert-Butyldimethylsilyl-2',3'-O-isopropylideneuridine (2.00 g, $5.02 \mathrm{mmol}, 1.0 \mathrm{eq}$.) was dissolved in THF $(30 \mathrm{~mL})$. The reaction mixture was cooled to $-75^{\circ} \mathrm{C}$. Then LDA dissolved in hexane (2.0 M, $5.00 \mathrm{~mL}, 10.0 \mathrm{mmol}, 2.0$ eq.) was added slowly. After $30 \mathrm{~min}$, methyl iodide (375 $\mu \mathrm{L}, 6.0 \mathrm{mmol}, 1.2$ eq.) was added dropwise to the reaction mixture, which was stirred for $30 \mathrm{~min}$ at $-75^{\circ} \mathrm{C}$ and an additional $1 \mathrm{~h}$ at room temperature. The reaction was quenched by adding sat. aq. ammonium chloride solution. The mixture was extracted with ethyl acetate and washed with sat. aq. $\mathrm{NaCl}$. The combined organic layers were dried over magnesium sulfate and the solvent was removed in vacuo. The crude product was purified by column chromatography $\left(\mathrm{SiO}_{2}\right.$; hexane/ ethyl acetate, gradient 3:1 to 1:1) to afford the title compound $(1.14 \mathrm{~g}, 2.76 \mathrm{mmol}, 55 \%)$ as a light-yellow oil. TLC, $R_{\mathrm{f}}=0.30$ hexane/ ethyl acetate $(2: 1)$.

${ }^{1}$ H-NMR (300 MHz, DMSO- $\left.d_{6}\right): \delta(\mathrm{ppm})=11.33(\mathrm{~s}, 1 \mathrm{H}, \mathrm{NH}), 5.71(\mathrm{~s}, 1 \mathrm{H}, \mathrm{C} 1$ 'H), 5.57 (s, 1H, C5H), 5.22 (d, $\left.J=6.3, \mathrm{~Hz}, 1 \mathrm{H}, \mathrm{C} 2{ }^{\prime} \mathrm{H}\right), 4.74$ (dd, $\left.J=6.3,4.1 \mathrm{~Hz}, 1 \mathrm{H}, \mathrm{C} 3{ }^{\prime} \mathrm{H}\right), 4.01-3.96$ (m, 1H, C4'H), 3.77- 3.66 (m, 2H, C5' $\left.\mathrm{H}_{2}\right), 2.27$ (s, 3H, $\left.\mathrm{CH}_{3}\right), 1.47$ (s, 3H, $\left.\mathrm{CH}_{3}\right), 1.28\left(\mathrm{~s}, 3 \mathrm{H}, \mathrm{CH}_{3}\right)$, $0.84\left(\mathrm{~s}, 9 \mathrm{H}, \mathrm{SiC}\left(\mathrm{CH}_{3}\right)_{3}\right), 0.00\left(\mathrm{~s}, 6 \mathrm{H}, \mathrm{Si}\left(\mathrm{CH}_{3}\right)\right)$.

${ }^{13}$ C-NMR (75 MHz, DMSO- $\left.d_{6}\right): \delta(\mathrm{ppm})=162.3$ (C4), 152.9 (C2), 150.8 (C6), $112.6\left(\underline{\mathrm{C}}\left(\mathrm{CH}_{3}\right)_{2}\right), 102.4(\mathrm{C} 5), 90.8$ (C1'), 88.8 (C4'), 83.8 (C2'), 81.6 (C3'), 63.6 (C5'), $27.1\left(\mathrm{CH}_{3}\right), 25.8\left(\mathrm{SiC}\left(\underline{\mathrm{CH}_{3}}\right)_{3}\right), 25.2\left(\mathrm{CH}_{3}\right), 19.4\left(\mathrm{CH}_{3}\right), 18.0\left(\mathrm{SiC}\left(\mathrm{CH}_{3}\right)_{3}\right),-5.3 \mathrm{Si}\left(\mathrm{CH}_{3}\right)$, $-5.4 \mathrm{Si}\left(\mathrm{CH}_{3}\right)$.

MS (ESI+, MeOH): m/z = $413.3[\mathrm{M}+\mathrm{H}]^{+}, 435.2[\mathrm{M}+\mathrm{Na}]^{+}$.

HRMS (ESI+): m/z calc. for $\mathrm{C}_{19} \mathrm{H}_{32} \mathrm{~N}_{2} \mathrm{O}_{6} \mathrm{Si}[\mathrm{M}+\mathrm{H}]^{+}: 413.2102$, found: 413.2099 .

(ESI+): $\mathrm{m} / \mathrm{z}$ calc. for $\mathrm{C}_{19} \mathrm{H}_{32} \mathrm{~N}_{2} \mathrm{O}_{6} \mathrm{Si}[\mathrm{M}+\mathrm{Na}]^{+}:$: 435.1922, found: 435.1927 . 
6. Experimental part

Synthesis of 6-methyluridine (40)

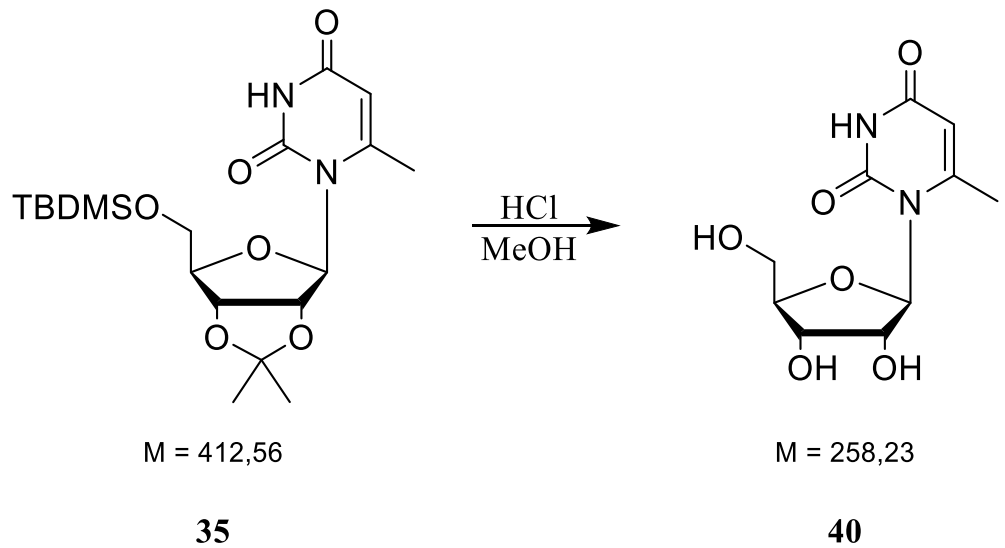

5'-O-tert-Butyldimethylsilyl-2',3'-O-isopropylidene-6-methyluridine $\quad(800 \mathrm{mg}, 1.94$ mmol, 1.0 eq.) was dissolved in methanolic $\mathrm{HCl}(0.5 \mathrm{M}, 10 \mathrm{~mL})$. The reaction mixture was stirred for $45 \mathrm{~min}$ at room temperature. The solvent was removed in vacuo to obtain the title compound (498 mg, quant.) which was used without further purification.

${ }^{1} \mathbf{H}-\mathrm{NMR}\left(300 \mathrm{MHz}, \mathrm{DMSO}-d_{6}\right): \delta(\mathrm{ppm})=11.24(\mathrm{~s}, 1 \mathrm{H}, \mathrm{NH}), 5.56\left(\mathrm{~s}, 1 \mathrm{H}, \mathrm{C} 1{ }^{\prime} \mathrm{H}\right), 5.46(\mathrm{~d}, 1 \mathrm{H}$, $\left.J=4.2 \mathrm{~Hz}, \mathrm{C} 5 \mathrm{H}), 4.54\left(\mathrm{dd}, J=6.1,4.2 \mathrm{~Hz}, 1 \mathrm{H}, \mathrm{C}{ }^{\prime} \mathrm{H}\right)\right), 4.06\left(\mathrm{t}, J=6.0 \mathrm{~Hz}, 1 \mathrm{H}, \mathrm{C}{ }^{\prime} \mathrm{H}\right)$, 3.73-3.68 (m, 1H, C4'H), 3.63- 3.58 (dd, $\left.J=11.8,3.6 \mathrm{~Hz} 1 \mathrm{H}, \mathrm{C}^{\prime}{ }^{\prime} \mathrm{H}_{2}\right), 3.46-3.41$ (dd, $J=11.8$, $\left.5.9 \mathrm{~Hz} 1 \mathrm{H}, \mathrm{C}^{\prime} \mathrm{H}_{2}\right), 2.25\left(\mathrm{~s}, 3 \mathrm{H}, \mathrm{CH}_{3}\right)$.

MS (ESI+, MeOH): m/z = 259.1 $[\mathrm{M}+\mathrm{H}]^{+}, 281.1[\mathrm{M}+\mathrm{Na}]^{+}$.

HRMS (ESI+): m/z calc. for $\mathrm{C}_{10} \mathrm{H}_{14} \mathrm{~N}_{2} \mathrm{O}_{6}[\mathrm{M}+\mathrm{Na}]^{+}:$281.0744, found: 281.0753 . 


\section{Synthesis of 6-methyl UMP (7)}

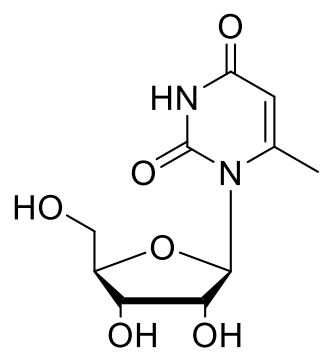

$M=258,23$

40

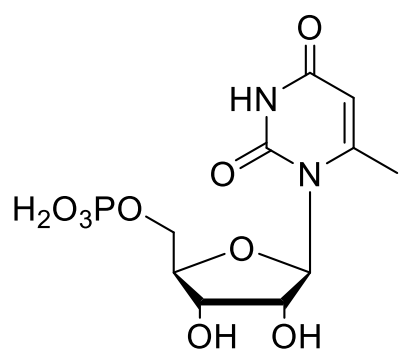

$M=338,21$

Phosphoryl chloride ( $280 \mu \mathrm{L}, 2.97 \mathrm{mmol}, 4.4$ eq. $)$ was dissolved in acetonitrile $(4.0 \mathrm{~mL})$ at $0^{\circ} \mathrm{C}$. Then, water ( $35 \mu \mathrm{L}, 1.90 \mathrm{mmol}, 2.8$ eq.) and pyridine ( $260 \mu \mathrm{L}, 3.20 \mathrm{mmol}, 4.8$ eq.) were added and the reaction mixture was stirred for $20 \mathrm{~min}$. 6-Methyluridine (172 mg, $675 \mu \mathrm{mol}, 1.0 \mathrm{eq}$.) was added and the reaction mixture was stirred for $5 \mathrm{~h}$ at $0^{\circ} \mathrm{C}$. The reaction was quenched by adding aqueous triethylammonium acetate buffer $(1.0 \mathrm{M})$ until neutral $\mathrm{pH}$. The solvent was removed in vacuo. The crude product was purified by HPLC (ion-exchange column) to obtain 6-methyl UMP as bis(triethylammonium) salt.

${ }^{1} \mathrm{H}-\mathrm{NMR}\left(300 \mathrm{MHz}, \mathrm{D}_{2} \mathrm{O}\right): \delta(\mathrm{ppm})=5.74(\mathrm{~s}, 1 \mathrm{H}, \mathrm{C} 5 \mathrm{H}), 5.67\left(\mathrm{~d}, J=3.0 \mathrm{~Hz}, 1 \mathrm{H}, \mathrm{C1}{ }^{\prime} \mathrm{H}\right)$, 4.79 (m, 1H, C2' $\mathrm{H}), 4.42$ (t, $\left.J=6.0 \mathrm{~Hz}, 1 \mathrm{H}, \mathrm{C} 3^{\prime} \mathrm{H}\right), 4.16-4.09$ (m, 1H, C4'H), 4.07- 3.96 (m, $\left.2 \mathrm{H}, \mathrm{C} 5{ }^{\prime} \mathrm{H}_{2}\right), 2.37\left(\mathrm{~s}, 3 \mathrm{H}, \mathrm{CH}_{3}\right)$.

${ }^{13}$ C-NMR (75 MHz, $\left.\mathrm{D}_{2} \mathrm{O}\right): \delta(\mathrm{ppm})=165.4(\mathrm{C} 4), 156.1$ (C2), 151.4 (C6), 114.5 (C5), 102.5 (C5), 92.0 (C1’), 81.8 (C4’), 71.3 (C2’), 69.1 (C3’), 64.7 (C5'), $19.65\left(\mathrm{CH}_{3}\right)$.

MS (ESI+, MeOH): m/z = $339.0[\mathrm{M}+\mathrm{H}]^{+}, 361.0[\mathrm{M}+\mathrm{Na}]^{+}$.

$(\mathrm{ESI}-, \mathrm{MeOH}): \mathrm{m} / \mathrm{z}=337.1[\mathrm{M}-\mathrm{H}]^{-}$.

HRMS (ESI+): m/z calc. for $\mathrm{C}_{10} \mathrm{H}_{15} \mathrm{~N}_{2} \mathrm{O}_{9} \mathrm{P}[\mathrm{M}+\mathrm{H}]^{+}:$339.0588, found: 339.0588 .

(ESI+): m/z calc. for $\mathrm{C}_{10} \mathrm{H}_{15} \mathrm{~N}_{2} \mathrm{O}_{9} \mathrm{P}[\mathrm{M}+\mathrm{Na}]^{+}: 361.0407$, found: 361.0413 .

(ESI-): $\mathrm{m} / \mathrm{z}$ calc. for $\mathrm{C}_{10} \mathrm{H}_{15} \mathrm{~N}_{2} \mathrm{O}_{9} \mathrm{P}[\mathrm{M}-\mathrm{H}]^{-}: 337.0442$, found: 337.0453 . 
6. Experimental part

\subsubsection{Synthesis of 6-ethyl UMP}

\section{Synthesis of 5'-O-tert-butyldimethylsilyl-2',3'-O-isopropylidene-6-ethyluridine (36)}

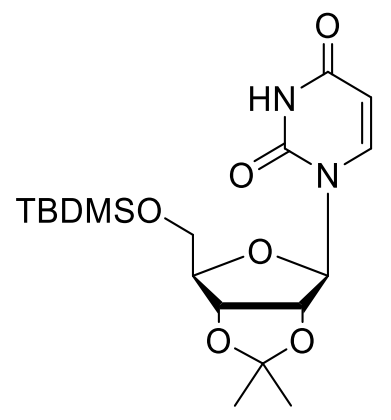

$M=398,53$

22

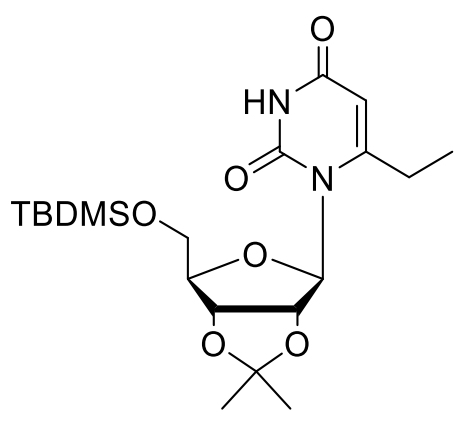

$M=426,59$

36

5'-O-tert-Butyldimethylsilyl-2',3'- $O$-isopropylideneuridine (2.04 g, $5.12 \mathrm{mmol}, 1.0$ eq.) was dissolved in THF $(30 \mathrm{~mL})$. The reaction mixture was cooled to $-75^{\circ} \mathrm{C}$. Then LDA dissolved in hexane (2.0 M, $5.10 \mathrm{~mL}, 10.2 \mathrm{mmol}, 2.0$ eq.) was added slowly. After $30 \mathrm{~min}$, ethyl iodide (500 $\mu \mathrm{L}, 6.22 \mathrm{mmol}, 1.2$ eq.) was added dropwise to the reaction mixture, which was stirred for $3 \mathrm{~h}$ at $-75^{\circ} \mathrm{C}$. The reaction was quenched by adding sat. aq. ammonium chloride. The mixture was extracted with ethyl acetate and washed with sat. aq. $\mathrm{NaCl}$. The combined organic layers were dried over magnesium sulfate and the solvent was removed in vacuo. The crude product was purified by column chromatography ( $\mathrm{SiO}_{2}$; hexane/ ethyl acetate, gradient $3: 1$ to $\left.1: 1\right)$ to afford the title compound (459 mg, $1.076 \mathrm{mmol}, 21 \%$ ) as a light-yellow oil.

TLC, $R_{\mathrm{f}}=0.30$ hexane/ ethyl acetate $(2: 1)$

${ }^{1} \mathbf{H}$-NMR $\left(300 \mathrm{MHz}, \mathrm{CDCl}_{3}\right): \delta(\mathrm{ppm})=8.09(\mathrm{~s}, 1 \mathrm{H}, \mathrm{NH}), 5.72(\mathrm{~s}, 1 \mathrm{H}, \mathrm{C} 5 \mathrm{H}), 5.58(\mathrm{~d}$, $\left.J=1.8 \mathrm{~Hz}, 1 \mathrm{H}, \mathrm{C} 1^{\prime} \mathrm{H}\right), 5.20$ (d, $\left.J=6.2 \mathrm{~Hz}, 1 \mathrm{H}, \mathrm{C} 2^{\prime} \mathrm{H}\right), 4.81$ (m, 1H, C3'H), 4.13 (m, 1H, C4'H), $3.80\left(\mathrm{~m}, 2 \mathrm{H}, \mathrm{C} 5{ }^{\prime} \mathrm{H}_{2}\right), 2.63\left(\mathrm{q}, J=7.4 \mathrm{~Hz}, 2 \mathrm{H}, \mathrm{CH}_{2}\right), 1.54\left(\mathrm{~s}, 3 \mathrm{H}, \mathrm{CH}_{3}\right), 1.34$ (s, 3H, CH 3$), 1.27$ (t, $\left.J=7.5 \mathrm{~Hz}, 3 \mathrm{H}, \mathrm{CH}_{3}\right), 0.88\left(\mathrm{~s}, 9 \mathrm{H}, \mathrm{SiC}\left(\mathrm{CH}_{3}\right)_{3}\right), 0.05$ (s, $\left.6 \mathrm{H}, \mathrm{Si}\left(\mathrm{CH}_{3}\right)\right)$.

MS $(\mathrm{ESI}+\mathrm{MeOH}): \mathrm{m} / \mathrm{z}=427.2[\mathrm{M}+\mathrm{H}]^{+}, 449.2[\mathrm{M}+\mathrm{Na}]^{+}, 875.2[2 \mathrm{M}+\mathrm{Na}]^{+}$.

HRMS (ESI+): $\mathrm{m} / \mathrm{z}$ calc. for $\mathrm{C}_{20} \mathrm{H}_{34} \mathrm{~N}_{2} \mathrm{O}_{6} \mathrm{Si}[\mathrm{M}+\mathrm{H}]^{+}:$: 427.2259, found: 427.2258.

(ESI+): m/z calc. for $\mathrm{C}_{20} \mathrm{H}_{34} \mathrm{~N}_{2} \mathrm{O}_{6} \mathrm{Si}[\mathrm{M}+\mathrm{Na}]^{+}:$449.2078, found: 449.2077. 


\section{Synthesis of 5'-O-tert-butyldimethylsilyl-2',3'-O-isopropylidene-6-ethyluridine (36)}

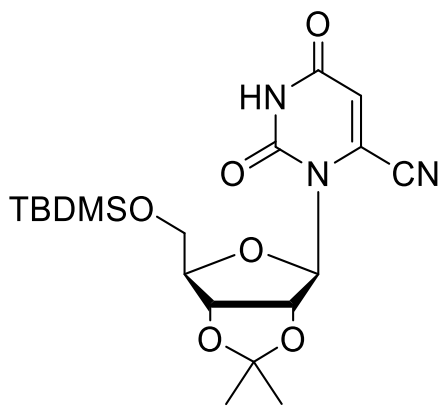

$M=423,54$

31

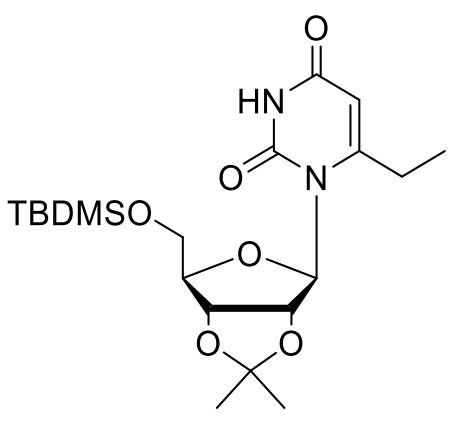

$M=426,59$

36

5'-O-tert-Butyldimethylsilyl-2',3'-O-isopropylidene-6-cyanouridine $\quad(0.80 \mathrm{~g}, \quad 1.89 \mathrm{mmol}$, 1.00 eq.) and $\mathrm{ZnCl}_{2}$ (129 mg, $0.95 \mathrm{mmol}, 0.50$ eq.) were dissolved in dry THF (20 mL) and the reaction mixture was cooled to $0^{\circ} \mathrm{C}$. Then, freshly prepared $\mathrm{EtMgBr}^{[196]}$ in $\mathrm{Et}_{2} \mathrm{O}(1.0 \mathrm{M}$, $630 \mathrm{mg}, 4.73 \mathrm{~mL}, 4.73 \mathrm{mmol}, 2.5 \mathrm{eq}$.) was added slowly and stirred for $4 \mathrm{~h}$ at room temperature. The reaction was quenched by adding sat. aq. ammonium chloride. The mixture was extracted with THF and washed with sat. aq. $\mathrm{NaCl}$. The combined organic layers were dried over magnesium sulfate and the solvent was removed in vacuo. The crude product was purified by column chromatography ( $\mathrm{SiO}_{2}$; hexane/ ethyl acetate, gradient $3: 1$ to $\left.1: 1\right)$ to afford the title compound ( $258 \mathrm{mg}, 0.60 \mathrm{mmol}, 32 \%$ ) as a light-yellow oil.

TLC, $R_{\mathrm{f}}=0.30$ hexane/ ethyl acetate $(2: 1)$

${ }^{1} \mathbf{H}-\mathbf{N M R}\left(300 \mathrm{MHz}, \mathrm{CDCl}_{3}\right): \delta(\mathrm{ppm})=8.09(\mathrm{~s}, 1 \mathrm{H}, \mathrm{NH}), 5.72(\mathrm{~s}, 1 \mathrm{H}, \mathrm{C} 5 \mathrm{H}), 5.58(\mathrm{~d}$, $\left.J=1.8 \mathrm{~Hz}, 1 \mathrm{H}, \mathrm{C} 1{ }^{\prime} \mathrm{H}\right), 5.20\left(\mathrm{~d}, J=6.2 \mathrm{~Hz}, 1 \mathrm{H}, \mathrm{C} 2{ }^{\prime} \mathrm{H}\right), 4.81$ (m, 1H, C3'H), $4.13\left(\mathrm{~m}, 1 \mathrm{H}, \mathrm{C} 4{ }^{\prime} \mathrm{H}\right)$, $3.80\left(\mathrm{~m}, 2 \mathrm{H}, \mathrm{C} 5{ }^{\prime} \mathrm{H}_{2}\right), 2.63$ (q, J = 7.4 Hz, 2H, CH 2$), 1.54$ (s, 3H, $\left.\mathrm{CH}_{3}\right), 1.34$ (s, 3H, $\left.\mathrm{CH}_{3}\right), 1.27$ (t, $\left.J=7.5 \mathrm{~Hz}, 3 \mathrm{H}, \mathrm{CH}_{3}\right), 0.88\left(\mathrm{~s}, 9 \mathrm{H}, \mathrm{SiC}\left(\mathrm{CH}_{3}\right)_{3}\right), 0.05\left(\mathrm{~s}, 6 \mathrm{H}, \mathrm{Si}\left(\mathrm{CH}_{3}\right)\right)$.

MS (ESI+, MeOH): m/z = $427.2[\mathrm{M}+\mathrm{H}]^{+}, 449.2[\mathrm{M}+\mathrm{Na}]^{+}$.

HRMS (ESI+): m/z calc. for $\mathrm{C}_{20} \mathrm{H}_{34} \mathrm{~N}_{2} \mathrm{O}_{6} \mathrm{Si}[\mathrm{M}+\mathrm{Na}]^{+}:$449.2078, found: 449.2076 . 
6. Experimental part

\section{Synthesis of 6-ethyluridine (41)}

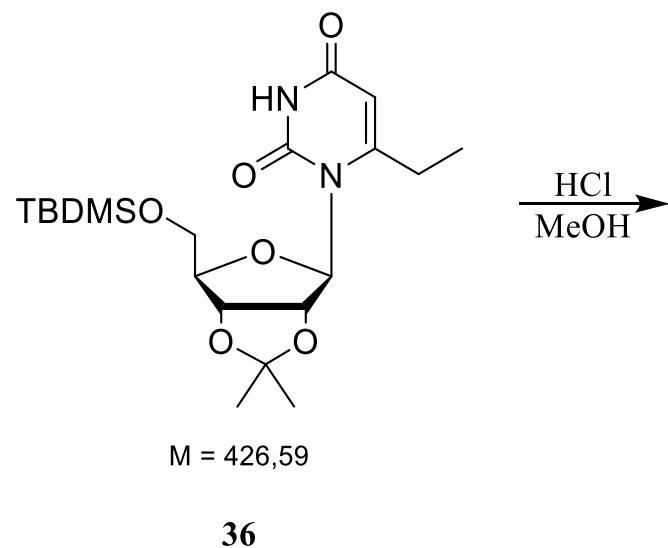

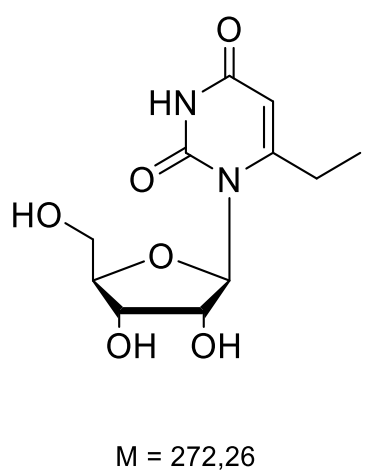

41

5'-O-tert-Butyldimethylsilyl-2',3'-O-isopropylidene-6-ethyluridine $\quad(180 \mathrm{mg}, \quad 422 \mu \mathrm{mol}$, 1.0 eq.) was dissolved in methanolic $\mathrm{HCl}(0.5 \mathrm{M}, 10 \mathrm{~mL})$. The reaction mixture was stirred for $45 \mathrm{~min}$ at room temperature. The solvent was removed in vacuo to obtain 6-ethyl uridine (110 mg, quant.) which was used without further purification.

${ }^{1} \mathbf{H}-\mathbf{N M R}\left(300 \mathrm{MHz}, \mathrm{CDCl}_{3}\right): \delta(\mathrm{ppm})=5.49(\mathrm{~s}, 1 \mathrm{H}, \mathrm{C} 5 \mathrm{H}), 5.43\left(\mathrm{~d}, J=4.2 \mathrm{~Hz}, 1 \mathrm{H}, \mathrm{C} 1^{\prime} \mathrm{H}\right)$, 4.68-4.64 (m, 1H, C2’'H), 4.32 (t, $\left.J=5.7 \mathrm{~Hz}, 1 \mathrm{H}, \mathrm{C} 3^{\prime} \mathrm{H}\right), 3.91-3.85$ (m, 1H, C4'H), 3.78-3.73 $\left(\mathrm{dd}, J=12.1,2.5 \mathrm{~Hz}, 1 \mathrm{H}, \mathrm{C}^{\prime} \mathrm{H}_{2}\right) 3.62-3.57\left(\mathrm{dd}, J=12.0,3.5 \mathrm{~Hz}, 1 \mathrm{H}, \mathrm{C} 5^{\prime} \mathrm{H}_{2}\right), 2.52$ (q, $\left.J=7.5 \mathrm{~Hz}, 2 \mathrm{H}, \mathrm{CH}_{3}\right), 1.18\left(\mathrm{t}, J=7.5 \mathrm{~Hz}, 3 \mathrm{H}, \mathrm{CH}_{3}\right)$.

MS $(\mathrm{ESI}+\mathrm{MeOH}): \mathrm{m} / \mathrm{z}=295.1[\mathrm{M}+\mathrm{Na}]^{+}$.

HRMS (ESI+): m/z calc. for $\mathrm{C}_{11} \mathrm{H}_{16} \mathrm{~N}_{2} \mathrm{O}_{6}[\mathrm{M}+\mathrm{Na}]^{+}: 295.0901$, found: 295.0895 . 


\section{Synthesis of 6-ethyl UMP (8)}

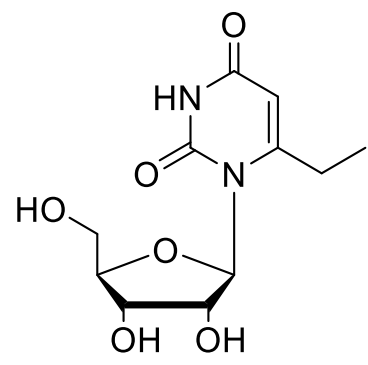

$M=272,26$

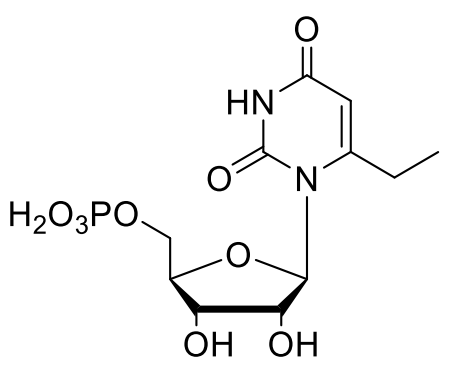

$M=352,24$

41

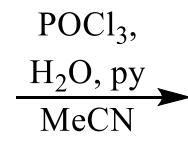

8

Phosphoryl chloride ( $140 \mu \mathrm{L}, 1.47 \mathrm{mmol}, 4.4$ eq. $)$ was dissolved in acetonitrile $(4.0 \mathrm{~mL})$ at $0^{\circ} \mathrm{C}$. Then, water (17 $\mu \mathrm{L}, 0.93 \mathrm{mmol}, 2.8$ eq.) and pyridine (127 $\mu \mathrm{L}, 1.59 \mathrm{mmol}, 4.4$ eq.) were added and the reaction mixture was stirred for $30 \mathrm{~min}$. 6-Ethyluridine (90 mg, $330 \mu \mathrm{mol}, 1.0$ eq.) was added and the reaction mixture was stirred for $4 \mathrm{~h}$ at $0^{\circ} \mathrm{C}$. The reaction was quenched by adding aqueous triethylammonium acetate buffer $(1.0 \mathrm{M})$ until neutral $\mathrm{pH}$. The solvent was removed in vacuo. The crude product was purified by HPLC (ion-exchange column) to obtain 6-ethyl UMP as bis(triethylammonium) salt.

${ }^{1} \mathbf{H}$-NMR $\left(300 \mathrm{MHz}, \mathrm{D}_{2} \mathrm{O}\right): \delta(\mathrm{ppm})=5.76(\mathrm{~s}, 1 \mathrm{H}, \mathrm{C} 5 \mathrm{H}), 5.68(\mathrm{~d}, J=3.2 \mathrm{~Hz}, 1 \mathrm{H}, \mathrm{C} 1$ 'H), 4.72 (m, 1H, C2'H), 4.44 (t, J=6.8 Hz, 1H, C3'H), 4.18-4.13 (m, 1H, C4'H), 4.06-4.02 (m, $\left.2 \mathrm{H}, \mathrm{C}^{\prime} \mathrm{H}_{2}\right), 2.70\left(\mathrm{q}, J=7.5 \mathrm{~Hz}, 2 \mathrm{H}, \mathrm{CH}_{3}\right), 1.23\left(\mathrm{~m}, 3 \mathrm{H}, \mathrm{CH}_{3}\right)$.

MS (ESI-, $\mathrm{MeOH}): \mathrm{m} / \mathrm{z}=351.0[\mathrm{M}-\mathrm{H}]^{-}$.

HRMS (ESI-): m/z calc. for $\mathrm{C}_{11} \mathrm{H}_{17} \mathrm{~N}_{2} \mathrm{O}_{9} \mathrm{P}[\mathrm{M}-\mathrm{H}]^{-}:$351.0599, found: 351.0598 . 
6. Experimental part

\subsubsection{Synthesis of 6-isopropenyl UMP}

\section{Synthesis of 5'-O-tert-butyldimethylsilyl-2',3'-O-isopropylidene-6-iodouridine (38)}

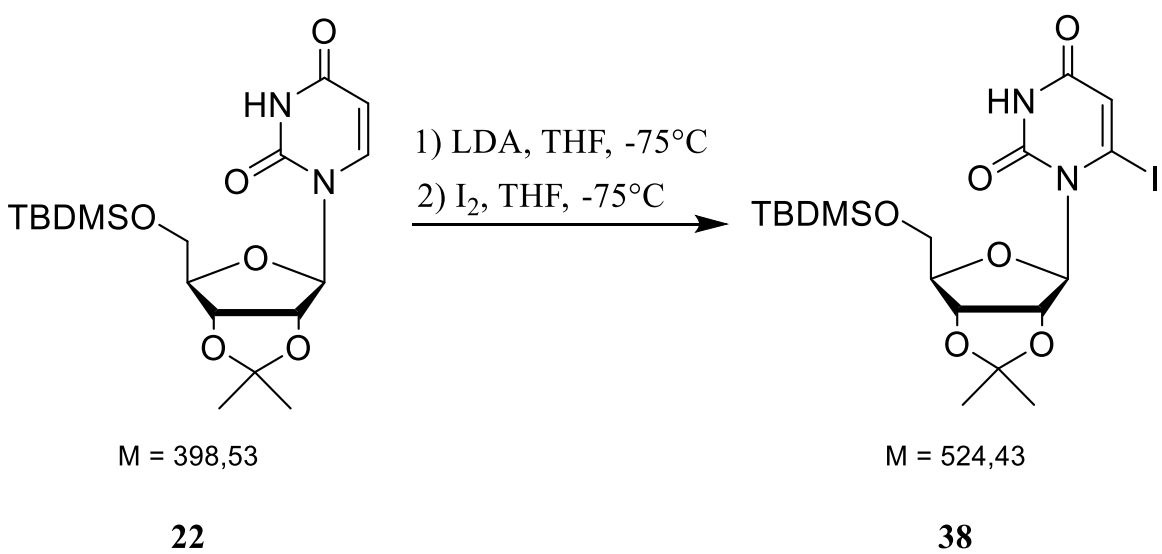

5'-O-tert-Butyldimethylsilyl-2',3'-O-isopropylideneuridine (3.60 g, $9.03 \mathrm{mmol}, 1.0$ eq.) was dissolved in THF $(40 \mathrm{~mL})$. The reaction mixture was cooled to $-75^{\circ} \mathrm{C}$. Then LDA dissolved in hexane (2.0 M, $10.0 \mathrm{~mL}, 20.0 \mathrm{mmol}, 2.2 \mathrm{eq}$.) was added slowly and the solution was stirred for $30 \mathrm{~min}$. Iodine ( $3.47 \mathrm{~g}, 13.7 \mathrm{mmol}, 1.5 \mathrm{eq}$.) dissolved in THF (20 mL) was added dropwise to the reaction mixture, which was stirred for $4 \mathrm{~h}$ at $-75^{\circ} \mathrm{C}$. The reaction was quenched by addition of sat. aq. ammonium chloride and extracted with ethyl acetate. The organic layers were washed with sat. aq. $\mathrm{NaCl}$ and dried over magnesium sulfate. The solvent was removed under reduced pressure and the crude product was purified by column chromatography $\left(\mathrm{SiO}_{2}\right.$; hexane/ ethyl acetate, gradient 3:1 to 1:1) to afford the title compound (1.18 g, $2.26 \mathrm{mmol}$, $25 \%$ ) as a yellow oil.

TLC, $R_{\mathrm{f}}=0.28$ hexane/ ethyl acetate $(2: 1)$.

${ }^{1}$ H-NMR (300 MHz, DMSO- $\left.d_{6}\right): \delta(\mathrm{ppm})=11.64(\mathrm{~s}, 1 \mathrm{H}, \mathrm{NH}), 6.36\left(\mathrm{~d}, J=2.0 \mathrm{~Hz}, 1 \mathrm{H}, \mathrm{C} 1^{\prime} \mathrm{H}\right)$, $6.02(\mathrm{~s}, 1 \mathrm{H}, \mathrm{C} 5 \mathrm{H}), 5.23\left(\mathrm{dd}, J=6.3,1.1 \mathrm{~Hz}, 1 \mathrm{H}, \mathrm{C} 2^{\prime} \mathrm{H}\right), 4.71\left(\mathrm{dd}, J=6.3,3.9 \mathrm{~Hz}, 1 \mathrm{H}, \mathrm{C}{ }^{\prime} \mathrm{H}\right)$, 4.02 (m, 1H, C4'H), 3.80- 3.61 (m, 2H, C5 ' $\left.\mathrm{H}_{2}\right), 1.48$ (s, 3H, CH 3$), 1.29$ (s, 3H, $\left.\mathrm{CH}_{3}\right), 0.85$ (s, $\left.9 \mathrm{H}, \mathrm{SiC}\left(\mathrm{CH}_{3}\right)_{3}\right), 0.01$ (s, 6H, $\left.\mathrm{Si}\left(\mathrm{CH}_{3}\right)_{2}\right)$.

${ }^{13}$ C-NMR (75 MHz, DMSO- $\left.d_{6}\right): \delta(\mathrm{ppm})=161.9(\mathrm{C} 4), 148.9$ (C2), 117.2 (C6), 115.8 (C1'), $113.0\left(\underline{\mathrm{C}}\left(\mathrm{CH}_{3}\right)_{2}\right), 101.2$ (C5), 89.9 (C4'), 84.4 (C2'), 82.4 (C3'), $64.1\left(\mathrm{C}^{\prime}\right.$ '), $27.5\left(\mathrm{CH}_{3}\right), 26.3$ $\left(\mathrm{SiC}\left(\underline{\mathrm{CH}}_{3}\right)_{3}\right), 25.6\left(\mathrm{CH}_{3}\right), 18.5\left(\mathrm{SiC}\left(\mathrm{CH}_{3}\right)_{3}\right),-4.8 \mathrm{Si}\left(\mathrm{CH}_{3}\right),-4.9 \mathrm{Si}\left(\mathrm{CH}_{3}\right)$.

MS (ESI+, MeOH): m/z = 525.1 [M+H] $]^{+}, 547.1[\mathrm{M}+\mathrm{Na}]^{+}$.

HRMS (ESI+): m/z calc. for $\mathrm{C}_{18} \mathrm{H}_{29} \mathrm{~N}_{2} \mathrm{IO}_{6} \mathrm{Si}[\mathrm{M}+\mathrm{H}]^{+}:$525.0912, found: 525.0916. 


\section{Synthesis of isopropenylboronic acid (42)}

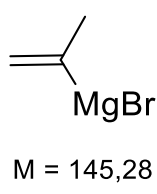

45
1) $\mathrm{B}(\mathrm{OEt})_{3}, \mathrm{THF}$

$1.5 \mathrm{~h},-78^{\circ} \mathrm{C}$

2) $\mathrm{HCl}, \mathrm{THF}$

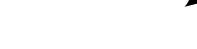

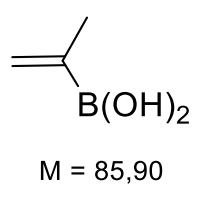

42

Triethyl borate $(0.50 \mathrm{~mL}, 2.94 \mathrm{mmol}, 2.2 \mathrm{eq}$.$) , was dissolved in THF (20 mL) and the mixture$ was cooled to $-78^{\circ} \mathrm{C}$ under argon atmosphere. Isopropenylmagnesium bromide solution $(0.5 \mathrm{M}, 13.0 \mathrm{~mL}, 6.5 \mathrm{mmol}, 1.0$ eq.) was added slowly. The reaction was stirred for $1.5 \mathrm{~h}$ and quenched by adding aq. $\mathrm{HCl}(1.0 \mathrm{M}, 5.0 \mathrm{~mL})$. Then, $\mathrm{Et}_{2} \mathrm{O}$ was added and the organic layer was washed with sat. aq. $\mathrm{NaCl}$. The combined organic layers were dried over magnesium sulfate and the solvent was removed in vacuo. The crude product was used without further purification.

MS (ESI+, $\mathrm{MeOH}): \mathrm{m} / \mathrm{z}=109.0[\mathrm{M}+\mathrm{Na}]^{+}$

$(\mathrm{ESI}-, \mathrm{MeOH}): \mathrm{m} / \mathrm{z}=85.0[\mathrm{M}-\mathrm{H}]^{-}$. 


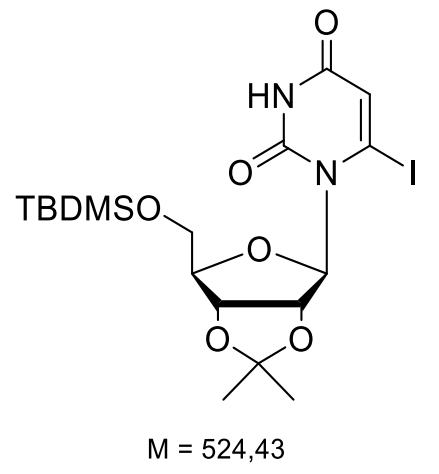

38
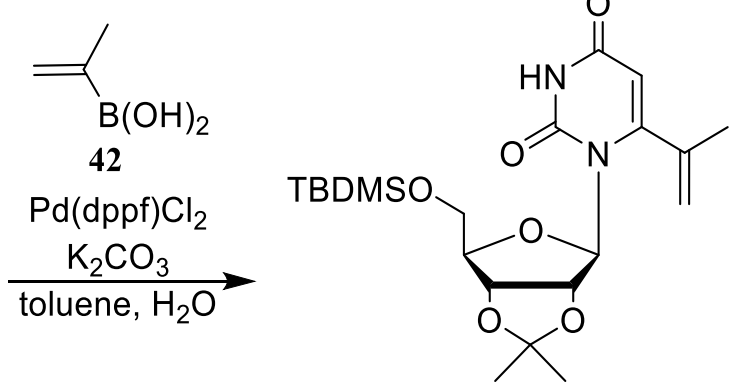

$M=438,60$

39

5'-O-tert-Butyldimethylsilyl-2',3'-O-isopropylidene-6-iodouridine $\quad(250 \mathrm{mg}, \quad 0.48 \mathrm{mmol}$, 1.0 eq.), (1,1'-bis(diphenylphosphino)ferrocene) palladium (II) dichloride (62 mg, $0.08 \mathrm{mmol}$, 0.17 eq.), potassium carbonate $(98.9 \mathrm{mg}, 0.72 \mathrm{mmol}, 1.5 \mathrm{eq}$.$) and isopropenylboronic acid$ (66 mg, $0.76 \mathrm{mmol}, 1.6$ eq.) were dissolved in toluene $(10 \mathrm{~mL})$ and the mixture was heated to reflux. After $5 \mathrm{~min}$, water $(2.0 \mathrm{~mL})$ was added and reaction was stirred for $1 \mathrm{~h}$ at $100^{\circ} \mathrm{C}$. The reaction was quenched by adding sat. aq. ammonium chloride. Then ethyl acetate was added, and the organic layer was washed with brine. The combined organic layers were dried over magnesium sulfate and the solvent was removed in vacuo. The crude product was purified by column chromatography ( $\mathrm{SiO}_{2}$; hexane/ ethyl acetate, gradient $3: 1$ to $\left.1: 1\right)$ to afford the title compound (198 mg, $451 \mu \mathrm{mol}, 94 \%)$ as a light-yellow oil. TLC, $R_{\mathrm{f}}=0.35$ hexane/ ethyl acetate $(2: 1)$

${ }^{1} \mathbf{H}-\mathrm{NMR}\left(300 \mathrm{MHz}, \mathrm{DMSO}-d_{6}\right): \delta(\mathrm{ppm})=11.47(\mathrm{sbr}, 1 \mathrm{H}, \mathrm{NH}), 5.47-5.42(\mathrm{~m}, 3 \mathrm{H}, \mathrm{C} 5 \mathrm{H}, \mathrm{C1}$ 'H, $\left.\mathrm{C}=\mathrm{CH}_{2}\right)$, 5.24-5.19 (m, 2H, C2' $\left.\mathrm{H}, \mathrm{C}=\mathrm{CH}_{2}\right), 4.72-4.69\left(\mathrm{~m}, 1 \mathrm{H}, \mathrm{C} 3{ }^{\prime} \mathrm{H}\right), 4.01-3.96\left(\mathrm{~m}, 1 \mathrm{H}, \mathrm{C} 4{ }^{\prime} \mathrm{H}\right)$, 3.76-3.74 (m, 2H, C5'H $\mathrm{H}_{2}$ ), 2.00 (s, 3H, CH $), 1.45$ (s, 3H, CH $), 1.27$ (s, 3H, CH $), 0.85$ (s, 9H, $\left.\mathrm{C}\left(\mathrm{CH}_{3}\right)_{3}\right), 0.01\left(\mathrm{~s}, 6 \mathrm{H}, \mathrm{Si}\left(\mathrm{CH}_{3}\right)_{2}\right)$.

${ }^{13}$ C-NMR (75 MHz, DMSO- $\left.d_{6}\right): \delta(\mathrm{ppm})=163.8(\mathrm{C} 4), 157.5$ (C6), $151.0(\mathrm{C} 2), 138.2\left(\underline{\mathrm{C}}=\mathrm{CH}_{2}\right)$, $120.7\left(\mathrm{C}=\underline{\mathrm{CH}}_{2}\right), 113.1\left(\underline{\mathrm{C}}\left(\mathrm{CH}_{3}\right)_{2}\right), 101.3(\mathrm{C} 5), 93.0\left(\mathrm{C} 1^{\prime}\right), 89.6\left(\mathrm{C} 4{ }^{\prime}\right), 84.3\left(\mathrm{C}^{\prime}\right), 82.4\left(\mathrm{C}^{\prime}\right), 64.3$

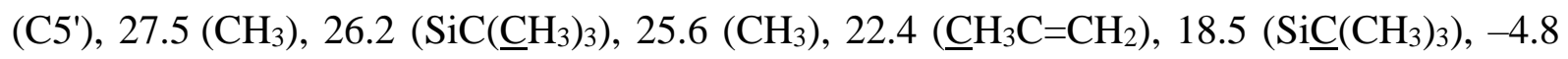
$\mathrm{Si}\left(\mathrm{CH}_{3}\right),-4.9 \mathrm{Si}\left(\mathrm{CH}_{3}\right)$.

MS (ESI+, MeOH): m/z = $439.3[\mathrm{M}+\mathrm{H}]^{+}, 461.3[\mathrm{M}+\mathrm{Na}]^{+}, 899.5[2 \mathrm{M}+\mathrm{Na}]^{+}$.

HRMS (ESI+): $\mathrm{m} / \mathrm{z}$ calc. for $\mathrm{C}_{21} \mathrm{H}_{34} \mathrm{~N}_{2} \mathrm{O}_{6} \mathrm{Si}[\mathrm{M}+\mathrm{H}]^{+}:$: 439.2259, found: 439.2255 .

(ESI+): $\mathrm{m} / \mathrm{z}$ calc. for $\mathrm{C}_{21} \mathrm{H}_{34} \mathrm{~N}_{2} \mathrm{O}_{6} \mathrm{Si}[\mathrm{M}+\mathrm{Na}]^{+}:$461.2078, found: 461.2076. 


\section{Synthesis of 6-isopropenyl uridine (43)}

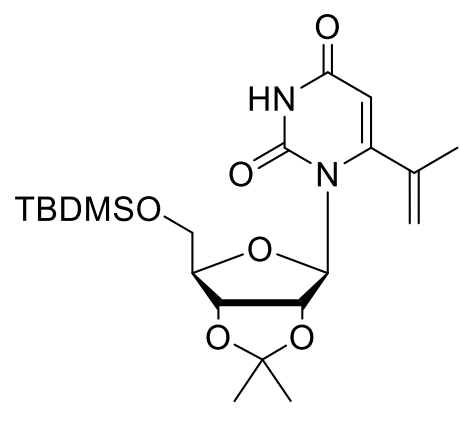

$M=438,60$

39<smiles>C=C(C)c1cc(=O)[nH]c(=O)n1C1O[C@H](O)[C@@H](CO)[C@@H](O)[C@@H]1O</smiles>

$M=284,27$

43

5'-O-tert-Butyldimethylsilyl-2',3'-O-isopropylidene-6-isopropenyluridine (198 mg, 422 $\mu \mathrm{mol}$, 1.0 eq.) was dissolved in methanolic $\mathrm{HCl}(0.5 \mathrm{M}, 10 \mathrm{~mL})$. The reaction mixture was stirred for $45 \mathrm{~min}$ at room temperature. The solvent was removed in vacuo to obtain 6-isopropenyl uridine (120 mg, $395 \mu \mathrm{mol}, 94 \%$ ) which was used without further purification.

${ }^{1}$ H-NMR (300 MHz, DMSO- $\left.d_{6}\right): \delta(\mathrm{ppm})=11.36$ (sbr, 1H, NH), $5.42(\mathrm{~s}, 1 \mathrm{H}, \mathrm{C} 5), 5.37$ (s, 1H, $\left.\mathrm{C}=\mathrm{CH}_{2}\right), 5.21\left(\mathrm{~s}, 1 \mathrm{H}, \mathrm{C}=\mathrm{CH}_{2}\right), 5.16\left(\mathrm{~d}, J=3.8 \mathrm{~Hz}, 1 \mathrm{H}, \mathrm{C} 1^{\prime} \mathrm{H}\right), 4.58-4.55\left(\mathrm{~m}, 1 \mathrm{H}, \mathrm{C} 2{ }^{\prime} \mathrm{H}\right), 4.06(\mathrm{t}$, $\left.J=5.9 \mathrm{~Hz}, 1 \mathrm{H}, \mathrm{C}^{\prime} \mathrm{H}\right), 3.70-3.65$ (m, 1H, C4'H), 3.61-3.56 (m, 1H, C5' $\left.\mathrm{H}_{2}\right), 3.45-3.40$ (m, 1H, $\left.\mathrm{C}^{\prime} \mathrm{H}_{2}\right), 2.01\left(\mathrm{~s}, 3 \mathrm{H}, \mathrm{CH}_{3}\right)$.

${ }^{13}$ C-NMR (75 MHz, DMSO- $\left.d_{6}\right): \delta(\mathrm{ppm})=162.7(\mathrm{C} 4), 158.1$ (C6), $150.4(\mathrm{C} 2), 138.3\left(\underline{\mathrm{C}}=\mathrm{CH}_{2}\right)$, $119.8\left(\mathrm{C}=\underline{\mathrm{CH}_{2}}\right), 100.8$ (C5), 93.8 (C1'), 85.0 (C4'), 70.9 (C2'), 70.0 (C3'), 62.2 (C5'), $22.1\left(\underline{\left.\mathrm{CH}_{3} \mathrm{C}=\mathrm{CH}_{2}\right)}\right.$.

MS (ESI+, MeOH): m/z = 285.1 [M+H] $]^{+}, 307.1[\mathrm{M}+\mathrm{Na}]^{+}$.

HRMS (ESI+): $\mathrm{m} / \mathrm{z}$ calc. for $\mathrm{C}_{12} \mathrm{H}_{16} \mathrm{~N}_{2} \mathrm{O}_{6}[\mathrm{M}+\mathrm{H}]^{+}:$285.1081, found: 285.1083 .

(ESI+): m/z calc. for $\mathrm{C}_{12} \mathrm{H}_{16} \mathrm{~N}_{2} \mathrm{O}_{6}[\mathrm{M}+\mathrm{Na}]^{+}:$307.0901, found: 307.0903 . 
6. Experimental part

\section{Synthesis of 6-isopropenyl UMP (10)}<smiles>C=C(C)c1cc(=O)[nH]c(=O)n1C1OC(O)C(O)C1O</smiles>

$M=284,27$

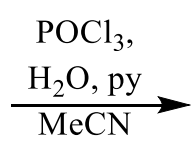

43<smiles>C=C(C)c1cc(=O)[nH]c(=O)n1C1O[C@H](CO[13CH3])[C@@H](O)[C@H](O)[C@H]1O</smiles>

$M=364,25$

10

Phosphoryl chloride (160 $\mu \mathrm{L}, 1.69 \mathrm{mmol}, 4.4$ eq. $)$ was dissolved in acetonitrile $(5.0 \mathrm{~mL})$ at $0^{\circ} \mathrm{C}$. Then, water ( $25 \mu \mathrm{L}, 1.08 \mathrm{mmol}, 2.8$ eq.) and pyridine (150 $\mu \mathrm{L}, 1.86 \mathrm{mmol}, 4.4$ eq.) were added and the reaction mixture was stirred for $30 \mathrm{~min}$. 6-isopropenyl uridine $(110 \mathrm{mg}, 387 \mu \mathrm{mol}$, 1.0 eq.) was added and the reaction mixture was stirred for $4 \mathrm{~h}$ at $0^{\circ} \mathrm{C}$. The reaction was quenched by adding aqueous triethylammonium acetate buffer $(1.0 \mathrm{M})$ until neutral $\mathrm{pH}$. The solvent was removed in vacuo. The crude product was purified by HPLC (ion-exchange column) to obtain 6-ethyl UMP as bis(triethylammonium) salt.

${ }^{1} \mathbf{H}-\mathrm{NMR}\left(300 \mathrm{MHz}, \mathrm{D}_{2} \mathrm{O}\right): \delta(\mathrm{ppm})=5.72(\mathrm{~s}, 1 \mathrm{H}, \mathrm{C} 5), 5.50\left(\mathrm{~d}, J=3.0 \mathrm{~Hz}, 1 \mathrm{H}, \mathrm{C} 1{ }^{\prime} \mathrm{H}\right), 5.45(\mathrm{~s}$, $\left.1 \mathrm{H}, \mathrm{C}=\mathrm{CH}_{2}\right), 5.31\left(\mathrm{~s}, 1 \mathrm{H}, \mathrm{C}=\mathrm{CH}_{2}\right), 4.63\left(\mathrm{~m}, 1 \mathrm{H}, \mathrm{C} 2^{\prime} \mathrm{H}\right), 4.43-4.39\left(\mathrm{~m}, 1 \mathrm{H}, \mathrm{C} 3{ }^{\prime} \mathrm{H}\right), 4.14-4.10$ (m, 1H, C4'H), 4.03-3.97 (m, 2H, C5' $\left.\mathrm{H}_{2}\right), 2.04$ (s, 3H, $\left.\mathrm{CH}_{3}\right)$.

MS (ESI+, MeOH): m/z = 365.1 $[\mathrm{M}+\mathrm{H}]^{+}$.

$$
(\mathrm{ESI}-, \mathrm{MeOH}): \mathrm{m} / \mathrm{z}=363.1[\mathrm{M}-\mathrm{H}]^{-} \text {. }
$$

HRMS (ESI+): $\mathrm{m} / \mathrm{z}$ calc. for $\mathrm{C}_{12} \mathrm{H}_{17} \mathrm{~N}_{2} \mathrm{O}_{9} \mathrm{P}[\mathrm{M}+\mathrm{H}]^{+}: 365.0744$, found: 365.0734 .

(ESI-): m/z calc. for $\mathrm{C}_{12} \mathrm{H}_{17} \mathrm{~N}_{2} \mathrm{O}_{9} \mathrm{P}[\mathrm{M}-\mathrm{H}]^{-}: 363.0599$, found: 363.0595 . 


\subsubsection{Synthesis of 6-carboxy CMP}

\section{Synthesis of 2',3'-O-isopropylidenecytidine (51)}<smiles>Nc1ccn(C2OC(O)C(O)C2O)c(=O)n1</smiles>

$M=243,22$

50<smiles>CC1(C)O[C@H]2[C@@H](CO)O[C@H](O[C@H]2n2ccc(N)nc2=O)O1</smiles>

$M=283,28$

51

Cytidine (5.0 g, $20.6 \mathrm{mmol}, 1.0$ eq.) was suspended in acetone $(150 \mathrm{~mL}), \mathrm{H}_{2} \mathrm{SO}_{4}(2.5 \mathrm{~mL})$ was added and the resulting solution was stirred for $8 \mathrm{~h}$ at room temperature. The reaction mixture was quenched by addition of $\mathrm{NEt}_{3}(5.0 \mathrm{~mL})$ and the solvent was evaporated in vacuo. The crude product was purified by column chromatography $\left(\mathrm{SiO}_{2} ; \mathrm{DCM} / \mathrm{MeOH}\right.$, gradient 95:5 to 85:15) to afford the title compound $(3.0 \mathrm{~g}, 10.6 \mathrm{mmol}, 51 \%)$ as a light-yellow solid.

TLC, $R_{\mathrm{f}}=0.22 \mathrm{DCM} / \mathrm{MeOH}(95: 5)$.

${ }^{1}$ H-NMR (300 MHz, DMSO- $\left.d_{6}\right): \delta(\mathrm{ppm})=7.74(\mathrm{~d}, J=7.4 \mathrm{~Hz}, 1 \mathrm{H}, \mathrm{C} 6 \mathrm{H}), 7.54\left(\mathrm{sbr}, 1 \mathrm{H}, \mathrm{NH}_{2}\right)$, 7.27 (sbr, 1H, NH 2$), 5.85$ (d, J=7.3 Hz, 1H, C5H), 5.78 (d, J = 2.3 Hz, 1H, C1'H), 4.83-4.75 (m, 2H, C2'H, C3'H), 4.05-4.01 (m, 1H, C4'H), 3.62-3.50 (m, 2H, C5' $\left.\mathrm{H}_{2}\right), 1.46$ (s, 3H, $\left.\mathrm{CH}_{3}\right)$, $1.26\left(\mathrm{~s}, 3 \mathrm{H}, \mathrm{CH}_{3}\right)$.

${ }^{13}$ C-NMR (75 MHz, DMSO- $\left.d_{6}\right): \delta(\mathrm{ppm})=165.9$ (C4), 155.1 (C2), 142.8 (C6), $112.7\left(\underline{\mathrm{C}}\left(\mathrm{CH}_{3}\right)_{2}\right), 94.5$ (C5), 92.4 (C1'), 86.6 (C4'), 84.2 (C2'), 80.8 (C3'), 61.5 (C5'), 27.1 $\left(\mathrm{CH}_{3}\right), 25.2\left(\mathrm{CH}_{3}\right)$.

MS (ESI+, MeOH): m/z = 284.1 [M+H $]^{+}, 306.1[\mathrm{M}+\mathrm{Na}]^{+}$.

HRMS (ESI+): m/z calc. for $\mathrm{C}_{12} \mathrm{H}_{17} \mathrm{~N}_{3} \mathrm{O}_{5}[\mathrm{M}+\mathrm{Na}]^{+}:$306.1060, found: 306.1050 . 
6. Experimental part

Synthesis of 5'-O-tert-butyldimethylsilyl-2',3'-O-isopropylidenecytidine (52)

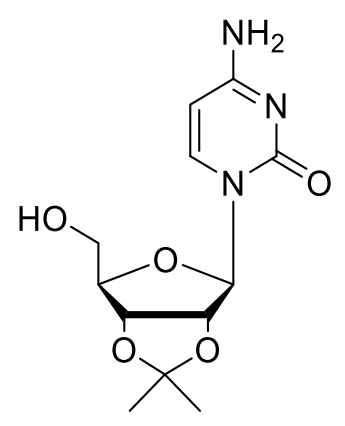

$M=283,28$

51

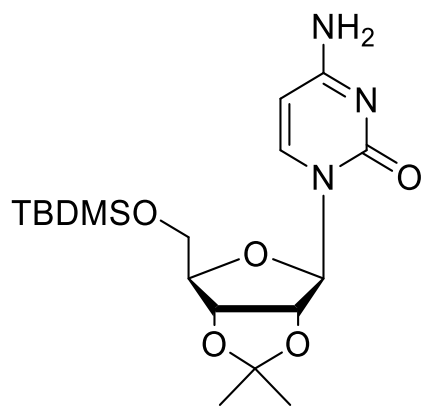

$M=397,55$

52

2',3'-O-Isopropylidenecytidine (4.00 g, $14.1 \mathrm{mmol}, 1.0 \mathrm{eq}$.), imidazole (2.41 g, $35.3 \mathrm{mmol}$, 2.5 eq.) and TBDMSCl (3.20 g, $21.2 \mathrm{mmol}, 1.5$ eq.) were dissolved in DMF (30 mL) and the resulting solution was stirred for $22 \mathrm{~h}$ at room temperature. The solvent was evaporated in vacuo and the crude product was purified by column chromatography $\left(\mathrm{SiO}_{2} ; \mathrm{DCM} / \mathrm{MeOH} 20: 1\right)$. The product (5.35 g, $13.5 \mathrm{mmol}, 95 \%)$ was obtained as a white solid.

TLC, $R_{\mathrm{f}}=0.25 \mathrm{DCM} / \mathrm{MeOH}(20: 1)$.

${ }^{1}$ H-NMR (300 MHz, DMSO- $\left.d_{6}\right): \delta(\mathrm{ppm})=7.66(\mathrm{~d}, J=7.5 \mathrm{~Hz}, 1 \mathrm{H}, \mathrm{C} 6 \mathrm{H}), 7.21\left(\mathrm{sbr}, 1 \mathrm{H}, \mathrm{NH}_{2}\right)$, $5.80\left(\mathrm{~d}, J=1.9 \mathrm{~Hz}, 1 \mathrm{H}, \mathrm{C} 1^{\prime} \mathrm{H}\right), 5.69$ (d, $\left.J=7.5 \mathrm{~Hz}, 1 \mathrm{H}, \mathrm{C} 5 \mathrm{H}\right), 4.83(\mathrm{dd}, J=6.2,1.9 \mathrm{~Hz}$, $\left.1 \mathrm{H}, \mathrm{C} 2{ }^{\prime} \mathrm{H}\right) 4.72\left(\mathrm{dd}, J=6.2,3.6 \mathrm{~Hz}, 1 \mathrm{H}, \mathrm{C} 3{ }^{\prime} \mathrm{H}\right), 4.07-4.03$ (m, 1H, C4'H), 3.80-3.74 (m, 2H, C5 $\left.{ }^{\prime} \mathrm{H}_{2}\right), 1.47$ (s, 3H, CH$\left.)_{3}\right), 1.28\left(\mathrm{~s}, 3 \mathrm{H}, \mathrm{CH}_{3}\right), 0.86$ (s, 9H, $\left.\mathrm{SiC}\left(\mathrm{CH}_{3}\right)_{3}\right), 0.03\left(\mathrm{~s}, 6 \mathrm{H}, \mathrm{Si}\left(\mathrm{CH}_{3}\right)_{2}\right)$.

${ }^{13}$ C-NMR (75 MHz, DMSO-d $\left.d_{6}\right): \delta(\mathrm{ppm})=165.8$ (C4), 154.8 (C2), 142.6 (C6), 112.6 $\left(\underline{\mathrm{C}}\left(\mathrm{CH}_{3}\right)_{2}\right), 93.9$ (C5), $92.7\left(\mathrm{C}^{\prime}\right.$ '), 86.8 (C4'), 84.5 (C2'), 80.5 (C3'), $63.2\left(\mathrm{C}^{\prime}\right.$ '), $27.0\left(\mathrm{CH}_{3}\right)$, $25.8\left(\mathrm{SiC}\left(\underline{\mathrm{CH}}_{3}\right)_{3}\right), 25.2\left(\mathrm{CH}_{3}\right), 18.0\left(\mathrm{Si} \underline{\mathrm{C}}\left(\mathrm{CH}_{3}\right)_{3}\right),-5.5 \mathrm{Si}\left(\mathrm{CH}_{3}\right)_{2}$.

MS (ESI+, MeOH): m/z = $398.2[\mathrm{M}+\mathrm{H}]^{+}, 420.2[\mathrm{M}+\mathrm{Na}]^{+}$.

HRMS (ESI+): m/z calc. for $\mathrm{C}_{18} \mathrm{H}_{31} \mathrm{~N}_{3} \mathrm{O}_{5} \mathrm{Si}[\mathrm{M}+\mathrm{H}]^{+}:$398.2106, found: 398.2100.

(ESI+): m/z calc. for $\mathrm{C}_{18} \mathrm{H}_{31} \mathrm{~N}_{3} \mathrm{O}_{5} \mathrm{Si}[\mathrm{M}+\mathrm{Na}]^{+}:$420.1925, found: 420.1915 . 


\section{Synthesis of 5'-O-tert-butyldimethylsilyl-2',3'- $O$-isopropylidene-6-carboxycytidine (106)}

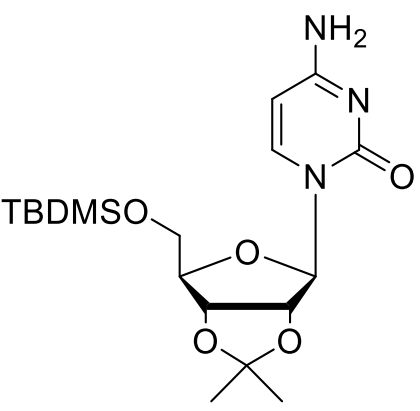

$M=397,55$

52
1) LDA, THF

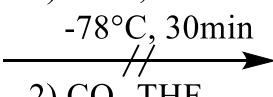

2) $\mathrm{CO}_{2}, \mathrm{THF}$ $-78^{\circ} \mathrm{C}, 5 \mathrm{~h}$

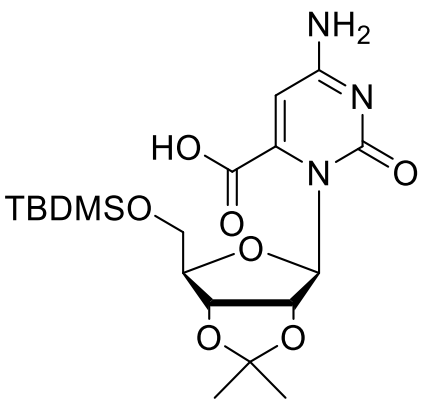

$M=441,56$

106

5'-O-tert-Butyldimethylsilyl-2',3'-O-isopropylidenecytidine (1.25 g, $3.14 \mathrm{mmol}, 1.0$ eq.) was dissolved in THF $(30 \mathrm{~mL})$ and the solution was cooled to $-78^{\circ} \mathrm{C}$. LDA $(2.0 \mathrm{M}, 3.14 \mathrm{~mL}$, $6.28 \mathrm{mmol}, 2.0$ eq.) was added dropwise. The resulting solution was stirred for $30 \mathrm{~min}$ at $-78^{\circ} \mathrm{C}$. carbon dioxide was bubbled through the solution for $5 \mathrm{~h}$ at $-78^{\circ} \mathrm{C}$. The mixture was quenched by the addition of acetic acid $(1.0 \mathrm{~mL})$ and the solvent was evaporated in vacuo, but no product formation could be observed.

\section{Synthesis of}

\section{5'-O-tert-butyldimethylsilyl-2',3'-O-isopropylidene-6-carboxymethyl ester cytidine (107)}

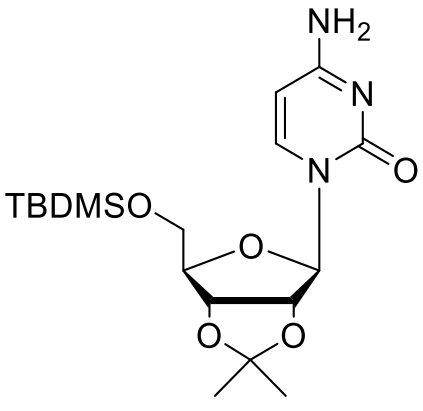

$M=397,55$

52<smiles>COC(=O)c1cc(N)nc(=O)n1C1O[C@H]2O[C@@H](COC(C)(C)C)[C@H]1OC(C)(C)O2</smiles>

$M=455,58$

107

5'-O-tert-Butyldimethylsilyl-2',3'-O-isopropylidenecytidine (1.25 g, $3.14 \mathrm{mmol}, 1.0$ eq.) was dissolved in THF $(30 \mathrm{~mL})$ and the solution was cooled to $-78^{\circ} \mathrm{C}$. LDA $(2.0 \mathrm{M}, 4.5 \mathrm{~mL}$, $9.0 \mathrm{mmol}, 2.86$ eq.) was added dropwise. The resulting solution was stirred for $30 \mathrm{~min}$ at $-78^{\circ} \mathrm{C}$. Methyl chloroformate $(290 \mu \mathrm{L}, 3.70 \mathrm{mmol}, 1.2$ eq. $)$ was added dropwise and the solution was stirred for $4 \mathrm{~h}$ at $-78^{\circ} \mathrm{C}$. The mixture was quenched by the addition of acetic acid $(1.0 \mathrm{~mL})$ and the solvent was evaporated in vacuo, but the product was not formed. 
6. Experimental part

\section{Synthesis of 5'-O-tert-butyldimethylsilyl-2',3'-O-isopropylidenecytidine-yl-4-tert- butylcarbamate (53)}

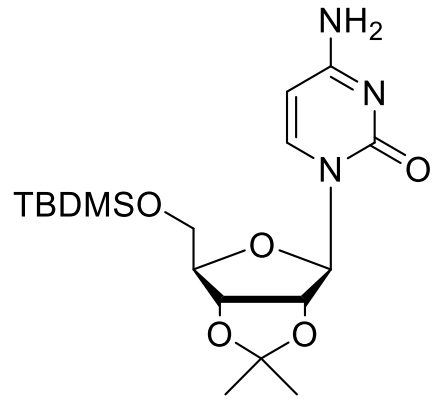

$M=397,55$

52

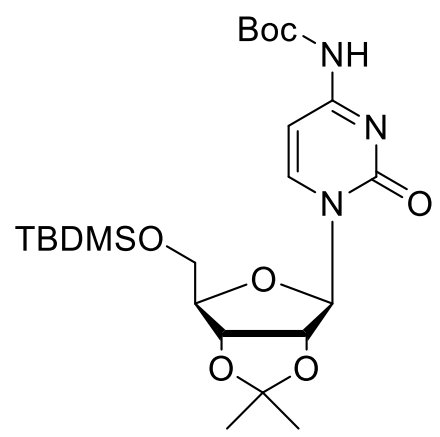

$M=497,66$

53

5'-O-tert-Butyldimethylsilyl-2',3'-O-isopropylidenecytidine ( $1.10 \mathrm{~g}, 2.77 \mathrm{mmol}, 1.0$ eq.) was dissolved in DCM (15 mL) and cooled to $0^{\circ} \mathrm{C}$. $\mathrm{Boc}_{2} \mathrm{O}(1.20 \mathrm{~g}, 5.54 \mathrm{mmol}, 2.0$ eq. $)$ and $\mathrm{NEt}_{3}$ ( $385 \mu \mathrm{L}, 3.05 \mathrm{mmol}, 1.1 \mathrm{eq}$.) were added slowly and the solution was stirred for $1 \mathrm{~h}$ at $0^{\circ} \mathrm{C}$ and additional $20 \mathrm{~h}$ at room temperature. The solvent was evaporated in vacuo and the crude product was purified by column chromatography ( $\mathrm{SiO}_{2}$; ethyl acetate/MeOH gradient 100:0 to 95:5). The product ( $820 \mathrm{mg}, 1.65 \mathrm{mmol}, 60 \%$ ) was obtained as a white solid.

${ }^{1}$ H-NMR (300 MHz, DMSO- $\left.d_{6}\right): \delta(\mathrm{ppm})=10.39(\mathrm{~s}, 1 \mathrm{H}, \mathrm{NH}), 8.10(\mathrm{~d}, J=7.5 \mathrm{~Hz}, 1 \mathrm{H}, \mathrm{C} 6 \mathrm{H})$, $6.98(\mathrm{~d}, J=7.5 \mathrm{~Hz}, 1 \mathrm{H}, \mathrm{C} 5 \mathrm{H}), 5.79\left(\mathrm{~d}, J=1.9 \mathrm{~Hz}, 1 \mathrm{H}, \mathrm{C} 1{ }^{\prime} \mathrm{H}\right), 4.84(\mathrm{dd}, J=6.2,1.9 \mathrm{~Hz}$, $\left.1 \mathrm{H}, \mathrm{C} 2{ }^{\prime} \mathrm{H}\right) 4.71\left(\mathrm{dd}, J=6.1,3.0 \mathrm{~Hz}, 1 \mathrm{H}, \mathrm{C} 3{ }^{\prime} \mathrm{H}\right), 4.27-4.23$ (m, 1H, C4'H), 3.85-3.77 (m, 2H, $\left.\mathrm{C}^{\prime}{ }^{\prime} \mathrm{H}_{2}\right), 1,48$ (s, 3H, CH$)_{3}, 1.45$ (s, 9H, C( $\left.\left.\mathrm{CH}_{3}\right)_{3}\right), 1.29$ (s, 3H, $\left.\mathrm{CH}_{3}\right), 0.83$ (s, 9H, $\left.\mathrm{SiC}\left(\mathrm{CH}_{3}\right)_{3}\right)$, $0.02\left(\mathrm{~s}, 6 \mathrm{H}, \mathrm{Si}\left(\mathrm{CH}_{3}\right)_{2}\right)$.

MS (ESI+, MeOH): m/z = $498.3[\mathrm{M}+\mathrm{H}]^{+}$.

HRMS (ESI+): $\mathrm{m} / \mathrm{z}$ calc. for $\mathrm{C}_{23} \mathrm{H}_{39} \mathrm{~N}_{3} \mathrm{O}_{7} \mathrm{Si}[\mathrm{M}+\mathrm{H}]^{+}$: 498.2616, found: 498.2624.

(ESI+): m/z calc. for $\mathrm{C}_{23} \mathrm{H}_{39} \mathrm{~N}_{3} \mathrm{O}_{7} \mathrm{Si}[\mathrm{M}+\mathrm{Na}]^{+}:$520.2449, found: 520.2443. 


\section{Synthesis of 5'-O-tert-butyldimethylsilyl-2',3'-O-isopropylidene-6-carboxycytidine-yl-4- tert-butylcarbamate (56)}

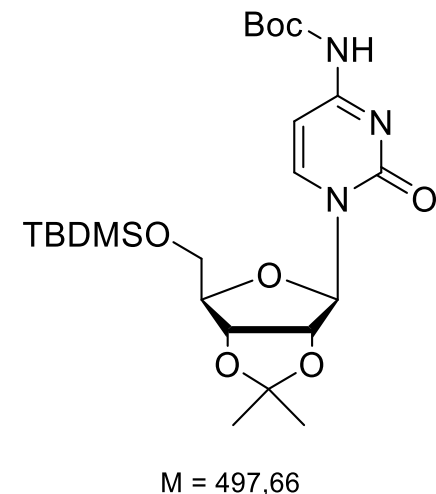

53
1) $\mathrm{LDA}, \mathrm{THF},-78^{\circ} \mathrm{C}$ 2) $\mathrm{CO} 2(\mathrm{~s}),-70^{\circ} \mathrm{C}$

\section{TB}

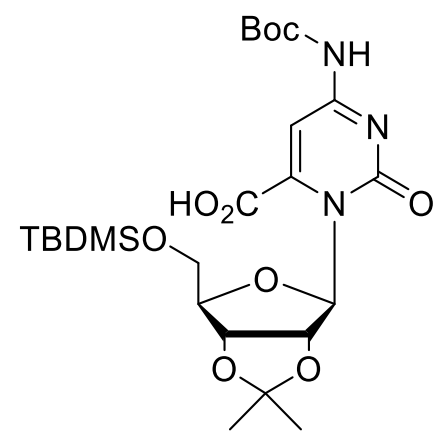

$M=541,67$

56

5'-O-tert-Butyldimethylsilyl-2',3'-O-isopropylidenecytidine-yl-4-tert-butylcarbamate (420 mg, $0.85 \mathrm{mmol}, 1.0$ eq.) was dissolved in THF (10 mL) and the solution was cooled to $-78^{\circ} \mathrm{C}$. LDA (2.0 M, $1.05 \mathrm{~mL}, 2.10 \mathrm{mmol}, 2.5$ eq. $)$ was added dropwise. The resulting brownish solution was stirred at $-78^{\circ} \mathrm{C}$ for $40 \mathrm{~min}$. Carbon dioxide was bubbled through the solution for $4 \mathrm{~h}$ at $-70^{\circ} \mathrm{C}$. The mixture was quenched by the addition of sat. aq. ammonium chloride and extracted with ethyl acetate. The solvent was evaporated in vacuo and the crude product was purified by column chromatography $\left(\mathrm{SiO}_{2}\right.$; ethyl acetate/MeOH gradient 100:0 to 95:5). The product (285 mg, $0.53 \mathrm{mmol}, 62 \%$ ) was obtained as a white solid.

${ }^{1}$ H-NMR (300 MHz, DMSO- $\left.d_{6}\right): \delta(\mathrm{ppm})=10.19(\mathrm{~s}, 1 \mathrm{H}, \mathrm{NH}), 6.81(\mathrm{~s}, 1 \mathrm{H}, \mathrm{C} 5 \mathrm{H}), 6.09$ (s, 1H, C1'H), 5.10 (d, $\left.J=6.5 \mathrm{~Hz}, 1 \mathrm{H}, \mathrm{C} 2{ }^{\prime} \mathrm{H}\right)$ 4.80-4.77 (m, 1H, C3'H), 3.97-3.93 (m, 1H, C4'H), 3.80-3.73 (m, 2H, C5' $\left.\mathrm{H}_{2}\right), 1.45\left(\mathrm{~s}, 9 \mathrm{H}, \mathrm{C}\left(\mathrm{CH}_{3}\right)_{3}\right), 1,43\left(\mathrm{~s}, 3 \mathrm{H}, \mathrm{CH}_{3}\right), 1.26\left(\mathrm{~s}, 3 \mathrm{H}, \mathrm{CH}_{3}\right), 0.85$ (s, $\left.9 \mathrm{H}, \mathrm{SiC}\left(\mathrm{CH}_{3}\right)_{3}\right), 0.01\left(\mathrm{~s}, 6 \mathrm{H}, \mathrm{Si}\left(\mathrm{CH}_{3}\right)_{2}\right)$.

${ }^{13}$ C-NMR (75 MHz, DMSO-d6): $\delta(\mathrm{ppm})=163.3(\mathrm{C} 4), 161.6(\mathrm{COOH}), 154.3(\mathrm{C} 2), 152.1$ (Boc), 141.6 (C6), 112.3 ( $\left.\underline{\mathrm{C}}\left(\mathrm{CH}_{3}\right)_{2}\right), 93.4$ (C5), 90.6 (C1'), 89.5 (C4'), 84.5 (C2'), 82.3 (C3'), $\left.80.8\left(\mathrm{C}_{\mathrm{q}}\right), 64.0(\mathrm{C} 5), 27.8\left(\mathrm{CH}_{3}\right), 27.1\left(\mathrm{CH}_{3}\right), 25.9\left(\mathrm{SiC}(\underline{\mathrm{CH}})_{3}\right)_{3}\right), 25.1\left(\mathrm{CH}_{3}\right), 18.1\left(\mathrm{SiC}\left(\mathrm{CH}_{3}\right)_{3}\right)$, $-5.1 \mathrm{Si}\left(\mathrm{CH}_{3}\right),-5.5 \mathrm{Si}\left(\mathrm{CH}_{3}\right)$.

MS (ESI-, MeOH): m/z = 540.2 [M-H] $]^{-}$

HRMS (ESI-): m/z calc. for $\mathrm{C}_{24} \mathrm{H}_{39} \mathrm{~N}_{3} \mathrm{O}_{9} \mathrm{Si}[\mathrm{M}-\mathrm{H}]^{-}:$: 540.2383, found: 540.2383. 
6. Experimental part

\section{Synthesis of 6-carboxycytidine (59)}<smiles>CC(C)(C)CC(=O)Nc1cc(C(=O)O)n(C2OC3CC(COC(=O)c4ccccc4)OC2OC3(C)C)c(=O)n1</smiles>

$M=541,67$

56
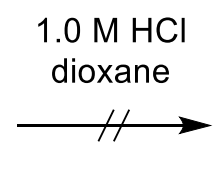

$M=287,23$

59

5'-O-tert-Butyldimethylsilyl-2',3'-O-isopropylidene-6-carboxycytidine-yl-4-tert-butylcarbamate $(130 \mathrm{mg}, 240 \mu \mathrm{mol}, 1.0$ eq.) was dissolved in ethereal $\mathrm{HCl}(1.0 \mathrm{M}, 4.0 \mathrm{~mL})$. The reaction mixture was stirred for $45 \mathrm{~min}$ at room temperature. The solvent was removed in vacuo without product formation. Instead, the glycosidic bond was cleaved.

\section{Synthesis of 6-carboxycytidine (59)}<smiles></smiles>

$M=541,67$

56

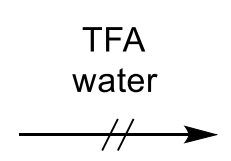

$M=287,23$

59

5'-O-tert-Butyldimethylsilyl-2',3'-O-isopropylidene-6-carboxycytidine-yl-4-tert-butylcarbamate $(130 \mathrm{mg}, 240 \mu \mathrm{mol}, 1.0 \mathrm{eq}$.) was dissolved in TFA $(10 \mathrm{~mL})$. The reaction mixture was stirred for $30 \mathrm{~min}$ at room temperature. The solvent was removed but deprotections remain incomplete. 


\section{Synthesis of 5'-O-tert-butyldimethylsilyl-2',3'-O-isopropylidenecytidine-yl-4- benzyloxycarbamate $(\mathbf{5 4})$}

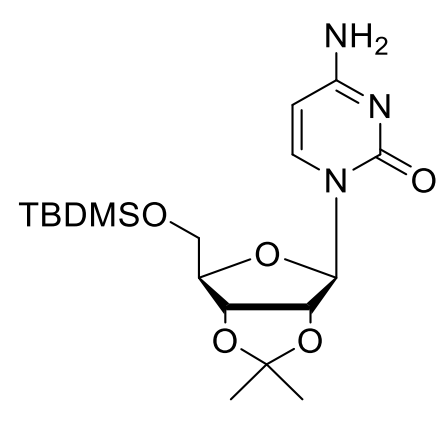

$M=397,55$

52

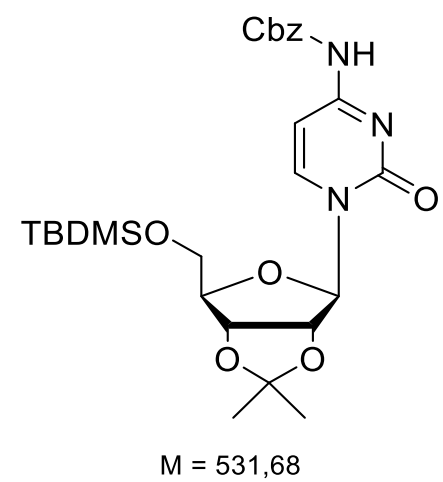

54

5'-O-tert-Butyldimethylsilyl-2',3'-O-isopropylidenecytidine (1.00 g, $2.52 \mathrm{mmol}, 1.0 \mathrm{eq}$.) was dissolved in DCM $(20 \mathrm{~mL})$ and cooled to $0^{\circ} \mathrm{C}$. $\mathrm{CbzCl}(450 \mu \mathrm{L}, 3.15 \mathrm{mmol}, 1.25$ eq. $)$ and $\mathrm{NEt}_{3}$ ( $385 \mu \mathrm{L}, 3.05 \mathrm{mmol}, 1.2 \mathrm{eq}$.) were added slowly and the solution was stirred for $1 \mathrm{~h}$ at $0^{\circ} \mathrm{C}$ and additional $20 \mathrm{~h}$ at room temperature. The solvent was evaporated in vacuo and the crude product was purified by column chromatography ( $\mathrm{SiO}_{2}$; ethyl acetate/MeOH gradient 100:0 to 95:5). The product (550 mg, $1.03 \mathrm{mmol}, 41 \%$ ) was obtained as a white solid.

${ }^{1} \mathbf{H}-\mathbf{N M R}\left(300 \mathrm{MHz}, \mathrm{CDCl}_{3}\right): \delta(\mathrm{ppm})=8.13(\mathrm{~m}, 1 \mathrm{H}, \mathrm{C} 6 \mathrm{H}), 8.08(\mathrm{sbr}, 1 \mathrm{H}, \mathrm{NH}), 7,40-7.30(\mathrm{~m}$, $\left.5 \mathrm{H}, \mathrm{C}_{\text {arom }}\right), 7.00$ (m, 1H, C5H), 5.94 (d, J = 1.7 Hz, 1H, C1'H), 5.35 (s, 2H, $\left.\mathrm{CH}_{2}\right), 4.77-4.72$ (m, 2H, C2'H, C3'H), 4.40-4.37 (m, 1H, C4'H), 3.95-3.91 (m, 1H, C5' $\left.\mathrm{H}_{2}\right), 3.80-3.75$ (m, 1H, $\left.\mathrm{C}^{\prime}{ }^{\prime} \mathrm{H}_{2}\right), 1.50\left(\mathrm{~s}, 3 \mathrm{H}, \mathrm{CH}_{3}\right), 1.27\left(\mathrm{~s}, 3 \mathrm{H}, \mathrm{CH}_{3}\right), 0.80\left(\mathrm{~s}, 9 \mathrm{H}, \mathrm{SiC}\left(\mathrm{CH}_{3}\right)_{3}\right), 0.01\left(\mathrm{~s}, 6 \mathrm{H}, \mathrm{Si}\left(\mathrm{CH}_{3}\right)_{2}\right)$. MS (ESI+, $\mathrm{MeOH}): \mathrm{m} / \mathrm{z}=532.2[\mathrm{M}+\mathrm{H}]^{+}$.

HRMS (ESI+): m/z calc. for $\mathrm{C}_{26} \mathrm{H}_{37} \mathrm{~N}_{3} \mathrm{O}_{7} \mathrm{Si}[\mathrm{M}+\mathrm{H}]^{+}:$532.2474, found: 532.2477 . 
6. Experimental part

Synthesis of 5'-O-tert-butyldimethylsilyl-2',3'-O-isopropylidene-6-carboxycytidine-yl-4benzyloxycarbamate (57)

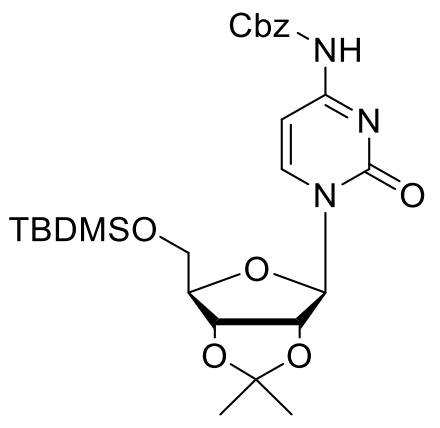

$M=531,68$
1) $\mathrm{LDA}, \mathrm{THF},-78^{\circ} \mathrm{C}$ 2) $\mathrm{CO} 2(\mathrm{~s}),-70^{\circ} \mathrm{C}$

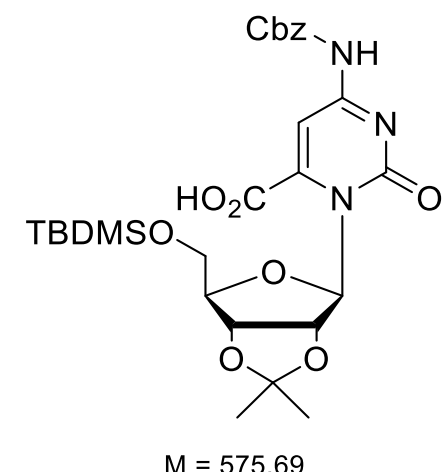

57

5'-O-tert-Butyldimethylsilyl-2',3'-O-isopropylidenecytidine-yl-4-benzyloxycarbamate ( $290 \mathrm{mg}, 545 \mu \mathrm{mol}, 1.0$ eq.) was dissolved in THF $(10 \mathrm{~mL}$ ) and the solution was cooled to $-78^{\circ} \mathrm{C}$. LDA $(2.0 \mathrm{M}, 680 \mu \mathrm{L}, 1.36 \mathrm{mmol}, 2.5$ eq. $)$ was added. The resulting brownish solution was stirred for $30 \mathrm{~min}$ at $-78^{\circ} \mathrm{C}$. Carbon dioxide was bubbled through the solution for $4 \mathrm{~h}$ at $-70^{\circ} \mathrm{C}$. The mixture was quenched by the addition of sat. aq. ammonium chloride and extracted with ethyl acetate. The solvent was evaporated in vacuo and the crude product was purified by column chromatography $\left(\mathrm{SiO}_{2}\right.$; ethyl acetate/MeOH gradient 100:0 to 95:5). The title compound (175 mg, $0.30 \mathrm{mmol}, 55 \%)$ was obtained as a white solid.

${ }^{1} \mathbf{H}-\mathrm{NMR}\left(300 \mathrm{MHz}, \mathrm{CDCl}_{3}\right): \delta(\mathrm{ppm})=8.05(\mathrm{sbr}, 1 \mathrm{H}, \mathrm{NH}), 7,40-7.28\left(\mathrm{~m}, 5 \mathrm{H}, \mathrm{C}_{\text {arom }}\right), 7.00(\mathrm{~m}$, 1H, C5H), 5.92 (d, J=1.8 Hz, 1H, C1'H), 5.35 (s, 2H, CH $), 4.77-4.72$ (m, 2H, C2'H, C3'H), 4.40-4.37 (m, 1H, C4'H), 3.95-3.91 (m, 1H, C5' $\left.\mathrm{H}_{2}\right), 3.82-3.77\left(\mathrm{~m}, 1 \mathrm{H}, \mathrm{C}^{\prime} \mathrm{H}_{2}\right), 1.49$ (s, 3H, $\left.\mathrm{CH}_{3}\right), 1.28$ (s, 3H, $\left.\mathrm{CH}_{3}\right), 0.84$ (s, 9H, $\left.\mathrm{SiC}\left(\mathrm{CH}_{3}\right)_{3}\right), 0.04$ (s, 6H, $\left.\mathrm{Si}\left(\mathrm{CH}_{3}\right)_{2}\right)$.

MS (ESI-, MeOH): m/z = 574.2 [M-H] $]^{-}$

HRMS (ESI-): $\mathrm{m} / \mathrm{z}$ calc. for $\mathrm{C}_{27} \mathrm{H}_{37} \mathrm{~N}_{3} \mathrm{O}_{9} \mathrm{Si}[\mathrm{M}-\mathrm{H}]^{-}:$574.2226, found: 574.2199. 


\section{Synthesis of 6-carboxycytidine (59)}

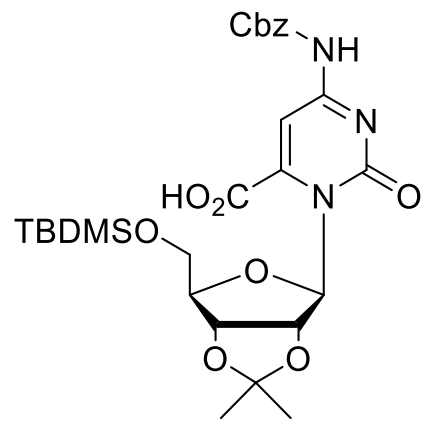

$M=575,69$

57<smiles></smiles>

$M=287,23$

59

5'-O-tert-Butyldimethylsilyl-2',3'-O-isopropylidene-6-carboxycytidine-yl-4-benzyloxycarbamate $(90 \mathrm{mg}, 156 \mu \mathrm{mol}, 1.0$ eq.) was dissolved in dioxane $\mathrm{HCl}(1.0 \mathrm{M}, 5 \mathrm{~mL})$. The reaction mixture was stirred for 45 min at room temperature. The deprotection was not successful.

\section{Synthesis of 5'-O-tert-butyldimethylsilyl-2',3'-O-isopropylidene-6-carboxycytidine (106)}<smiles>CC(C)(C)OCC1OC2OC(C)(C)OC1OC2n1c(C(=O)O)cc(NC(=O)OCc2ccccc2)nc1=O</smiles>

$M=575,69$

57

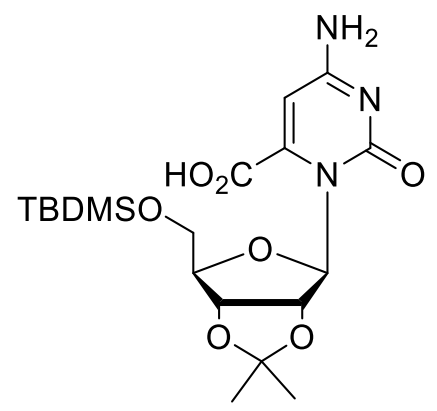

$M=441,56$

106

5'-O-tert-Butyldimethylsilyl-2',3'-O-isopropylidene-6-carboxycytidine-yl-4-benzyloxycarbamate (90 mg, $156 \mu \mathrm{mol}, 1.0$ eq.) was dissolved in $\mathrm{MeOH}(5 \mathrm{~mL})$ and $\mathrm{H}_{2} \mathrm{O}(5 \mathrm{~mL}) . \mathrm{Pd} / \mathrm{C}$ (5 wt.\%, $30 \mathrm{mg}$ ) was added and the reaction was stirred under hydrogen atmosphere for $10 \mathrm{~h}$ at room temperature. The solvent was removed under reduced pressure, but the title compound was not formed. 
6. Experimental part

Synthesis of 4-benzyl-5' -O-tert-butyldimethylsilyl-2',3'-O-isopropylidenecytidine (55)

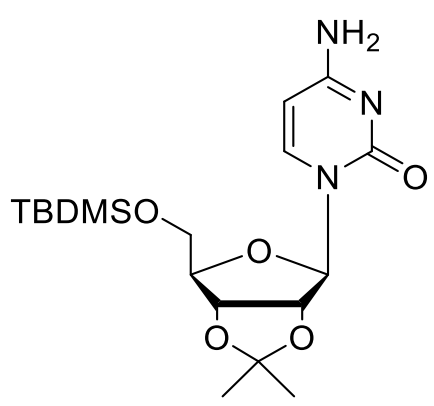

$M=397,55$

52<smiles>CC(C)(C)OS(=O)(=O)OC[C@H]1O[C@@H]2OC(C)(C)O[C@@H]1O[C@H]2n1ccc(NCc2ccccc2)nc1=O</smiles>

$M=487,67$

55

5'-O-tert-Butyldimethylsilyl-2',3'-O-isopropylidenecytidine (1.00 g, $2.52 \mathrm{mmol}, 1.0$ eq.) and potassium carbonate $(520 \mathrm{mg}, 3.78 \mathrm{mmol}, 1.5$ eq.) were dissolved in acetone $(20 \mathrm{~mL})$ and DMSO (10 mL). Benzyl chloride ( $363 \mu \mathrm{L}, 3.15 \mathrm{mmol}, 1.25$ eq.) was added slowly and the solution was stirred overnight at room temperature. The solvent was evaporated in vacuo and the crude product was purified by column chromatography $\left(\mathrm{SiO}_{2}\right.$; hexane/ethyl acetate gradient 5:1 to 3:1). The title compound $(1.15 \mathrm{~g}, 2.29 \mathrm{mmol}, 91 \%)$ was obtained as a yellowish solid.

${ }^{1} \mathbf{H}-\mathbf{N M R}\left(300 \mathrm{MHz}, \mathrm{CDCl}_{3}\right): \delta(\mathrm{ppm})=8.13(\mathrm{~m}, 1 \mathrm{H}, \mathrm{C} 6 \mathrm{H}), 8.02(\mathrm{sbr}, 1 \mathrm{H}, \mathrm{NH}), 7,35-7.24(\mathrm{~m}$, $\left.5 \mathrm{H}, \mathrm{C}_{\text {arom }}\right), 5.94(\mathrm{~d}, J=1.7 \mathrm{~Hz}, 1 \mathrm{H}, \mathrm{C} 1$ ' $\mathrm{H}), 5.82(\mathrm{~m}, 1 \mathrm{H}, \mathrm{C} 5 \mathrm{H}), 5.05\left(\mathrm{~s}, 2 \mathrm{H}, \mathrm{CH}_{2}\right), 4.77-4.72$ (m, 2H, C2'H, C3'H), 4.40-4.37 (m, 1H, C4'H), 3.95-3.91 (m, 1H, C5'H2), 3.80-3.75 (m, 1H, C5 ' $\left.\mathrm{H}_{2}\right), 1.50\left(\mathrm{~s}, 3 \mathrm{H}, \mathrm{CH}_{3}\right), 1.27$ (s, 3H, CH 3$), 0.80$ (s, 9H, $\left.\mathrm{SiC}\left(\mathrm{CH}_{3}\right)_{3}\right), 0.01\left(\mathrm{~s}, 6 \mathrm{H}, \mathrm{Si}\left(\mathrm{CH}_{3}\right)_{2}\right)$. MS (ESI+, MeOH): m/z $=488.3[\mathrm{M}+\mathrm{H}]^{+}$.

HRMS (ESI+): $\mathrm{m} / \mathrm{z}$ calc. for $\mathrm{C}_{25} \mathrm{H}_{37} \mathrm{~N}_{3} \mathrm{O}_{5} \mathrm{Si}[\mathrm{M}+\mathrm{H}]^{+}:$488.2634, found: 488.2628 . 


\section{Synthesis of}

\section{4-benzyl-5'-O-tert-butyldimethylsilyl-2',3'-O-isopropylidene-6-carboxycytidine (58)}<smiles>CC(C)COCC1OC2OC(n3ccc(NCc4ccccc4)nc3=O)C1OC(C)(C)O2</smiles>

55

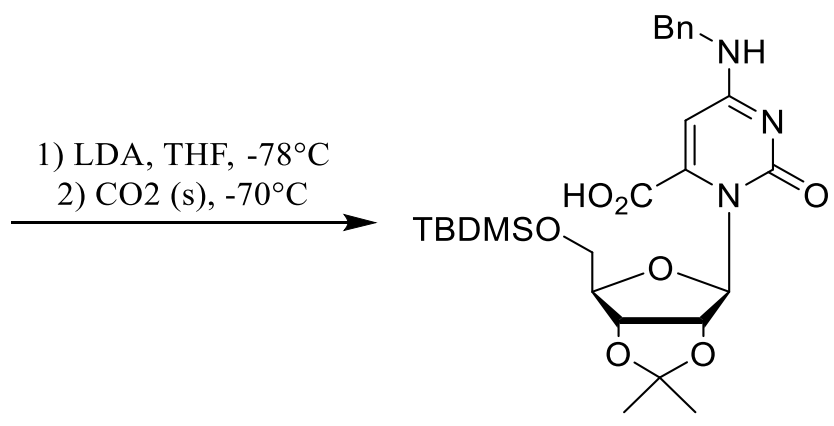

$M=531,68$

58

4-Benzyl-5'-O-tert-butyldimethylsilyl-2',3'-O-isopropylidenecytidine (500 mg, $1.03 \mathrm{mmol}$, 1.0 eq.) was dissolved in THF $(15 \mathrm{~mL})$ and the solution was cooled to $-78^{\circ} \mathrm{C}$. Then, LDA (2.0 M, $1.29 \mathrm{~mL}, 2.58 \mathrm{mmol}, 2.5$ eq.) was added and the reaction mixture was stirred at $-78^{\circ} \mathrm{C}$ for $30 \mathrm{~min}$. Carbon dioxide was bubbled through the solution for $4 \mathrm{~h}$ at $-70^{\circ} \mathrm{C}$. The mixture was quenched by the addition of sat. aq. $\mathrm{NH}_{4} \mathrm{Cl}$ and extracted with EtOAc. The solvent was evaporated in vacuo and the crude product was purified by column chromatography $\left(\mathrm{SiO}_{2}\right.$; ethyl acetate/MeOH gradient 100:0 to 95:5). The title compound (191 mg, $0.36 \mathrm{mmol}, 35 \%$ ) was obtained as a white solid.

${ }^{1}$ H-NMR (300 MHz, $\left.\mathrm{CDCl}_{3}\right): \delta(\mathrm{ppm})=8.03(\mathrm{sbr}, 1 \mathrm{H}, \mathrm{NH}), 7.55-7.35\left(\mathrm{~m}, 5 \mathrm{H}, \mathrm{C}_{\text {arom}}\right), 7.00$ (m, 1H, C5H), 5.95 (d, J = 1.7 Hz, 1H, C1'H), 5.35 (s, 2H, CH $), 4.77-4.72$ (m, 2H, C2'H, C3'H), 4.40-4.37 (m, 1H, C4'H), 3.95-3.91 (m, 1H, C5' $\left.{ }^{\prime} \mathrm{H}_{2}\right), 3.80-3.75$ (m, 1H, C5' $\left.\mathrm{H}_{2}\right), 1.48$ (s, 3H, $\left.\mathrm{CH}_{3}\right), 1.26$ (s, 3H, $\left.\mathrm{CH}_{3}\right), 0.82$ (s, 9H, $\left.\mathrm{SiC}\left(\mathrm{CH}_{3}\right)_{3}\right), 0.03$ (s, 6H, $\left.\mathrm{Si}\left(\mathrm{CH}_{3}\right)_{2}\right)$.

MS (ESI-, MeOH): m/z = 530.2 [M-H] . 
6. Experimental part

Synthesis of 5'-O-tert-butyldimethylsilyl-2',3'-O-isopropylidene-6-carboxycytidine (106)

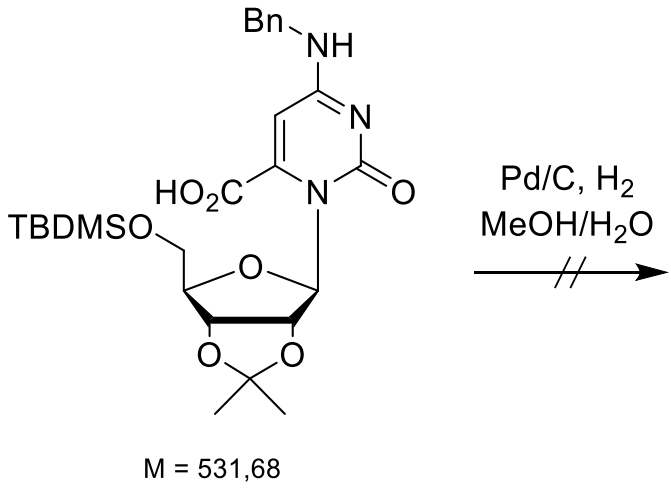

58<smiles>CC(C)COCC1O[C@H]2O[C@@H](n3c(C(=O)O)cc(N)nc3=O)[C@H]1OC(C)(C)O2</smiles>

106

4-Benzyl-5'-O-tert-butyldimethylsilyl-2',3'-O-isopropylidene-6-carboxycytidine

(95 mg, $178 \mu \mathrm{mol}, 1.0$ eq.) was dissolved in $\mathrm{MeOH}(4.0 \mathrm{~mL})$ and $\mathrm{H}_{2} \mathrm{O}$ (4.0 mL). $\mathrm{Pd} / \mathrm{C}(5 \mathrm{wt} . \%, 30 \mathrm{mg})$ was added and the reaction was stirred under hydrogen atmosphere for $10 \mathrm{~h}$ at room temperature. The solvent was removed under reduced pressure, but the title compound was not formed.

Synthesis of 5'-O-tert-butyldimethylsilyl-2',3'- $O$-isopropylidene-6-carboxycytidine (106)<smiles>CC(C)CC(=O)OCC1OC2OC(C)(C)OC1C1OC2OC1C(=O)O</smiles>

$M=531,68$

58

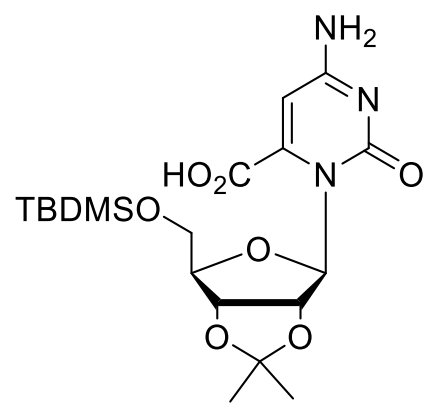

$M=441,56$

106

4-Benzyl-5'-O-tert-Butyldimethylsilyl-2',3'-O-isopropylidene-6-carboxycytidine $\quad$ (95 mg, $178 \mu \mathrm{mol}, 1.0$ eq. $)$ was dissolved in DCM $(7.0 \mathrm{~mL})$ and cooled to $-78^{\circ} \mathrm{C}$. Then, pentamethyl benzene ( $144 \mu \mathrm{L}, 890 \mu \mathrm{mol}, 5.0$ eq.) and $\mathrm{BCl}_{3}(1.0 \mathrm{M}, 356 \mathrm{~mL}, 356 \mu \mathrm{mol}, 2.0$ eq.) were added and the reaction was stirred for $20 \mathrm{~min}$ at $-78^{\circ} \mathrm{C}$. The solvent was removed under reduced pressure, but the deprotection was not observed. 


\section{Synthesis of 5-bromocytidine (60)}

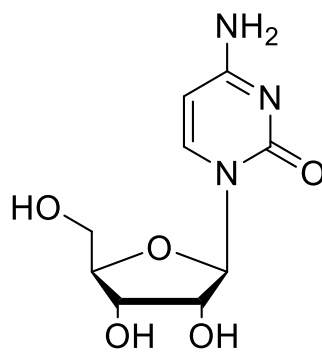

$M=243,22$

50

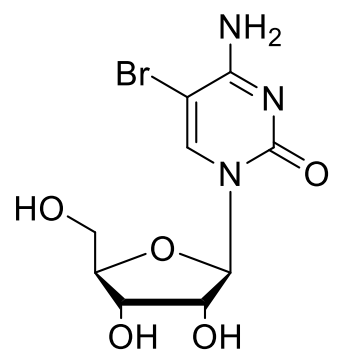

$M=322,12$

60

Cytidine (3.00 g, $12.3 \mathrm{mmol}, 1.0$ eq.) was dissolved in $\mathrm{MeCN}(250 \mathrm{~mL})$ and water $(25 \mathrm{~mL})$. Then, $\mathrm{NaN}_{3}(2.50 \mathrm{~g}, 38.3 \mathrm{mmol}, 3.1$ eq.) and SMBI (2.92 g, 12.9 mmol, 1.0 eq.) were added and the mixture stirred for $3 \mathrm{~h}$. After $1 \mathrm{~h}$ and $2 \mathrm{~h}$ additional SMBI (0.57 g, $2.48 \mathrm{mmol}, 0.2 \mathrm{eq}$.) was added portion wise respectively. Then, the reaction mixture was filtered and the solvent was removed under reduced pressure. The crude product was purified by column chromatography $\left(\mathrm{SiO}_{2} ; \mathrm{DCM} / \mathrm{MeOH}\right.$, gradient 20:1 to 10:1) to afford 5-bromocytidine (2.56 g, $8.0 \mathrm{mmol}, 65 \%$ ) as a light-yellow solid.

${ }^{1}$ H-NMR $\left(300 \mathrm{MHz}\right.$, DMSO- $\left.d_{6}\right): \delta(\mathrm{ppm})=8.38(\mathrm{~s}, 1 \mathrm{H}, \mathrm{C} 6 \mathrm{H}), 7.00$ (sbr, 1H), $5.71(\mathrm{~d}$, $\left.J=3.2 \mathrm{~Hz}, 1 \mathrm{H}, \mathrm{C} 1{ }^{\prime} \mathrm{H}\right), 3.98-3.92$ (m, 2H, C2' $\left.\mathrm{H}, \mathrm{C} 3{ }^{\prime} \mathrm{H}\right), 3.85-3.82$ (m, 1H, C4'H), 3.72-3.67 (m, $\left.1 \mathrm{H}, \mathrm{C}^{\prime} \mathrm{H}_{2}\right), 3.58-3.53\left(\mathrm{~m}, 1 \mathrm{H}, \mathrm{C}^{\prime} \mathrm{H}_{2}\right)$.

${ }^{13}$ C-NMR (75 MHz, DMSO- $\left.d_{6}\right): \delta(\mathrm{ppm})=161.8(\mathrm{C} 4), 153.9$ (C2), 142.3 (C6), 89.5 (C1'), 86.2 (C5), $84.1\left(\mathrm{C} 4^{\circ}\right), 74.3\left(\mathrm{C}^{\circ}\right), 68.8\left(\mathrm{C} 3^{\circ}\right), 59.9\left(\mathrm{C} 5^{\circ}\right)$.

HRMS (ESI+): $\mathrm{m} / \mathrm{z}$ calc. for $\mathrm{C}_{9} \mathrm{H}_{12}{ }^{79} \mathrm{Br}_{1} \mathrm{~N}_{3} \mathrm{O}_{5}[\mathrm{M}+\mathrm{H}]^{+}: 322.0033$, found: 322.0033 .

(ESI+): $\mathrm{m} / \mathrm{z}$ calc. for $\mathrm{C}_{9} \mathrm{H}_{12}{ }^{81} \mathrm{Br}_{1} \mathrm{~N}_{3} \mathrm{O}_{5}[\mathrm{M}+\mathrm{H}]^{+}:$324.0013, found: 324.0012 .

(ESI+): m/z calc. for $\mathrm{C}_{9} \mathrm{H}_{12}{ }^{79} \mathrm{Br}_{1} \mathrm{~N}_{3} \mathrm{O}_{5}[\mathrm{M}+\mathrm{Na}]^{+}:$343.9853, found: 343.9851 .

(ESI+): $\mathrm{m} / \mathrm{z}$ calc. for $\mathrm{C}_{9} \mathrm{H}_{12}{ }^{81} \mathrm{Br}_{1} \mathrm{~N}_{3} \mathrm{O}_{5}[\mathrm{M}+\mathrm{Na}]^{+}:$345.9833, found: 345.9835 . 
6. Experimental part

\section{Synthesis of 2',3'- $O$-isopropylidene-5-bromocytidine (61)}<smiles>Nc1nc(=O)n(C2OC(CO)C(O)C2O)cc1Br</smiles>

$M=322,12$

60<smiles>CC1(C)O[C@H]2[C@@H](CO)O[C@H](O[C@H]2n2cc(Br)c(N)nc2=O)O1</smiles>

$M=362,18$

61

To a stirred suspension of 5-bromocytidine $(3.57 \mathrm{~g}, 11.1 \mathrm{mmol}, 1.0$ eq. $)$ in acetone $(200 \mathrm{~mL})$, $\mathrm{HClO}_{4}(70 \%, 1.60 \mathrm{~mL})$ was added and the resulting solution was stirred for $3 \mathrm{~h}$ at room temperature. The mixture was quenched with $\mathrm{NEt}_{3}(5.0 \mathrm{~mL})$ and the solvent was evaporated in vасио. The crude product was purified by column chromatography $\left(\mathrm{SiO}_{2} ; \mathrm{EtOAc} / \mathrm{MeOH} 20: 1\right)$. The title compound (3.32 g, $9.2 \mathrm{mmol}, 83 \%)$ was obtained as a yellow solid.

TLC, $R_{\mathrm{f}}=0.15 \mathrm{EtOAc} / \mathrm{MeOH}(20: 1)$.

${ }^{1}$ H-NMR (300 MHz, DMSO-d6): $\delta(\mathrm{ppm})=8.20(\mathrm{~s}, 1 \mathrm{H}, \mathrm{C} 6 \mathrm{H}), 7.93\left(\mathrm{sbr}, 1 \mathrm{H}, \mathrm{NH}_{2}\right), 7.07(\mathrm{sbr}$, 1H, $\left.\mathrm{NH}_{2}\right), 5.79$ (s, 1H, C1'H), 4.84 (m, 1H, C2' $\left.\mathrm{H}\right), 4.77$ (m, 1H, C3'H), 4.09 (m, 1H, C4'H), $3.58\left(\mathrm{~m}, 2 \mathrm{H}, \mathrm{C}^{\prime} \mathrm{H}_{2}\right), 1.47$ (s, 3H, $\left.\mathrm{CH}_{3}\right), 1.27$ (s, 3H, $\left.\mathrm{CH}_{3}\right)$.

${ }^{13}$ C-NMR $\left(75 \mathrm{MHz}\right.$, DMSO- $\left.d_{6}\right): \delta(\mathrm{ppm})=162.1$ (C4), 153.5 (C2), 143.5 (C6), 112.7 $\left(\underline{\mathrm{C}}\left(\mathrm{CH}_{3}\right)_{2}\right), 92.4\left(\mathrm{C} 1^{\prime}\right), 87.0$ (C5), 86.5 (C4'), 84.3 (C2'), $80.4\left(\mathrm{C}^{\prime}{ }^{\prime}\right), 61.3\left(\mathrm{C}^{\prime}\right.$ '), $27.1\left(\mathrm{CH}_{3}\right)$, $25.2\left(\mathrm{CH}_{3}\right)$.

MS $(\mathrm{ESI}+\mathrm{MeOH}): \mathrm{m} / \mathrm{z}=384.0[\mathrm{M}+\mathrm{Na}]^{+}$.

HRMS (ESI+): $\mathrm{m} / \mathrm{z}$ calc. for $\mathrm{C}_{12} \mathrm{H}_{16}{ }^{79} \mathrm{Br}_{1} \mathrm{~N}_{3} \mathrm{O}_{5}[\mathrm{M}+\mathrm{H}]^{+}:$362.0346, found: 362.0345. (ESI+): $\mathrm{m} / \mathrm{z}$ calc. for $\mathrm{C}_{12} \mathrm{H}_{16}{ }^{81} \mathrm{Br}_{1} \mathrm{~N}_{3} \mathrm{O}_{5}[\mathrm{M}+\mathrm{H}]^{+}:$364.0326, found: 364.0334 . (ESI+): $\mathrm{m} / \mathrm{z}$ calc. for $\mathrm{C}_{12} \mathrm{H}_{16}{ }^{79} \mathrm{Br}_{1} \mathrm{~N}_{3} \mathrm{O}_{5}$ [M+Na] $]^{+}$: 384.0166, found: 384.0167. (ESI+): $\mathrm{m} / \mathrm{z}$ calc. for $\mathrm{C}_{12} \mathrm{H}_{16}{ }^{81} \mathrm{Br}_{1} \mathrm{~N}_{3} \mathrm{O}_{5}[\mathrm{M}+\mathrm{Na}]^{+}:$386.0146, found: 386.0140. 


\section{Synthesis of 5'-O-tert-butyldimethylsilyl-2',3'-O-isopropylidene-5-bromocytidine (62)}

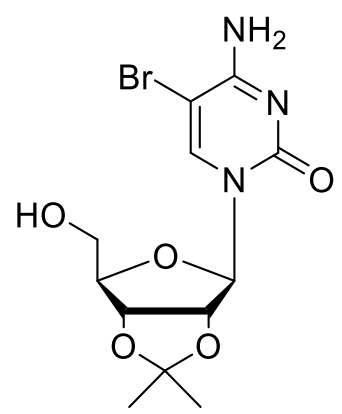

$M=362,18$

61

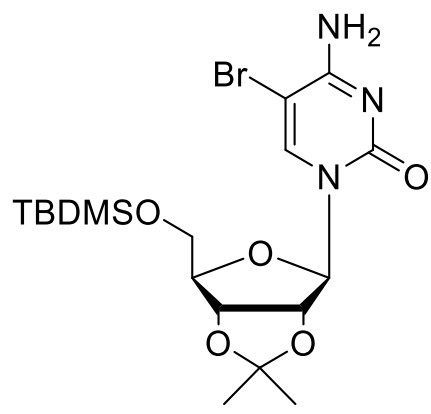

$M=476,44$

62

2',3'-O-isopropylidene-5-bromocytidine (3.33 g, $9.20 \mathrm{mmol}, 1.0$ eq.), imidazole (1.55 g, $22.4 \mathrm{mmol}, 2.4$ eq.) and TBDMSCl (2.67 g, $17.7 \mathrm{mmol}, 1.9$ eq.) were dissolved in DMF $(20 \mathrm{~mL})$ and the solution was stirred for $22 \mathrm{~h}$ at room temperature. The solvent was evaporated in vacuo and the crude product was purified by column chromatography $\left(\mathrm{SiO}_{2} ; \mathrm{EtOAc} / \mathrm{MeOH}\right.$ gradient 99:1 to 97:3). The product (3.58 g, $7.52 \mathrm{mmol}, 82 \%)$ was obtained as a white solid.

TLC, $R_{\mathrm{f}}=0.18$ EtOAc $(100 \%)$.

${ }^{1} \mathbf{H}-\mathbf{N M R}\left(300 \mathrm{MHz}, \mathrm{CDCl}_{3}\right): \delta(\mathrm{ppm})=7.94(\mathrm{~s}, 1 \mathrm{H}, \mathrm{C} 6 \mathrm{H}), 5.87(\mathrm{~s}, 1 \mathrm{H}, \mathrm{C} 1$ 'H) 4.69 (m, 2H, C2'H, C3'H), 4.38 (m, 1H, C4'H), 3.95-3.91(m, 1H, C5' $\mathrm{H}_{2}$ ), 3.80-3.75 (m, 1H, C5' $\mathrm{H}_{2}$ ), 1.55 (s, $\left.3 \mathrm{H}, \mathrm{CH}_{3}\right), 1.33\left(\mathrm{~s}, 3 \mathrm{H}, \mathrm{CH}_{3}\right), 0.88\left(\mathrm{~s}, 9 \mathrm{H}, \mathrm{C}\left(\mathrm{CH}_{3}\right)_{3}\right), 0.06\left(\mathrm{~s}, 6 \mathrm{H}, \mathrm{Si}\left(\mathrm{CH}_{3}\right)_{2}\right)$.

${ }^{13} \mathrm{C}-\mathrm{NMR}\left(75 \mathrm{MHz}, \mathrm{CDCl}_{3}\right): \delta(\mathrm{ppm})=162.3(\mathrm{C} 4), 154.5(\mathrm{C} 2), 141.8(\mathrm{C} 6), 113.7\left(\underline{\mathrm{C}}\left(\mathrm{CH}_{3}\right)_{2}\right)$, 94.4 (C1'), 87.7 (C5), 86.5 (C4'), 84.3 (C2'), 80.7 (C3'), 63.5 (C5'), 27.3 (CH3), $26.1\left(\mathrm{C}\left(\mathrm{CH}_{3}\right)_{3}\right), 25.4\left(\mathrm{CH}_{3}\right), 18.5(\mathrm{Cq}),-5.2\left(\mathrm{Si}\left(\mathrm{CH}_{3}\right)\right),-5.3\left(\mathrm{Si}\left(\mathrm{CH}_{3}\right)\right)$.

MS (ESI+, MeOH): m/z = 478.1 $[\mathrm{M}+\mathrm{H}]^{+}, 953.3[2 \mathrm{M}+\mathrm{H}]^{+}$.

HRMS (ESI+): m/z calc. for $\mathrm{C}_{18} \mathrm{H}_{30}{ }^{79} \mathrm{Br}_{1} \mathrm{~N}_{3} \mathrm{O}_{5}[\mathrm{M}+\mathrm{H}]^{+}:$: 476.1211, found: 476.1200 .

(ESI+): m/z calc. for $\mathrm{C}_{18} \mathrm{H}_{30}{ }^{81} \mathrm{Br}_{1} \mathrm{~N}_{3} \mathrm{O}_{5}[\mathrm{M}+\mathrm{H}]^{+}:$478.1191, found: 478.1184.

(ESI+): $\mathrm{m} / \mathrm{z}$ calc. for $\mathrm{C}_{18} \mathrm{H}_{30}{ }^{79} \mathrm{Br}_{1} \mathrm{~N}_{3} \mathrm{O}_{5}[\mathrm{M}+\mathrm{Na}]^{+}:$498.1030, found: 498.1018 . (ESI+): m/z calc. for $\mathrm{C}_{18} \mathrm{H}_{30}{ }^{81} \mathrm{Br}_{1} \mathrm{~N}_{3} \mathrm{O}_{5}[\mathrm{M}+\mathrm{Na}]^{+}:$500.1011, found: 500.1004 . 
6. Experimental part

\section{Synthesis of 5'-O-tert-butyldimethylsilyl-2',3'-O-isopropylidene-6-cyanocytidine (63)}

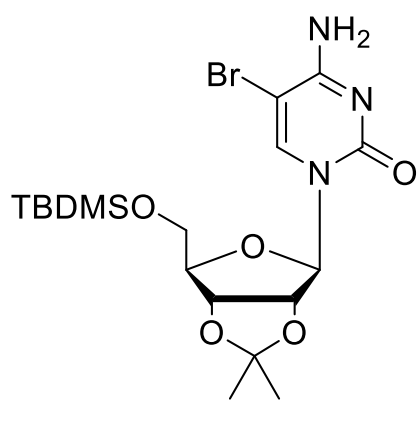

$M=476,44$

62

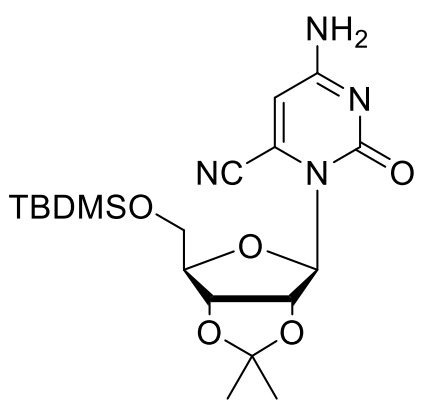

$M=422,56$

63

5'-O-tert-Butyldimethylsilyl-2',3'-O-isopropylidene-5-bromocytidine (325 mg, $0.70 \mathrm{mmol}$, 1.0 eq.), potassium cyanide (50.1 mg, $0.77 \mathrm{mmol}, 1.1$ eq.) and 18-crown-6 (20.3 mg, $0.08 \mathrm{mmol}, 0.1$ eq.) were dissolved in DMF $(15 \mathrm{~mL})$. The reaction mixture was stirred overnight at room temperature. The solvent was removed in vacuo. The crude product was purified by column chromatography $\left(\mathrm{SiO}_{2}\right.$; hexane/ EtOAc, gradient 3:1 to 5:95) to obtain the product (160 mg, $0.38 \mathrm{mmol}, 54 \%)$ as a light-yellow solid.

TLC, $R_{\mathrm{f}}=0.48$ EtOAc $(100 \%)$.

${ }^{1} \mathbf{H}-\mathbf{N M R}\left(300 \mathrm{MHz}, \mathrm{CDCl}_{3}\right): \delta(\mathrm{ppm})=6.37(\mathrm{~s}, 1 \mathrm{H}, \mathrm{C} 5 \mathrm{H}), 6.03\left(\mathrm{~d}, J=1.9 \mathrm{~Hz}, 1 \mathrm{H}, \mathrm{C} 1^{\prime} \mathrm{H}\right)$, $5.16\left(\mathrm{dd}, J=6.5,1.8 \mathrm{~Hz}, 1 \mathrm{H}, \mathrm{C} 2{ }^{\prime} \mathrm{H}\right), 4.78$ (m, 1H, C3’H), 4.19 (m, 1H, C4'H), 3.92(m, 2H, C5' $\left.{ }^{\prime} \mathrm{H}_{2}\right), 1.57$ (s, 3H, $\left.\mathrm{CH}_{3}\right), 1.34$ (s, 3H, $\left.\mathrm{CH}_{3}\right), 0.89$ (s, 9H, C(CH $\left.\mathrm{CH}_{3}\right), 0.08$ (s, 6H, $\left.\mathrm{Si}\left(\mathrm{CH}_{3}\right)_{2}\right)$.

${ }^{13}$ C-NMR (75 MHz, $\left.\mathrm{CDCl}_{3}\right): \delta(\mathrm{ppm})=164.2(\mathrm{C} 4), 153.7(\mathrm{C} 2), 126.2(\mathrm{C} 6), 114.2\left(\underline{\mathrm{C}}\left(\mathrm{CH}_{3}\right)_{2}\right)$, 111.3 (CN), 105.2 (C5) 95.0 (C1'), 89.2 (C4'), 84.1 (C2'), 81.8 (C3'), 63.9 (C5'), 27.3 (CH3), $26.1\left(\mathrm{SiC}\left(\underline{\mathrm{CH}}_{3}\right)_{3}\right), 25.5\left(\mathrm{CH}_{3}\right), 18.0\left(\underline{\mathrm{C}}\left(\mathrm{CH}_{3}\right)_{3}\right),-5.0\left(\mathrm{Si}\left(\mathrm{CH}_{3}\right)_{2}\right)$.

MS (ESI+, MeOH): m/z = $423.2[\mathrm{M}+\mathrm{H}]^{+}, 845.4[2 \mathrm{M}+\mathrm{H}]^{+}$.

HRMS (ESI+): $\mathrm{m} / \mathrm{z}$ calc. for $\mathrm{C}_{19} \mathrm{H}_{30} \mathrm{~N}_{4} \mathrm{O}_{5}[\mathrm{M}+\mathrm{H}]^{+}: 423.2058$, found: 423.2059 .

(ESI+): m/z calc. for $\mathrm{C}_{19} \mathrm{H}_{30} \mathrm{~N}_{4} \mathrm{O}_{5}[\mathrm{M}+\mathrm{Na}]^{+}:$445.1878, found: 445.1878 .

(ESI+): m/z calc. for $\mathrm{C}_{19} \mathrm{H}_{30} \mathrm{~N}_{4} \mathrm{O}_{5}[\mathrm{M}+\mathrm{K}]^{+}: 461.1617$, found: 461.1627 . 


\section{Synthesis of 5'-O-tert-butyldimethylsilyl-2',3'-O-isopropylidene-6-amidocytidine (66)}

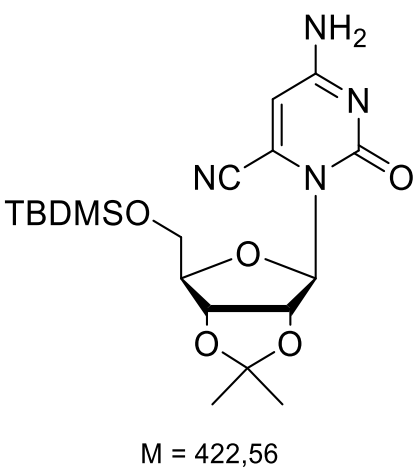

63

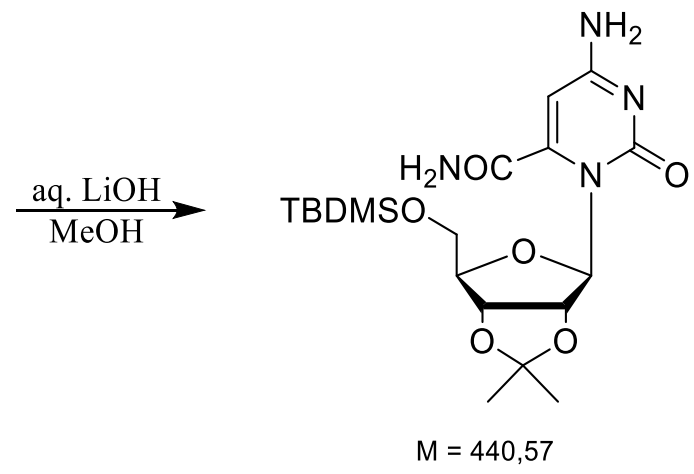

66

5'-O-tert-Butyldimethylsilyl-2',3'-O-isopropylidene-6-cyanocytidine $\quad(250 \mathrm{mg}, \quad 0.59 \mathrm{mmol}$, 1.00 eq.) was dissolved in $\mathrm{MeOH}(6.0 \mathrm{~mL})$. Then, aq. $\mathrm{LiOH}(1.0 \mathrm{M}, 0.75 \mathrm{~mL}, 0.75 \mathrm{mmol}$, 1.25 eq.) was added and the reaction mixture was heated for $1 \mathrm{~h}$ to $50^{\circ} \mathrm{C}$ and stirred additional $18 \mathrm{~h}$ at room temperature. The solvent was removed in vacuo and the crude product was purified by column chromatography $\left(\mathrm{SiO}_{2} ; \mathrm{EtOAc} / \mathrm{MeOH}, 95: 5\right)$ to obtain the title compound (149 $\mathrm{mg}$, $0.34 \mathrm{mmol}, 57 \%$ ) as a light-yellow oil.

TLC, $R_{\mathrm{f}}=0.19 \mathrm{EtOAc} / \mathrm{MeOH}(95: 5)$.

${ }^{1}$ H-NMR (300 MHz, DMSO- $\left.d_{6}\right): \delta(\mathrm{ppm})=8.43\left(\mathrm{sbr}, 1 \mathrm{H}, \mathrm{NH}_{2}\right), 8.01\left(\mathrm{sbr}, 1 \mathrm{H}, \mathrm{NH}_{2}\right), 7.51(\mathrm{sbr}$, $\left.1 \mathrm{H}, \mathrm{NH}_{2}\right), 7.46\left(\mathrm{sbr}, 1 \mathrm{H}, \mathrm{NH}_{2}\right), 5.74(\mathrm{~s}, 1 \mathrm{H}, \mathrm{C} 5 \mathrm{H}), 5.62$ (d, $J=1.5 \mathrm{~Hz}, 1 \mathrm{H}, \mathrm{C} 1$ 'H), 5.10 (dd, $\left.J=6.5,1.4 \mathrm{~Hz}, 1 \mathrm{H}, \mathrm{C} 2{ }^{\prime} \mathrm{H}\right), 4.79-4.71$ (m, 1H, C3'H), 3.95-3.89 (m, 1H, C4'H), 3.63-3.48 (m, $\left.2 \mathrm{H}, \mathrm{C}^{\prime} \mathrm{H}_{2}\right), 1.43\left(\mathrm{~s}, 3 \mathrm{H}, \mathrm{CH}_{3}\right), 1.26\left(\mathrm{~s}, 3 \mathrm{H}, \mathrm{CH}_{3}\right), 0.87$ (s, 9H, $\left.\mathrm{C}\left(\mathrm{CH}_{3}\right)_{3}\right), 0.04\left(\mathrm{~s}, 6 \mathrm{H}, \mathrm{Si}\left(\mathrm{CH}_{3}\right)_{2}\right)$.

${ }^{13}$ C-NMR $\left(75 \mathrm{MHz}, \mathrm{DMSO}-d_{6}\right): \delta(\mathrm{ppm})=165.8\left(\mathrm{CONH}_{2}\right), 164.3(\mathrm{C} 4), 155.1(\mathrm{C} 2), 151.3$ (C6), 112.9 ( $\left.\underline{\mathrm{C}}\left(\mathrm{CH}_{3}\right)_{2}\right), 93.8$ (C5) 93.2 (C1'), 89.2 (C4'), 84.7 (C2'), 82.4 (C3'), 62.4 (C5'), $27.3\left(\mathrm{CH}_{3}\right), 26.1\left(\mathrm{SiC}\left(\underline{\mathrm{CH}_{3}}\right)_{3}\right), 25.5\left(\mathrm{CH}_{3}\right), 17.9\left(\underline{\mathrm{C}}\left(\mathrm{CH}_{3}\right)_{3}\right),-5.2\left(\mathrm{Si}\left(\mathrm{CH}_{3}\right)_{2}\right)$.

MS (ESI+, MeOH): m/z = 441.2[M+H] $]^{+}, 463.2[\mathrm{M}+\mathrm{Na}]^{+}$.

HRMS (ESI+): $\mathrm{m} / \mathrm{z}$ calc. for $\mathrm{C}_{19} \mathrm{H}_{32} \mathrm{~N}_{4} \mathrm{O}_{6}[\mathrm{M}+\mathrm{H}]^{+}:$441.2164, found: 441.2161 .

(ESI+): m/z calc. for $\mathrm{C}_{19} \mathrm{H}_{32} \mathrm{~N}_{4} \mathrm{O}_{6}[\mathrm{M}+\mathrm{Na}]^{+}:$463.1983, found: 463.1972 . 
6. Experimental part

\section{Synthesis of 5'-O-tert-butyldimethylsilyl-2',3'-O-isopropylidene-6-carboxycytidine (65)}

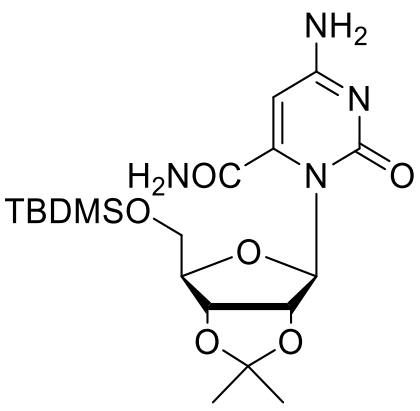

$M=440,57$

66

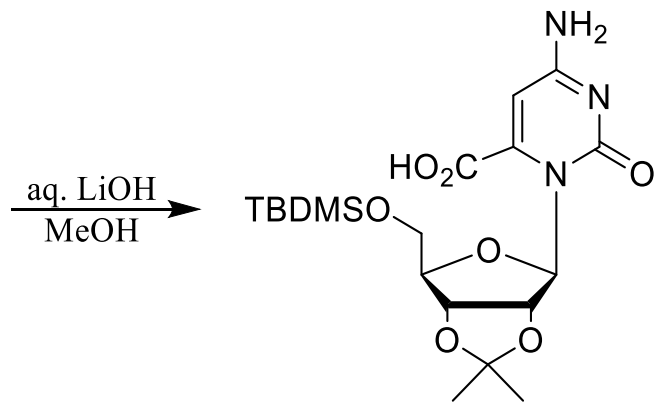

$M=441,56$

65

5'-O-tert-Butyldimethylsilyl-2',3'-O-isopropylidene-6-amidocytidine $\quad(149 \mathrm{mg}, \quad 0.34 \mathrm{mmol}$, 1.00 eq.) was dissolved in $\mathrm{MeOH}(6.0 \mathrm{~mL})$. Then, aq. $\mathrm{LiOH}(1.0 \mathrm{M}, 1.67 \mathrm{~mL}, 1.67 \mathrm{mmol}$, 5.0 eq.) was added and the reaction mixture was heated for $15 \mathrm{~h}$ to $60^{\circ} \mathrm{C}$. The solvent was removed in vacuo and the crude product was purified by column chromatography $\left(\mathrm{SiO}_{2}\right.$; EtOAc/MeOH, gradient 95:5 to 50:50) to obtain the title compound (89 mg, $0.20 \mathrm{mmol}, 59 \%$ ) as a light-yellow solid.

TLC, $R_{\mathrm{f}}=0.18 \mathrm{EtOAc} / \mathrm{MeOH}(4: 1)$.

${ }^{1}$ H-NMR (300 MHz, DMSO- $\left.d_{6}\right): \delta(\mathrm{ppm})=5.76(\mathrm{~s}, 1 \mathrm{H}, \mathrm{C} 5 \mathrm{H}), 5.61\left(\mathrm{~d}, J=1.5 \mathrm{~Hz}, 1 \mathrm{H}, \mathrm{C} 1^{\prime} \mathrm{H}\right)$, $5.11\left(\mathrm{dd}, J=6.5,1.4 \mathrm{~Hz}, 1 \mathrm{H}, \mathrm{C} 2^{\prime} \mathrm{H}\right), 4.79-4.72$ (m, 1H, C3'H), 3.95-3.90 (m, 1H, C4'H), 3.62-3.49 (m, 2H, C5' $\left.\mathrm{H}_{2}\right), 1.42\left(\mathrm{~s}, 3 \mathrm{H}, \mathrm{CH}_{3}\right), 1.27$ (s, 3H, $\left.\mathrm{CH}_{3}\right), 0.89$ (s, 9H, C( $\left.\left.\mathrm{CH}_{3}\right)_{3}\right), 0.06$ (s, $\left.6 \mathrm{H}, \mathrm{Si}\left(\mathrm{CH}_{3}\right)_{2}\right)$.

HRMS (ESI-): m/z calc. for $\mathrm{C}_{19} \mathrm{H}_{32} \mathrm{~N}_{4} \mathrm{O}_{6}[\mathrm{M}-\mathrm{H}]^{-}: 440.1859$, found: 440.1844 . 


\section{Synthesis of 5'-O-tert-butyldimethylsilyl-2',3'-O-isopropylidene-6- methoxycarboximidocytidine (108)}

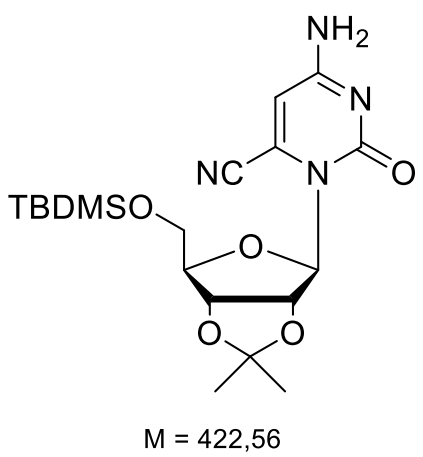

63

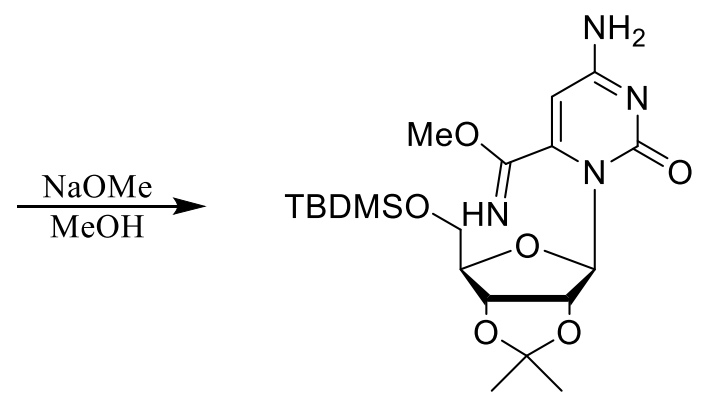

$M=454,60$

108

5'-O-tert-Butyldimethylsilyl-2',3'-O-isopropylidene-6-cyanocytidine $\quad(1.0 \mathrm{~g}, \quad 2.37 \mathrm{mmol}$, 1.0 eq.) was dissolved in $\mathrm{MeOH}(10.0 \mathrm{~mL})$. Then, $\mathrm{NaOMe}(15.0 \mathrm{~mL}, 3.25 \mathrm{mmol}, 1.4$ eq.) was added and the reaction mixture was stirred fro16 $\mathrm{h}$ at room temperature. The solvent was removed in vacuo and the crude product was purified by column chromatography $\left(\mathrm{SiO}_{2}\right.$; EtOAc/MeOH, 95:5) to obtain the title compound (240 mg, $528 \mu \mathrm{mol}, 22 \%$ ) as a light-yellow oil.

${ }^{1}$ H-NMR $\left(300 \mathrm{MHz}, \mathrm{CDCl}_{3}\right): \delta(\mathrm{ppm})=8.25(\mathrm{sbr}, 1 \mathrm{H}, \mathrm{NH}), 5.86(\mathrm{~s}, 1 \mathrm{H}, \mathrm{C} 5 \mathrm{H}), 5.45(\mathrm{~s}, 1 \mathrm{H}$, C1’H), 5.25 (m, 1H, C2’H), $4.86\left(\mathrm{~m}, 1 \mathrm{H}, \mathrm{C} 3{ }^{\prime} \mathrm{H}\right), 4.18\left(\mathrm{~m}, 1 \mathrm{H}, \mathrm{C} 4{ }^{\prime} \mathrm{H}\right), 3.92\left(\mathrm{~s}, 3 \mathrm{H}, \mathrm{OCH}_{3}\right)$, 3.88-3.85 (m, 2H, C5' $\left.\mathrm{H}_{2}\right), 1.53$ (s, 3H, CH 3$), 1.34$ (s, 3H, CH 3$), 0.89$ (s, 9H, C( $\left.\left.\mathrm{CH}_{3}\right)_{3}\right), 0.05$ (s, $\left.6 \mathrm{H}, \mathrm{Si}\left(\mathrm{CH}_{3}\right)_{2}\right)$.

MS (ESI+, MeOH): m/z = 455.2[M+H $]^{+}, 478.1[\mathrm{M}+\mathrm{Na}]^{+}$.

HRMS (ESI+): m/z calc. for $\mathrm{C}_{20} \mathrm{H}_{34} \mathrm{~N}_{4} \mathrm{O}_{6} \mathrm{Si}[\mathrm{M}+\mathrm{H}]^{+}:$455.2320, found: 455.2324 .

(ESI+): $\mathrm{m} / \mathrm{z}$ calc. for $\mathrm{C}_{20} \mathrm{H}_{34} \mathrm{~N}_{4} \mathrm{O}_{6} \mathrm{Si}[\mathrm{M}+\mathrm{Na}]^{+}:$477.2140, found: 477.2135. 
6. Experimental part

\section{Synthesis of 6-carboxycytidine (59)}

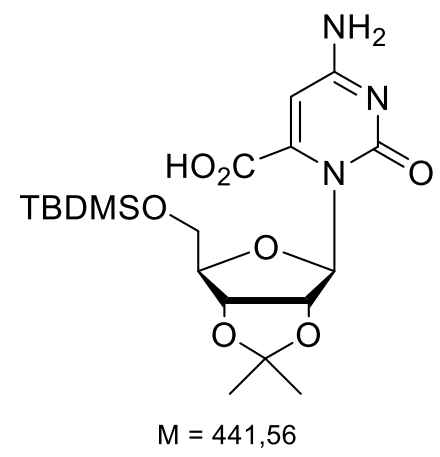

65<smiles></smiles>

$M=287,23$

59

5'-O-Tertbutyldimethylsilyl-2',3'-O-isopropylidene-6-carboxycytidine $\quad(178 \mathrm{mg}, 404 \mu \mathrm{mol}$, 1.0 eq.) was dissolved in methanolic $\mathrm{HCl}(0.5 \mathrm{M}, 6.0 \mathrm{~mL})$. The reaction mixture was stirred for $60 \mathrm{~min}$ at room temperature. The solvent was removed in vacuo obtaining the deprotected 6-carboxycytidine (115 mg, quant.) which was used without further purification.

${ }^{1} \mathbf{H}-\mathbf{N M R}\left(300 \mathrm{MHz}, \mathrm{D}_{2} \mathrm{O}\right): \delta(\mathrm{ppm})=6.05(\mathrm{~s}, 1 \mathrm{H}, \mathrm{C} 5 \mathrm{H}), 5.57\left(\mathrm{~d}, J=3.3 \mathrm{~Hz}, 1 \mathrm{H}, \mathrm{Cl}{ }^{\prime} \mathrm{H}\right), 3.90$ (m, 2H, C2’ H, C3’H), 3.81 (m, 1H, C4’ $\mathrm{H}), 3.72-3.66$ (m, 2H, C5 $\left.{ }^{\prime} \mathrm{H}_{2}\right)$.

MS (ESI-, MeOH): m/z = 286.1 [M-H] $]^{-}$

HRMS (ESI-): m/z calc. for $\mathrm{C}_{10} \mathrm{H}_{13} \mathrm{~N}_{3} \mathrm{O}_{7}[\mathrm{M}-\mathrm{H}]^{-}:$: 286.0681, found: 286.0679. 


\section{Synthesis of 6-amidocytidine (69)}

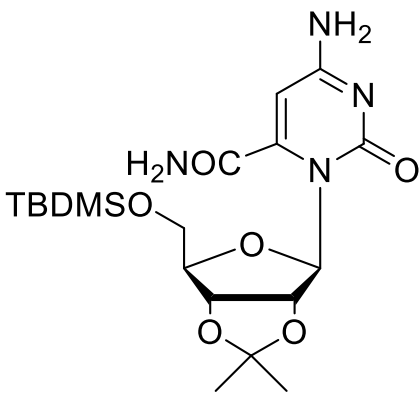

$M=440,57$

66

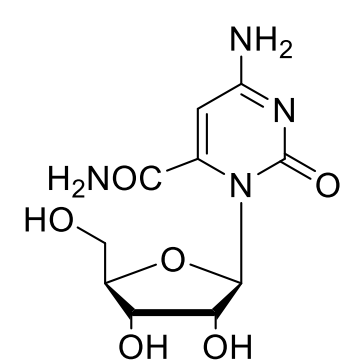

$M=286,24$

69

5'-O-Tertbutyldimethylsilyl-2',3'-O-isopropylidene-6-amidocytidine $\quad(180 \mathrm{mg}, \quad 408 \mu \mathrm{mol}$, 1.0 eq.) was dissolved in methanolic $\mathrm{HCl}(0.5 \mathrm{M}, 6.0 \mathrm{~mL})$. The reaction mixture was stirred for $60 \mathrm{~min}$ at room temperature. The solvent was removed in vacuo obtaining the deprotected 6-amidocytidine (115 mg, quant.) which was used without further purification.

${ }^{1}$ H-NMR (300 MHz, DMSO- $\left.d_{6}\right): \delta(\mathrm{ppm})=5.74(\mathrm{~s}, 1 \mathrm{H}, \mathrm{C} 5 \mathrm{H}), 5.62\left(\mathrm{~s}, 1 \mathrm{H}, \mathrm{C} 1{ }^{\prime} \mathrm{H}\right), 5.11$ (dd, $\left.J=6.4,1.6 \mathrm{~Hz}, 1 \mathrm{H}, \mathrm{C} 2^{\prime} \mathrm{H}\right), 4.74\left(\mathrm{~m}, 1 \mathrm{H}, \mathrm{C} 3^{\prime} \mathrm{H}\right), 3.92\left(\mathrm{~m}, 1 \mathrm{H}, \mathrm{C} 4{ }^{\prime} \mathrm{H}\right), 3.55$ (m, 2H, C5' $\left.\mathrm{H}_{2}\right)$.

MS $(\mathrm{ESI}+\mathrm{MeOH}): \mathrm{m} / \mathrm{z}=287.2[\mathrm{M}+\mathrm{H}]^{+}$. 
6. Experimental part

\section{Synthesis of 6-cyanocytidine (70)}

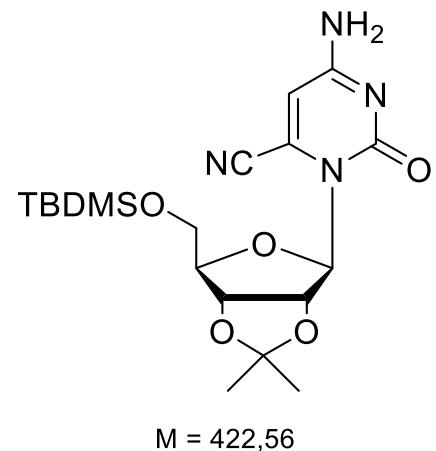

63<smiles>N#Cc1cc(N)nc(=O)n1C1OC(O)C(O)C1O</smiles>

$M=268,23$

70

5'-O-Tertbutyldimethylsilyl-2',3'-O-isopropylidene-6-cyanocytidine $\quad(310 \mathrm{mg}, \quad 733 \mu \mathrm{mol}$, 1.0 eq.) was dissolved in methanolic $\mathrm{HCl}(0.5 \mathrm{M}, 8.0 \mathrm{~mL})$. The reaction mixture was stirred for $60 \mathrm{~min}$ at room temperature. The solvent was removed in vacuo obtaining the deprotected 6-cyanocytidine (195 mg, quant.) which was used without further purification.

${ }^{1}$ H-NMR (300 MHz, DMSO- $\left.d_{6}\right): \delta(\mathrm{ppm})=6.27(\mathrm{~s}, 1 \mathrm{H}, \mathrm{C} 5 \mathrm{H}), 5.97\left(\mathrm{~d}, J=1.9 \mathrm{~Hz}, 1 \mathrm{H}, \mathrm{C1}{ }^{\prime} \mathrm{H}\right)$, $5.11\left(\mathrm{dd}, J=6.5,1.8 \mathrm{~Hz}, 1 \mathrm{H}, \mathrm{C} 2^{\prime} \mathrm{H}\right), 4.73$ (m, 1H, C3’H), 4.07 (m, 1H, C4'H), 3.72 (m, 2H, $\left.\mathrm{C}^{\prime} \mathrm{H}_{2}\right)$,

MS (ESI-, MeOH): m/z = 267.1 [M-H] $]^{-}$

$(\mathrm{ESI}+\mathrm{MeOH}): \mathrm{m} / \mathrm{z}=269.1[\mathrm{M}+\mathrm{H}]^{+}, 291.1[\mathrm{M}+\mathrm{Na}]^{+}$.

HRMS (ESI-): m/z calc. for $\mathrm{C}_{10} \mathrm{H}_{12} \mathrm{~N}_{4} \mathrm{O}_{5}[\mathrm{M}-\mathrm{H}]^{-}:$: 267.0735, found: 267.0735.

(ESI+): m/z calc. for $\mathrm{C}_{10} \mathrm{H}_{12} \mathrm{~N}_{4} \mathrm{O}_{5}[\mathrm{M}+\mathrm{H}]^{+}:$269.0880, found: 269.0877 .

(ESI+): m/z calc. for $\mathrm{C}_{10} \mathrm{H}_{12} \mathrm{~N}_{4} \mathrm{O}_{5}[\mathrm{M}+\mathrm{Na}]^{+}:$291.0700, found: 291.0705 . 


\section{Synthesis of 6-carboxy CMP (11)}<smiles>Nc1cc(C(=O)O)n(C2OC(O)C(CO)OC2O)c(=O)n1</smiles>

$M=287,23$

59<smiles></smiles>

$M=367,21$

11

6-Carboxycytidine (80 mg, $278 \mu \mathrm{mol}, 1.0$ eq.) was dissolved in $\mathrm{PO}(\mathrm{OMe})_{3}(3.0 \mathrm{~mL})$ and cooled to $0^{\circ} \mathrm{C}$. Then $\mathrm{POCl}_{3}(55.0 \mu \mathrm{L}, 557 \mu \mathrm{mol}, 2.0$ eq.) was added and the reaction mixture was stirred for $5 \mathrm{~h}$ at $0^{\circ} \mathrm{C}$. The reaction was quenched by adding aqueous triethylammonium acetate buffer $(1.0 \mathrm{M})$ until neutral $\mathrm{pH}$. The solvent was removed in vacuo. ESI-MS and ${ }^{1} \mathrm{H}-\mathrm{NMR}$ confirmed that the title compound was not formed.

\section{Synthesis of 6-carboxy CMP (11)}<smiles>Nc1cc(C(=O)O)n(C2OC(O)C(CO)OC2O)c(=O)n1</smiles>

$M=287,23$

59<smiles>Nc1cc(C(=O)O)n(C2OC(O)C(OP(=O)(O)O)C(O)C2O)c(=O)n1</smiles>

$M=367,21$

11

Phosphoryl chloride (115 $\mu \mathrm{L}, 1.22 \mathrm{mmol}, 4.4$ eq.) was dissolved in $\mathrm{MeCN}$ (5.0 mL) at $0^{\circ} \mathrm{C}$. Then, water (15 $\mu \mathrm{L}, 0.78 \mathrm{mmol}, 2.8$ eq.) and pyridine (100 $\mu \mathrm{L}, 1.22 \mathrm{mmol}, 4.4$ eq.) were added and the reaction mixture was stirred for $30 \mathrm{~min}$. 6-carboxycytidine ( $80 \mathrm{mg}, 278 \mu \mathrm{mol}, 1.0 \mathrm{eq}$.) was added and the reaction mixture was stirred for $4 \mathrm{~h}$ at $0^{\circ} \mathrm{C}$. The reaction was quenched by adding aqueous triethylammonium acetate buffer $(1.0 \mathrm{M})$ until neutral $\mathrm{pH}$. The solvent was removed in vacuo, but no product could be isolated. 
6. Experimental part

Synthesis of 6-amido CMP (12)<smiles>NC(=O)c1cc(N)nc(=O)n1C1OC(O)C(O)C1O</smiles>

$M=286,24$

69<smiles>NC(=O)c1cc(N)nc(=O)n1C1O[C@H](O)[C@@H](COP(=O)(O)O)[C@@H](O)[C@H]1O</smiles>

$M=366,22$

12

6-Amidocytidine (105 mg, $367 \mu \mathrm{mol}, 1.0$ eq.) was dissolved in $\mathrm{PO}(\mathrm{OMe})_{3}(4.0 \mathrm{~mL})$ and cooled to $0^{\circ} \mathrm{C}$. Then $\mathrm{POCl}_{3}(72.0 \mu \mathrm{L}, 734 \mu \mathrm{mol}, 2.0$ eq. $)$ was added and the reaction mixture was stirred for $5 \mathrm{~h}$ at $0^{\circ} \mathrm{C}$. The reaction was quenched by adding aqueous triethylammonium acetate buffer $(1.0 \mathrm{M})$ until neutral $\mathrm{pH}$. The solvent was removed in vacuo. ESI-MS and ${ }^{1} \mathrm{H}-\mathrm{NMR}$ confirmed that the title compound was not formed.

\section{Synthesis of 6-amido CMP (12)}<smiles>NC(=O)c1cc(N)nc(=O)n1C1OC(O)C(O)C1O</smiles>

$M=286,24$

69<smiles>NC(=O)c1cc(N)nc(=O)n1[C@@H]1O[C@H](COP(=O)(O)O)[C@@H](O)[C@H](O)[C@H]1O</smiles>

$M=366,22$

12

Phosphoryl chloride ( $155 \mu \mathrm{L}, 1.61 \mathrm{mmol}, 4.4$ eq.) was dissolved in $\mathrm{MeCN}(5.0 \mathrm{~mL})$ at $0^{\circ} \mathrm{C}$. Then, water (18 $\mu \mathrm{L}, 1.03 \mathrm{mmol}, 2.8$ eq.) and pyridine (130 $\mu \mathrm{L}, 1.61 \mathrm{mmol}, 4.4$ eq.) were added and the reaction mixture was stirred for $30 \mathrm{~min}$. 6-Amidocytidine (105 mg, $367 \mu \mathrm{mol}, 1.0 \mathrm{eq}$.) was added and the reaction mixture was stirred for $4 \mathrm{~h}$ at $0^{\circ} \mathrm{C}$. The reaction was quenched by adding aqueous triethylammonium acetate buffer $(1.0 \mathrm{M})$ until neutral $\mathrm{pH}$. The solvent was removed in vacuo, but no product could be isolated. 


\section{Synthesis of 6-cyano CMP (71)}<smiles>N#Cc1cc(N)nc(=O)n1C1OC(O)C(O)C1O</smiles>

$M=268,23$

70<smiles>N#Cc1cc(N)nc(=O)n1C1OC(O)C(COP(=O)(O)O)O1</smiles>

$M=348,21$

71

6-Cyanocytidine (250 mg, $933 \mu \mathrm{mol}, 1.0$ eq.) was dissolved in $\mathrm{PO}(\mathrm{OMe})_{3}(6.0 \mathrm{~mL})$ and cooled to $0^{\circ} \mathrm{C}$. Then $\mathrm{POCl}_{3}(174.0 \mu \mathrm{L}, 1.87 \mathrm{mmol}, 2.0$ eq. $)$ was added and the reaction mixture was stirred for $5 \mathrm{~h}$ at $0^{\circ} \mathrm{C}$. The reaction was quenched by adding aqueous triethylammonium acetate buffer $(1.0 \mathrm{M})$ until neutral $\mathrm{pH}$. The solvent was removed in vacuo. ESI-MS and ${ }^{1} \mathrm{H}-\mathrm{NMR}$ confirmed that the title compound was not formed.

\section{Synthesis of 6-cyano CMP (71)}<smiles>N#Cc1cc(N)nc(=O)n1C1OC(O)C(O)C1O</smiles>

$M=268,23$

70<smiles>N#Cc1cc(N)nc(=O)n1C1OC(O)C(COP(=O)(O)O)O1</smiles>

$M=348,21$

71

Phosphoryl chloride (385 $\mu \mathrm{L}, 4.11 \mathrm{mmol}, 4.4$ eq.) was dissolved in $\mathrm{MeCN}(5.0 \mathrm{~mL})$ at $0^{\circ} \mathrm{C}$. Then, water (47 $\mu \mathrm{L}, 2.61 \mathrm{mmol}, 2.8$ eq.) and pyridine (330 $\mu \mathrm{L}, 4.11 \mathrm{mmol}, 4.4$ eq.) were added and the reaction mixture was stirred for $30 \mathrm{~min}$. 6-Cyanocytidine $(250 \mathrm{mg}, 933 \mu \mathrm{mol}, 1.0 \mathrm{eq}$.) was added and the reaction mixture was stirred for $4 \mathrm{~h}$ at $0^{\circ} \mathrm{C}$. The reaction was quenched by adding aqueous triethylammonium acetate buffer $(1.0 \mathrm{M})$ until neutral $\mathrm{pH}$. The solvent was removed in vacuo, but no product could be isolated. 
6. Experimental part

Synthesis of 5'-O-tert-butyldimethylsilyl-2',3'-O-isopropylidenecytidine (52)

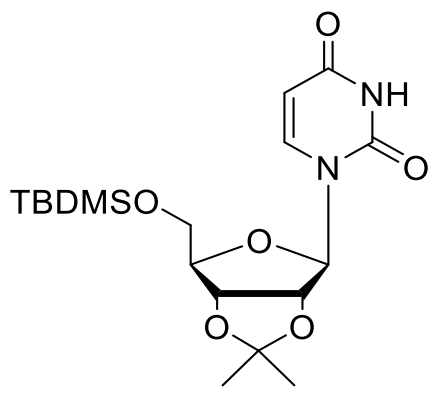

$M=398,53$

22
1) $p$-TsCl, DMAP $\mathrm{NEt}_{3}, \mathrm{DCM}$

2) $\mathrm{NH}_{3}$<smiles>CC(C)COCC1O[C@H]2O[C@@H](n3ccc(N)nc3=O)[C@H]1OC(C)(C)O2</smiles>

$M=397,55$

52

5'-O-tert-Butyldimethylsilyl-2',3'- $O$-isopropylideneuridine (200 mg, $502 \mu \mathrm{mol}, 1.0$ eq.) and DMAP (123 mg, $101 \mu \mathrm{mol}, 0.2$ eq.) were dissolved in DCM $(8.0 \mathrm{~mL}) . \mathrm{NEt}_{3}(0.21 \mathrm{~mL}$, $1.51 \mathrm{mmol}, 3.0$ eq.) was added, and under vigorous stirring $p$ - $\mathrm{TsCl}$ (215 mg, $1.0 \mathrm{mmol}, 2.0$ eq.) was added slowly. The reaction mixture was stirred for $18 \mathrm{~h}$ at room temperature. Then, aq. $\mathrm{NH}_{3}$ $(33 \%, 9.0 \mathrm{~mL})$ was added dropwise at $0^{\circ} \mathrm{C}$ followed by stirring $1 \mathrm{~h}$ at room temperature. The solvent was removed under reduced pressure and the crude product was purified by column chromatography $\left(\mathrm{SiO}_{2}\right.$; gradient hexane/EtOAc 3:1 to 1:1). The title compound (140 mg, $360 \mu \mathrm{mol}, 72 \%$ ) was obtained as a white solid.

${ }^{1} \mathbf{H}-\mathrm{NMR}\left(300 \mathrm{MHz}, \mathrm{DMSO}-d_{6}\right): \delta(\mathrm{ppm})=7.66(\mathrm{~d}, J=7.5 \mathrm{~Hz}, 1 \mathrm{H}, \mathrm{C} 6 \mathrm{H}), 7.21\left(\mathrm{~s}_{\mathrm{br}}, 1 \mathrm{H}, \mathrm{NH}_{2}\right)$, $5.80\left(\mathrm{~d}, J=1.9 \mathrm{~Hz}, 1 \mathrm{H}, \mathrm{C} 1{ }^{\prime} \mathrm{H}\right), 5.69(\mathrm{~d}, J=7.5 \mathrm{~Hz}, 1 \mathrm{H}, \mathrm{C} 5 \mathrm{H}), 4.83(\mathrm{dd}, J=6.2,1.9 \mathrm{~Hz}$, 1H,C2'H) 4.72 (dd, $\left.J=6.2,3.6 \mathrm{~Hz}, 1 \mathrm{H}, \mathrm{C} 3{ }^{\prime} \mathrm{H}\right), 4.07-4.03$ (m, 1H, C4'H), 3.80-3.74 (m, 2H, C5' $\left.{ }^{\prime} \mathrm{H}_{2}\right), 1.47$ (s, 3H, CH $\mathrm{CH}_{3}, 1.28$ (s, 3H, CH 3$), 0.86$ (s, 9H, $\left.\mathrm{SiC}\left(\mathrm{CH}_{3}\right)_{3}\right), 0.03\left(\mathrm{~s}, 6 \mathrm{H}, \mathrm{Si}\left(\mathrm{CH}_{3}\right)_{2}\right)$.

${ }^{13}$ C-NMR (75 MHz, DMSO- $\left.d_{6}\right): \delta(\mathrm{ppm})=165.8(\mathrm{C} 4), 154.8(\mathrm{C} 2), 142.6$ (C6), 112.6 $\left(\underline{\mathrm{C}}\left(\mathrm{CH}_{3}\right)_{2}\right), 93.9$ (C5), $92.7\left(\mathrm{Cl}^{\prime}\right), 86.8$ (C4'), 84.5 (C2'), 80.5 (C3'), $63.2\left(\mathrm{C}^{\prime}\right.$ '), $27.0\left(\mathrm{CH}_{3}\right)$, $25.8\left(\mathrm{SiC}\left(\underline{\mathrm{CH}}_{3}\right)_{3}\right), 25.2\left(\mathrm{CH}_{3}\right), 18.0\left(\mathrm{Si} \underline{\mathrm{C}}\left(\mathrm{CH}_{3}\right)_{3}\right),-5.5 \mathrm{Si}\left(\mathrm{CH}_{3}\right)_{2}$.

MS (ESI+, MeOH): m/z = $398.2[\mathrm{M}+\mathrm{H}]^{+}, 420.2[\mathrm{M}+\mathrm{Na}]^{+}$.

HRMS (ESI+): m/z calc. for $\mathrm{C}_{18} \mathrm{H}_{31} \mathrm{~N}_{3} \mathrm{O}_{5} \mathrm{Si}[\mathrm{M}+\mathrm{H}]^{+}:$398.2106, found: 398.2109.

(ESI+): m/z calc. for $\mathrm{C}_{18} \mathrm{H}_{31} \mathrm{~N}_{3} \mathrm{O}_{5} \mathrm{Si}[\mathrm{M}+\mathrm{Na}]^{+}:$420.1925, found: 420.1923. 


\section{Synthesis of 2',3'-O-isopropylideneorotidine (73)}

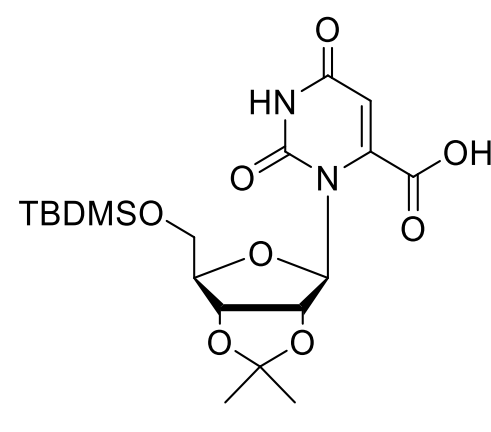

$M=442,54$

48

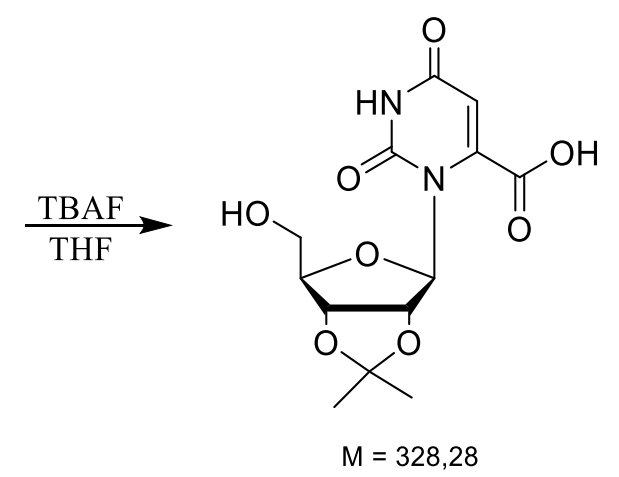

73

5'-O-tert-Butyldimethylsilyl-2',3'-O-isopropylideneorotidine (1.50 g, $3.39 \mathrm{mmol}, 1.0$ eq.) was dissolved in THF (25 mL). TBAF ( $8.5 \mathrm{~mL}, 8.48 \mathrm{mmol}, 2.5$ eq.) was added slowly and the solution was stirred overnight at room temperature. The solvent was removed under reduced pressure and the crude product was purified by column chromatography $\left(\mathrm{SiO}_{2}\right.$; gradient EtOAc/ $\mathrm{MeOH}$ 90:10 to 70:30). The title compound (980 mg, $2.98 \mathrm{mmol}, 88 \%$ ) was obtained as a white solid.

${ }^{1}$ H-NMR $\left(300 \mathrm{MHz}, \mathrm{DMSO}-d_{6}\right): \delta(\mathrm{ppm})=6.05(\mathrm{~s}, 1 \mathrm{H}, \mathrm{C} 1$ 'H), $5.35(\mathrm{~s}, 1 \mathrm{H}, \mathrm{C} 5 \mathrm{H}), 5.11(\mathrm{~d}$, $\left.J=6.4 \mathrm{~Hz}, 1 \mathrm{H}, \mathrm{C} 2{ }^{\prime} \mathrm{H}\right), 4.72\left(\mathrm{dd}, J=6.4,4.3 \mathrm{~Hz}, 1 \mathrm{H}, \mathrm{C}{ }^{\prime}{ }^{\prime} \mathrm{H}\right), 3.93-3.86$ (m, 1H, C4'H), 3.78-3.68 (m, 2H, C5'H2), 1.43 (s, 3H, $\left.\mathrm{CH}_{3}\right), 1.25$ (s, 3H, $\left.\mathrm{CH}_{3}\right)$.

${ }^{13}$ C-NMR (125 MHz, DMSO- $\left.d_{6}\right): \delta(\mathrm{ppm})=163.4(\mathrm{COOH}), 163.1(\mathrm{C} 4), 156.3(\mathrm{C} 2)$, 150.5 (C6), 112.1 (C(CH$\left.)_{2}\right), 97.0$ (C5), 92.3 (C1'), 88.7 (C4'), 84.3 (C2'), 82.0 (C3'), $63.9\left(\mathrm{C}^{\prime}{ }^{\prime}\right), 27.1\left(\mathrm{CH}_{3}\right), 25.2\left(\mathrm{CH}_{3}\right)$.

MS (ESI-, MeOH): m/z = $327.1[\mathrm{M}-\mathrm{H}]^{-}$.

HRMS (ESI-): m/z calc. for $\mathrm{C}_{13} \mathrm{H}_{16} \mathrm{~N}_{2} \mathrm{O}_{8}[\mathrm{M}-\mathrm{H}]^{-}: 327.0834$, found: 327.0833 . 
6. Experimental part

\section{Synthesis of 2',3'-O-isopropylidene OMP (76)}<smiles>CC1(C)OC2OC(CO)C1OC2n1c(C(=O)O)cc(=O)[nH]c1=O</smiles>

$M=328,28$

73

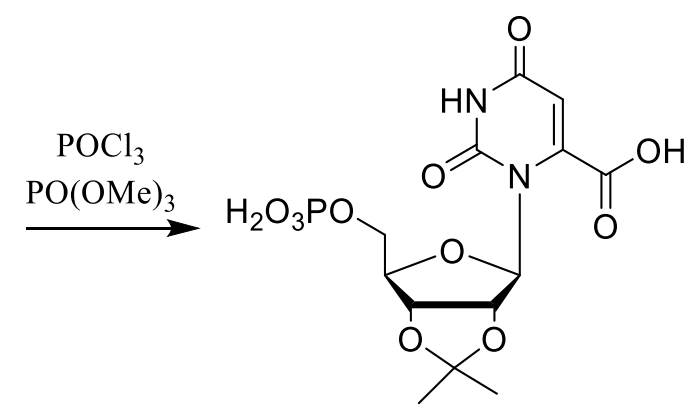

$M=408,26$

76

2',3'-O-Isopropylideneorotidine ( $330 \mathrm{mg}, 1.0 \mathrm{mmol}, 1.0$ eq.) was dissolved in $\mathrm{PO}(\mathrm{OMe})_{3}$ $(8.0 \mathrm{~mL})$ and cooled to $0^{\circ} \mathrm{C}$. Then $\mathrm{POCl}_{3}(280 \mu \mathrm{L}, 3.0 \mathrm{mmol}, 3.0$ eq. $)$ was added and the reaction mixture was stirred for $5 \mathrm{~h}$ at $0^{\circ} \mathrm{C}$. The reaction was quenched by adding aqueous triethylammonium acetate buffer $(1.0 \mathrm{M})$ until neutral $\mathrm{pH}$. The solvent was removed under reduced pressure.

MS (ESI-, MeOH): m/z = 407.1 [M-H] $]^{-}$

HRMS (ESI-): m/z calc. for $\mathrm{C}_{13} \mathrm{H}_{17} \mathrm{~N}_{2} \mathrm{O}_{11} \mathrm{P}[\mathrm{M}-\mathrm{H}]^{-}$: 407.0497, found: 407.0500. 


\section{Synthesis of 2',3'-O-isopropylidene-6-carboxy CMP (80)}

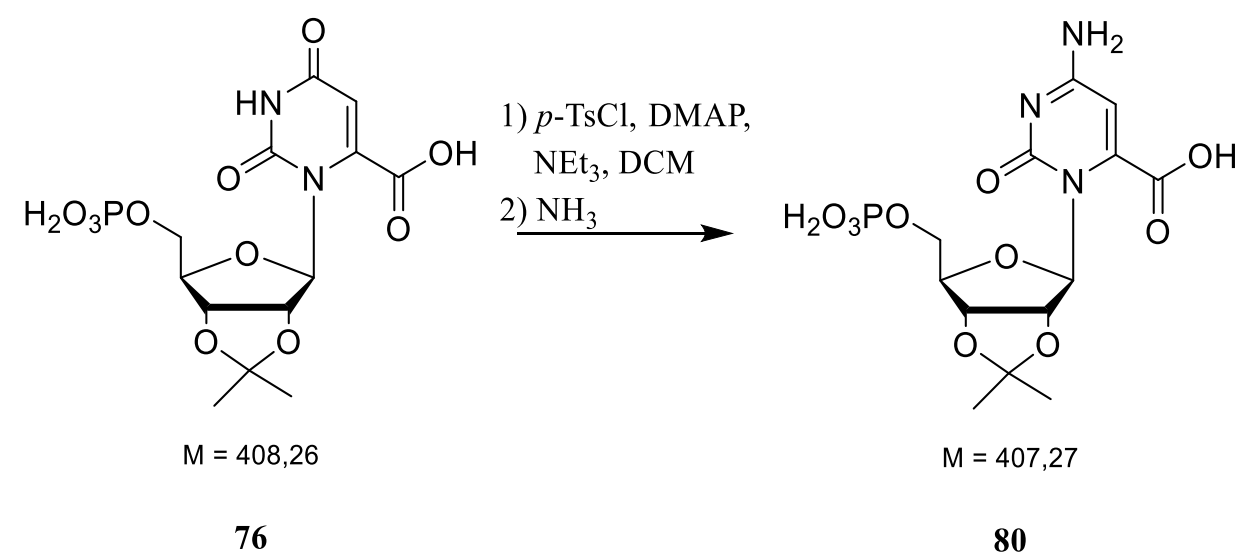

2',3'-O-Isopropylidene OMP (150 mg, $367 \mu \mathrm{mol}, 1.0$ eq.) and DMAP (89 mg, $73 \mu \mathrm{mol}$, 0.2 eq.) were dissolved in DCM (10.0 mL). $\mathrm{NEt}_{3}(155 \mu \mathrm{L}, 1.10 \mathrm{mmol}, 3.0$ eq. $)$ was added, and under vigorous stirring $p$-TsCl (175 mg, $917 \mu \mathrm{mol}, 2.5$ eq.) was added slowly. The reaction mixture was stirred for $18 \mathrm{~h}$ at room temperature. Then, aq. $\mathrm{NH}_{3}(33 \%, 6.0 \mathrm{~mL})$ was added dropwise at $0^{\circ} \mathrm{C}$ followed by stirring $1 \mathrm{~h}$ at room temperature. The solvent was removed under reduced pressure and the crude product was purified by HPLC.

MS (ESI-, MeOH): m/z = 406.1 [M-H] .

HRMS (ESI-): m/z calc. for $\mathrm{C}_{13} \mathrm{H}_{18} \mathrm{~N}_{3} \mathrm{O}_{10} \mathrm{P}[\mathrm{M}-\mathrm{H}]^{-}:$406.0657, found: 406.0659 . 
6. Experimental part

\section{Synthesis of 6-carboxy CMP (11)}

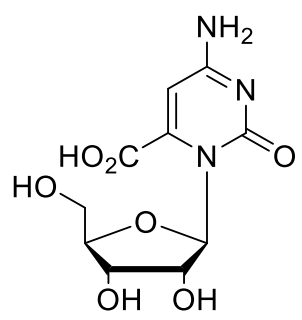

$M=287,23$

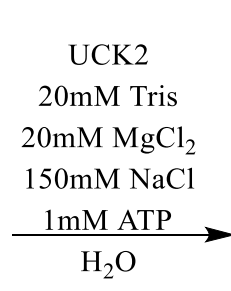

(59)

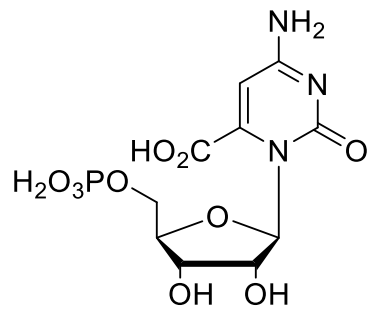

$M=367,21$

(11)

6-Carboxycytidine (50 mg, $174 \mu \mathrm{mol}, 1.0$ eq.) was dissolved in $\mathrm{H}_{2} \mathrm{O}$ (3.0 mL) and DMSO $(1.0 \mathrm{~mL})$. Then, aq. $\mathrm{MgCl}_{2}(20 \mathrm{mM}, 38 \mu \mathrm{L})$ and ATP $(1 \mathrm{mM}, 76 \mu \mathrm{L})$ were added. UCK2 $(\sim 63 \mu \mathrm{M}, 2 \mathrm{mg})$ dissolved in tris buffer $(20 \mathrm{mM}, 2.0 \mathrm{~mL})$ and aq. $\mathrm{NaCl}(150 \mathrm{mM})$ at $\mathrm{pH}=7.5$ was added to start the enzymatic reaction. The reaction was stirred for $22 \mathrm{~h}$ at room temperature and quenched by the denaturation of the UCK2. The reaction mixture was divided into four batches with different heat shock times $(1 \mathrm{~min}, 5 \mathrm{~min}, 10 \mathrm{~min}, 15 \mathrm{~min})$ at $85^{\circ} \mathrm{C}$. Then, the samples were centrifuged, filtered, and purified by HPLC (ion-exchange chromatography). The title compound (1.5 mg, $4.1 \mu \mathrm{mol}, 2 \%)$ was just obtained in very low yields.

MS (ESI-, MeOH): m/z = 366.0 [M-H $]^{-}$.

HRMS (ESI-): m/z calc. for $\mathrm{C}_{10} \mathrm{H}_{14} \mathrm{~N}_{3} \mathrm{O}_{10} \mathrm{P}[\mathrm{M}-\mathrm{H}]^{-}$: 366.0344 , found: 366.0339 . 


\section{Synthesis of 6-amido CMP (12)}

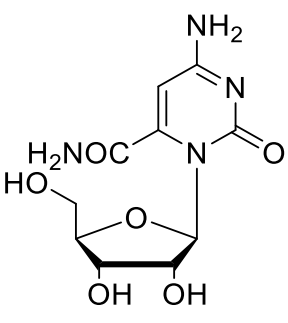

$M=286,24$

(68)

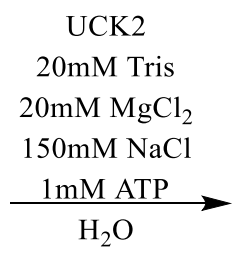

$20 \mathrm{mM} \mathrm{MgCl} 2$

$\underset{\mathrm{H}_{2} \mathrm{O}}{1 \mathrm{mM} \text { ATP }}$

$\mathrm{H}_{2} \mathrm{O}_{3} \mathrm{PO}$<smiles></smiles>

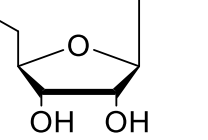

$M=366,22$

(12)

6-Amidocytidine $\left(60 \mathrm{mg}, 210 \mu \mathrm{mol}, 1.0\right.$ eq.) was dissolved in $\mathrm{H}_{2} \mathrm{O}$ (3.0 mL) and DMSO $(1.0 \mathrm{~mL})$. Then, aq. $\mathrm{MgCl}_{2}(20 \mathrm{mM}, 38 \mu \mathrm{L})$ and ATP $(1 \mathrm{mM}, 76 \mu \mathrm{L})$ were added. UCK2 $(\sim 63 \mu \mathrm{M}, 2 \mathrm{mg})$ dissolved in tris buffer $(20 \mathrm{mM}, 2.0 \mathrm{~mL})$ and aq. $\mathrm{NaCl}(150 \mathrm{mM})$ at $\mathrm{pH}=7.5$ was added to start the enzymatic reaction. The reaction was stirred for $22 \mathrm{~h}$ at room temperature and quenched by the denaturation of the UCK2. The reaction mixture was divided into three batches with different heat shock times ( $5 \mathrm{~min}, 10 \mathrm{~min}, 15 \mathrm{~min}$ ) at $85^{\circ} \mathrm{C}$. Then, the samples were centrifuged, filtered, and purified by HPLC (ion-exchange chromatography). 
6. Experimental part

\subsubsection{Synthesis of 6-boronic acid UMP}

\section{Synthesis of 3-benzyl-5' -O-tert-butyldimethylsilyl-2',3'-O-isopropylideneuridine (82)}

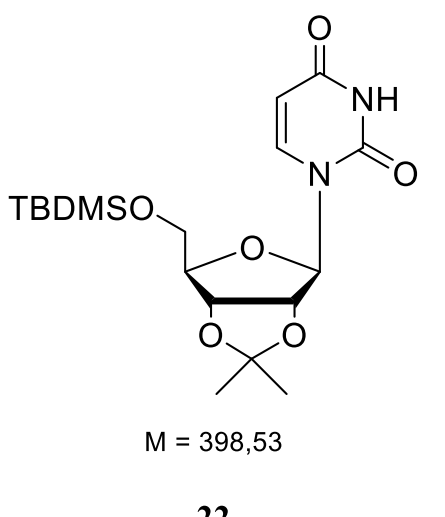

22

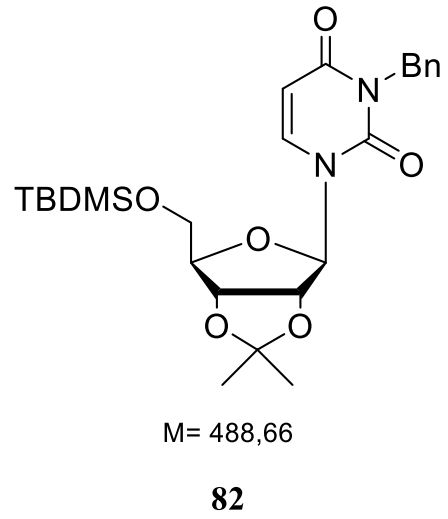

82

5'-O-tert-butyldimethylsilyl-2',3'-O-isopropylideneuridine (5.00 g, $12.5 \mathrm{mmol}, 1.0 \mathrm{eq}$.) and potassium carbonate $(2.6 \mathrm{~g}, 18.7 \mathrm{mmol}, 1.5$ eq.) were dissolved in acetone $(45 \mathrm{~mL})$ and DMSO (20 mL). Then benzyl bromide ( $2.3 \mathrm{~mL}, 18.7 \mathrm{mmol}, 1.5$ eq.) was added dropwise. The reaction mixture was stirred overnight at room temperature. The solvent was removed in vacuo and the crude product was purified by column chromatography $\left(\mathrm{SiO}_{2}\right.$; hexane/ ethyl acetate, 5:1) to afford the title compound (5.94 g, $12.1 \mathrm{mmol} 97 \%$ ) as a colorless oil.

TLC, $R_{\mathrm{f}}=0.25$ hexane/ ethyl acetate $(5: 1)$.

${ }^{1}$ H-NMR (300 MHz, DMSO- $\left.d_{6}\right): \delta(\mathrm{ppm})=7.79(\mathrm{~d}, J=8.1 \mathrm{~Hz}, 1 \mathrm{H}, \mathrm{C} 6 \mathrm{H}), 7.32-7.24(\mathrm{~m}, 5 \mathrm{H}$, $\mathrm{CH}), 5.83\left(\mathrm{~d}, J=2.2 \mathrm{~Hz}, 1 \mathrm{H}, \mathrm{Cl}{ }^{\prime} \mathrm{H}\right), 5.77(\mathrm{~d}, J=8.1 \mathrm{~Hz}, 1 \mathrm{H}, \mathrm{C} 5 \mathrm{H}), 4.97(\mathrm{~d}, J=2.1 \mathrm{~Hz}, 2 \mathrm{H}$, $\mathrm{CH}_{2}$ ), 4.92 (dd, $\left.J=6.2,2.2 \mathrm{~Hz}, 1 \mathrm{H}, \mathrm{C} 2{ }^{\prime} \mathrm{H}\right), 4.72\left(\mathrm{dd}, J=6.2,3.3 \mathrm{~Hz}, 1 \mathrm{H}, \mathrm{C} 3{ }^{\prime} \mathrm{H}\right), 4.17$ (q, $\left.J=3.9 \mathrm{~Hz}, 1 \mathrm{H}, \mathrm{C} 4{ }^{\prime} \mathrm{H}\right), 3.79$ (m, 2H, C5'H $\left.{ }^{\prime}\right), 1.48$ (s, 3H, CH $), 1.29$ (s, 3H, CH $), 0.84$ (s, 9H, $\left.\mathrm{SiC}\left(\mathrm{CH}_{3}\right)_{3}\right), 0.02\left(\mathrm{~s}, 6 \mathrm{H}, \mathrm{Si}\left(\mathrm{CH}_{3}\right)_{2}\right)$.

${ }^{13}$ C-NMR (126 MHz, DMSO- $\left.d_{6}\right): \delta(\mathrm{ppm})=161.6(\mathrm{C} 4), 150.2(\mathrm{C} 2), 140.3$ (C6), $136.6\left(\mathrm{C}_{\text {quart }}\right)$, 128.0 ( $\left.\mathrm{C}_{\text {arom}}\right), 127.4$ ( $\left.\mathrm{C}_{\text {arom }}\right), 126.9$ ( $\left.\mathrm{C}_{\text {arom }}\right), 112.6\left(\underline{\mathrm{C}}\left(\mathrm{CH}_{3}\right)_{2}\right), 100.5$ (C5), 92.9 (C1'), 86.9 (C4'), $84.1\left(\mathrm{C}^{\prime}\right), 80.4\left(\mathrm{C}^{\prime}\right), 63.0\left(\mathrm{C}^{\prime}{ }^{\prime} \mathrm{H}_{2}\right), 43.23\left(\mathrm{CH}_{2}\right), 26.9\left(\mathrm{CH}_{3}\right), 25.6\left(\mathrm{SiC}\left(\mathrm{CH}_{3}\right)_{3}\right), 25.1\left(\mathrm{CH}_{3}\right)$, $17.8\left(\mathrm{C}_{\text {quart }}\right),-5.56\left(\mathrm{Si}\left(\mathrm{CH}_{3}\right)_{2}\right)$.

MS $(\mathrm{ESI}+\mathrm{MeOH}): \mathrm{m} / \mathrm{z}=489.3[\mathrm{M}+\mathrm{H}]^{+}, 511.2[\mathrm{M}+\mathrm{Na}]^{+}$.

HRMS (ESI+): m/z calc. for $\mathrm{C}_{25} \mathrm{H}_{36} \mathrm{~N}_{2} \mathrm{O}_{6} \mathrm{Si}[\mathrm{M}+\mathrm{H}]^{+}:$489.2415, found 489.2408.

(ESI+): $\mathrm{m} / \mathrm{z}$ calc. for $\mathrm{C}_{25} \mathrm{H}_{36} \mathrm{~N}_{2} \mathrm{O}_{6} \mathrm{Si}[\mathrm{M}+\mathrm{Na}]^{+}:$511.2235, found 511.2227. 


\section{Synthesis of}

\section{3-benzyl-5'-O-tert-butyldimethylsilyl-2',3'-O-isopropylidene-6-iodouridine (83)}

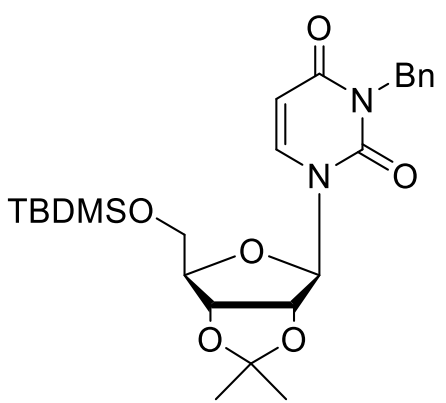

Molecular Weight: 488,66

82
1) LDA, THF, $\underset{2)}{\stackrel{-78^{\circ} \mathrm{C}, 1 \mathrm{~h}}{\mathrm{I}}, \mathrm{THF},}$ $-78^{\circ} \mathrm{C}, 4 \mathrm{~h}$

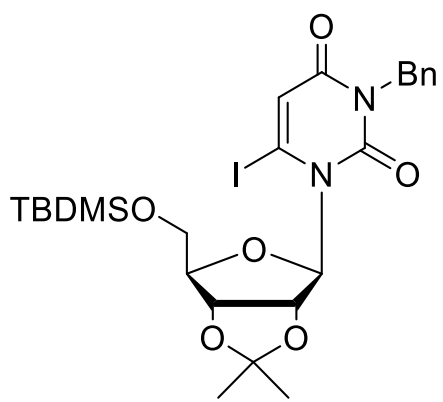

Molecular Weight: 614,55

83

3-Benzyl-5'-O-tert-butyldimethylsilyl-2',3'-O-isopropylideneuridine (82) (2.00 g, $4.1 \mathrm{mmol}$, 1.0 eq.) was dissolved in THF $(30 \mathrm{~mL})$ and cooled to $-78^{\circ} \mathrm{C}$. Then, LDA $(1.5 \mathrm{M}, 5.5 \mathrm{~mL}$, $8.2 \mathrm{mmol}, 2.0$ eq.) was added slowly. After $1 \mathrm{~h}$, iodine (1.05 g, $8.2 \mathrm{mmol}, 2.0$ eq.) dissolved in THF $(20 \mathrm{~mL})$ was added dropwise and the mixture was stirred for $4 \mathrm{~h}$ at $-78^{\circ} \mathrm{C}$. The reaction was quenched by the addition of acetic acid $(1.0 \mathrm{~mL})$. Then, the crude product was extracted with ethyl acetate and washed with aq. $\mathrm{Na}_{2} \mathrm{~S}_{2} \mathrm{O}_{3}(10 \%)$ and with aq. sat. $\mathrm{NaCl}$. The combined organic layers were dried over $\mathrm{MgSO}_{4}$, and the solvent was removed in vacuo. The crude product was purified by column chromatography $\left(\mathrm{SiO}_{2}\right.$; hexane/ ethyl acetate, gradient 7:1 to 1:1) to afford the title compound (83) $(1.11 \mathrm{~g}, 1.8 \mathrm{mmol}, 44 \%)$ as a light-yellow oil.

TLC, $R_{\mathrm{f}}=0.20$ hexane/ ethyl acetate $(4: 1)$.

${ }^{1} \mathbf{H}-\mathrm{NMR}\left(600 \mathrm{MHz}, \mathrm{CDCl}_{3}\right): \delta(\mathrm{ppm})=7.30-7.25\left(\mathrm{~m}, 5 \mathrm{H}, \mathrm{CH}_{\text {arom }}\right), 6.48(\mathrm{~s}, 1 \mathrm{H}, \mathrm{C} 5 \mathrm{H}), 6.08(\mathrm{~s}$, 1H, C1'H), 5.18 (m, 1H, C2'H), 5.04 (m, 1H, C3'H), 4.97 (m, 2H, CH $), 4.18$ (m, 1H, C4'H), 3.79-3.72 (m, 2H, C5 ' $\mathrm{H}_{2}$ ), 1.53 (s, 3H, $\left.\mathrm{CH}_{3}\right), 1.32$ (s, 3H, $\left.\mathrm{CH}_{3}\right), 0.89$ (s, 9H, $\left.\mathrm{SiC}\left(\mathrm{CH}_{3}\right)_{3}\right), 0.08$ (s, 6H, $\left.\mathrm{Si}\left(\mathrm{CH}_{3}\right)_{2}\right)$.

${ }^{13} \mathrm{C}-\mathrm{NMR}\left(126 \mathrm{MHz}, \mathrm{CDCl}_{3}\right): \delta(\mathrm{ppm})=160.4(\mathrm{C} 4), 147.9(\mathrm{C} 2), 135.8\left(\mathrm{C}_{\text {quart }}\right), 128.8\left(\mathrm{C}_{\text {arom }}\right)$, 128.4( $\left.\mathrm{C}_{\text {arom}}\right), 127.8,\left(\mathrm{C}_{\text {arom}}\right), 116.4(\mathrm{C} 6), 113.6\left(\underline{\mathrm{C}}\left(\mathrm{CH}_{3}\right)_{2}\right), 111.1(\mathrm{C} 5), 102.7$ (C1'), 89.8 (C4'),

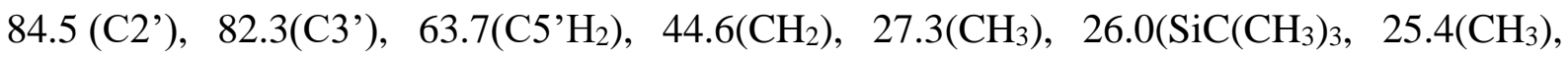
$17.9\left(\mathrm{C}_{\text {quart }}\right),-5.1\left(\mathrm{Si}\left(\mathrm{CH}_{3}\right)\right),-5.2\left(\mathrm{Si}\left(\mathrm{CH}_{3}\right)\right)$.

MS (ESI+, MeOH): m/z = 637.1 [M+Na $]^{+}$.

HRMS (ESI+): m/z calc. for $\mathrm{C}_{25} \mathrm{H}_{36} \mathrm{~N}_{2} \mathrm{O}_{6} \mathrm{Si}_{1} \mathrm{I}[\mathrm{M}+\mathrm{H}]^{+}:$615.1382, found 615.1375.

(ESI+): $\mathrm{m} / \mathrm{z}$ calc. for $\mathrm{C}_{25} \mathrm{H}_{36} \mathrm{~N}_{2} \mathrm{O}_{6} \mathrm{Si}_{1} \mathrm{I}[\mathrm{M}+\mathrm{Na}]^{+}:$: 637.1201, found 637.1186. 


\section{Synthesis of}

\section{3-benzyl-5'-O-tert-butyldimethylsilyl-2',3'-O-isopropylidene-6-b(pin)uridine (87)}

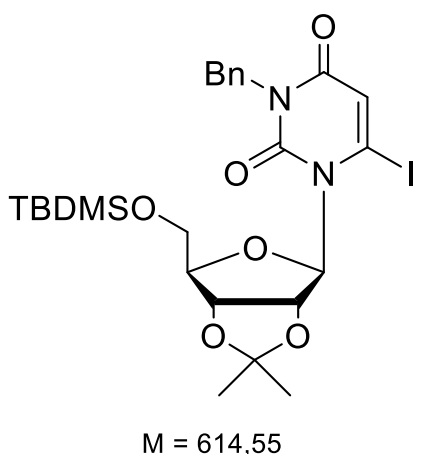

83

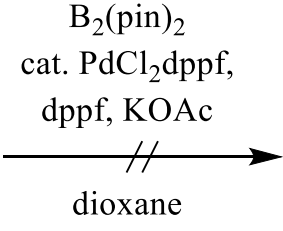

dioxane

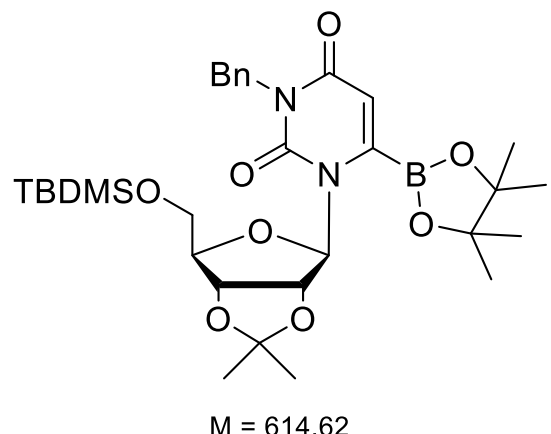

87

Bis(pinacolato)diboron (125 mg, $0.47 \mathrm{mmol}, 1.2 \mathrm{eq}$.$) and potassium acetate (120 mg,$ $1.17 \mathrm{mmol}, 3.0$ eq.) were dissolved in dioxane $(25 \mathrm{~mL})$ under argon atmosphere. Then $\mathrm{PdCl}_{2} \mathrm{dppf}(29 \mathrm{mg}, 10 \mathrm{~mol} \%)$ and dppf $(22 \mathrm{mg}, 10 \mathrm{~mol} \%)$ were added and the mixture was stirred for $30 \mathrm{~min}$. 3-Benzyl-5'-O-tert-butyldimethylsilyl-2',3'-O-isopropylidene-6-iodouridine $(0.24 \mathrm{~g}, 0.39 \mathrm{mmol}, 1.0 \mathrm{eq}$.) was added and the reaction mixture was stirred overnight at $75^{\circ} \mathrm{C}$. No product formation could be observed in TLC, or MS analytics.

\section{Synthesis of 5'-O-tert-butyldimethylsilyl-2',3'-O-isopropylidene-6-b(pin)uridine (85)}

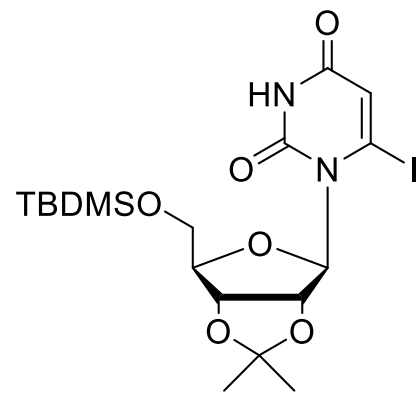

$M=524,43$

38

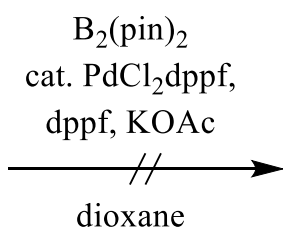

dioxane

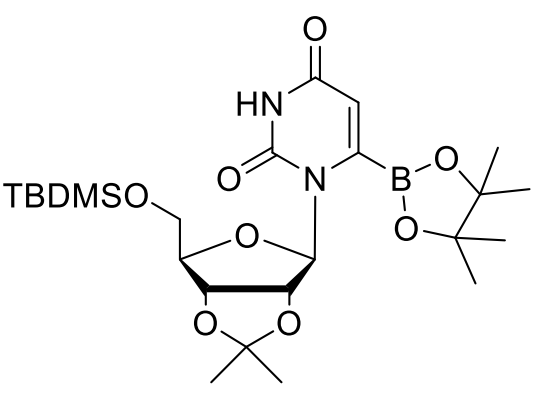

85

Bis(pinacolato)diboron (125 mg, $0.47 \mathrm{mmol}, 1.2$ eq.) and potassium acetate (120 mg, $1.17 \mathrm{mmol}, 3.0$ eq.) were dissolved in dioxane $(25 \mathrm{~mL})$ under argon atmosphere. Then $\mathrm{PdCl}_{2} \mathrm{dppf}(29 \mathrm{mg}, 10 \mathrm{~mol} \%)$ and dppf (22 mg, $10 \mathrm{~mol} \%$ ) were added and the mixture was stirred for $30 \mathrm{~min}$. 5'-O-tert-Butyldimethylsilyl-2',3'-O-isopropylidene-6-iodouridine (200 mg, $0.39 \mathrm{mmol}, 1.0$ eq.) was added and the reaction mixture was stirred overnight at $75^{\circ} \mathrm{C}$. No product formation could be observed in TLC, or MS analytics. 


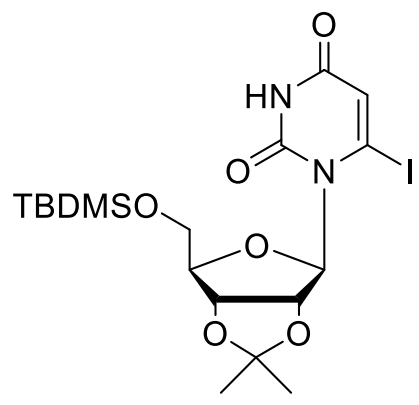

$M=524,43$

38

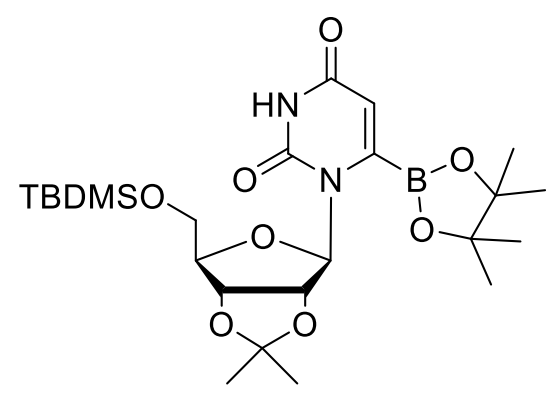

$M=524,49$

85

Bis(pinacolato)diboron (120 mg, $0.45 \mathrm{mmol}, 1.1 \mathrm{eq}$.$) and sodium tert-butoxide (45 mg,$ $0.45 \mathrm{mmol}, 1.1$ eq.) were suspended in THF $(5.0 \mathrm{~mL})$ under argon atmosphere. Diethylzinc (45 $\mu \mathrm{L}, 0.40 \mathrm{mmol}, 1.0$ eq.) was added very slowly and the mixture was stirred for $30 \mathrm{~min}$. Then, 5'-O-tert-butyldimethylsilyl-2',3'-O-isopropylidene-6-iodouridine (200 mg, $0.39 \mathrm{mmol}$, 1.0 eq.) dissolved in THF (5.0 mL) was added and the reaction was stirred over night at reflux. The reaction was quenched by addition of aq. sat. $\mathrm{NH}_{4} \mathrm{Cl}$, but no product formation was observed.

\section{Synthesis of}

\section{3-benzyl-5'-O-tert-butyldimethylsilyl-2',3'-O-isopropylidene-6-b(pin)uridine (87)}

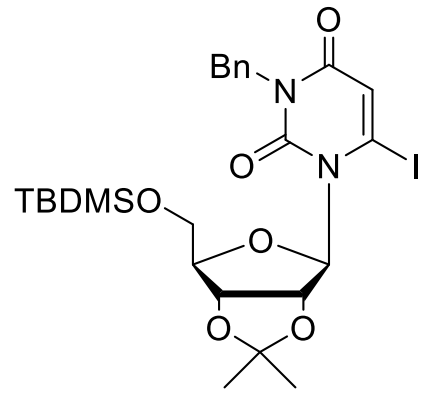

$M=614,55$

83

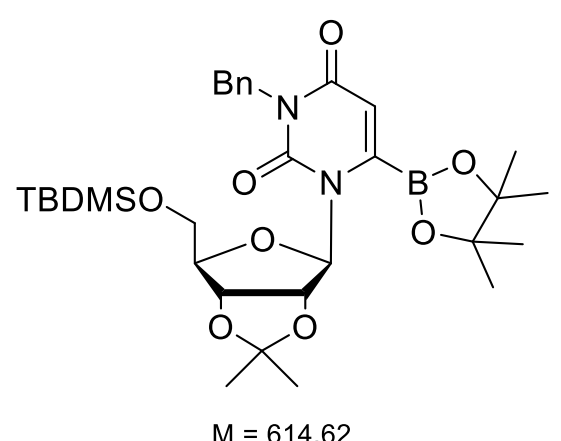

87

Bis(pinacolato)diboron (120 mg, $0.45 \mathrm{mmol}, 1.1 \mathrm{eq}$.$) and sodium tert-butoxide (45 mg,$ $0.45 \mathrm{mmol}, 1.1$ eq.) were suspended in THF $(5.0 \mathrm{~mL})$ under argon atmosphere. Diethylzinc (45 $\mu \mathrm{L}, 0.40 \mathrm{mmol}, 1.0$ eq.) was added very slowly and the mixture was stirred for $30 \mathrm{~min}$. Then, 3-benzyl-5'-O-tert-butyldimethylsilyl-2',3'-O-isopropylidene-6-iodouridine $\quad(0.25 \mathrm{~g}$, $0.39 \mathrm{mmol}, 1.0$ eq.) dissolved in THF $(5.0 \mathrm{~mL})$ was added and the reaction was stirred over night at reflux. After quenching, no product formation was observed. 


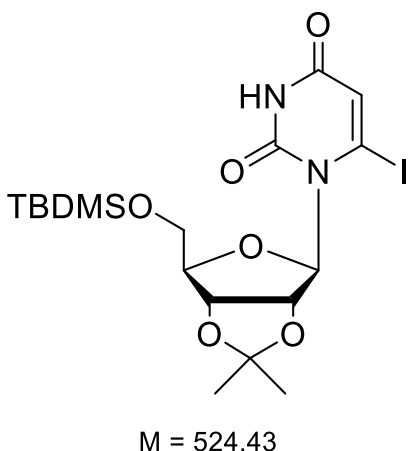

38

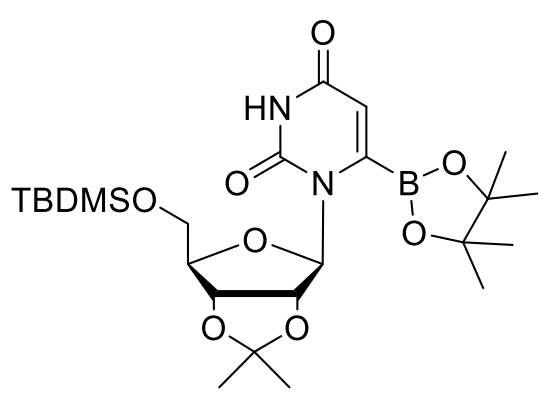

$M=524,49$

85

5'-O-tert-Butyldimethylsilyl-2',3'-O-isopropylidene-6-iodouridine (38) (200 mg, 0.39 mmol, 1.0 eq. $)$ was dissolved in THF $(8.0 \mathrm{~mL})$ and cooled to $-78^{\circ} \mathrm{C}$. Then, $n$-BuLi $(2.0 \mathrm{M}, 0.40 \mathrm{~mL}$, $0.79 \mathrm{mmol}, 2.0$ eq.) was added dropwise and the mixture was stirred for $30 \mathrm{~min}$. The freshly synthesized chloro-B(pin) (100 mg, $0.60 \mathrm{mmol}, 1.5$ eq.) was added and the mixture was stirred for $3 \mathrm{~h}$ at $-78^{\circ} \mathrm{C}$. The reaction was quenched by adding aq. $\mathrm{NH}_{4} \mathrm{Cl}$, but no product formation was observed. Instead, 5'-O-tert-butyldimethylsilyl-2',3'-O-isopropylideneuridine (22) was isolated.

\section{Synthesis of}

3-benzyl-5'-O-tert-butyldimethylsilyl-2',3'-O-isopropylidene-6-b(pin)uridine (87)

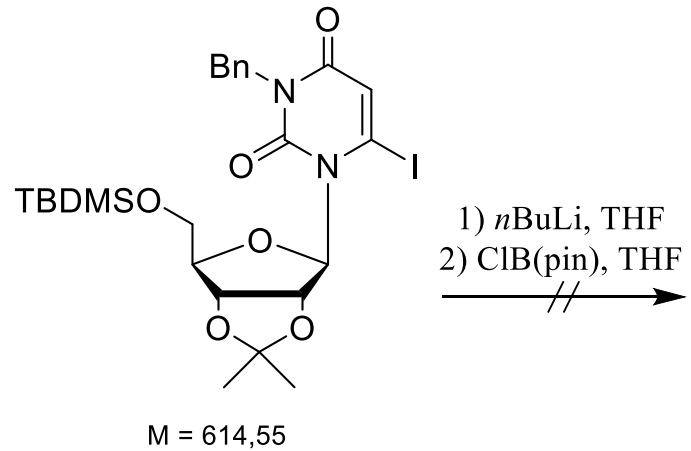

83

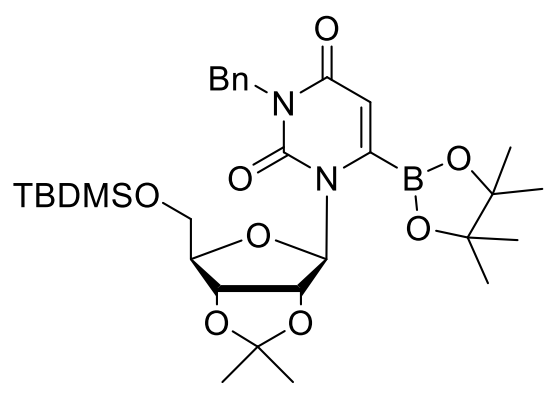

87

3-Benzyl-5'-O-tert-butyldimethylsilyl-2',3'-O-isopropylidene-6-iodouridine $\quad(\mathbf{8 3}) \quad(0.25 \mathrm{~g}$, $0.40 \mathrm{mmol}, 1.0$ eq. $)$ was dissolved in THF $(8.0 \mathrm{~mL})$ and cooled to $-78^{\circ} \mathrm{C}$. Then, $n$-BuLi $(2.0 \mathrm{M}$, $0.40 \mathrm{~mL}, 0.79 \mathrm{mmol}, 2.0$ eq.) was added dropwise and the mixture was stirred for $30 \mathrm{~min}$. The freshly synthesized chloro-B(pin) (100 mg, $0.60 \mathrm{mmol}, 1.5$ eq.) was added and the mixture was stirred for $3 \mathrm{~h}$ at $-78^{\circ} \mathrm{C}$. The reaction was quenched by the addition of aq. $\mathrm{NH}_{4} \mathrm{Cl}$, but no product formation was observed. 


\section{Synthesis of}

\section{3-benzyl-5'-O-tert-butyldimethylsilyl-2',3'-O-isopropylidene-6-b(pin)uridine (87)}

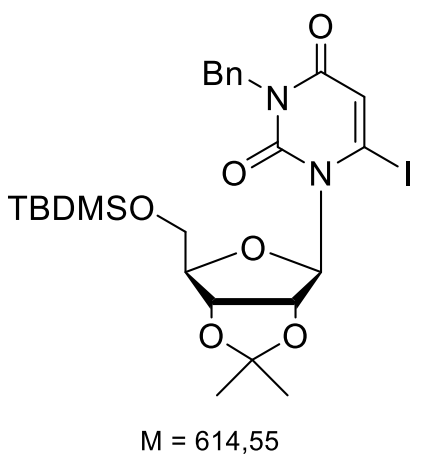

83

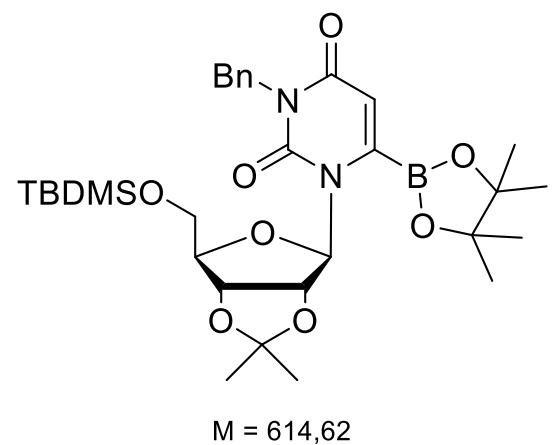

87

Bis(pinacolato)diboron (255 mg, $1.00 \mathrm{mmol}, 2.00 \mathrm{eq}$. ), NaOMe (55 mg, $1.00 \mathrm{mmol}, 2.0$ eq.) and 3-benzyl-5'-O-tert-butyldimethylsilyl-2',3'-O-isopropylidene-6-iodouridine $\quad(0.31 \mathrm{~g}$, $0.50 \mathrm{mmol}, 1.0$ eq.) were dissolved in $\mathrm{mtbe}(10 \mathrm{~mL})$ in a sealed tube. Then, $p$-phenylpyridine (35 mg, $20 \mathrm{~mol} \%$.) was added and stirred overnight at $80^{\circ} \mathrm{C}$. The reaction was poured into water $(20 \mathrm{~mL})$ and extracted with $\mathrm{Et}_{2} \mathrm{O}$. No product formation could be observed.

\section{Synthesis of 5'-O-tert-butyldimethylsilyl-2',3'-O-isopropylidene-6-b(pin)uridine (85)}

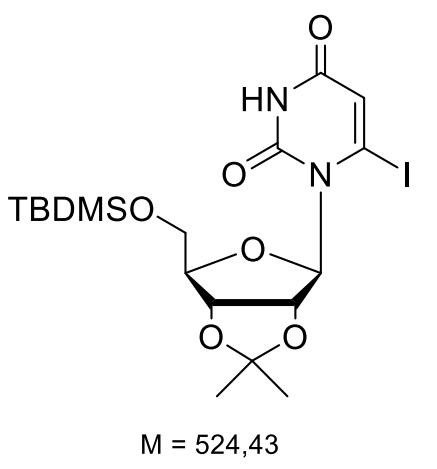

38
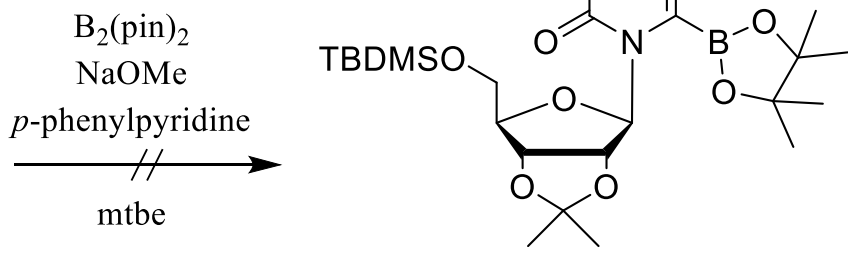

$M=524,49$

85

Bis(pinacolato)diboron (255 mg, $1.00 \mathrm{mmol}, 2.00$ eq.), NaOMe (55 mg, $1.00 \mathrm{mmol}, 2.00 \mathrm{eq}$.) and 5'-O-tert-butyldimethylsilyl-2',3'-O-isopropylidene-6-iodouridine $(0.26 \mathrm{~g}, 0.50 \mathrm{mmol}$, 1.00 eq.) were dissolved in mtbe $(10 \mathrm{~mL})$ in a sealed tube. Then, $p$-phenylpyridine $(35 \mathrm{mg}$, $20 \mathrm{~mol} \%$.) was added and stirred overnight at $80^{\circ} \mathrm{C}$. The reaction was poured into water $(20 \mathrm{~mL})$ and extracted with $\mathrm{Et}_{2} \mathrm{O}$. No product formation could be observed. 
6. Experimental part

\section{Synthesis of 2,4,6-tribromopyrimidine (93)}<smiles>O=C1CC(=O)NC(=O)N1</smiles>

92

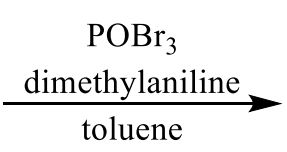

toluene<smiles>Brc1cc(Br)nc(Br)n1</smiles>

$M=316,78$

93

Phosphoryl bromide $(6.50 \mathrm{~g}, 22.6 \mathrm{mmol}, 3.9$ eq. $)$ was dissolved in toluene $(50 \mathrm{~mL})$ at room temperature under argon atmosphere. Freshly distilled $N, N$-dimethylaniline $(1.4 \mathrm{~mL}$, $11.1 \mathrm{mmol}, 1.7$ eq.) was added slowly. Then, barbituric acid (0.75 g, $5.8 \mathrm{mmol}, 1.0$ eq.) was added and the reaction mixture was stirred overnight at $80^{\circ} \mathrm{C}$. The mixture was poured into ice and the organic layer was washed with aq. sat. $\mathrm{NaCl}(3 \times 15 \mathrm{~mL})$ and dried over $\mathrm{MgSO}_{4}$. The solvent was removed under reduced pressure and the product (1.48 g, $4.7 \mathrm{mmol}, 79 \%)$, which was obtained as a light-yellow solid was used without further purifications.

${ }^{\mathbf{1}} \mathbf{H}-\mathbf{N M R}\left(300 \mathrm{MHz}, \mathrm{CDCl}_{3}\right): \delta(\mathrm{ppm})=7.69(\mathrm{~s}, 1 \mathrm{H}, \mathrm{CH})$.

HRMS (ESI+): $\mathrm{m} / \mathrm{z}$ calc. for $\mathrm{C}_{4} \mathrm{HN}_{2}{ }^{79} \mathrm{Br}_{3} \quad[\mathrm{M}+\mathrm{H}]^{+}: 314.7763$, found: 314.7758 .

(ESI+): $\mathrm{m} / \mathrm{z}$ calc. for $\mathrm{C}_{4} \mathrm{HN}_{2}{ }^{79} \mathrm{Br}_{2}{ }^{81} \mathrm{Br}_{1}[\mathrm{M}+\mathrm{H}]^{+}: 316.7742$, found: 316.7731 .

(ESI+): m/z calc. for $\mathrm{C}_{4} \mathrm{HN}_{2}{ }^{79} \mathrm{Br}_{1}{ }^{81} \mathrm{Br}_{2}[\mathrm{M}+\mathrm{H}]^{+}:$318.7722, found: 318.7707 .

(ESI+): $\mathrm{m} / \mathrm{z}$ calc. for $\mathrm{C}_{4} \mathrm{HN}_{2}{ }^{81} \mathrm{Br}_{3} \quad[\mathrm{M}+\mathrm{H}]^{+}:$: 20.7701 , found: 320.7687 . 


\section{Synthesis of 2,4-bis(benzyloxy)-6-bromopyrimidine (94)}<smiles>Brc1cc(Br)nc(Br)n1</smiles>

93

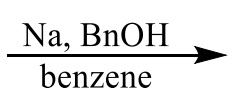

94<smiles>Brc1nc(OCc2ccccc2)cc(OCc2ccccc2)n1</smiles>

95

2,4,6-Tribromopyrimidine (1.48 g, $4.7 \mathrm{mmol}, 1.0 \mathrm{eq}$.) was dissolved in benzene (15 mL) and benzyl alcohol $(10 \mathrm{~mL})$ and cooled to $0^{\circ} \mathrm{C}$. In a second flask, sodium $(0.33 \mathrm{~g}, 14.0 \mathrm{mmol})$ was dissolved in benzyl alcohol $(14 \mathrm{~mL})$ and stirred for $1 \mathrm{~h}$ at room temperature. Then, the prepared sodium alkoxide solution (1.0 M, $10 \mathrm{~mL}, 10 \mathrm{mmol}, 2.1 \mathrm{eq})$ was added dropwise and the reaction mixture was stirred overnight at room temperature. The resulting precipitate was filtered and washed with diethyl ether. The solvent was removed under reduced pressure and the crude product was purified by column chromatography $\left(\mathrm{SiO}_{2}\right.$; hexane/EtOAc 10:1) to obtain the title compound $(0.89 \mathrm{~g}, 2.4 \mathrm{mmol}, 51 \%)$ as a light-yellow oil.

MS (ESI+, MeOH): m/z = $371.0[\mathrm{M}+\mathrm{H}]^{+}, 393.0[\mathrm{M}+\mathrm{Na}]^{+}$.

HRMS (ESI+): $\mathrm{m} / \mathrm{z}$ calc. for $\mathrm{C}_{18} \mathrm{H}_{15} \mathrm{~N}_{2} \mathrm{O}_{2}{ }^{79} \mathrm{Br}_{1}[\mathrm{M}+\mathrm{H}]^{+}: 371.0390$, found: 371.0393 .

(ESI+): m/z calc. for $\mathrm{C}_{18} \mathrm{H}_{15} \mathrm{~N}_{2} \mathrm{O}_{2}{ }^{81} \mathrm{Br}_{1}[\mathrm{M}+\mathrm{H}]^{+}:$373.0370, found: 373.0372 .

(ESI+): $\mathrm{m} / \mathrm{z}$ calc. for $\mathrm{C}_{18} \mathrm{H}_{15} \mathrm{~N}_{2} \mathrm{O}_{2}{ }^{79} \mathrm{Br}_{1}[\mathrm{M}+\mathrm{Na}]^{+}:$393.0209, found: 393.0211 .

(ESI+): $\mathrm{m} / \mathrm{z}$ calc. for $\mathrm{C}_{18} \mathrm{H}_{15} \mathrm{~N}_{2} \mathrm{O}_{2}{ }^{81} \mathrm{Br}_{1}[\mathrm{M}+\mathrm{Na}]^{+}: 395.0189$, found: 395.0192 . 
6. Experimental part

\section{Synthesis of (2,6-bis(benzyloxy)pyrimidin-4-yl)boronic acid (96)}<smiles>Brc1cc(OCc2ccccc2)nc(OCc2ccccc2)n1</smiles>

$M=371,23$

1) ${ }^{\mathrm{n}} \mathrm{BuLi}, \mathrm{THF},-95^{\circ} \mathrm{C}$

2) $\mathrm{B}(\mathrm{OEt})_{3}, \mathrm{THF}$

3) $1 \mathrm{M} \mathrm{HCl}$

$$
\text { /I }
$$<smiles>[Tl]</smiles>

95<smiles>OB(O)c1cc(OCc2ccccc2)nc(OCc2ccccc2)n1</smiles>

$M=336,15$

2,4-Bis(benzyloxy)-6-bromopyrimidine $(0.25 \mathrm{~g}, 0.67 \mathrm{mmol}, 1.0$ eq. $)$ was dissolved in THF $(20 \mathrm{~mL})$ and cooled to $-95^{\circ} \mathrm{C}$. Then, $n$-BuLi $(2.5 \mathrm{M}, 0.40 \mathrm{~mL}, 1.0 \mathrm{mmol}, 1.5$ eq.) was added slowly and subsequently triethyl borate $(0.20 \mathrm{~mL}, 1.0 \mathrm{mmol}, 1.5 \mathrm{eq}$.$) was added, the solution$ was stirred for $30 \mathrm{~min}$ and was allowed to warm up to room temperature within $2 \mathrm{~h}$. The solvent was removed in vacuo and the residue was dissolved in water which was then acidified to $\mathrm{pH}=3$ with $\mathrm{HCl}(1.0 \mathrm{M})$ and extracted with $\mathrm{Et}_{2} \mathrm{O}$. Unfortunately, no product formation was observed.

This synthesis was repeated several times changing the borate species, equivalents of BuLi and borates as well as reaction time and temperature without successful product formation. 


\subsubsection{Synthesis of 5-methyl OMP}

\section{Synthesis of 2',3'-O-isopropylidene-5-methyluridine (98)}<smiles>Cc1cn(C2OC(CO)C(O)C2O)c(=O)[nH]c1=O</smiles>

$M=258,23$

97<smiles>Cc1cn(C23O[C@H](OC(C)(C)O2)C2OC3(CO)O2)c(=O)[nH]c1=O</smiles>

$M=298,30$

98

5-Methyluridine $\left(2.01 \mathrm{~g}, 7.79 \mathrm{mmol}, 1.00 \mathrm{eq}\right.$ ) was suspended in acetone $(50 \mathrm{~mL}), \mathrm{HClO}_{4}$ $(1.0 \mathrm{~mL})$ was added, and the reaction mixture was stirred at room temperature for $12 \mathrm{~h}$. The reaction was quenched by adding $\mathrm{NEt}_{3}(3.0 \mathrm{~mL})$ and the solvent was evaporated in vacuo. The crude product was purified by column chromatography $\left(\mathrm{SiO}_{2}\right.$; gradient ethyl acetate/MeOH 100:0 to 95:5). The title compound (1.81 g, $6.07 \mathrm{mmol}, 78 \%)$ was obtained as a white solid.

${ }^{1}$ H-NMR (300 MHz, DMSO- $\left.d_{6}\right): \delta(\mathrm{ppm})=7.64(\mathrm{~s}, 1 \mathrm{H}, \mathrm{C} 6 \mathrm{H}), 5.82(\mathrm{~d}, J=2.8 \mathrm{~Hz}, 1 \mathrm{H}, \mathrm{C1}$ 'H), 4.88 (dd, $J=6.4,2.9 \mathrm{~Hz}, 1 \mathrm{H}, \mathrm{C} 2$ 'H), 4.75 (dd, $J=6.4,3.7 \mathrm{~Hz}, 1 \mathrm{H}, \mathrm{C} 3$ 'H), 4.06-4.01 (m, 1H, C4'H), 3.60-3.57 (m, 2H, C5' $\left.\mathrm{H}_{2}\right), 1.76\left(\mathrm{~s}, 3 \mathrm{H}, \mathrm{CH}_{3}\right), 1.48\left(\mathrm{~s}, 3 \mathrm{H}, \mathrm{CH}_{3}\right), 1.28\left(\mathrm{~s}, 3 \mathrm{H}, \mathrm{CH}_{3}\right)$.

${ }^{13}$ C-NMR (75 MHz, DMSO-d6): $\delta(\mathrm{ppm})=164.2$ (C4), 150.8 (C2), 137.9 (C6), 113.6 ( $\left.\underline{\mathrm{C}}\left(\mathrm{CH}_{3}\right)_{2}\right), 109.9$ (C5), 90.9 (C1'), 86.5 (C4'), 83.8 (C2'), 80.8 (C3'), $61.7\left(\mathrm{C}^{\prime}{ }^{\prime}\right), 27.5\left(\mathrm{CH}_{3}\right)$, $25.8\left(\mathrm{CH}_{3}\right), 12.6\left(\mathrm{CH}_{3}\right)$.

MS (ESI+, MeOH): m/z = 299.1 [M+H] $]^{+}, 321.1[\mathrm{M}+\mathrm{Na}]^{+}$.

HRMS (ESI+): m/z calc. for $\mathrm{C}_{13} \mathrm{H}_{18} \mathrm{~N}_{2} \mathrm{O}_{6}[\mathrm{M}+\mathrm{H}]^{+}:$299.1238, found: 299.1240 .

(ESI+): $\mathrm{m} / \mathrm{z}$ calc. for $\mathrm{C}_{13} \mathrm{H}_{18} \mathrm{~N}_{2} \mathrm{O}_{6}[\mathrm{M}+\mathrm{Na}]^{+}: 321.1057$, found: 321.1062 . 


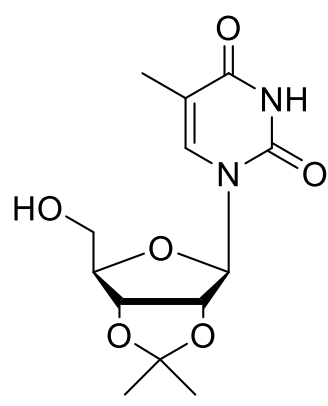

$M=298,30$

98

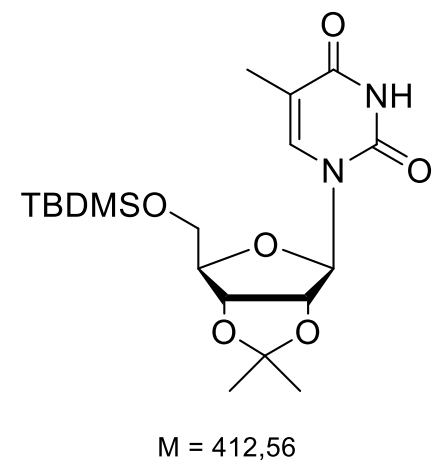

99

2',3'-O-Isopropylidene-5-methyluridine $(1.81 \mathrm{~g}, 6.07 \mathrm{mmol}, 1.0$ eq.), imidazole (1.03 g, $15.2 \mathrm{mmol}, 2.5$ eq.) and TBDMSCl (1.38 g, $9.11 \mathrm{mmol}, 1.5$ eq.) were dissolved in DMF $(20 \mathrm{~mL})$ and the solution was stirred overnight at room temperature. The solvent was removed under reduced pressure and the crude product was purified by column chromatography $\left(\mathrm{SiO}_{2}\right.$; hexane/ ethyl acetate 1:1). The title compound (2.38 g, $5.76 \mathrm{mmol}, 95 \%)$ was obtained as a white solid.

${ }^{1}$ H-NMR $\left(300 \mathrm{MHz}, \mathrm{DMSO}-d_{6}\right): \delta(\mathrm{ppm})=7.47(\mathrm{~s}, 1 \mathrm{H}, \mathrm{C} 6 \mathrm{H}), 5.79\left(\mathrm{~d}, J=2.8 \mathrm{~Hz}, 1 \mathrm{H}, \mathrm{C} 1{ }^{\prime} \mathrm{H}\right)$, $4.91\left(\mathrm{dd}, J=6.3,2.2 \mathrm{~Hz}, 1 \mathrm{H}, \mathrm{C} 2{ }^{\prime} \mathrm{H}\right), 4.72$ (dd, $\left.J=6.2,3.7 \mathrm{~Hz}, 1 \mathrm{H}, \mathrm{C} 3{ }^{\prime} \mathrm{H}\right), 4.07$ (m, 1H, C4'H), $3.80\left(\mathrm{dd}, J=11.4,4.1 \mathrm{~Hz}, 1 \mathrm{H}, \mathrm{C}^{\prime} \mathrm{H}_{2}\right), 3.74\left(\mathrm{dd}, J=11.2,4.9 \mathrm{~Hz}, 1 \mathrm{H}, \mathrm{C}^{\prime} \mathrm{H}_{2}\right) 1.77(\mathrm{~s}, 3 \mathrm{H}$, $\left.\mathrm{CH}_{3}\right), 1.48$ (s, 3H, $\left.\mathrm{CH}_{3}\right), 1.29$ (s, 3H, $\left.\mathrm{CH}_{3}\right) .0 .86$ (s, 9H, $\left.\mathrm{SiC}\left(\mathrm{CH}_{3}\right)_{3}\right), 0.04\left(\mathrm{~s}, 6 \mathrm{H}, \mathrm{Si}\left(\mathrm{CH}_{3}\right)_{2}\right)$.

${ }^{13}$ C-NMR $\left(75 \mathrm{MHz}\right.$, DMSO- $\left.d_{6}\right): \delta(\mathrm{ppm})=164.2$ (C4), 150.8 (C2), 137.9 (C6), 113.5 $\left(\underline{\mathrm{C}}\left(\mathrm{CH}_{3}\right)_{2}\right), 109.8$ (C5), $91.6\left(\mathrm{C}^{\prime}\right.$ '), 86.6 (C4'), 84.0 (C2'), 80.8 (C3'), 63.5 (C5'), $27.5\left(\mathrm{CH}_{3}\right)$, $25.6\left(\mathrm{SiC}\left(\underline{\mathrm{CH}}_{3}\right)_{3}\right), 25.6\left(\mathrm{CH}_{3}\right), 18.4\left(\mathrm{SiC}\left(\mathrm{CH}_{3}\right)_{3}\right), 12.5\left(\mathrm{CH}_{3}\right) .-4.9 \mathrm{Si}\left(\mathrm{CH}_{3}\right)_{2},-5.0 \mathrm{Si}\left(\mathrm{CH}_{3}\right)_{2}$.

MS (ESI+, MeOH): m/z = 435.2[M+Na $]^{+}, 847.4[2 \mathrm{M}+\mathrm{Na}]^{+}, 1259.6[3 \mathrm{M}+\mathrm{Na}]^{+}$.

HRMS (ESI+): m/z calc. for $\mathrm{C}_{19} \mathrm{H}_{32} \mathrm{~N}_{2} \mathrm{O}_{6}[\mathrm{M}+\mathrm{H}]^{+}:$413.2102, found: 413.2108.

(ESI+): m/z calc. for $\mathrm{C}_{19} \mathrm{H}_{32} \mathrm{~N}_{2} \mathrm{O}_{6}[\mathrm{M}+\mathrm{Na}]^{+}:$435.1922, found: 435.1921 . 


\section{Synthesis of 5'-O-tert-butyldimethylsilyl-2',3'- $O$-isopropylidene-5-methylorotidine (100)}

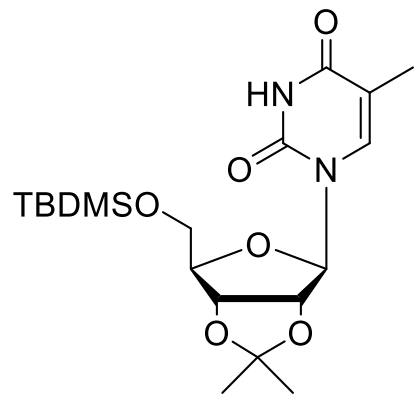

$M=412,56$

99

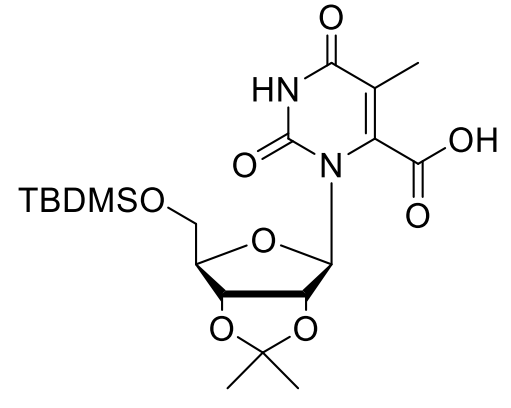

$M=456,57$

100

5'-O-tert-Butyldimethylsilyl-2',3'-O-isopropylidene-5-methyluridine $\quad(2.38 \mathrm{~g}, \quad 5.76 \mathrm{mmol}$, 1.0 eq.) was dissolved in THF $(25 \mathrm{~mL})$ and the solution was cooled to $-78^{\circ} \mathrm{C}$. Then, LDA (2.0 M, $5.76 \mathrm{~mL}, 11.5 \mathrm{mmol}, 2.0$ eq.) was added slowly. The resulting reaction mixture was stirred at $-78^{\circ} \mathrm{C}$ for $30 \mathrm{~min}$. Carbon dioxide was bubbled through the solution for $4 \mathrm{~h}$ at $-78^{\circ} \mathrm{C}$. The reaction was quenched by the addition of acetic acid $(1.0 \mathrm{~mL})$ and the solvent was removed under reduced pressure. The crude product was purified by column chromatograohy $\left(\mathrm{SiO}_{2}\right.$; pentane/EtOAc 1:1). The title compound ( $865 \mathrm{mg}, 1.90 \mathrm{mmol}, 33 \%)$ was obtained as a yellowish solid.

${ }^{1}$ H-NMR (300 MHz, DMSO- $\left.d_{6}\right): \delta(\mathrm{ppm})=5.62\left(\mathrm{~s}, 1 \mathrm{H}, \mathrm{C} 1^{\prime} \mathrm{H}\right), 5.05\left(\mathrm{~d}, J=6.3 \mathrm{~Hz}, 1 \mathrm{H}, \mathrm{C} 2{ }^{\prime} \mathrm{H}\right)$, 4.70-4.67 (m, 1H, C3'H), 3.90-3.85 (m, 1H, C4'H), 3.73-3.67 (m, 2H, C5' $\left.\mathrm{H}_{2}\right), 1.65$ (s, 3H, $\left.\mathrm{CH}_{3}\right), 1.41$ (s, 3H, $\left.\mathrm{CH}_{3}\right), 1.25\left(\mathrm{~s}, 3 \mathrm{H}, \mathrm{CH}_{3}\right) .0 .88$ (s, 9H, $\left.\mathrm{SiC}\left(\mathrm{CH}_{3}\right)_{3}\right), 0.08\left(\mathrm{~s}, 6 \mathrm{H}, \mathrm{Si}\left(\mathrm{CH}_{3}\right)_{2}\right)$.

${ }^{13}$ C-NMR (75 MHz, DMSO- $\left.d_{6}\right): \delta(\mathrm{ppm})=165.2(\mathrm{COOH}), 163.9(\mathrm{C} 4), 150.7(\mathrm{C} 2), 134.5(\mathrm{C} 6)$, 116.9 (C5), $112.8\left(\underline{\mathrm{C}}\left(\mathrm{CH}_{3}\right)_{2}\right), 94.0$ (C1'), 89.2 (C4'), 84.9 (C2'), 82.5 (C3'), 64.3 (C5'), $27.6\left(\mathrm{CH}_{3}\right), 26.0\left(\mathrm{SiC}\left(\underline{\mathrm{CH}}_{3}\right)_{3}\right), 25.6\left(\mathrm{CH}_{3}\right), 18.5\left(\mathrm{SiC}\left(\mathrm{CH}_{3}\right)_{3}\right), 11.4\left(\mathrm{CH}_{3}\right)$. $-4.9 \mathrm{Si}\left(\mathrm{CH}_{3}\right)_{2}$.

MS (ESI-, $\mathrm{MeOH}): \mathrm{m} / \mathrm{z}=455.2[\mathrm{M}-\mathrm{H}]^{-}$.

HRMS (ESI-): m/z calc. for $\mathrm{C}_{20} \mathrm{H}_{32} \mathrm{~N}_{2} \mathrm{O}_{8}[\mathrm{M}-\mathrm{H}]^{-}: 455.1855$, found: 455.1854 . 
6. Experimental part

\section{Synthesis of 5-methylorotidine (101)}

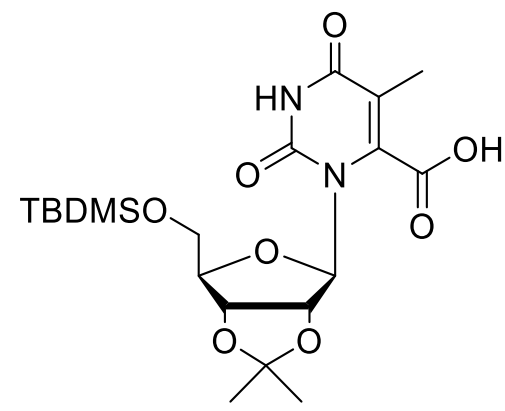

$M=456,57$

100<smiles>Cc1c(C(=O)O)n(C2OC(CO)C(O)C2O)c(=O)[nH]c1=O</smiles>

$M=302,24$

101

5'-O-tert-Butyldimethylsilyl-2',3'-O-isopropylidene-5-methylorotidine (290 mg, 0.64 mmol, 1.0 eq.) was dissolved in methanolic $\mathrm{HCl}(0.25 \mathrm{M}, 4.0 \mathrm{~mL})$. The reaction mixture was stirred for $50 \mathrm{~min}$ at room temperature. The solvent was removed in vacuo obtaining the deprotected 5-methylorotidine (190 mg, quant.) which was used without further purification.

${ }^{1}$ H-NMR (300 MHz, DMSO- $\left.d_{6}\right): \delta(\mathrm{ppm})=5.16\left(\mathrm{~d}, J=3.9 \mathrm{~Hz}, 1 \mathrm{H}, \mathrm{C} 1{ }^{\prime} \mathrm{H}\right), 4.50(\mathrm{dd}, J=6.0$, $\left.4.0 \mathrm{~Hz}, 1 \mathrm{H}, \mathrm{C} 2{ }^{\prime} \mathrm{H}\right), 3.83$ (m, 1H, C3’H), 3.70-3.65 (m, 1H, C4’H), 3.60-3.55 (m, 2H, C5' $\left.\mathrm{H}_{2}\right)$, $1.73\left(\mathrm{~s}, 3 \mathrm{H}, \mathrm{CH}_{3}\right)$.

MS (ESI-, MeOH): m/z = $301.1[\mathrm{M}-\mathrm{H}]^{-}$.

HRMS (ESI-): $\mathrm{m} / \mathrm{z}$ calc. for $\mathrm{C}_{11} \mathrm{H}_{14} \mathrm{~N}_{2} \mathrm{O}_{8}[\mathrm{M}-\mathrm{H}]^{-}:$301.0677, found: 301.0677 . 


\section{Synthesis of 5-methylorotidine 5'-monophosphate (23)}<smiles>Cc1c(C(=O)O)n(C2OC(CO)[C@@H](O)[C@H](O)[C@H]2O)c(=O)[nH]c1=O</smiles>

101<smiles>CC1=C(C(=O)O)n2c(=O)[nH]c(=O)n2C2O[C@H](O)[C@H](COP(=O)(O)O)[C@H]1O2</smiles>

$M=382,22$

23

Phosphoryl chloride ( $260 \mu \mathrm{L}, 2.80 \mathrm{mmol}, 4.4$ eq.) was dissolved in $\mathrm{MeCN}(5.0 \mathrm{~mL})$ at $0^{\circ} \mathrm{C}$. Then, water ( $32 \mu \mathrm{L}, 1.78 \mathrm{mmol}, 2.8$ eq.) and pyridine $(230 \mu \mathrm{L}, 2.80 \mathrm{mmol}, 4.4$ eq.) were added and the reaction mixture was stirred for $30 \mathrm{~min}$. 5-Methylorotidine (190 mg, $636 \mu \mathrm{mol}, 1.0 \mathrm{eq}$.) was added and the reaction mixture was stirred for $4 \mathrm{~h}$ at $0^{\circ} \mathrm{C}$. The reaction was quenched by adding aqueous triethylammonium acetate buffer $(1.0 \mathrm{M})$ until neutral $\mathrm{pH}$. The solvent was removed in vacuo, but no product could be isolated.

\section{Synthesis of 5-methylorotidine 5'-monophosphate (23)}<smiles>Cc1c(C(=O)O)n(C2OC(CO)C(O)C(OP(=O)(O)OC(C)(C)C)C2O)c(=O)[nH]c1=O</smiles><smiles>Cc1c(C(=O)O)n(C2OC(COP(=O)(O)O)C(O)C(O)C2O)c(=O)[nH]c1=O</smiles>

5-Methylorotidine (190 mg, $0.64 \mathrm{mmol}, 1.0$ eq.) was dissolved in $\mathrm{PO}(\mathrm{OMe})_{3}(4.5 \mathrm{~mL})$ under argon atmosphere. Then, $\mathrm{POCl}_{3}(120 \mu \mathrm{L}, 1.27 \mathrm{mmol}, 2.0$ eq. $)$ was added at $0{ }^{\circ} \mathrm{C}$. The reaction mixture was stirred for $5 \mathrm{~h}$ at $0^{\circ} \mathrm{C}$ and was quenched by adding aqueous triethylammonium acetate buffer $(1.0 \mathrm{M})$ until neutral $\mathrm{pH}$. The solvent was removed in vacuo, but no product was formed. 
6. Experimental part

\subsubsection{Synthesis of 6-carboxy TMP}

\section{Synthesis of 3',5'-bis-O-(tert-butyldimethylsilyl)thymidine (103)}<smiles>Cc1cn(C2CC3OCC2O3)c(=O)[nH]c1=O</smiles>

$M=242,23$

102
TBDMSCl imidazole DMF

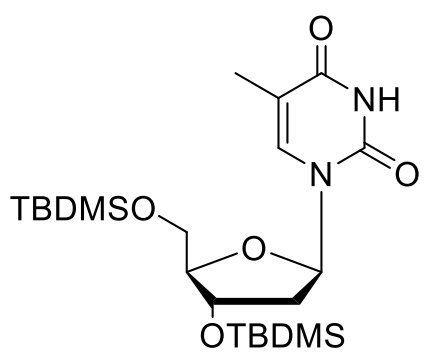

$M=470,76$

103

Thymidine ( $2.50 \mathrm{~g}, 10.3 \mathrm{mmol}, 1.0$ eq.) and imidazole ( $1.76 \mathrm{~g}, 25.8 \mathrm{mmol}, 2.5$ eq.) were dissolved in DMF (20 mL). Then, TBDMSCl (3.10 g, $20.6 \mathrm{mmol}, 2.0$ eq.) was added and the solution was stirred overnight at room temperature. The solvent was removed under reduced pressure and the crude product was purified by column chromatography $\left(\mathrm{SiO}_{2}\right.$; gradient hexane/ ethyl acetate $3: 1$ to $1: 1)$. The title compound $(4.46 \mathrm{~g}, 9.47 \mathrm{mmol}, 92 \%)$ was obtained as a white solid.

TLC, $R_{\mathrm{f}}=0.30$ hexane/ ethyl acetate $(3: 1)$.

${ }^{1} \mathbf{H}-\mathbf{N M R}\left(300 \mathrm{MHz}, \mathrm{CDCl}_{3}\right): \delta(\mathrm{ppm})=8.58(\mathrm{~s}, 1 \mathrm{H}, \mathrm{NH}), 7.46(\mathrm{~s}, 1 \mathrm{H}, \mathrm{C} 6 \mathrm{H}), 6.33(\mathrm{~m}, 1 \mathrm{H}$, C1'H), 4.40 (m, 1H, C3'H), 3.93 (m, 1H, C4'H), 3.82 (m, 2H, C5' $\left.\mathrm{H}_{2}\right), 2.10-2.02$ (m, 2H,

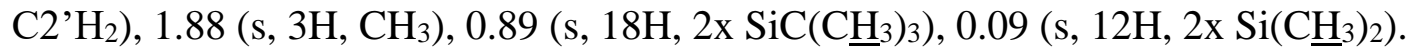

${ }^{13}$ C-NMR (75 MHz, $\left.\mathrm{CDCl}_{3}\right): \delta(\mathrm{ppm})=163.8$ (C4), 150.4 (C2), 135.6 (C6), 111.0 (C5), 88.0 (C1'), 85.0 (C4'), 72.4 (C3'), 60.5 (C5'), $41.5\left(\mathrm{C} 2^{\prime}\right), 26.1\left(\mathrm{SiC}\left(\underline{\mathrm{C}} \mathrm{H}_{3}\right)_{3}\right), 18.2\left(\mathrm{SiC}\left(\mathrm{CH}_{3}\right)_{3}\right), 12.7$ $\left(\mathrm{CH}_{3}\right),-4.7 \mathrm{Si}\left(\mathrm{CH}_{3}\right)_{2}$.

MS (ESI+, MeOH): m/z = $471.3[\mathrm{M}+\mathrm{H}]^{+}$.

HRMS (ESI+): m/z calc. for $\mathrm{C}_{22} \mathrm{H}_{42} \mathrm{~N}_{2} \mathrm{O}_{5} \mathrm{Si}_{2}[\mathrm{M}+\mathrm{H}]^{+}:$471.2705, found: 471.2707. 
Synthesis of 3',5'-bis- $O$-(tert-butyldimethylsilyl)-6-carboxythymidine (108)

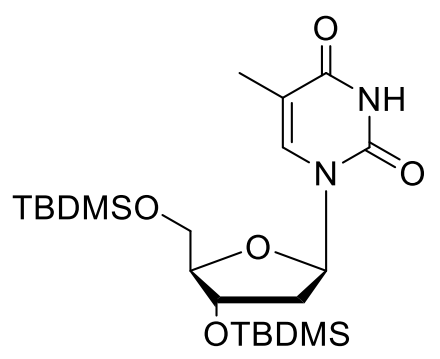

$M=470,76$

103
1) LDA, THF

$-78^{\circ} \mathrm{C}, 1 \mathrm{~h}$

2) $\mathrm{CO}_{2}, \mathrm{THF}$

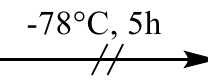

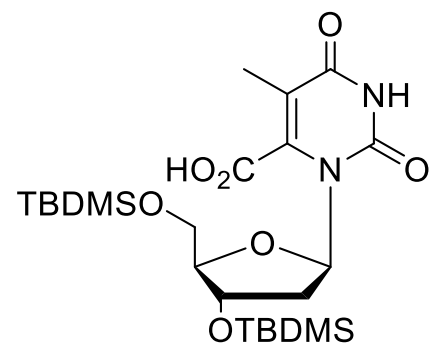

$M=514,77$

108

3',5'-Bis-O-(tert-butyldimethylsilyl)thymidine ( $1.50 \mathrm{~g}, 3.18 \mathrm{mmol}, 1.0 \mathrm{eq}$.) was dissolved in THF (20 mL) and the solution was cooled to $-78^{\circ} \mathrm{C}$. LDA (2.0 M, 3.18 mL, $6.37 \mathrm{mmol}, 2.0$ eq.) was added dropwise. The resulting brownish solution was stirred at $-78^{\circ} \mathrm{C}$ for $60 \mathrm{~min}$. Carbon dioxide was bubbled through the solution for $5 \mathrm{~h}$ at $-78^{\circ} \mathrm{C}$. The reaction was quenched by the addition of HOAc $(1.0 \mathrm{~mL})$ and the solvent was evaporated in vacuo. The crude product was purified by column chromatography ( $\mathrm{SiO}_{2}$; gradient ethyl acetate/ $\mathrm{MeOH}$ 100:0 to 85:15). The title compound ( $80 \mathrm{mg}, 0.16 \mathrm{mmol}, 5 \%$ ) was obtained as a white solid.

TLC, $R_{\mathrm{f}}=0.25$ ethyl acetate/ $\mathrm{MeOH}(85: 15)$.

MS (ESI+, $\mathrm{MeOH}): \mathrm{m} / \mathrm{z}=515.2[\mathrm{M}+\mathrm{H}]^{+}$.

Because of the poor yield the reaction was repeated with methyl chloroformate. 
6. Experimental part

Synthesis of 3',5'-bis-O-(tert-butyldimethylsilyl)-6-carboxymethylthymidine (104)

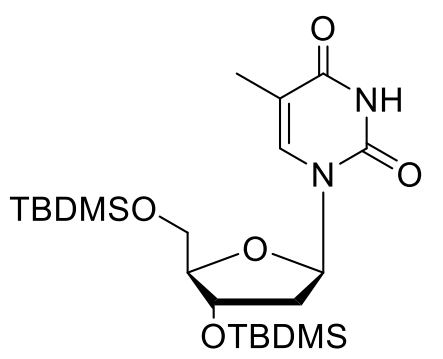

$M=470,76$

103

\author{
1) LDA, THF \\ $-78^{\circ} \mathrm{C}, 1 \mathrm{~h}$
}

2) $\mathrm{ClCO}_{2} \mathrm{Me}, \mathrm{THF}$

$\stackrel{-78^{\circ} \mathrm{C}, 4 \mathrm{~h} \rightarrow}{\longrightarrow}$

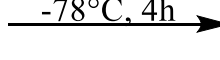

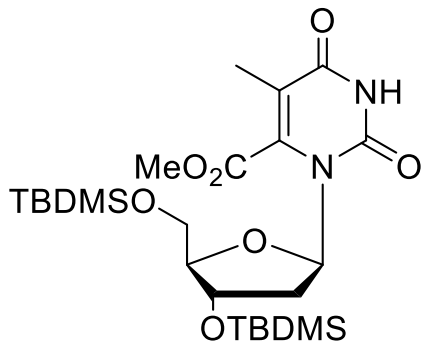

$M=528,79$

104

3',5'-Bis-O-(tert-butyldimethylsilyl)thymidine ( $1.00 \mathrm{~g}, 2.12 \mathrm{mmol}, 1.0 \mathrm{eq}$.) was dissolved in THF ( $15 \mathrm{~mL})$ and the solution was cooled to $-78^{\circ} \mathrm{C}$. LDA $(2.0 \mathrm{M}, 2.12 \mathrm{~mL}, 4.24 \mathrm{mmol}, 2.0$ eq. $)$ was added dropwise. The resulting brownish solution was stirred at $-78^{\circ} \mathrm{C}$ for $60 \mathrm{~min}$. Methyl chloroformate ( $165 \mu \mathrm{L}, 2.12 \mathrm{mmol}, 1.0$ eq.) was added dropwise at $-78^{\circ} \mathrm{C}$ and the solution was stirred for $4 \mathrm{~h}$. The reaction was quenched by the addition of aq. sat. $\mathrm{NH}_{4} \mathrm{Cl}$ and the solvent was evaporated in vacuo. The crude product was purified by column chromatography $\left(\mathrm{SiO}_{2}\right.$; gradient hexane/EtOAc 4:1 to 1:1). The title compound (400 mg, $0.76 \mathrm{mmol}, 36 \%$ ) was obtained as a yellowish solid.

${ }^{1} \mathbf{H}-\mathbf{N M R}\left(300 \mathrm{MHz}, \mathrm{CDCl}_{3}\right): \delta(\mathrm{ppm})=8.58(\mathrm{~s}, 1 \mathrm{H}, \mathrm{NH}), 6.28\left(\mathrm{~m}, 1 \mathrm{H}, \mathrm{Cl}{ }^{\prime} \mathrm{H}\right), 4.40(\mathrm{~m}, 1 \mathrm{H}$, C3'H), 3.95 (m, 1H, C4'H), 3.87 (s, 3H, CO $\left.{ }_{2} \mathrm{Me}\right) 3.82$ (m, 2H, C5' $\left.\mathrm{H}_{2}\right), 2.15-2.07$ (m, 2H, C2 $\left.{ }^{\prime} \mathrm{H}_{2}\right), 1.92$ (s, 3H, CH 3 ), 0.90 (s, 18H, 2x SiC( $\left.\left.\mathrm{C}_{3}\right)_{3}\right), 0.09$ (s, 12H, 2x Si( $\left.\left.\underline{\mathrm{C}}_{3}\right)_{2}\right)$.

MS (ESI+, MeOH): m/z = $529.3[\mathrm{M}+\mathrm{H}]^{+}$.

HRMS (ESI+): m/z calc. for $\mathrm{C}_{22} \mathrm{H}_{44} \mathrm{~N}_{2} \mathrm{O}_{7} \mathrm{Si}_{2}[\mathrm{M}+\mathrm{H}]^{+}:$529.2760, found: 529.2766. 


\section{Synthesis of 6-carboxymethylthymidine (105)}

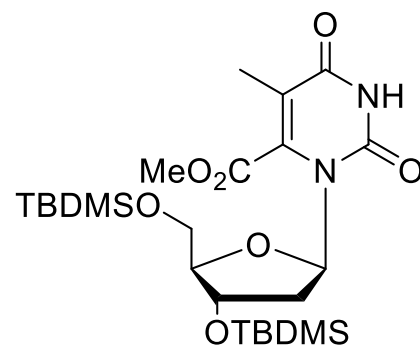

$M=528,79$

104

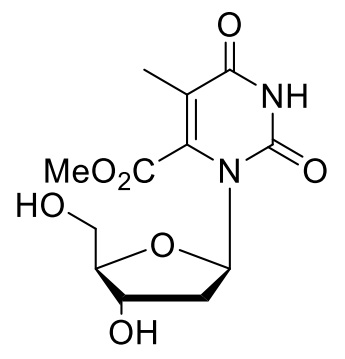

$M=300,27$

105

3',5'-bis- $O$-(tert-butyldimethylsilyl)-6-carboxymethylthymidine (200 mg, $378 \mu$ mol, 1.0 eq.) was dissolved in methanolic $\mathrm{HCl}(0.25 \mathrm{M}, 5.0 \mathrm{~mL})$. The reaction mixture was stirred for $60 \mathrm{~min}$ at room temperature. The solvent was removed in vacuo obtaining the deprotected 6-carboxymethylthymidine (110 mg, quant.) which was used without further purification.

${ }^{1} \mathbf{H}-\mathbf{N M R}\left(300 \mathrm{MHz}, \mathrm{CDCl}_{3}\right): \delta(\mathrm{ppm})=6.17\left(\mathrm{~m}, 1 \mathrm{H}, \mathrm{C1}{ }^{\prime} \mathrm{H}\right), 4.55\left(\mathrm{~m}, 1 \mathrm{H}, \mathrm{C} 3{ }^{\prime} \mathrm{H}\right), 3.98(\mathrm{~m}, 1 \mathrm{H}$, C4'H), 3.89 (s, 3H, CO $\left.{ }_{2} \mathrm{Me}\right) 3.67$ (m, 2H, C5'H $\left.{ }^{\prime}\right), 2.21-2.14$ (m, 2H, C2' $\left.\mathrm{H}_{2}\right), 1.93$ (s, 3H, $\mathrm{CH}_{3}$ ). MS (ESI+, $\mathrm{MeOH}): \mathrm{m} / \mathrm{z}=301.1[\mathrm{M}+\mathrm{H}]^{+}$.

HRMS (ESI+): m/z calc. for $\mathrm{C}_{12} \mathrm{H}_{16} \mathrm{~N}_{2} \mathrm{O}_{7}[\mathrm{M}+\mathrm{H}]^{+}: 301.1030$, found: 301.1032 . 
6. Experimental part

\section{Synthesis of 6-carboxymethyl TMP (109)}

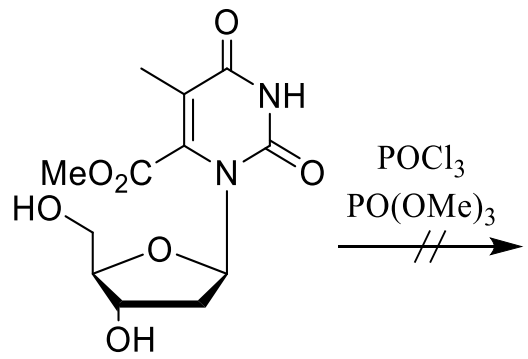

$M=300,27$

105<smiles>COC(=O)c1c(C)c(=O)[nH]c(=O)n1C1O[C@@H]2C[C@H]1O[C@@H](O)[C@H]2O</smiles>

$M=380,25$

109

6-Carboxymethylthymidine (110 mg, $378 \mu \mathrm{mol}, 1.0$ eq.) was dissolved in $\mathrm{PO}(\mathrm{OMe})_{3}(4.0 \mathrm{~mL})$ at $0^{\circ} \mathrm{C}$. Then, $\mathrm{POCl}_{3}(70 \mu \mathrm{L}, 755 \mu \mathrm{mol}, 2.0$ eq. $)$ was added and the mixture was stirred for $5 \mathrm{~h}$ at $0^{\circ} \mathrm{C}$. The reaction was quenched by addition of aq. triethylammonium acetate buffer $(1.0 \mathrm{M})$ until neutral $\mathrm{pH}$. The solvent was removed in vacuo. The crude product was purified by HPLC (ion-exchange column) to obtain 6-carboxymethyl TMP. Unfortunately, the yield was insufficient to perform NMR analysis and the following ester cleavage reaction.

MS (ESI-, MeOH): m/z = $379.1[\mathrm{M}-\mathrm{H}]^{-}$.

HRMS (ESI-): m/z calc. for $\mathrm{C}_{12} \mathrm{H}_{16} \mathrm{~N}_{2} \mathrm{O}_{7}[\mathrm{M}-\mathrm{H}]^{-}: 379.0548$, found: 379.0550 . 


\section{Appendix}

\subsection{Analytics of lead structures}

6-Thiocarboxamido UMP
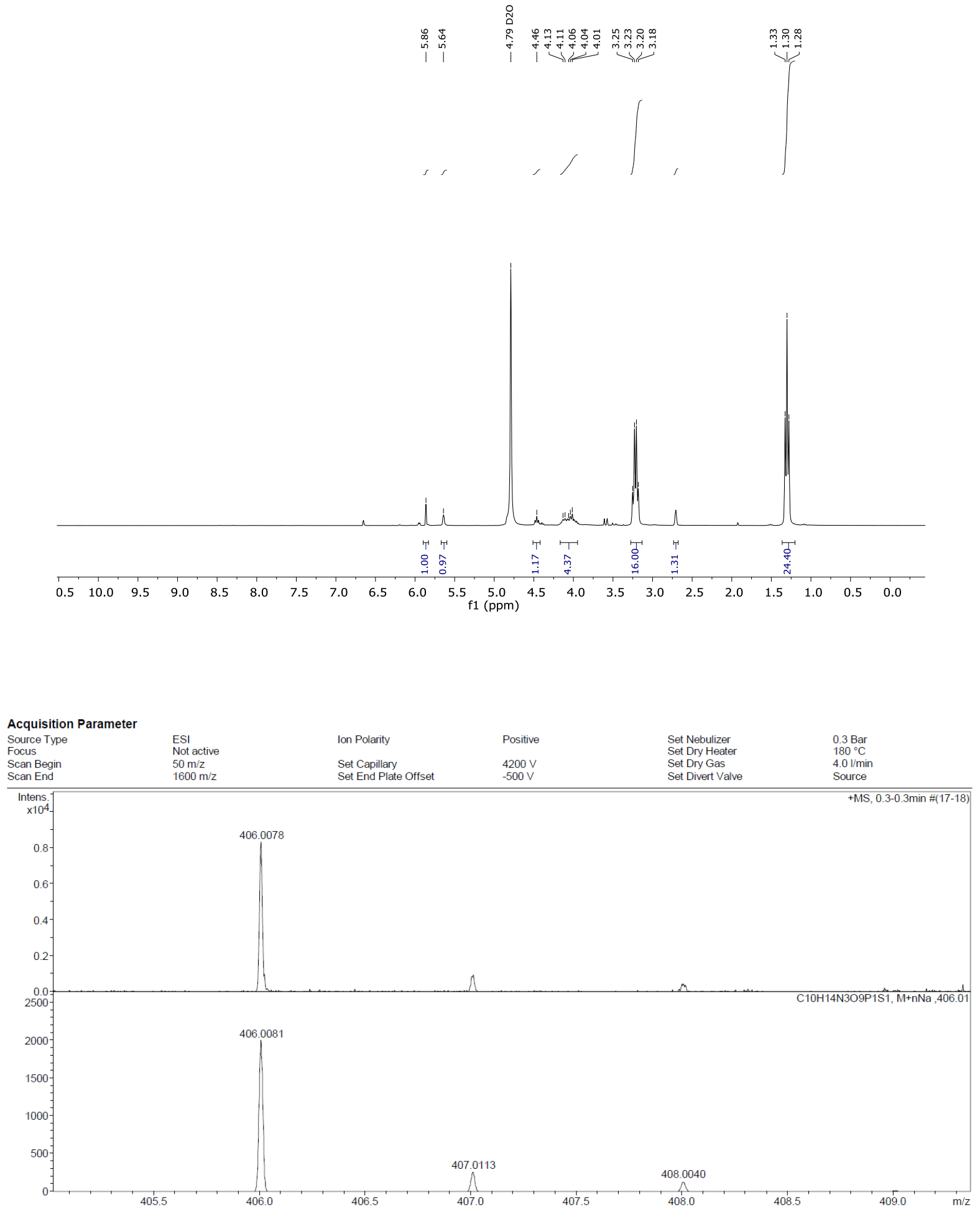
7. Appendix

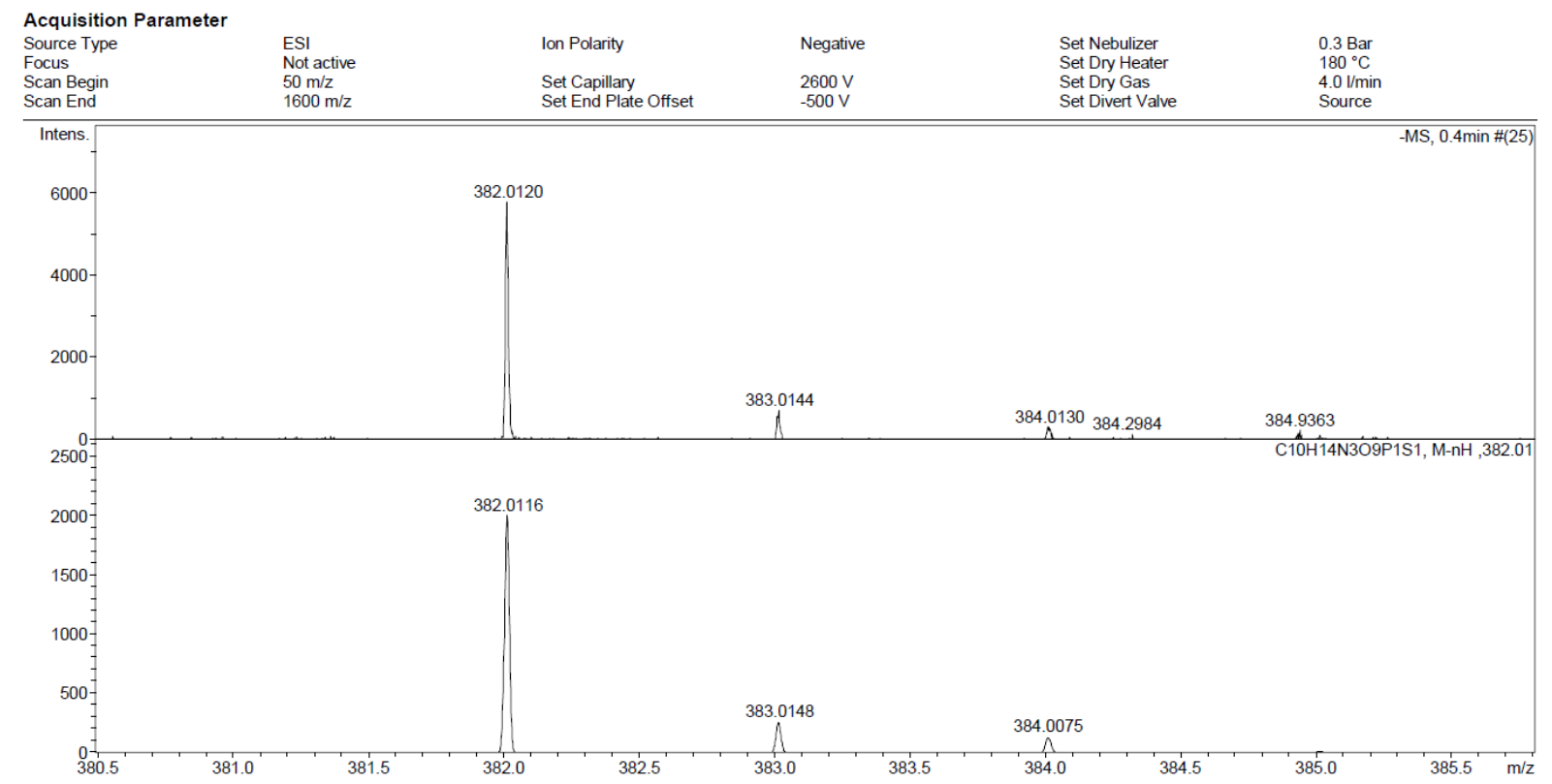


OMP methyl ester
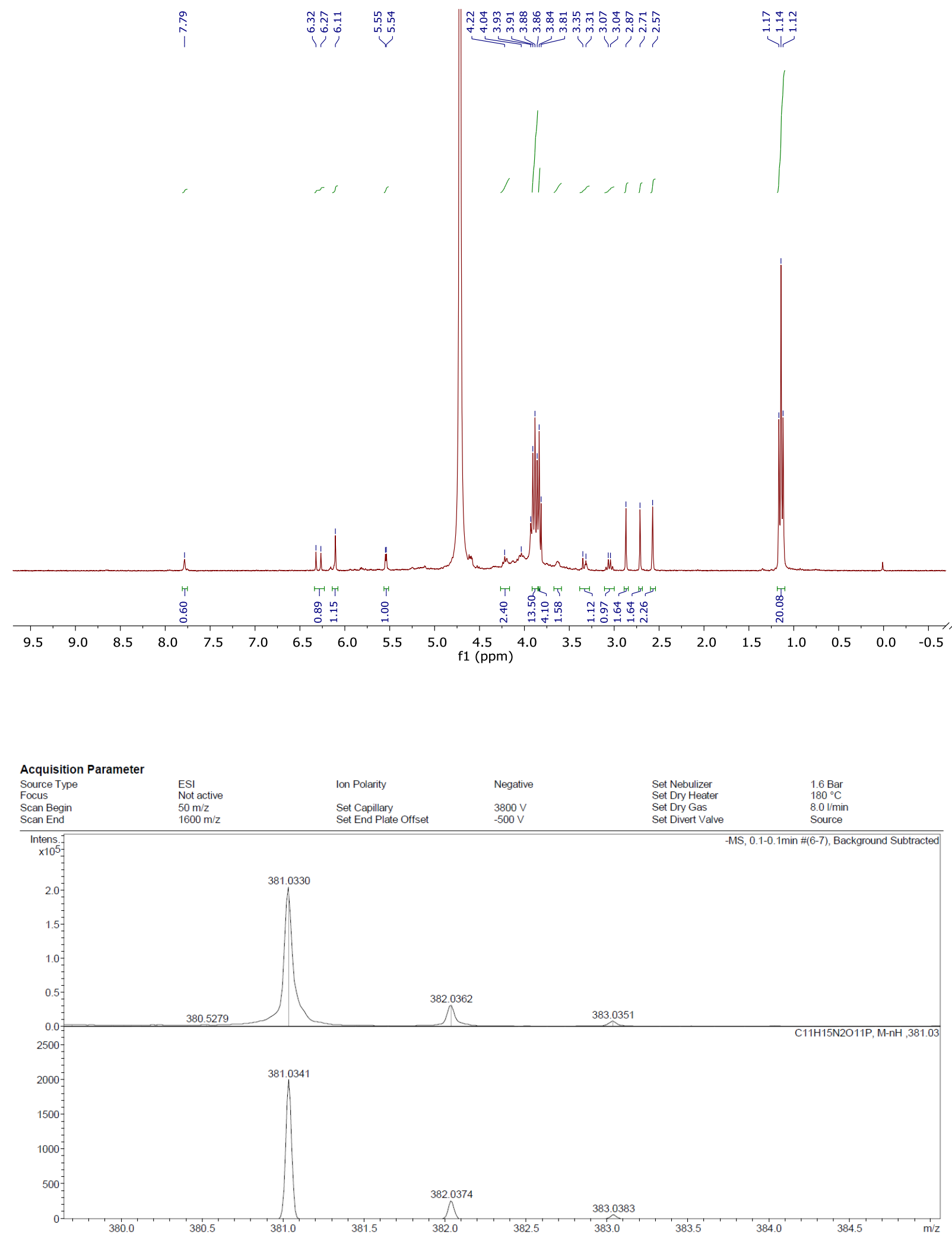
7. Appendix

\section{Reduced OMP}
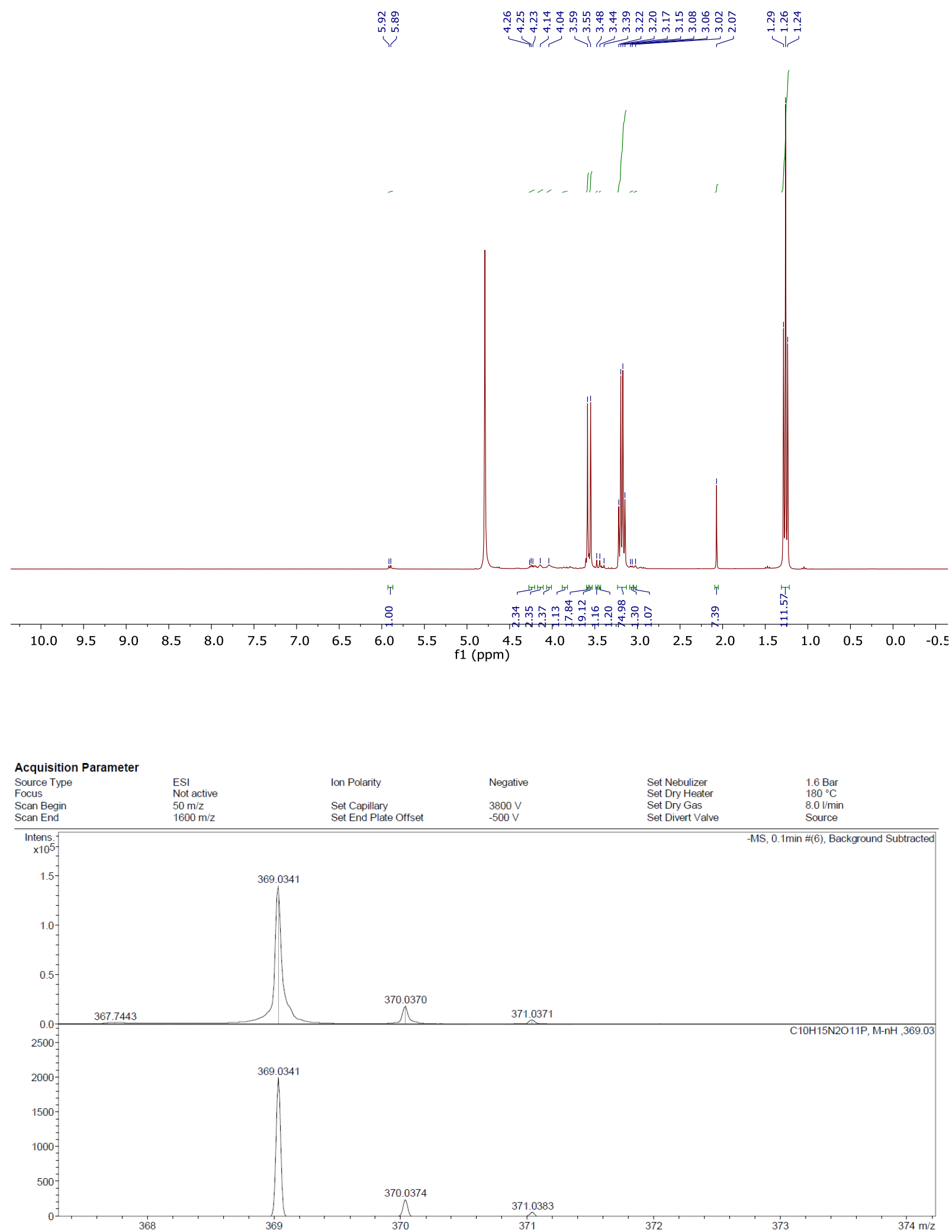
7. Appendix

6-Methyl UMP
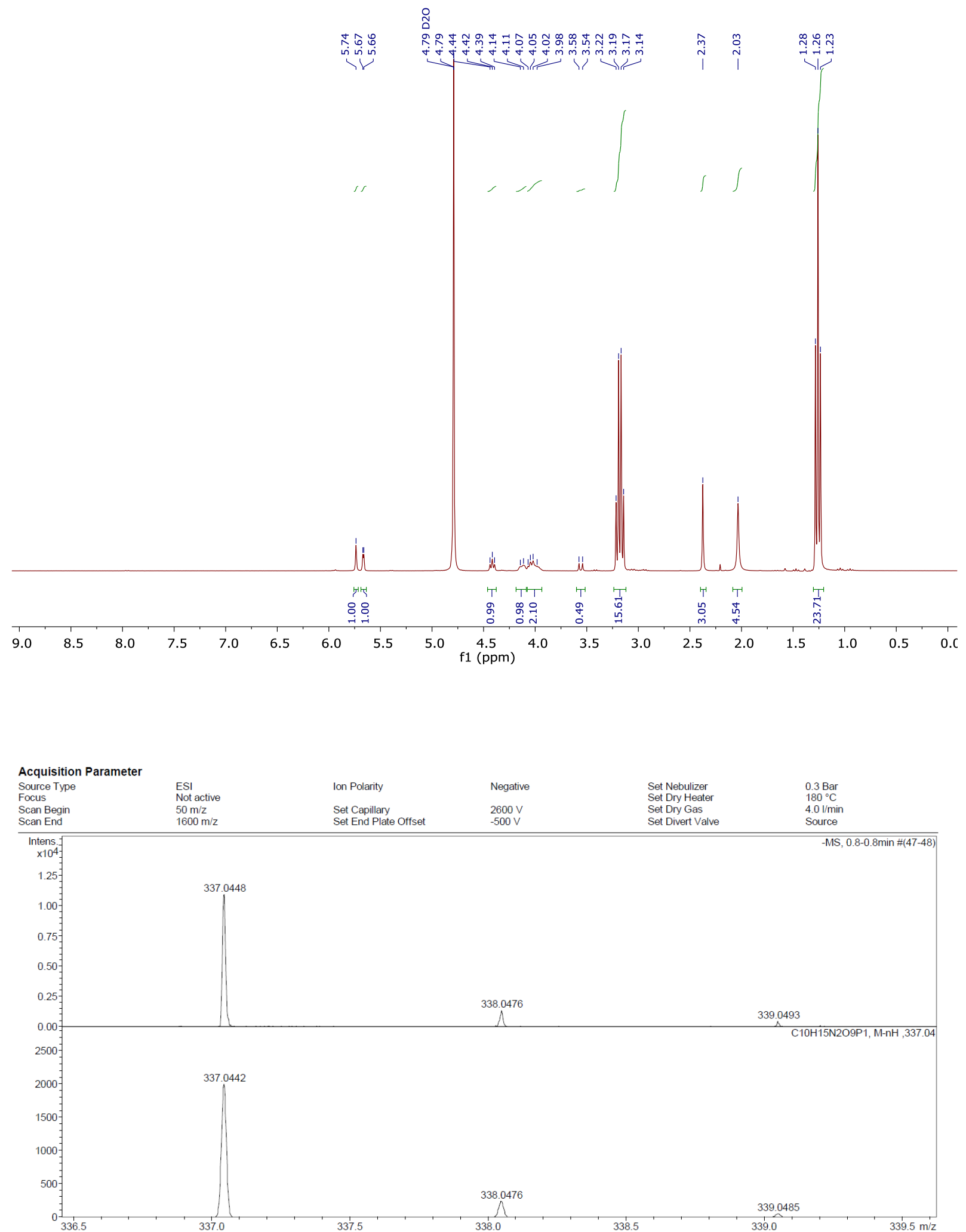
7. Appendix

6-Ethyl UMP
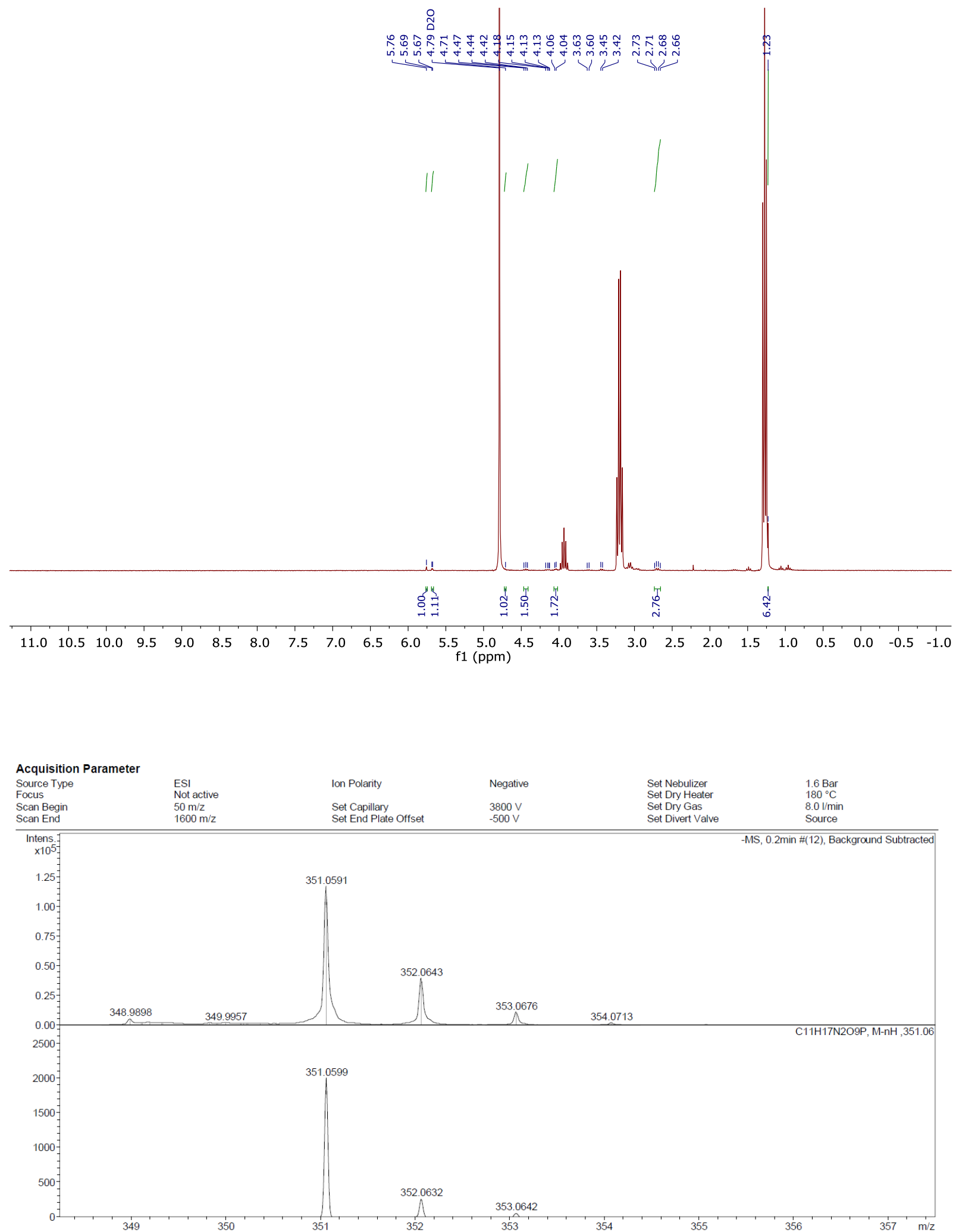
7. Appendix

\section{6-Isopropenyl UMP}
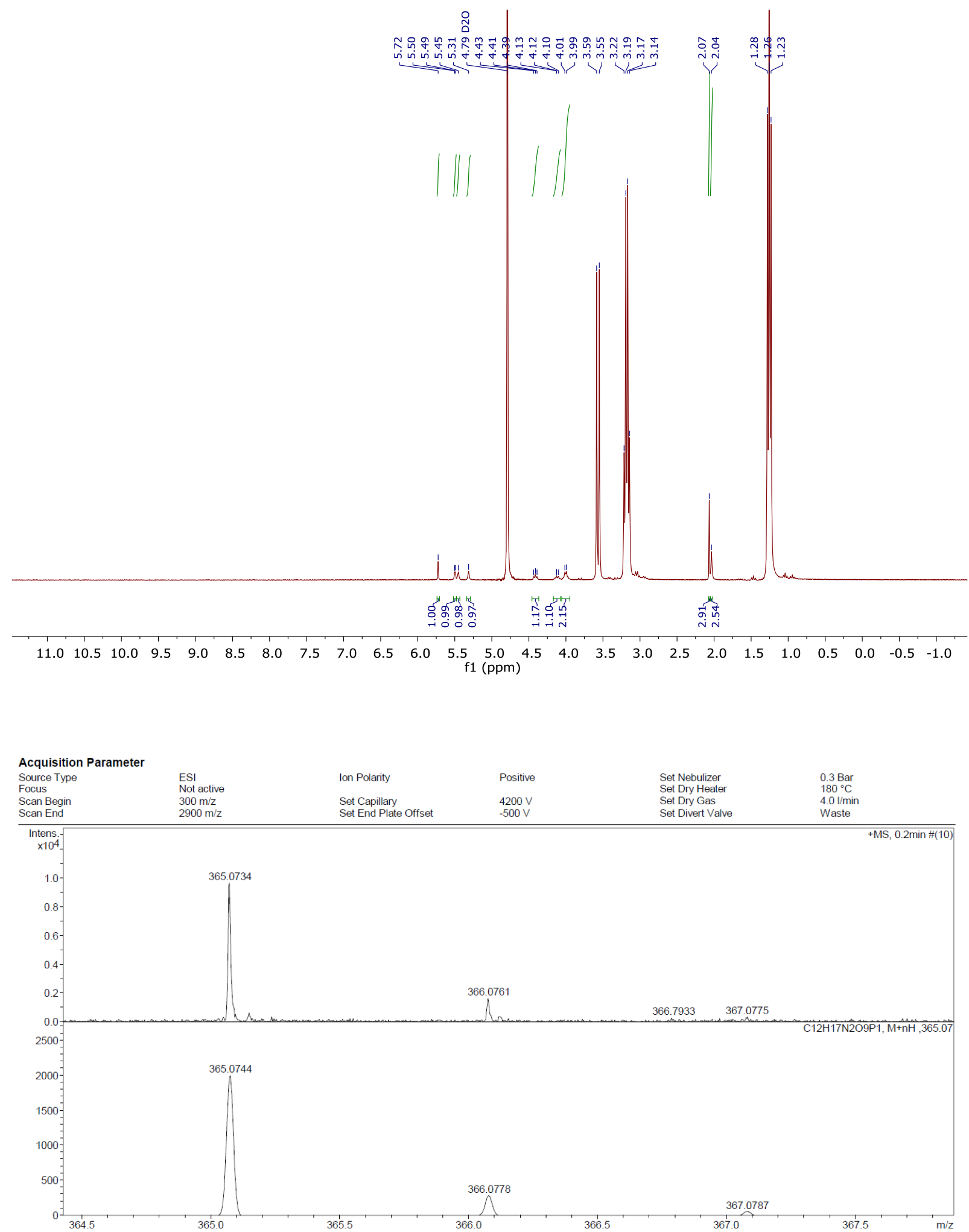
7. Appendix

Acquisition Parameter

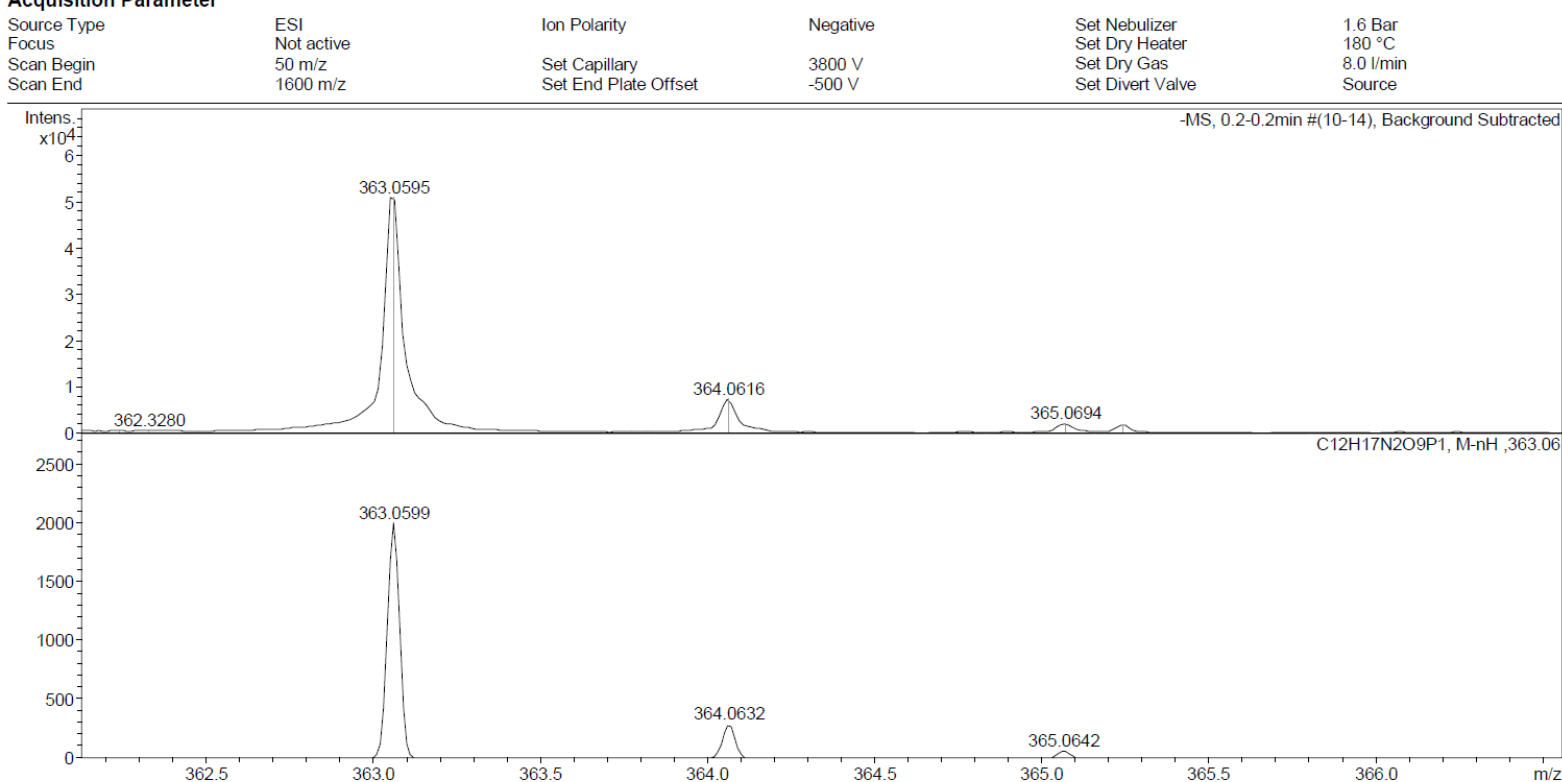




\subsection{HPLC chromatograms}

6-Methyl UMP

ÄKTA Purifier

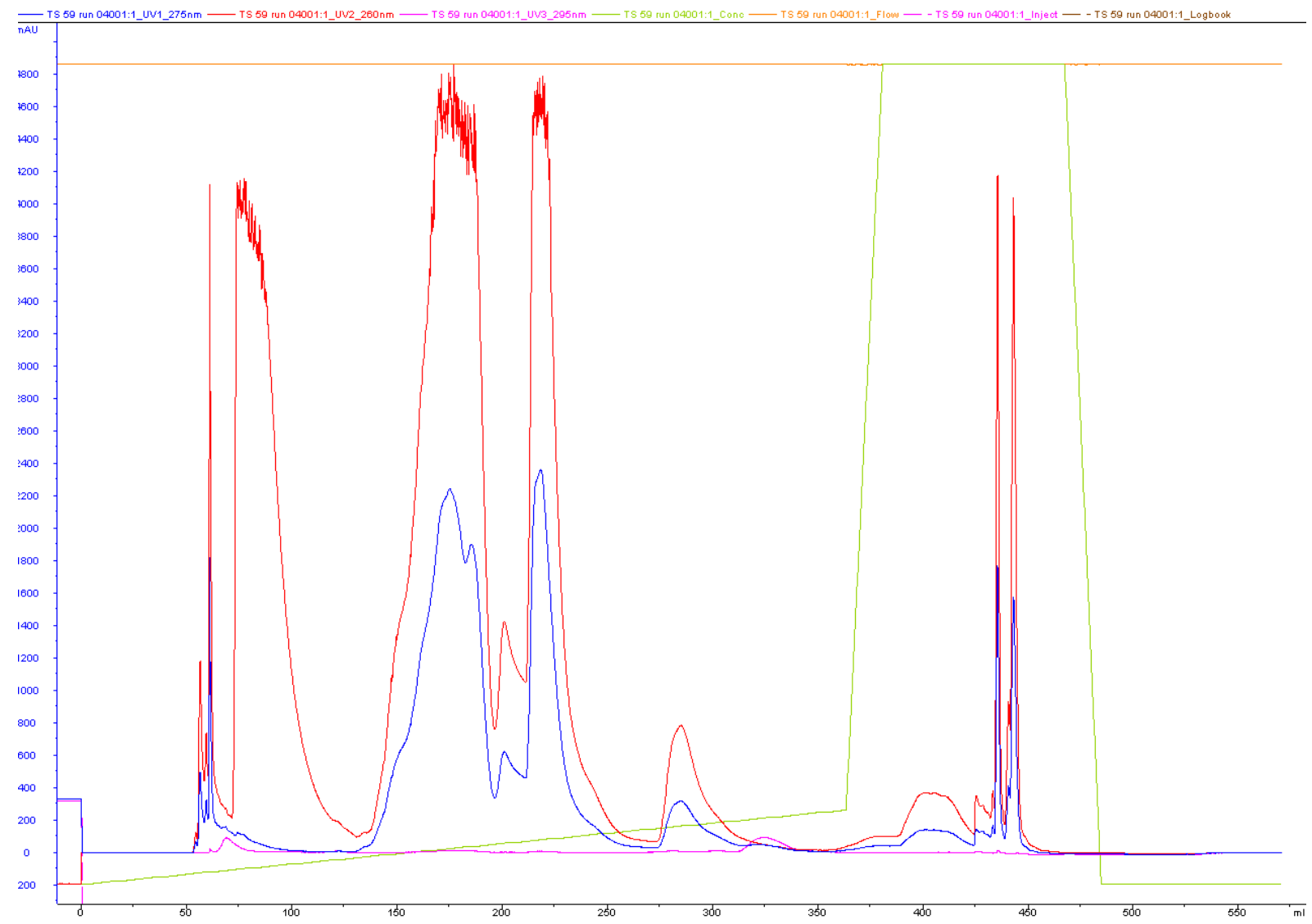

JASCO analytical run after lyophilization

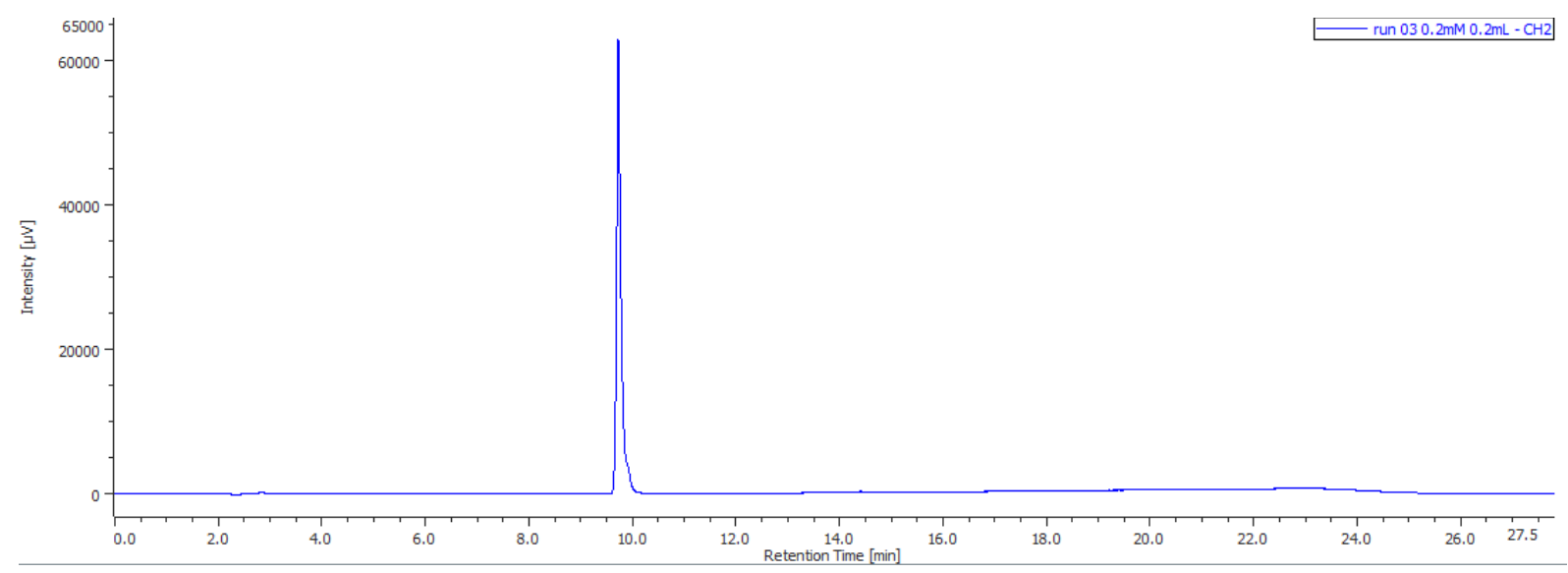


7. Appendix

\section{6-Ethyl UMP}

\section{ÄKTA Purifier}

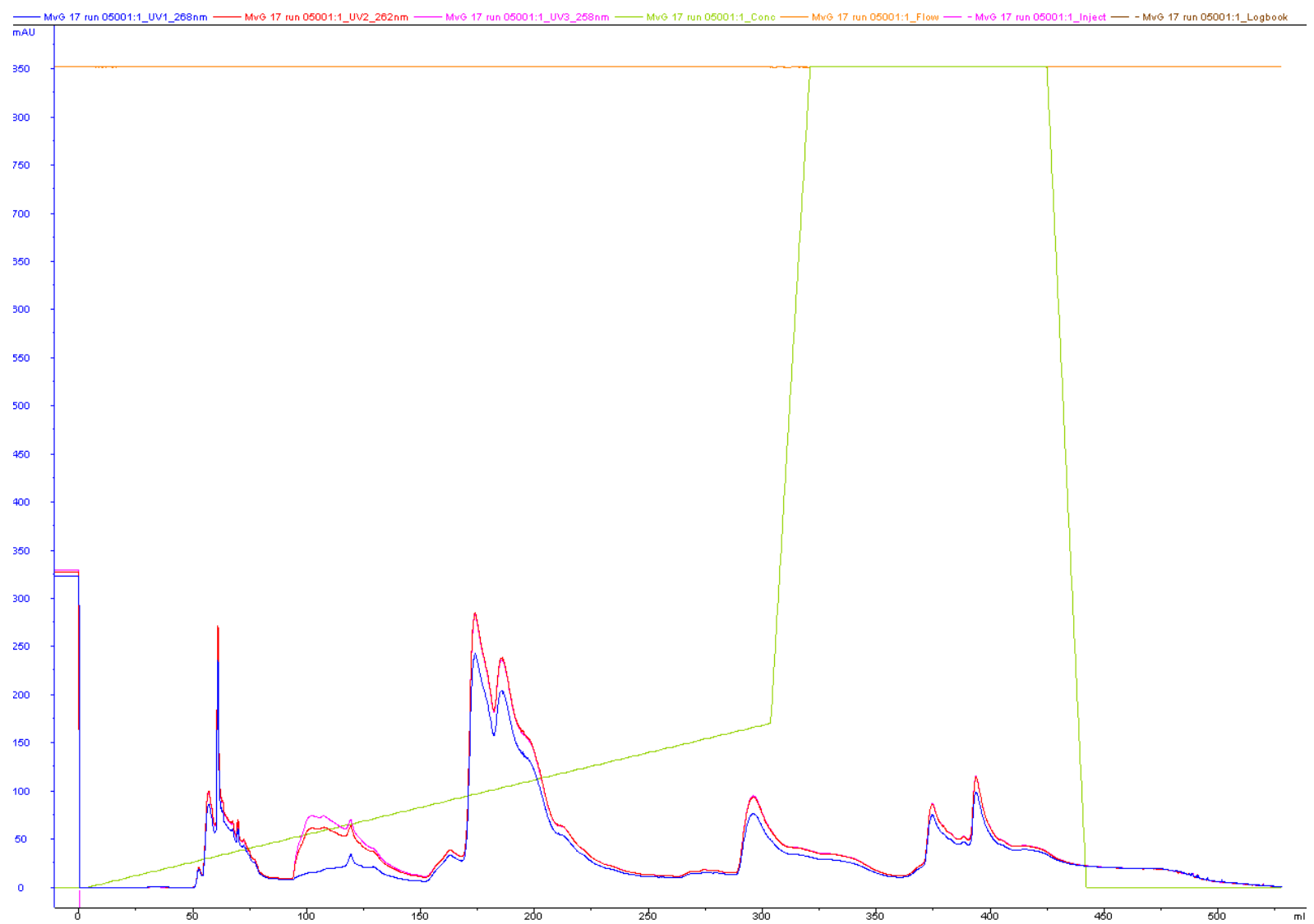

JASCO analytical run after lyophilization

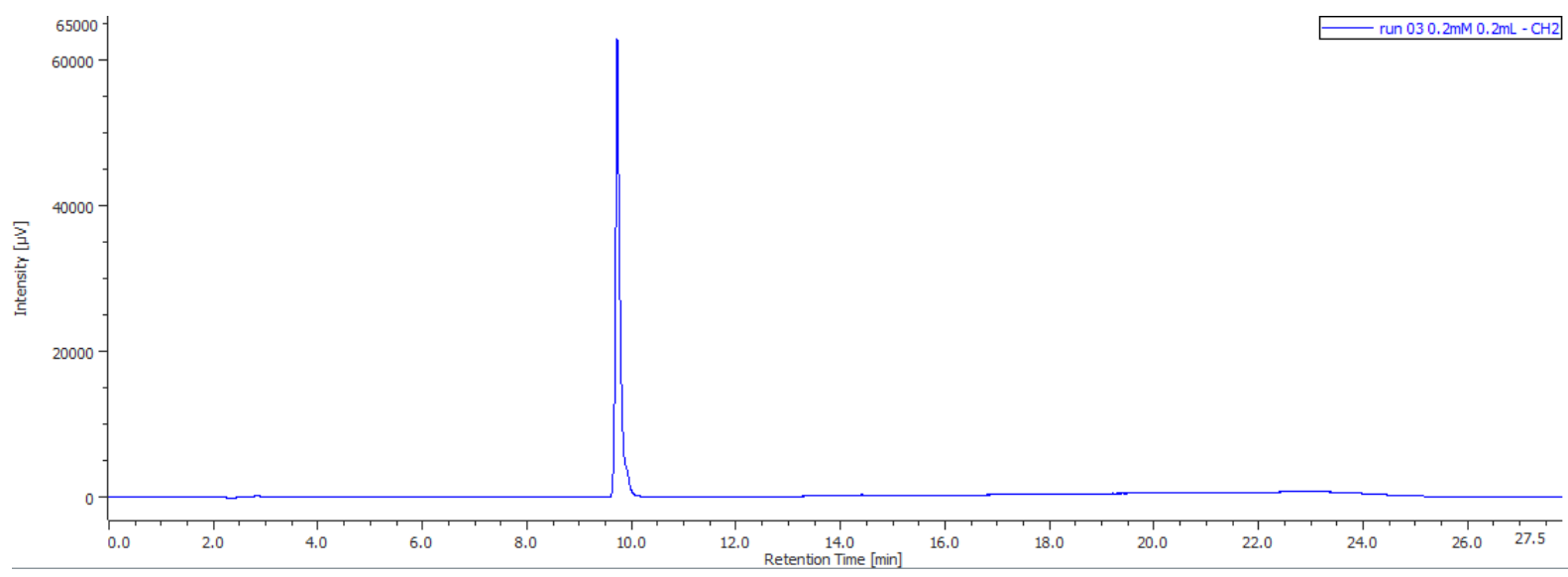


6-isopropenyl UMP

ÄKTA Purifier

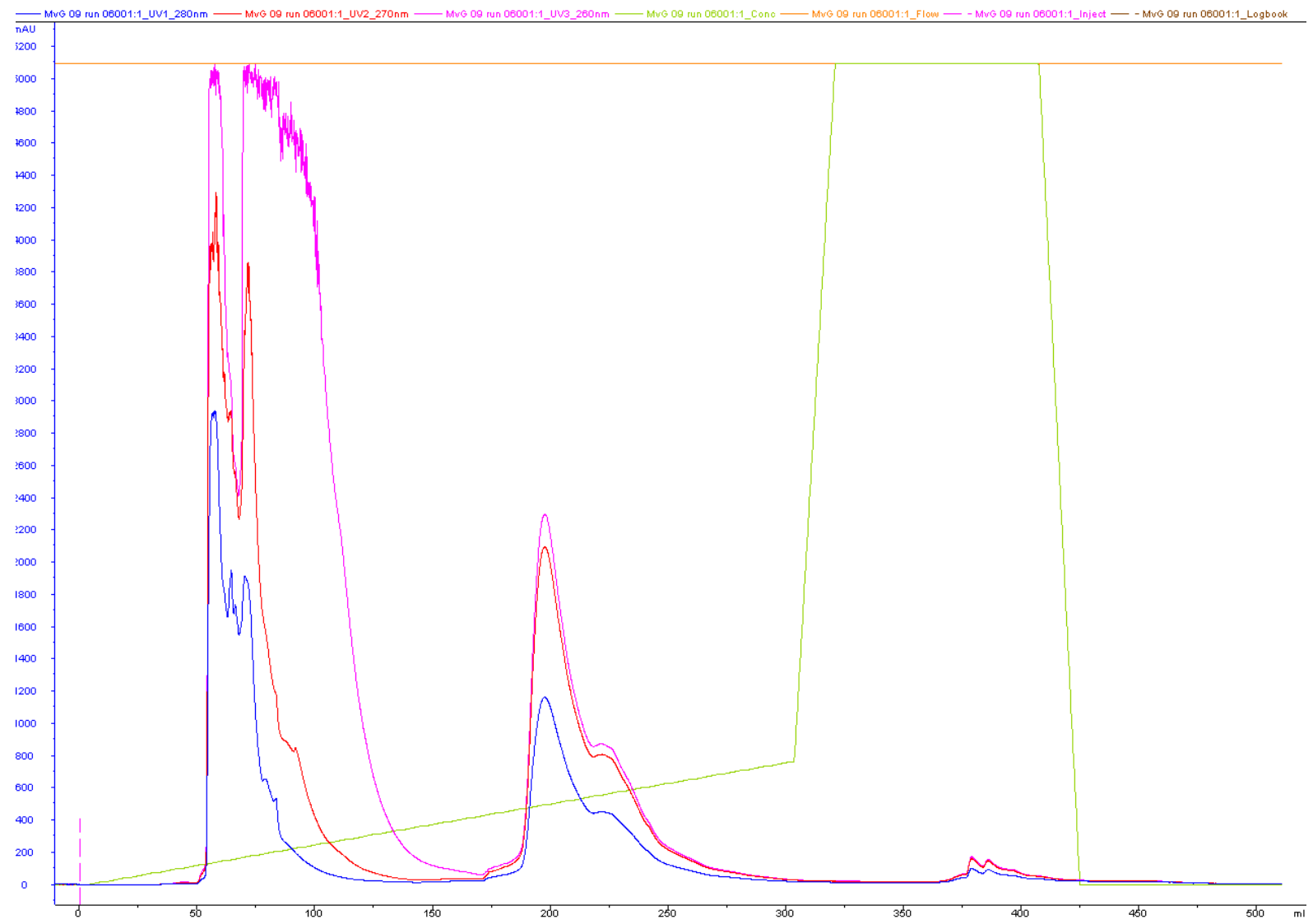

JASCO analytical run after lyophilization

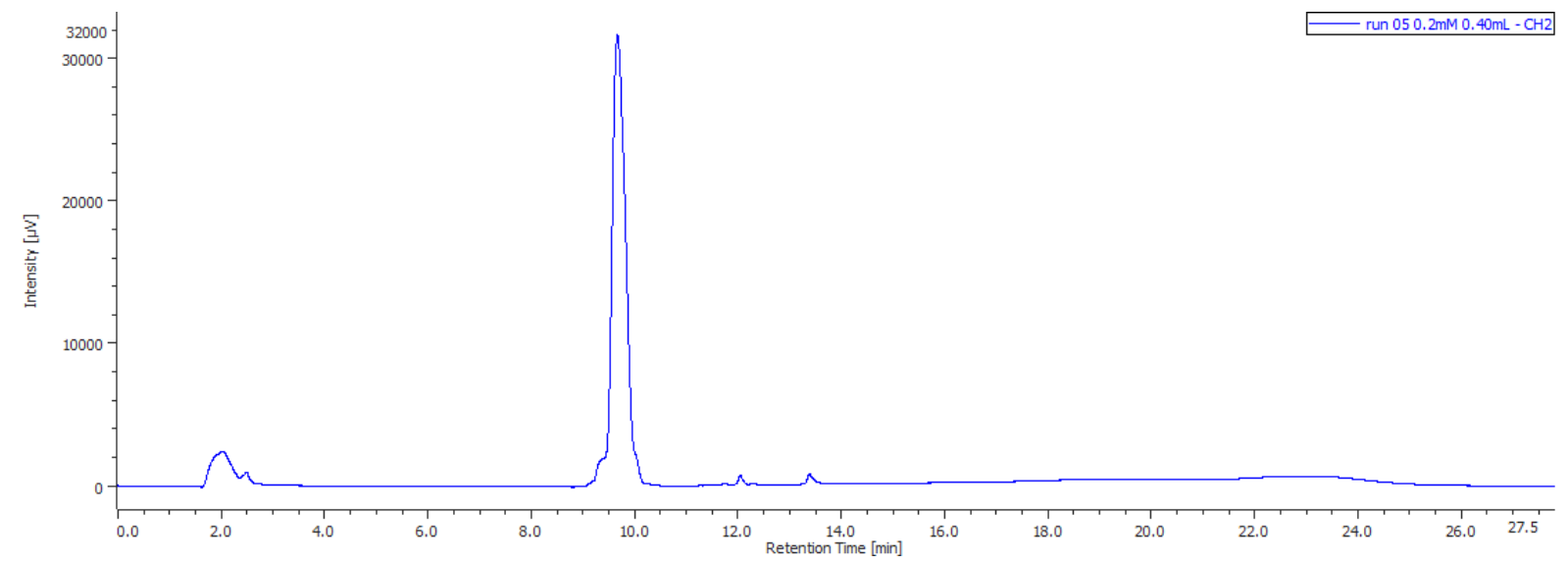


7. Appendix

7.3 Crystallography data collection and refinement

Table 1: Data collection of $h O M P D_{w T}$ resting state crystals.

\begin{tabular}{|c|c|}
\hline Space group & C 2 2 2 1 \\
\hline Cell dimensions & \\
\hline $\mathrm{a}, \mathrm{b}, \mathrm{c}(\AA)$ & 77.30116 .5661 .96 \\
\hline$\alpha, \beta, \gamma\left(^{\circ}\right)$ & 909090 \\
\hline Resolution range & $42.45-0.95(0.984-0.95)$ \\
\hline Multiplicity & $4.3(3.4)$ \\
\hline Completeness $(\%)$ & $98.20(99.30)$ \\
\hline $\mathrm{I} / \sigma(\mathrm{I})$ & $18.51(1.73)$ \\
\hline $\mathrm{Rmeas}$ & $0.037(0.724)$ \\
\hline $\mathrm{CC} 1 / 2$ & $0.999(0.698)$ \\
\hline
\end{tabular}

Table 2: Refinement of $h O M P D_{w T}$ resting state crystals.

\begin{tabular}{|c|c|}
\hline Reflections used in refinement & $172158(17279)$ \\
\hline R-work/ R-free [\%] & $12.0 / 13.4$ \\
\hline Number of non-hydrogen atoms & 2508 \\
\hline macromolecules & 2148 \\
\hline ligands & 33 \\
\hline solvent & 327 \\
\hline Average B-factor $\left[\AA^{2}\right]$ & 13.01 \\
\hline macromolecules & 11.10 \\
\hline ligands & 15.35 \\
\hline solvent & 25.33 \\
\hline \multicolumn{2}{|l|}{ Ramachandran statistics } \\
\hline Favored [\%] & 98.81 \\
\hline Allowed [\%] & 1.19 \\
\hline Outliers [\%] & 0.00 \\
\hline \multicolumn{2}{|l|}{ R.m.s. deviations } \\
\hline RMS (bonds) $[\AA]$ & 0.013 \\
\hline RMS (angles) $\left(^{\circ}\right)$ & 1.70 \\
\hline
\end{tabular}


Table 3: Data collection of $h \mathrm{OMPD}_{\mathrm{wT}}$ 6-thioamido UMP crystals.

\begin{tabular}{|c|c|}
\hline Space group & C 2 2 21 \\
\hline Cell dimensions & 77.46116 .1162 .13 \\
\hline $\mathrm{a}, \mathrm{b}, \mathrm{c}(\AA)$ & 909090 \\
\hline$\alpha, \beta, \gamma\left(^{\circ}\right)$ & $42.42-1.124(1.164-1.124)$ \\
\hline Resolution range & $6.2(3.7)$ \\
\hline Multiplicity & $96.64(69.24)$ \\
\hline Completeness $(\%)$ & $13.58(1.60)$ \\
\hline $\mathrm{I} / \sigma(\mathrm{I})$ & $0.078(0.867)$ \\
\hline Rmeas & $0.999(0.673)$ \\
\hline $\mathrm{CC} 1 / 2$ &
\end{tabular}

Table 4: Refinement of $h$ OMPDwT 6-thioamido UMP crystals.

\begin{tabular}{|c|c|}
\hline Reflections used in refinement & $102725(7278)$ \\
\hline R-work/ R-free [\%] & $12.5 / 15.2$ \\
\hline Number of non-hydrogen atoms & 2641 \\
\hline macromolecules & 2269 \\
\hline ligands & 43 \\
\hline solvent & 329 \\
\hline Average B-factor [ $\left.\AA^{2}\right]$ & 15.56 \\
\hline macromolecules & 13.42 \\
\hline ligands & 19.95 \\
\hline solvent & 29.78 \\
\hline Ramachandran statistics & 98.81 \\
\hline Favored [\%] & 1.19 \\
\hline Allowed [\%] & 0.00 \\
\hline Outliers [\%] & \\
\hline
\end{tabular}


7. Appendix

Table 5: Data collection of $h \mathrm{OMPD}_{\mathrm{Ac} 314 \mathrm{~K}}$ OMP crystals.

\begin{tabular}{|c|c|}
\hline Space group & C 2 2 21 \\
\hline Cell dimensions & 77.29116 .8261 .95 \\
\hline $\mathrm{a}, \mathrm{b}, \mathrm{c}(\AA)$ & 909090 \\
\hline$\alpha, \beta, \gamma\left({ }^{\circ}\right)$ & $44.67-1.2(1.243-1.2)$ \\
\hline Resolution range & $7.6(7.6)$ \\
\hline Multiplicity & $99.83(99.83)$ \\
\hline Completeness $(\%)$ & $15.57(1.59)$ \\
\hline $\mathrm{I} / \sigma(\mathrm{I})$ & $0.095(1.645)$ \\
\hline Rmeas & $0.999(0.648)$ \\
\hline $\mathrm{CC} 1 / 2$ & \\
\hline
\end{tabular}

Table 6: Refinement of $h$ OMPD $_{\mathrm{Ac} 314 \mathrm{~K}}$ OMP crystals.

\begin{tabular}{|c|c|}
\hline Reflections used in refinement & $87500(8667)$ \\
\hline R-work/ R-free [\%] & $13.5 / 15.8$ \\
\hline Number of non-hydrogen atoms & 2772 \\
\hline macromolecules & 2377 \\
\hline ligands & 67 \\
\hline solvent & 328 \\
\hline Average B-factor [̊²] & 16.40 \\
\hline macromolecules & 14.36 \\
\hline ligands & 23.30 \\
\hline solvent & 29.82 \\
\hline Ramachandran statistics & 98.79 \\
\hline Favored [\%] & 1.21 \\
\hline Allowed [\%] & 0.00 \\
\hline Outliers [\%] & \\
\hline
\end{tabular}


Table 7: Data collection of $h \mathrm{OMPD}_{\mathrm{wT}}$ 6-amido UMP crystals.

\begin{tabular}{|c|c|}
\hline Space group & C 2 2 21 \\
\hline Cell dimensions & 77.74116 .3062 .17 \\
\hline $\mathrm{a}, \mathrm{b}, \mathrm{c}(\AA)$ & 909090 \\
\hline$\alpha, \beta, \gamma\left({ }^{\circ}\right)$ & $42.47-1.2(1.243-1.2)$ \\
\hline Resolution range & $6.7(5.9)$ \\
\hline Multiplicity & $96.78(90.46)$ \\
\hline Completeness $(\%)$ & $13.40(1.80)$ \\
\hline $\mathrm{I} / \sigma(\mathrm{I})$ & $0.083(1.088)$ \\
\hline Rmeas & $0.999(0.668)$ \\
\hline $\mathrm{CC} 1 / 2$ & \\
\hline
\end{tabular}

Table 8: Refinement of $h$ OMPDwT 6-amido UMP crystals.

\begin{tabular}{|c|c|}
\hline Reflections used in refinement & $85217(7884)$ \\
\hline R-work/ R-free [\%] & $12.0 / 14.6$ \\
\hline Number of non-hydrogen atoms & 2615 \\
\hline macromolecules & 2222 \\
\hline ligands & 32 \\
\hline solvent & 361 \\
\hline Average B-factor [ $\left.\AA^{2}\right]$ & 16.21 \\
\hline macromolecules & 13.75 \\
\hline ligands & 16.57 \\
\hline solvent & 31.35 \\
\hline Ramachandran statistics & 98.41 \\
\hline Favored [\%] & 1.59 \\
\hline Allowed [\%] & 0.00 \\
\hline Outliers [\%] & \\
\hline
\end{tabular}


7. Appendix

Table 9: Data collection of $h$ OMPD $_{w T}$ BMP crystals.

\begin{tabular}{|c|c|}
\hline Space group & C 2 2 21 \\
\hline Cell dimensions & 77.90116 .4361 .97 \\
\hline $\mathrm{a}, \mathrm{b}, \mathrm{c}(\AA)$ & 909090 \\
\hline$\alpha, \beta, \gamma\left(^{\circ}\right)$ & $26.34-0.9(0.9322-0.9)$ \\
\hline Resolution range & $3.5(2.7)$ \\
\hline Multiplicity & $96.78(92.61)$ \\
\hline Completeness $(\%)$ & $15.53(1.16)$ \\
\hline $\mathrm{I} / \sigma(\mathrm{I})$ & $0.043(1.037)$ \\
\hline Rmeas & $0.999(0.525)$ \\
\hline $\mathrm{CC} 1 / 2$ & \\
\hline
\end{tabular}

Table 10: Refinement of $h$ OMPDwt BMP crystals.

\begin{tabular}{|c|c|}
\hline Reflections used in refinement & $200395(19012)$ \\
\hline R-work/ R-free [\%] & $11.0 / 12.0$ \\
\hline Number of non-hydrogen atoms & 2713 \\
\hline macromolecules & 2345 \\
\hline ligands & 67 \\
\hline solvent & 326 \\
\hline Average B-factor [̊²] & 12.51 \\
\hline macromolecules & 10.89 \\
\hline ligands & 12.96 \\
\hline solvent & 24.13 \\
\hline Ramachandran statistics & 98.81 \\
\hline Favored [\%] & 1.19 \\
\hline Allowed [\%] & 0.00 \\
\hline Outliers [\%] & \\
\hline
\end{tabular}


Table 11: Data collection of 6-methyl UMP crystals

\begin{tabular}{|c|c|}
\hline Resolution range & $42.5-1.122(1.162-1.122)$ \\
\hline Space group & C 2 2 2 1 \\
\hline Unit cell & 77.375116 .68762 .027909090 \\
\hline Total reflections & $104066(7617)$ \\
\hline Unique reflections & $5.9(3.2)$ \\
\hline Multiplicity & $97.07(71.93)$ \\
\hline Completeness (\%) & $12.34(1.54)$ \\
\hline Mean I/sigma(I) & 13.20 \\
\hline Wilson B-factor & $0.06168(0.5737)$ \\
\hline R-merge & $0.06729(0.6806)$ \\
\hline R-meas & $0.02652(0.3563)$ \\
\hline R-pim & $0.999(0.797)$ \\
\hline CC1/2 & $1(0.942)$ \\
\hline CC* &
\end{tabular}

Table 12: Refinement of 6-methyl UMP crystals

\begin{tabular}{|c|c|}
\hline Reflections used in refinement & $104059(7617)$ \\
\hline Reflections used for R-free & $5110(383)$ \\
\hline R-work & $0.1365(0.3311)$ \\
\hline R-free & $0.1527(0.3583)$ \\
\hline Number of non-hydrogen atoms & 2577 \\
\hline macromolecules & 2226 \\
\hline ligands & 43 \\
\hline solvent & 308 \\
\hline Average B-factor & 17.19 \\
\hline macromolecules & 15.12 \\
\hline ligands & 24.98 \\
\hline solvent & 31.05 \\
\hline Ramachandran favored (\%) & 98.81 \\
\hline Ramachandran allowed (\%) & 1.19 \\
\hline Ramachandran outliers (\%) & 0.00 \\
\hline
\end{tabular}


7. Appendix

Table 13: Data collection of 6-ethyl UMP crystals

\begin{tabular}{|c|c|}
\hline Resolution range & $42.47-1.3(1.346-1.3)$ \\
\hline Space group & C 2 2 2 1 \\
\hline Unit cell & 77.106116 .52362 .032909090 \\
\hline Total reflections & $68748(6782)$ \\
\hline Unique reflections & $6.6(6.5)$ \\
\hline Multiplicity & $99.83(99.91)$ \\
\hline Completeness (\%) & $11.96(1.37)$ \\
\hline Mean I/sigma(I) & 15.29 \\
\hline Wilson B-factor & $0.08351(1.369)$ \\
\hline R-merge & $0.09068(1.489)$ \\
\hline R-meas & $0.03494(0.5773)$ \\
\hline R-pim & $0.999(0.601)$ \\
\hline CC1/2 & $1(0.866)$ \\
\hline CC* & \\
\hline
\end{tabular}

Table 14: Refinement of 6-ethyl UMP crystals

\begin{tabular}{|c|c|}
\hline Reflections used in refinement & $68741(6782)$ \\
\hline Reflections used for R-free & $3335(322)$ \\
\hline R-work & $0.1434(0.3307)$ \\
\hline R-free & $0.1693(0.3662)$ \\
\hline Number of non-hydrogen atoms & 2411 \\
\hline macromolecules & 2119 \\
\hline ligands & 44 \\
\hline solvent & 248 \\
\hline Average B-factor & 19.39 \\
\hline macromolecules & 17.75 \\
\hline ligands & 24.23 \\
\hline solvent & 32.52 \\
\hline Ramachandran favored (\%) & 98.82 \\
\hline Ramachandran allowed (\%) & 1.18 \\
\hline Ramachandran outliers (\%) & 0.00 \\
\hline
\end{tabular}


Table 15: Data collection of 6-isopropyl UMP crystals

\begin{tabular}{|c|c|}
\hline Resolution range & $64.52-1.3(1.346-1.3)$ \\
\hline Space group & C 2 2 2 1 \\
\hline Unit cell & 74.562116 .2862 .075909090 \\
\hline Total reflections & $69057(6840)$ \\
\hline Unique reflections & $6.5(6.6)$ \\
\hline Multiplicity & $99.75(99.50)$ \\
\hline Completeness (\%) & $11.21(0.70)$ \\
\hline Mean I/sigma(I) & 18.52 \\
\hline Wilson B-factor & $0.08549(2.165)$ \\
\hline R-merge & $0.09297(2.35)$ \\
\hline R-meas & $0.03613(0.9043)$ \\
\hline R-pim & $0.998(0.433)$ \\
\hline CC1/2 & $1(0.778)$ \\
\hline CC* & \\
\hline
\end{tabular}

Table 16: Refinement of 6-isopropyl UMP crystals

\begin{tabular}{|c|c|}
\hline Reflections used in refinement & $69005(6821)$ \\
\hline Reflections used for R-free & $3344(332)$ \\
\hline R-work & $0.1371(0.3791)$ \\
\hline R-free & $0.1660(0.3497)$ \\
\hline Number of non-hydrogen atoms & 2639 \\
\hline macromolecules & 2259 \\
\hline ligands & 45 \\
\hline solvent & 335 \\
\hline Average B-factor & 18.97 \\
\hline macromolecules & 16.64 \\
\hline ligands & 21.99 \\
\hline solvent & 34.29 \\
\hline Ramachandran favored $(\%)$ & 98.01 \\
\hline Ramachandran allowed (\%) & 1.99 \\
\hline Ramachandran outliers (\%) & 0.00 \\
\hline
\end{tabular}


7. Appendix

Table 17: Data collection of 6-isopropenyl UMP crystals

\begin{tabular}{|c|c|}
\hline Resolution range & $44.97-1.15(1.191-1.15)$ \\
\hline Space group & P 1211 \\
\hline Unit cell & 70.77261 .97269 .46490112 .57890 \\
\hline Total reflections & $192202(19047)$ \\
\hline Unique reflections & $3.5(3.5)$ \\
\hline Multiplicity & $97.86(97.50)$ \\
\hline Completeness (\%) & $14.84(1.25)$ \\
\hline Mean I/sigma(I) & 16.69 \\
\hline Wilson B-factor & $0.03648(1.137)$ \\
\hline R-merge & $0.04338(1.343)$ \\
\hline R-meas & $0.02318(0.7065)$ \\
\hline R-pim & $0.999(0.503)$ \\
\hline CC1/2 & $1(0.818)$ \\
\hline CC* & \\
\hline
\end{tabular}

Table 18: Refinement of 6-isopropenyl UMP crystals

\begin{tabular}{|c|c|}
\hline Reflections used in refinement & $192165(19046)$ \\
\hline Reflections used for R-free & $9613(905)$ \\
\hline R-work & $0.1627(0.3595)$ \\
\hline R-free & $0.1725(0.3548)$ \\
\hline Number of non-hydrogen atoms & 5033 \\
\hline macromolecules & 4411 \\
\hline ligands & 117 \\
\hline solvent & 505 \\
\hline Average B-factor & 20.88 \\
\hline macromolecules & 19.38 \\
\hline ligands & 18.94 \\
\hline solvent & 34.37 \\
\hline Ramachandran favored (\%) & 98.21 \\
\hline Ramachandran allowed (\%) & 1.79 \\
\hline Ramachandran outliers (\%) & 0.00 \\
\hline
\end{tabular}




\section{List of Figures}

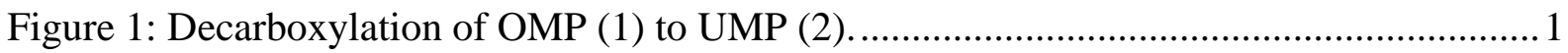

Figure 2: Targeted lead structures within the scope of this thesis......................................... 3

Figure 3: DNA base pairing, top row C-G and bottom row T-A with hydrogen bonds ............5

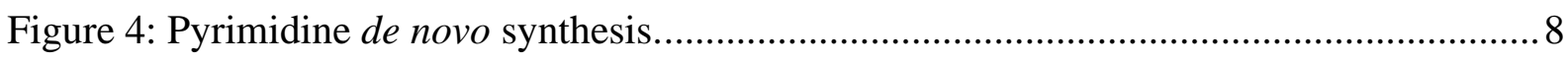

Figure 5: Structure of the resting state OMPD homodimer with one monomer colored. ..........9

Figure 6: Loop regions, pyrimidine umbrella and phosphate gripper loop ............................ 10

Figure 7: Catalytic tetrad consisting of Asp' ${ }_{317}$, Lys314, Asp 312 and Lys 281 . Picture taken from crystal structure of BMP complex with $h$ OMPD

Figure 8: H-bond network of the substrate (e.g., BMP) in the enzymatic pocket. ${ }^{[33]}$.............. 12

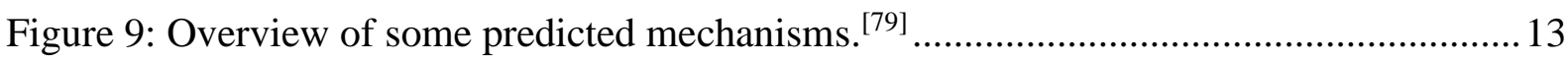

Figure 10: Proposed mechanism by BEAK and SIEGEL. ${ }^{[78]}$.................................................. 14

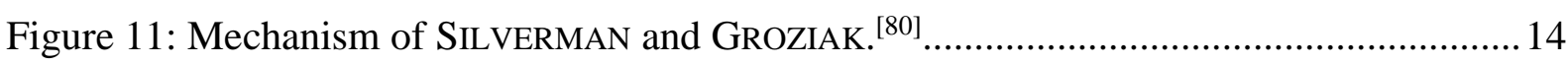

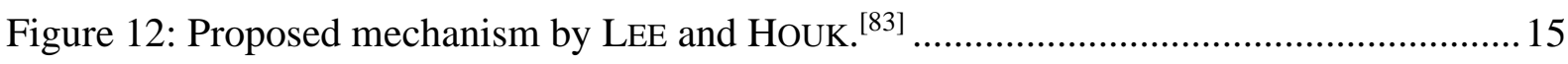

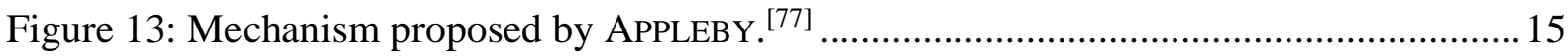

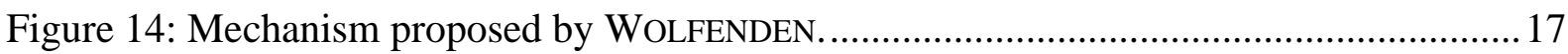

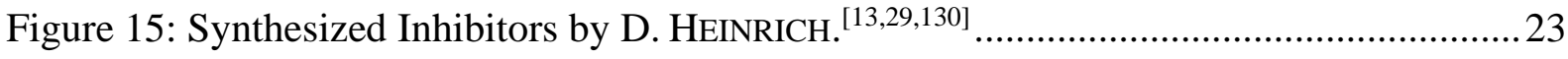

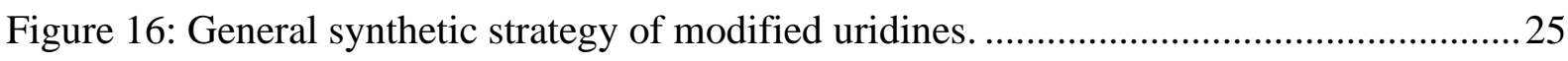

Figure 17: Standard procedure of hydroxy group protection in uridines. ..............................25

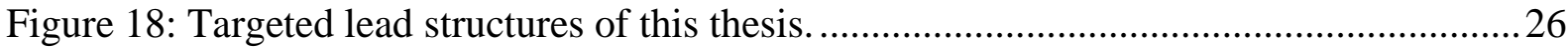

Figure 19: Left to right: OMP methyl ester, 6-thioamido UMP and 6-boronic acid UMP......27

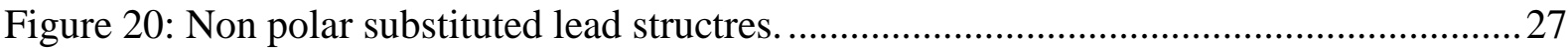

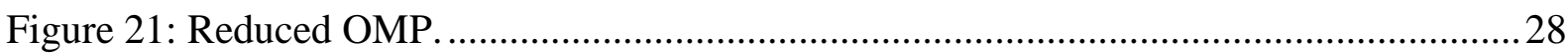

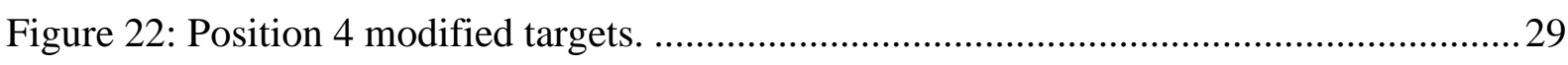

Figure 23: Targets bearing 5-Methyl and/or missing 2‘-OH group. ..................................... 30

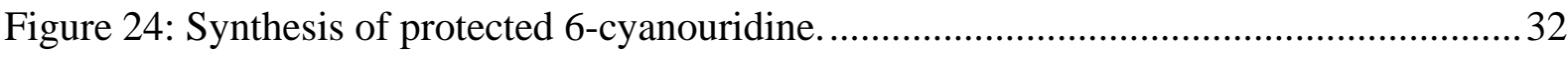

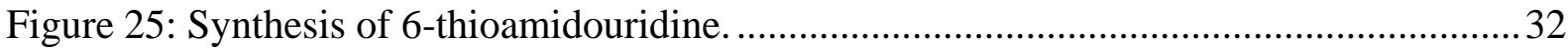

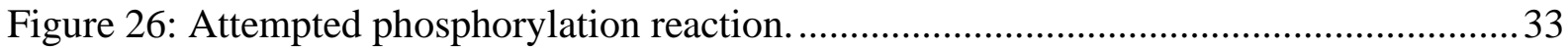

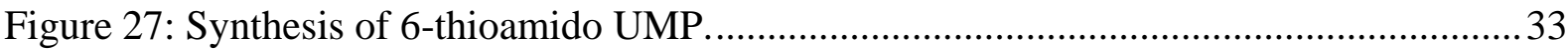




\section{List of Figures}

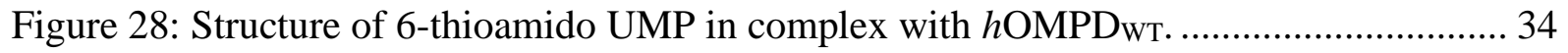

Figure 29: Structure of 6-amido UMP in complex with $h$ OMPDwT. .................................... 35

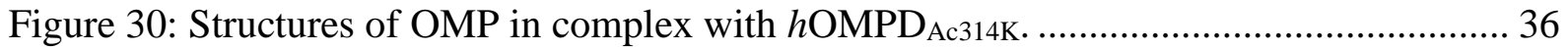

Figure 31: Structures of 6-amido UMP, 6-thioamido UMP and OMP .................................. 36

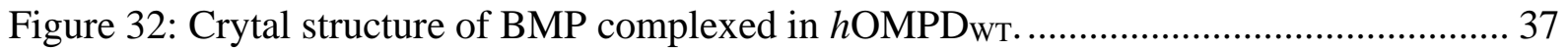

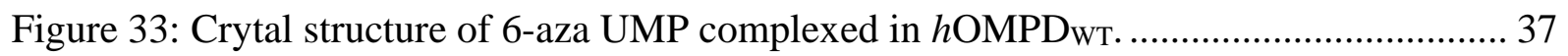

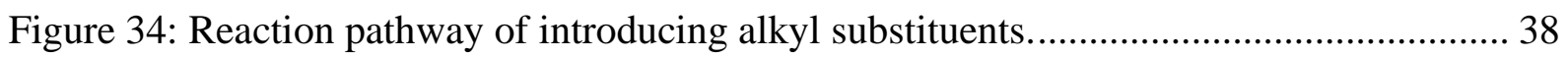

Figure 35: Synthetic pathway of alkyl uridines using Grignard reagents. ${ }^{[152]} \ldots \ldots \ldots \ldots \ldots \ldots \ldots \ldots . . . . . . . . . . . . .38$

Figure 36: Synthesis of 6-aryl- or 6-vinyl uridines using Suzuki Miyaura coupling. ............. 39

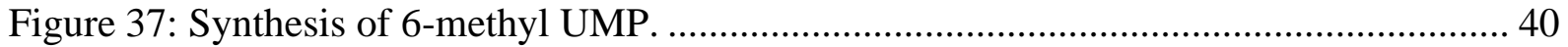

Figure 38: MiCHAELIS MENTEN plot of $h \mathrm{OMPD}_{\mathrm{WT}}$ and with 6-methyl UMP (black)............ 41

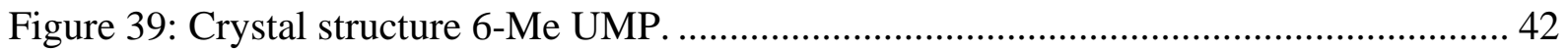

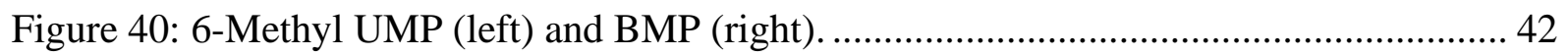

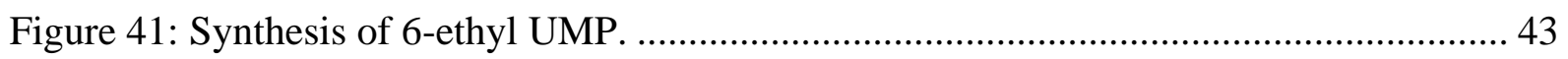

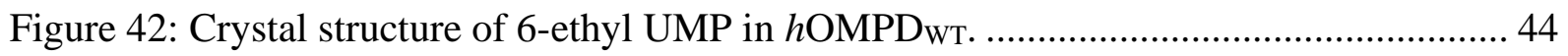

Figure 43: Crystal structure of 6-isopropyl UMP in $h$ OMPDwт.......................................... 45

Figure 46: Comparison of crystal structures of 6-methyl UMP (top left), 6-ethyl UMP (top

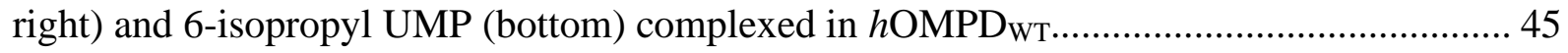

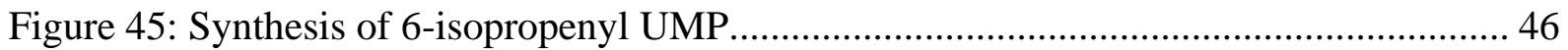

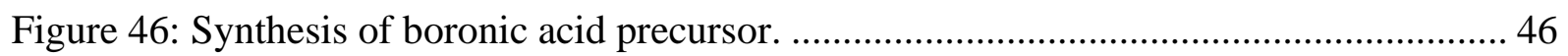

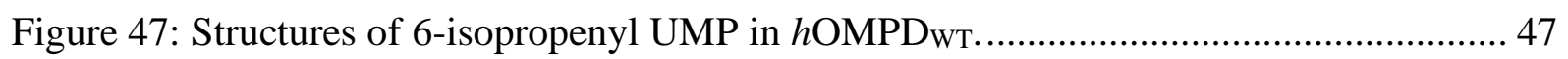

Figure 48 Comparison of structures of 6-isopropyl and 6-isopropenyl UMP. ...................... 47

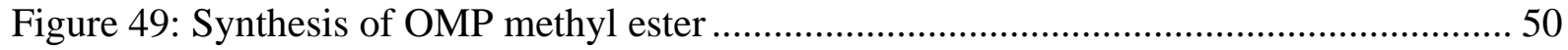

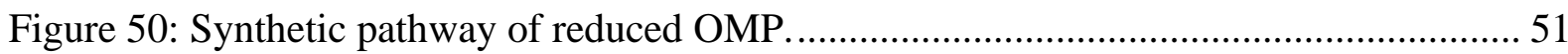

Figure 51: Electron density map of attempted crystal structure of reduced OMP. Enzymatic

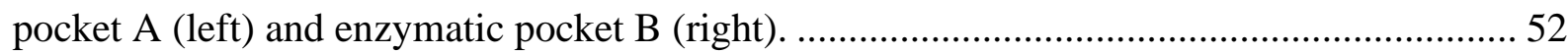

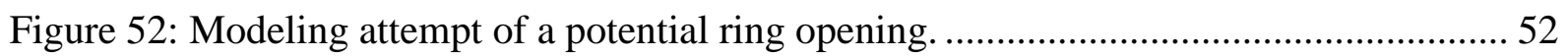

Figure 53: Synthetic pathway of 6-carboxycytidine, using differnt amino protecting groups in

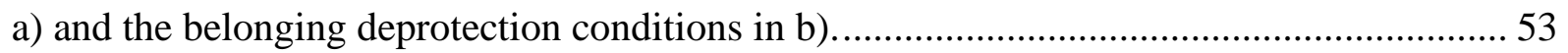

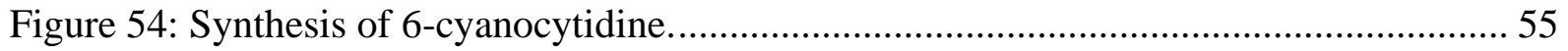

Figure 55: 6-Cyanocytidine as precursor of carboxy derivatives. ........................................ 56

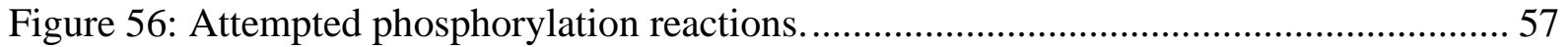

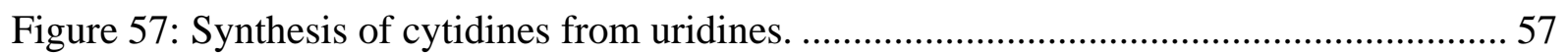

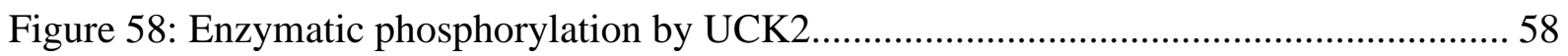




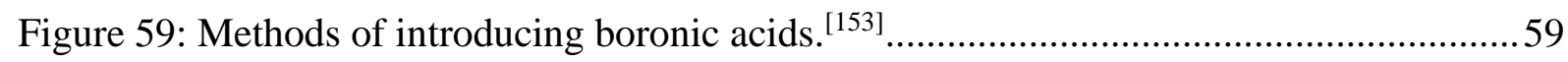

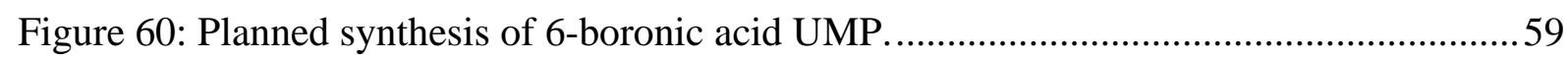

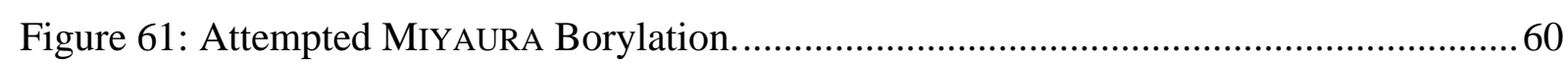

Figure 62: Attempted Borylation using activated boron species............................................6 60

Figure 63: Attempted Borylation using activated boron species........................................... 60

Figure 64: Attempted Borylation using activated boron species..........................................61

Figure 65: Convergent synthetic approach to synthesize 6-boronic acid UMP. ......................61

Figure 66: Synthesis of 2,4-bis(benzyloxy)-6-bromopyrimidine. ${ }^{[131]}$......................................6 62

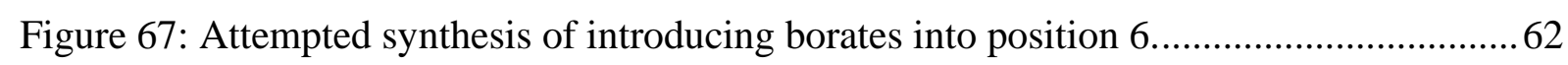

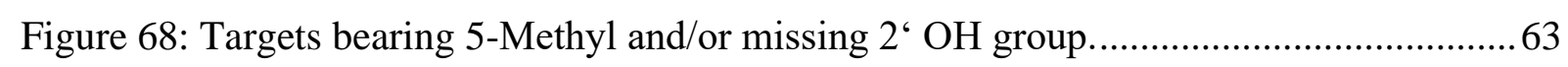

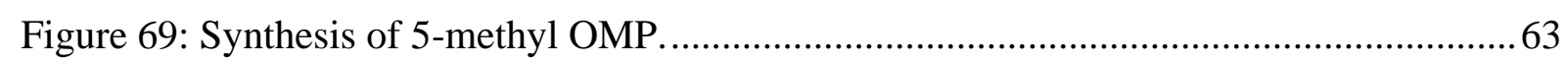

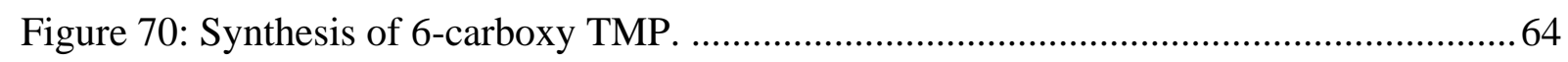

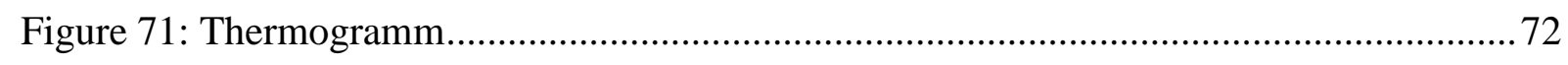

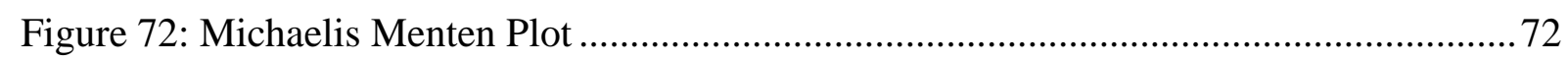





\section{Abbreviations}

\begin{tabular}{|c|c|}
\hline A & adenine \\
\hline$\AA$ & Ångström \\
\hline $\mathrm{AA}$ & amino acid \\
\hline Abs & absorption \\
\hline Ac & acetyl group \\
\hline $\mathrm{ACN}$ & acetonitrile \\
\hline aq. & aqueous \\
\hline arom. & aromatic \\
\hline Asp & aspartic acid \\
\hline ATC & aspartate transcarbamoylase \\
\hline $\mathrm{B}_{2} \mathrm{pin}_{2}$ & bis(pinacolato)diboron \\
\hline $\mathrm{BCl}_{3}$ & boron trichloride \\
\hline BMP & 6-hydroxyuridine-5'-monophosphate \\
\hline $\mathrm{Bn}$ & benzyl group \\
\hline Boc & tert-butyloxycarbonyl \\
\hline $\mathrm{Boc}_{2} \mathrm{O}$ & di tert butyl dicarbonate \\
\hline $\mathrm{Bp}$ & base pair \\
\hline br & broad singlet \\
\hline $\mathrm{Bu}$ & butyl group \\
\hline $\mathrm{C}$ & cytosine \\
\hline $\mathrm{c}$ & concentration \\
\hline CAD & $\begin{array}{l}\text { carbamoylphosphate synthase aspartate transcarbamoylase- } \\
\text { dihydroorotase }\end{array}$ \\
\hline calc. & calculated \\
\hline $\mathrm{Cbz}$ & benzyloxycarbonyl \\
\hline CMP & cytidine- $5^{\prime}$-monophosphate \\
\hline conc. & concentrated \\
\hline
\end{tabular}


9. Abbreviations

COVID-19 coronavirus disease 2019

CPS-2 carbamoyl phosphate synthetase 2

$\delta$

chemical shift

d

doublet

d day

Da

Dalton

DCM

dichloromethane

DESY

Deutsches Elektronen-Synchrotron

DHO

dihydroorotase

DHODH

dihydroorotate dehydrogenase

DIPEA

$\mathrm{N}, \mathrm{N}$-diisopropylethylamine

DMAP

4-dimethylaminopyridine

DMF dimethyl formamide

DMSO dimethyl sulfoxide

DNA deoxyribonucleic acid

Dppf 1,1'-bis diphenylphosphino ferrocene

E. coli Escherichia coli

eq.

equivalent

eq.

equation

ESI

electrospray ionisation

Et

ethyl

$\mathrm{Et}_{2} \mathrm{O}$

diethyl ether

$\mathrm{Et}_{3} \mathrm{~N}$

triethylamine

EtOAc

ethyl acetate

$\mathrm{EtOH}$

ethanol

EVB empirical valence bond

FA

formic acid

FDA

Food and Drug Administration

Fig.

figure

G

guanine 


\begin{tabular}{|c|c|}
\hline $\mathrm{g}$ & gram \\
\hline $\mathrm{h}$ & hours \\
\hline $\mathrm{HCl}$ & hydrochloric acid \\
\hline HEPES & 4-(2-hydroxyethyl)-1-piperazineethanesulfonic acid \\
\hline HMOA & 4-(2-hydroxy-4-methoxyphenyl)-4-oxobutanoic acid \\
\hline HOAc & acetic acid \\
\hline$h \mathrm{OMPD}_{\mathrm{WT}}$ & human wildtype orotidine- $5^{\prime}$-monophosphate decarboxylase \\
\hline HPLC & high performance liquid chromatography \\
\hline HR & high resolution \\
\hline $\mathrm{Hz}$ & Hertz \\
\hline ITC & isothermal titration calorimetry \\
\hline$J$ & coupling constant \\
\hline K & Kelvin \\
\hline K & rate constant \\
\hline $\mathrm{KCN}$ & potassium cyanide \\
\hline LC-MS & liquid chromatography - mass spectrometry \\
\hline LDA & lithium diisopropylamide \\
\hline $\mathrm{LiOH}$ & lithium hydroxide \\
\hline Lys & lysine \\
\hline M & molar \\
\hline $\mathrm{m}$ & mass \\
\hline $\mathrm{m}$ & multiplet \\
\hline M & molar mass \\
\hline MM & molecular mechanics \\
\hline $\mathrm{m} / \mathrm{z}$ & mass-to-charge ratio \\
\hline $\mathrm{Me}$ & methyl \\
\hline $\mathrm{MeOH}$ & methanol \\
\hline $\mathrm{Me}_{3} \mathrm{SiCl}$ & trimethylsilyl chloride \\
\hline $\mathrm{MHz}$ & megahertz \\
\hline $\min$ & minutes \\
\hline
\end{tabular}


9. Abbreviations

$\mathrm{mL} \quad$ millilitre

mtbe methyl tert-butyl ether

MtOMPD Methanothermobacter thermautotrophicus orotidine-5'-monophosphate decarboxylase

$\mu \mathrm{L} \quad$ microliter

MS mass spectrometry

$\mathrm{NaCN} \quad$ sodium cyanide

NAD nicotinamide adenine dinucleotide

$\mathrm{NADH}$ nicotinamide adenine dinucleotide hydrogen (reduced form)

NBS $\quad N$-bromosuccinimide

NIS $\quad N$-iodosuccinimide

NMR nuclear magnetic resonance

OAc acetate

$\mathrm{OMe} \quad$ methoxy

OMP orotidine-5'-monophosphate

OMPD $\quad$ orotidine- $5^{\prime}$-monophosphate decarboxylase

OPRT orotate phosphoribosyl transferase

p para

PG protecting group

$\mathrm{Ph} \quad$ phenyl

$\mathrm{POBr}_{3} \quad$ phosphoryl bromide

$\mathrm{POCl}_{3} \quad$ phosphoryl chloride

$\mathrm{PPh}_{3} \quad$ triphenylphosphin

$\mathrm{pK}_{\mathrm{a}} \quad$ logarithmic acid dissociation constant

PRPP phosphoribosyl pyrophosphate

ppm parts per million

q quartet

QM quantum mechanical

QTOF quadrupole time-of-flight

rel. relative 
$\mathrm{R}$

Rf

RNA

RP

$\mathrm{rt}$

s

S

sat.

ScOMPD

SMBI

$\mathrm{T}$

$\mathrm{T}$

$\mathrm{t}$

TBAF

TBDMS

TBDMSCl

$t$ - $\mathrm{Bu}$

TEAA

tert.

TFA

THF

TLC

$t_{R}$

UCK2

UMPS

$\mathrm{v} / \mathrm{v}$

WHO

wt rest

retardation factor

ribonucleic acid

reversed phase

room temperature

singlet

second

saturated

Saccharomyces cerevisiae orotidine-5'-monophosphate decarboxylase sodium monobromoisocyanurate

thymine

temperature

triplet

tetra- $n$-butylammonium fluoride

tert-butyldimethylsilyl

tert-butyldimethylsilyl chloride

tert-butyl

triethylammonium acetate

tertiary

trifluoroacetic acid

tetrahydrofuran

thin layer chromatography

retention time

uridine.cytidine kinase 2

uridine monophosphate synthetase

volume-to-volume ration

world health organization

wild type 



\section{References}

[1] H. Lodish, A. Berk, S. L. Zipursky, P. Matsudaira, D. Baltimore, J. Darnell, 2000.

[2] S. C. Hartman, J. M. Buchanan, Annu. Rev. Biochem. 1959, 28, 365-410.

[3] L. D. Langston, M. O’Donnell, Mol. Cell 2006, 23, 155-160.

[4] P. M. J. Burgers, T. A. Kunkel, Annu. Rev. Biochem. 2017, 86, 417-438.

[5] R. Zrenner, M. Stitt, U. Sonnewald, R. Boldt, 2006, 35.

[6] A. Radzicka, R. Wolfenden, Science 1995, 267, 90-93.

[7] B. G. Miller, R. Wolfenden, Annu. Rev. Biochem. 2002, 71, 847-885.

[8] C. Stasolla, R. Katahira, T. A. Thorpe, H. Ashihara, J. Plant Physiol. 2003, 160, 12711295.

[9] R. Steinberger, F. H. Westheimer, J. Am. Chem. Soc. 1951, 73, 429-435.

[10] C. S. Tsai, Can. J. Chem. 1967, 45, 873-880.

[11] K. Shostak, M. E. Jones, Biochemistry 1992, 31, 12155-12161.

[12] B. P. Callahan, B. G. Miller, Bioorganic Chem. 2007, 35, 465-469.

[13] D. Heinrich, U. Diederichsen, M. G. Rudolph, Chem. - Eur. J. 2009, 15, 6619-6625.

[14] M. Fujihashi, J. S. Mnpotra, R. K. Mishra, E. F. Pai, L. P. Kotra, J. Genet. Genomics 2015, 42, 221-234.

[15] J. P. Richard, T. L. Amyes, A. C. Reyes, Acc. Chem. Res. 2018, 51, 960-969.

[16] S. Rindfleisch, M. Krull, J. Uranga, T. Schmidt, F. Rabe von Pappenheim, T. Schneider, A. Chari, R. Kluger, G. Bourenkov, U. Diederichsen, R. A. Mata, K. Tittmann, Substrate Destabilisation by Electrostatic Repulsion Is No Driving Force in Enzyme Catalysis, Nat. Catal, in revision.

[17] A. Siddiqui, P. Ceppi, Mol. Metab. 2020, 35, 100962.

[18] H. Skipper, 1971, 21.

[19] A. M. Bello, D. Konforte, E. Poduch, C. Furlonger, L. Wei, Y. Liu, M. Lewis, E. F. Pai, C. J. Paige, L. P. Kotra, J. Med. Chem. 2009, 52, 1648-1658.

[20] J. Shelton, X. Lu, J. A. Hollenbaugh, J. H. Cho, F. Amblard, R. F. Schinazi, Chem. Rev. 2016, 116, 14379-14455.

[21] A. M. Bello, E. Poduch, M. Fujihashi, M. Amani, Y. Li, I. Crandall, R. Hui, P. I. Lee, K. C. Kain, E. F. Pai, L. P. Kotra, J. Med. Chem. 2007, 50, 915-921. 
10. References

[22] I. E. Crandall, E. Wasilewski, A. M. Bello, A. Mohmmed, P. Malhotra, E. F. Pai, K. C. Kain, L. P. Kotra, J. Med. Chem. 2013, 56, 2348-2358.

[23] S. Baloch, M. A. Baloch, T. Zheng, X. Pei, Tohoku J. Exp. Med. 2020, 250, 271-278.

[24] A. Manhas, S. Dubey, P. C. Jha, J. Biomol. Struct. Dyn. 2020, 38, 2704-2716.

[25] C. J. Murray, L. C. Rosenfeld, S. S. Lim, K. G. Andrews, K. J. Foreman, D. Haring, N. Fullman, M. Naghavi, R. Lozano, A. D. Lopez, The Lancet 2012, 379, 413-431.

[26] W. R. P. Novak, K. H. J. West, L. M. D. Kirkman, G. S. Brandt, Acta Crystallogr. Sect. F Struct. Biol. Commun. 2018, 74, 664-668.

[27] B. G. Miller, M. J. Snider, R. Wolfenden, S. A. Short, J. Biol. Chem. 2001, 276, 1517415176.

[28] S. A. Barnett, T. L. Amyes, B. M. Wood, J. A. Gerlt, J. P. Richard, Biochemistry 2008, 47, 7785-7787.

[29] J. G. Wittmann, D. Heinrich, K. Gasow, A. Frey, U. Diederichsen, M. G. Rudolph, Structure 2008, 16, 82-92.

[30] M. Fujihashi, T. Ishida, S. Kuroda, L. P. Kotra, E. F. Pai, K. Miki, J. Am. Chem. Soc. 2013, 135, 17432-17443.

[31] P. Neumann, K. Tittmann, Curr. Opin. Struct. Biol. 2014, 29, 122-133.

[32] M. Wensien, F. R. von Pappenheim, L.-M. Funk, P. Kloskowski, U. Curth, U. Diederichsen, J. Uranga, J. Ye, P. Fang, K.-T. Pan, H. Urlaub, R. A. Mata, V. Sautner, K. Tittmann, Nature 2021, 593, 460-464.

[33] S. Rindfleisch, Reaction Mechanism of HOMPD and CaAAD at Atomic Resolution, Georg-August-Universität Göttingen, 2018.

[34] M. Krull, Synthesis of Rare Nucleobases and Artificial Nucleotides for Invesigation of Catalytic Enzyme Activity, Georg-August-Universität Göttingen, 2019.

[35] S. Minchin, J. Lodge, Essays Biochem. 2019, 63, 433-456.

[36] T. Carell, C. Brandmayr, A. Hienzsch, M. Müller, D. Pearson, V. Reiter, I. Thoma, P. Thumbs, M. Wagner, Angew. Chem. Int. Ed. 2012, 51, 7110-7131.

[37] W. K. Olson, A. V. Colasanti, X.-J. Lu, V. B. Zhurkin, in Wiley Encycl. Chem. Biol., John Wiley \& Sons, Inc., Hoboken, NJ, USA, 2008.

[38] R. P. Bowater, Z. A. Waller, in ELS (Ed.: John Wiley \& Sons Ltd), John Wiley \& Sons, Ltd, Chichester, UK, 2014, p. a0006002.pub2.

[39] J. D. Watson, F. H. C. Crick, Nature 1953, 171, 737-738.

[40] M. Kemp, Nature 2003, 421, 416-420. 
[41] J. M. Berg, J. L. Tymoczko, L. Stryer, Biochemie, Spektrum Akad. Verl, Heidelberg, 2003.

[42] H. Lodish, A. Berk, S. L. Zipursky, P. Matsudaira, D. Baltimore, J. Darnell, 2000.

[43] M. E. Harris, in Wiley Encycl. Chem. Biol., John Wiley \& Sons, Inc., Hoboken, NJ, USA, 2008.

[44] K. J. McDowall, in Wiley Encycl. Chem. Biol., John Wiley \& Sons, Inc., Hoboken, NJ, USA, 2008.

[45] D. E. Koshland, Proc. Natl. Acad. Sci. 1958, 44, 98-104.

[46] A. Goldbeter, D. E. Koshland, Q. Rev. Biophys. 1982, 15, 555-591.

[47] International Union of Biochemistry and Molecular Biology, E. C. Webb, Eds. , Enzyme Nomenclature 1992: Recommendations of the Nomenclature Committee of the International Union of Biochemistry and Molecular Biology on the Nomenclature and Classification of Enzymes, Published For The International Union Of Biochemistry And Molecular Biology By Academic Press, San Diego, 1992.

[48] C. Bräsen, D. Esser, B. Rauch, B. Siebers, Microbiol. Mol. Biol. Rev. 2014, 78, 89-175.

[49] W. E. M. Lands, J. Biol. Chem. 1960, 235, 2233-2237.

[50] P. Talalay, Physiol. Rev. 1957, 37, 362-389.

[51] E. P. Kennedy, Annu Rev Biochem 1957, 119-148.

[52] C. B. Anfinsen, Science 1973, 181, 223-230.

[53] L. H. Chen, G. L. Kenyon, F. Curtin, S. Harayama, M. E. Bembenek, G. Hajipour, C. P. Whitman, J. Biol. Chem. 1992, 267, 17716-17721.

[54] S. Smith, FASEB J. 1994, 8, 1248-1259.

[55] E. Fischer, Eur. J. Inorg. Chem. 1894, 27, 2985-2993.

[56] H. Suzuki, How Enzymes Work: From Structure to Function, Pan Stanford Publishing, Singapore, 2015.

[57] In Enzyme Kinet., Wiley-VCH Verlag GmbH \& Co. KGaA, Weinheim, Germany, 2017, pp. $145-152$.

[58] G. E. Briggs, J. B. Haldane, Biochem. J. 1925, 19, 338-339.

[59] K. A. Johnson, R. S. Goody, Biochemistry 2011, 50, 8264-8269.

[60] T. L. Amyes, J. P. Richard, Biochemistry 2013, 52, 2021-2035.

[61] L. Pauling, Nature 1948, 161, 707-709.

[62] W. P. Jencks, in Adv. Enzymol. - Relat. Areas Mol. Biol. (Ed.: A. Meister), John Wiley \& Sons, Inc., Hoboken, NJ, USA, 1975, pp. 219-410.

[63] J. A. Smiley, L. Saleh, Bioorganic Chem. 1999, 27, 297-306. 
10. References

[64] W. Cui, J. G. DeWitt, S. M. Miller, W. Wu, Biochem. Biophys. Res. Commun. 1999, $259,133-135$.

[65] J. K. Lee, Ed., Orotidine Monophosphate Decarboxylase, Springer Berlin Heidelberg, Berlin, Heidelberg, 2004.

[66] K. Tokuoka, Y. Kusakari, S. R. Krungkrai, H. Matsumura, Y. Kai, J. Krungkrai, T. Horii, T. Inoue, J. Biochem. (Tokyo) 2007, 143, 69-78.

[67] J. B. Bell, M. E. Jones, J. Biol. Chem. 1991, 266, 12662-12667.

[68] B. G. Miller, T. W. Traut, R. Wolfenden, Bioorganic Chem. 1998, 26, 283-288.

[69] X. Sheng, K. Plasch, S. E. Payer, C. Ertl, G. Hofer, W. Keller, S. Braeuer, W. Goessler, S. M. Glueck, F. Himo, K. Faber, Front. Chem. 2018, 6, 608.

[70] B. G. Miller, M. J. Snider, S. A. Short, R. Wolfenden, Biochemistry 2000, 39, 81138118.

[71] B. G. Miller, G. L. Butterfoss, S. A. Short, R. Wolfenden, Biochemistry 2001, 40, 62276232.

[72] J. Yuan, A. M. Cardenas, H. F. Gilbert, T. Palzkill, Protein Sci. 2011, 20, 1891-1906.

[73] T. W. Traut, B. R. S. Temple, J. Biol. Chem. 2000, 275, 28675-28681.

[74] S. Pragobpol, A. M. Gero, C. S. Lee, W. J. O’Sullivan, Arch. Biochem. Biophys. 1984, 230, 285-293.

[75] M. Fujihashi, A. M. Bello, E. Poduch, L. Wei, S. C. Annedi, E. F. Pai, L. P. Kotra, J. Am. Chem. Soc. 2005, 127, 15048-15050.

[76] J. A. Smiley, P. Paneth, M. H. O’Leary, J. B. Bell, M. E. Jones, Biochemistry 1991, 30, 6216-6223.

[77] T. C. Appleby, C. Kinsland, T. P. Begley, S. E. Ealick, Proc. Natl. Acad. Sci. 2000, 97, 2005-2010.

[78] P. Beak, B. Siegel, J. Am. Chem. Soc. 1976, 98, 3601-3606.

[79] K. N. Houk, D. J. Tantillo, C. Stanton, Y. Hu, in Orotidine Monophosphate Decarboxylase (Ed.: J.K. Lee), Springer Berlin Heidelberg, Berlin, Heidelberg, 2004, pp. $1-22$.

[80] R. B. Silverman, M. P. Groziak, J. Am. Chem. Soc. 1982, 104, 6434-6439.

[81] J. A. Smiley, M. E. Jones, Biochemistry 1992, 31, 12162-12168.

[82] S. A. Acheson, J. B. Bell, M. E. Jones, R. Wolfenden, Biochemistry 1990, 29, 31983202.

[83] J. K. Lee and, Science 1997, 276, 942-945. 
[84] T.-S. Lee, L. T. Chong, J. D. Chodera, P. A. Kollman, J. Am. Chem. Soc. 2001, 123, $12837-12848$.

[85] P. Harris, J.-C. Navarro Poulsen, K. F. Jensen, S. Larsen, Biochemistry 2000, 39, 42174224.

[86] B. G. Miller, A. M. Hassell, R. Wolfenden, M. V. Milburn, S. A. Short, Proc. Natl. Acad. Sci. 2000, 97, 2011-2016.

[87] N. Wu, Y. Mo, J. Gao, E. F. Pai, Proc. Natl. Acad. Sci. 2000, 97, 2017-2022.

[88] A. Warshel, M. Štrajbl, J. Villà, J. Florián, Biochemistry 2000, 39, 14728-14738.

[89] A. Warshel, J. Florian, Proc Natl Acad Sci USA 1998, 6.

[90] A. Warshel, J. FloriaÂn, M. SÏtrajbl, J. VillaÁ, n.d., 3.

[91] R. V. Stanton, M. Pera, n.d., 10.

[92] B. Kuhn, P. A. Kollman, J. Am. Chem. Soc. 2000, 122, 2586-2596.

[93] J. Srinivasan, T. E. Cheatham, P. Cieplak, P. A. Kollman, D. A. Case, n.d., 9.

[94] C. A. Lewis, R. Wolfenden, Biochemistry 2007, 46, 13331-13343.

[95] K. Toth, T. L. Amyes, B. M. Wood, K. Chan, J. A. Gerlt, 2008, 8.

[96] T. L. Amyes, B. M. Wood, K. Chan, J. A. Gerlt, J. P. Richard, 2009, 10.

[97] L. M. Phillips, J. K. Lee, J. Org. Chem. 2005, 70, 1211-1221.

[98] P. Harris, J.-C. N. Poulsen, K. F. Jensen, S. Larsen, J. Mol. Biol. 2002, 318, 1019-1029.

[99] B. Goryanova, L. M. Goldman, T. L. Amyes, J. A. Gerlt, J. P. Richard, Biochemistry 2013, 52, 7500-7511.

[100] V. Iiams, B. J. Desai, A. A. Fedorov, E. V. Fedorov, S. C. Almo, J. A. Gerlt, Biochemistry 2011, 50, 8497-8507.

[101] B. M. Wood, K. K. Chan, T. L. Amyes, J. P. Richard, J. A. Gerlt, 2010, 22.

[102] B. J. Desai, B. M. Wood, A. A. Fedorov, E. V. Fedorov, B. Goryanova, T. L. Amyes, J.

P. Richard, S. C. Almo, J. A. Gerlt, Biochemistry 2012, 51, 8665-8678.

[103] S. A. Barnett, T. L. Amyes, B. McKay Wood, J. A. Gerlt, J. P. Richard, Biochemistry 2010, 49, 824-826.

[104] K. Toth, T. L. Amyes, B. M. Wood, K. Chan, J. A. Gerlt, J. P. Richard, J. Am. Chem. Soc. 2010, 132, 7018-7024.

[105] J. L. Van Vleet, L. A. Reinhardt, B. G. Miller, A. Sievers, W. W. Cleland, Biochemistry 2008, 47, 798-803.

[106] B. J. Desai, Y. Goto, A. Cembran, A. A. Fedorov, S. C. Almo, J. Gao, H. Suga, J. A. Gerlt, Proc. Natl. Acad. Sci. 2014, 111, 15066-15071. 
10. References

[107] E. Poduch, A. M. Bello, S. Tang, M. Fujihashi, E. F. Pai, L. P. Kotra, J. Med. Chem. 2006, 49, 4937-4945.

[108] A. C. Reyes, T. L. Amyes, J. P. Richard, J. Am. Chem. Soc. 2017, 139, 16048-16051.

[109] A. C. Reyes, D. C. Plache, A. P. Koudelka, T. L. Amyes, J. A. Gerlt, J. P. Richard, J. Am. Chem. Soc. 2018, 140, 17580-17590.

[110] B. Goryanova, T. L. Amyes, J. P. Richard, J. Am. Chem. Soc. 2019, 141, 13468-13478.

[111] T. A. S. Brandão, J. P. Richard, Biochemistry 2020, 59, 2032-2040.

[112] J. Rautio, N. A. Meanwell, L. Di, M. J. Hageman, Nat. Rev. Drug Discov. 2018, 17, $559-587$.

[113] K.-M. Wu, Pharmaceuticals 2009, 2, 77-81.

[114] Y. Mehellou, H. S. Rattan, J. Balzarini, J. Med. Chem. 2018, 61, 2211-2226.

[115] M. Slusarczyk, M. Serpi, F. Pertusati, Antivir. Chem. Chemother. 2018, 26, 204020661877524.

[116] R. J. DeBerardinis, N. Sayed, D. Ditsworth, C. B. Thompson, Curr. Opin. Genet. Dev. 2008, 18, 54-61.

[117] C. K. Chu, D. C. Baker, Eds., Nucleosides and Nucleotides as Antitumor and Antiviral Agents, Springer US, Boston, MA, 1993.

[118] D. J. Hammond, W. E. Gutteridge, Biochim. Biophys. Acta BBA - Gen. Subj. 1982, 718, $1-10$.

[119] P. K. Rathod, P. Reyes, J. Biol. Chem. 1983, 258, 2852-2855.

[120] K. K. Seymour, S. D. Lyons, L. Phillips, K. H. Rieckmann, R. I. Christopherson, Biochemistry 1994, 33, 5268-5274.

[121] M. Jashés, M. González, M. López-Lastra, E. De Clercq, A. Sandino, Antiviral Res. 1996, 29, 309-312.

[122] J. D. Morrey, D. F. Smee, R. W. Sidwell, C. Tseng, Antiviral Res. 2002, 55, 107-116.

[123] M. E. Meza-Avina, L. Wei, Y. Liu, E. Poduch, A. M. Bello, R. K. Mishra, E. F. Pai, L. P. Kotra, Bioorg. Med. Chem. 2010, 18, 4032-4041.

[124] J. B. French, P. A. Yates, D. R. Soysa, J. M. Boitz, N. S. Carter, B. Chang, B. Ullman,

S. E. Ealick, J. Biol. Chem. 2011, 286, 20930-20941.

[125] E. De Clercq, G. Li, Clin. Microbiol. Rev. 2016, 29, 695-747.

[126] J. Braun, R. Preuss, M. Bachmann, Eds. , Klinikleitfaden Intensivmedizin, Elsevier, Urban \& Fischer, München, 2016.

[127] Masson-Delmotte, Valérie; Zhai, Panmao; Pirani, Anna; Connors, Sarah L.; Péan, Clotilde; Berger, Sophie; Caud, Nada; Chen, Yang; Goldfarb, Leah; Gomis, Melissa I.; 
Huang, Mengtian; Leitzell, Katherine; Lonnoy, Elisabeth; Matthews, J. B. Robin; Maycock, Tom K.; Waterfield, Tim; Yelekçi, Ozge; Yu, Rong; Zhou, Baiquan, eds, Climate Change 2021: The Physical Science Basis, 2021.

[128] A. Gregson, C. V. Plowe, Pharmacol. Rev. 2005, 57, 117-145.

[129] Y. Takashima, E. Mizohata, S. R. Krungkrai, Y. Fukunishi, T. Kinoshita, T. Sakata, H. Matsumura, J. Krungkrai, T. Horii, T. Inoue, J. Biochem. (Tokyo) 2012, 152, 133-138.

[130] D. Heinrich, Untersuchung Des Mechanismus Der Katalytischen Aktivität von Orotidin-5'-Monophosphat Decarboxylase Im Hinblick Auf Die Entwicklung Maßgeschneiderter Wirkstoffe Und Synthese von Nucleotiden Zur Spezifischen Induktion von DNA-Überstrukturen, 2008.

[131] R. F. Schinazi, W. H. Prusoff, J. Org. Chem. 1985, 50, 841-847.

[132] H. Vorbrüggen, C. Ruh-Pohlenz, in Org. React. (Ed.: John Wiley \& Sons, Inc.), John Wiley \& Sons, Inc., Hoboken, NJ, USA, 1999, pp. 1-630.

[133] E. Wittenburg, Z. Für Chem. 1964, 4, 303-304.

[134] G. L. Beutner, M. S. Bultman, B. M. Cohen, J. Fan, J. Marshall, C. Sfouggatakis, Org. Process Res. Dev. 2019, 23, 2050-2056.

[135] H. Tanaka, H. Hayakawa, T. Miyasaka, Tetrahedron 1982, 38, 2635-2642.

[136] T. W. Greene, Wuts, Peter G. M, Protective Groups in Organic Synthesis, 2002.

[137] R. L. Letsinger, P. S. Miller, J. Am. Chem. Soc. 1969, 91, 3356-3359.

[138] Y. Xu, H. Jin, Z. Yang, L. Zhang, L. Zhang, Tetrahedron 2009, 65, 5228-5239.

[139] E. J. Corey, A. Venkateswarlu, J. Am. Chem. Soc. 1972, 94, 6190-6191.

[140] K. K. Ogilvie, Can. J. Chem. 1973, 51, 3799-3807.

[141] P. W. Landesman, Design, Synthesis and Evaluation of Potential Inhibitors of Pyrimidine Biosynthesis: A Mechanistic Approach., 1982.

[142] A. M. Bello, E. Poduch, Y. Liu, L. Wei, I. Crandall, X. Wang, C. Dyanand, K. C. Kain, E. F. Pai, L. P. Kotra, J. Med. Chem. 2008, 51, 439-448.

[143] K. K. Chan, B. M. Wood, A. A. Fedorov, E. V. Fedorov, H. J. Imker, T. L. Amyes, J.

P. Richard, S. C. Almo, J. A. Gerlt, Biochemistry 2009, 48, 5518-5531.

[144] N. Wu, W. Gillon, E. F. Pai, Biochemistry 2002, 41, 4002-4011.

[145] E. Poduch, L. Wei, E. F. Pai, L. P. Kotra, J. Med. Chem. 2008, 51, 432-438.

[146] M. K. Purohit, E. Poduch, L. W. Wei, I. E. Crandall, T. To, K. C. Kain, E. F. Pai, L. P. Kotra, J. Med. Chem. 2012, 55, 9988-9997.

[147] M. Lewis, M. E. Meza-Avina, L. Wei, I. E. Crandall, A. M. Bello, E. Poduch, Y. Liu, C. J. Paige, K. C. Kain, E. F. Pai, L. P. Kotra, J. Med. Chem. 2011, 54, 2891-2901. 
[148] H. Inoue, T. Ueda, Chem. Pharm. Bull. (Tokyo) 1978, 26, 2657-2663.

[149] P. A. Levene, R. S. Tipson, J. Biol. Chem. 1934, 106, 113-124.

[150] T. Sowa, S. Ouchi, Bull. Chem. Soc. Jpn. 1975, 48, 2084-2090.

[151] H. L. Levine, R. S. Brody, F. H. Westheimer, Biochemistry 1980, 19, 4993-4999.

[152] Y.-C. Shih, Y.-Y. Yang, C.-C. Lin, T.-C. Chien, J. Org. Chem. 2013, 78, 4027-4036.

[153] G. A. Molander, S. L. J. Trice, S. M. Kennedy, S. D. Dreher, M. T. Tudge, J. Am. Chem. Soc. 2012, 134, 11667-11673.

[154] R. Nencka, D. Sinnaeve, I. Karalic, J. C. Martins, S. Van Calenbergh, Org. Biomol. Chem. 2010, 8, 5234.

[155] H. Tanaka, H. Hayakawa, S. Shibata, K. Haraguchi, T. Miyasaka, K. Hirota, Nucleosides Nucleotides 1992, 11, 319-328.

[156] G. Palmisano, M. Santagostino, Tetrahedron 1993, 49, 2533-2542.

[157] Y.-C. Shih, T.-C. Chien, Tetrahedron 2011, 67, 3915-3923.

[158] B. N. Hemric, K. Shen, Q. Wang, J. Am. Chem. Soc. 2016, 138, 5813-5816.

[159] F. Kerins, D. F. O'Shea, J. Org. Chem. 2002, 67, 4968-4971.

[160] R. Kluger, Acc. Chem. Res. 2015, 48, 2843-2849.

[161] J. G. Moffatt, J. Am. Chem. Soc. 1963, 85, 1118-1123.

[162] J. P. Guthrie, Can. J. Chem. 1978, 56, 2342-2354.

[163] F. Felpin, E. Fouquet, Chem. - Eur. J. 2010, 16, 12440-12445.

[164] K. Okano, K. Okuyama, T. Fukuyama, H. Tokuyama, Synlett 2008, 2008, 1977-1980.

[165] A. Matsuda, H. Inoue, T. Ueda, Chem. Pharm. Bull. (Tokyo) 1978, 26, 2340-2345.

[166] J. Maity, R. Stromberg, Molecules 2013, 18, 12740-12750.

[167] H. Taguchi, S. Y. Wang, J. Org. Chem. 1979, 44, 4385-4393.

[168] P. C. Srivastava, K. L. Nagpal, Experientia 1970, 26, 220-220.

[169] J. Farràs, C. Serra, J. Vilarrasa, Tetrahedron Lett. 1998, 39, 327-330.

[170] S. Becker, J. Feldmann, S. Wiedemann, H. Okamura, C. Schneider, K. Iwan, A. Crisp, M. Rossa, T. Amatov, T. Carell, Science 2019, 366, 76-82.

[171] A. R. Van Rompay, A. Norda, K. Lindén, M. Johansson, A. Karlsson, Mol. Pharmacol. 2001, 59, 1181-1186.

[172] T. Leermann, F. R. Leroux, F. Colobert, Org. Lett. 2011, 13, 4479-4481.

[173] M. Alessi, A. L. Larkin, K. A. Ogilvie, L. A. Green, S. Lai, S. Lopez, V. Snieckus, J. Org. Chem. 2007, 72, 1588-1594.

[174] I. A. I. Mkhalid, J. H. Barnard, T. B. Marder, J. M. Murphy, J. F. Hartwig, Chem. Rev. 2010, 110, 890-931. 
[175] T. Ishiyama, M. Murata, N. Miyaura, J. Org. Chem. 1995, 60, 7508-7510.

[176] Y. Nagashima, R. Takita, K. Yoshida, K. Hirano, M. Uchiyama, J. Am. Chem. Soc. 2013, 135, 18730-18733.

[177] H. F. Bettinger, M. Filthaus, H. Bornemann, I. M. Oppel, Angew. Chem. Int. Ed. 2008, 47, 4744-4747.

[178] L. Zhang, L. Jiao, J. Am. Chem. Soc. 2017, 139, 607-610.

[179] B. W. Langley, J. Am. Chem. Soc. 1956, 78, 2136-2141.

[180] J. D. Bryant, N. J. Leonard, J. Org. Chem. 1978, 43, 511-516.

[181] G. Glockler, J. Phys. Chem. 1958, 62, 1049-1054.

[182] R. T. Sanderson, Chemical Bonds and Bond Energy, Academic Press, New York, 1976.

[183] T. Henkel, A. Klauck, K. Seppelt, Phosphorus Sulfur Silicon Relat. Elem. 1994, 95, $313-314$.

[184] K. Seppelt, Pure Appl. Chem. 1987, 59, 1057-1062.

[185] G. C. Cheng, in Prog. Med. Chem., Elsevier, 1969, pp. 67-134.

[186] H. C. Brown, Proc. Roy. Australian Chem. Inst. 1966, 33, 57.

[187] T. T. Tidwell, Angew. Chem. Int. Ed. 2001, 40, 331-337.

[188] C. M. Davis, K. A. Curran, J. Chem. Educ. 2007, 84, 1822.

[189] J. G. Wittmann, M. G. Rudolph, Acta Crystallogr. D Biol. Crystallogr. 2007, 63, 744749.

[190] A. le Maire, M. Gelin, S. Pochet, F. Hoh, M. Pirocchi, J.-F. Guichou, J.-L. Ferrer, G. Labesse, Acta Crystallogr. D Biol. Crystallogr. 2011, 67, 747-755.

[191] B. Heras, J. L. Martin, Acta Crystallogr. D Biol. Crystallogr. 2005, 61, 1173-1180.

[192] M. Cianci, G. Bourenkov, G. Pompidor, I. Karpics, J. Kallio, I. Bento, M. Roessle, F.

Cipriani, S. Fiedler, T. R. Schneider, J. Synchrotron Radiat. 2017, 24, 323-332.

[193] W. Kabsch, Acta Crystallogr. D Biol. Crystallogr. 2010, 66, 125-132.

[194] G. N. Murshudov, P. Skubák, A. A. Lebedev, N. S. Pannu, R. A. Steiner, R. A. Nicholls, M. D. Winn, F. Long, A. A. Vagin, Acta Crystallogr. D Biol. Crystallogr. 2011, 67, 355367.

[195] G. M. Sheldrick, Acta Crystallogr. Sect. C Struct. Chem. 2015, 71, 3-8.

[196] Org. Synth. 1931, 11, 98. 



\section{Acknowledgement}

First, I would like to thank Prof. Dr. Ulf DIEDERICHSEN for giving me the opportunity to work in his group on this very interesting research project. I also want to thank him for the continuous support during this time. The independence he gave me, encouraged the free exchange of ideas. This, along with his insights helped me to develop as a researcher and as a person. For this I am deeply grateful.

I want to thank Prof. Dr. LutZ ACKERMANN, and Prof. Dr. KAI TITTMANN, for agreeing to assess this work as co-examiner. I am thankful for every advice and discussion in the thesis committee meetings and beyond. Thank you, for fortifying my work in this interdisciplinary research field of OMPD, with synthesis of biomolecules, enzymology, and crystallography. The whole thesis committee for the assistance they gave me throughout my graduate career, I really appreciated that! I would also like to thank my other committee members, Prof Dr. RICARDO MATA, Dr. Michael John and Dr Holm FraUENDORF.

Special thanks go to MATthias KRULl, SÖREn RindFLEISCH, FABIAN RAABE VON PAPPENHEIM, LAURA KIRCK and Elisa SANTAgOSTINO for working in close cooperation on the OMPD project. MATTHIAS and ELISA, I really enjoyed the time working as a synthetic team together on this challenging project. SÖREN, FABIAN and LAURA, I am grateful that we were working in such a close cooperation, no matter if crystallization processes, substrate soaking or x-ray data collection, sitting hours and hours at the beamline, performing ITC measurements or testing new enzymatic reactions, I really enjoyed working with you together expanding my biochemical horizon.

I want to thank my undergrad students MORITZ VON GEYSO and MARIUS REINHOLD for joining my lab, participating highly motivated in the synthetic work and contributing with their engagement to the overall project. Furthermore, I would like to thank all members of the DIEDERICHSEN group, especially Lab 109, for the amazing and enjoyable atmosphere and all the great experiences during my time in the working group. In addition, I am beholden to everyone who helped me with proofreading parts of this thesis

Moreover, I want to thank the department of NMR spectroscopy and the department of central analytics of Georg-August-University for measuring my samples.

Lastly, I thank my family and my friends for their support during my studies. 

12. Curriculum vitae

12. Curriculum vitae 